Aus der Klinik für Kardiologie und Pneumologie

(Prof. Dr. med. G. Hasenfuß)

der Medizinischen Fakultät der Universität Göttingen

\title{
Der Stellenwert von Biomarkern zur Prognoseabschätzung bei diastolischer Dysfunktion und HFpEF
}

\author{
INAUGURAL - DISSERTATION \\ zur Erlangung des Doktorgrades \\ für Zahnheilkunde \\ der Medizinischen Fakultät der \\ Georg-August-Universität zu Göttingen
}

vorgelegt von

Stefan Gonschior

aus

Bremen 
Dekan: Prof. Dr. rer. nat. H. K. Kroemer

Referent: Prof. Dr. med. F. Edelmann

Ko-Referent: Prof. Dr. mult. T. Meyer

Drittreferent: Prof. Dr. med. dent. R. Mausberg

Datum der mündlichen Prüfung: 20.03.2017 


\section{Inhaltsverzeichnis}

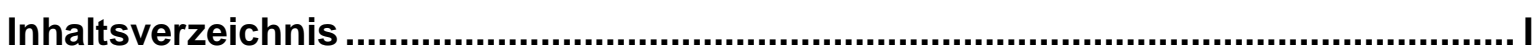

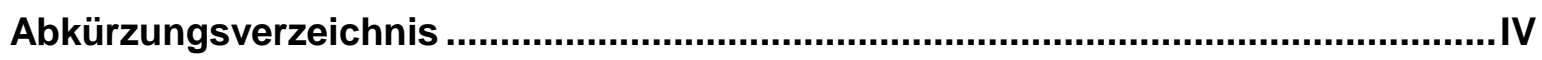

Einheitenverzeichnis .....................................................................................

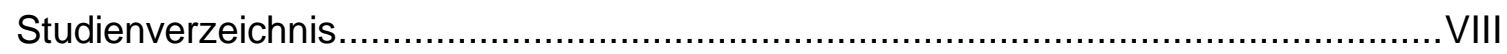

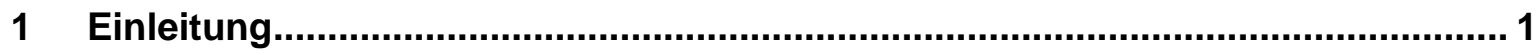

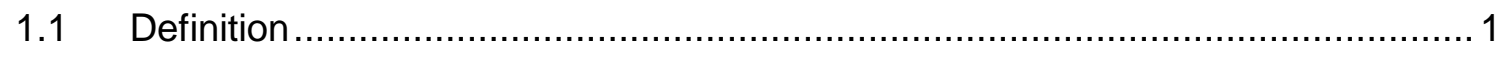

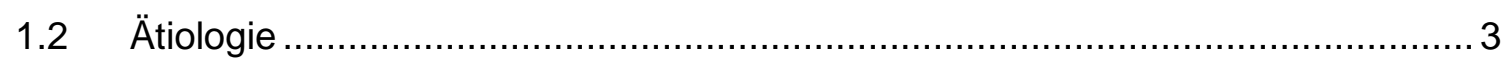

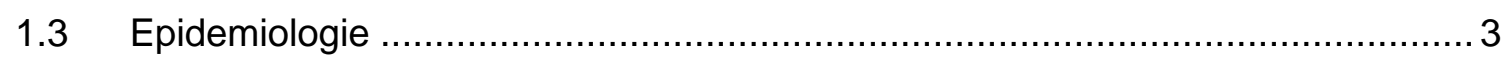

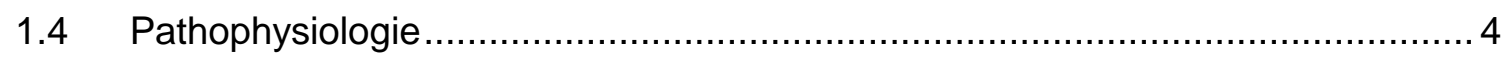

1.5 Stellenwert von Biomarkern bei der Prognosefindung ................................... 7

1.5.1 Neurohumorale Marker .............................................................. 8

1.5.1.1 Myokardialer Stress (ANP, BNP, ADM) ...................................... 8

1.5.1.2 Weitere Neurohormone (Renin, Aldosteron, AVP, ET-1) .................... 10

1.5.2 Entzündungsmarker (hsCRP) …................................................... 14

1.5.3 Matrix-Remodelling (Kollagen III) ................................................... 14

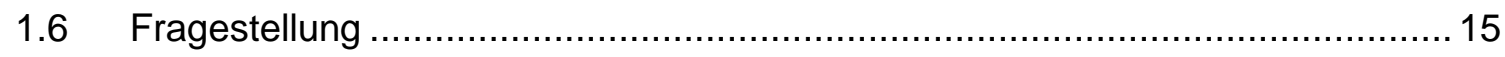

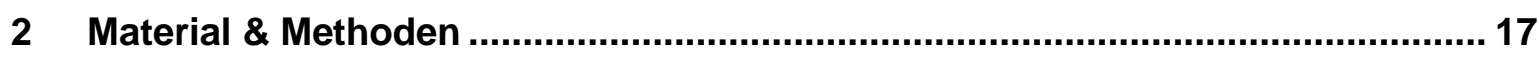

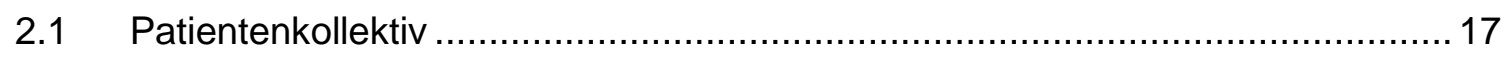

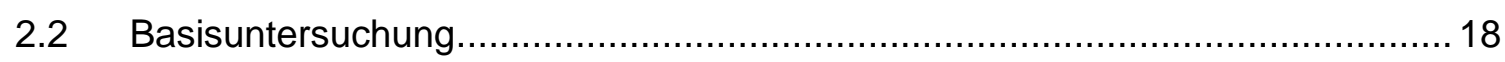

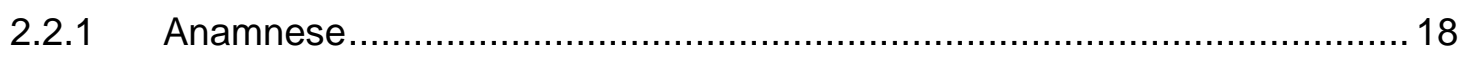

2.2.2 Körperliche Untersuchung ............................................................. 19

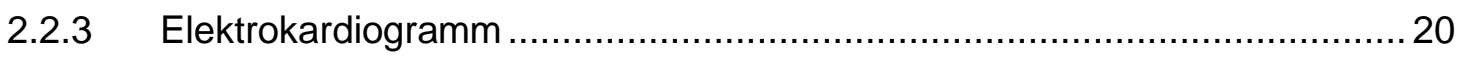

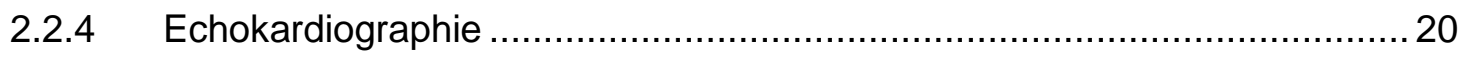

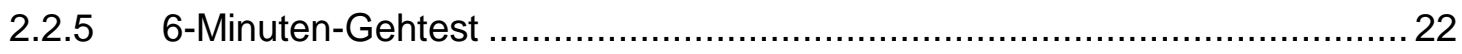

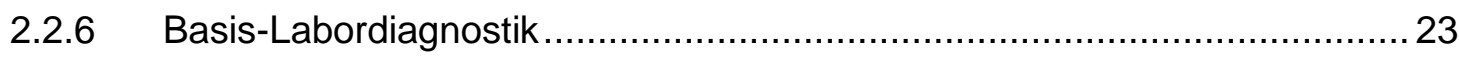

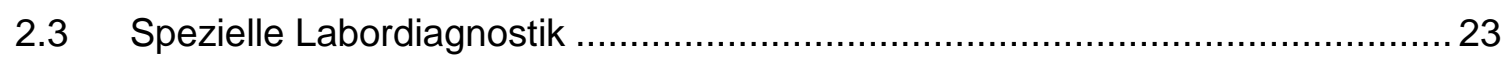

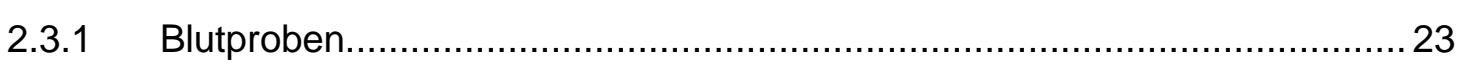

2.3.2 ADM und MRproADM .............................................................. 24

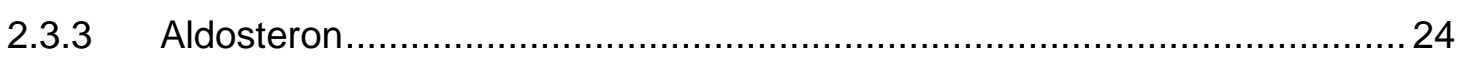

2.3.4 ANP und MRproANP/NTproANP..................................................... 24

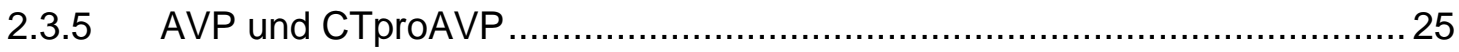

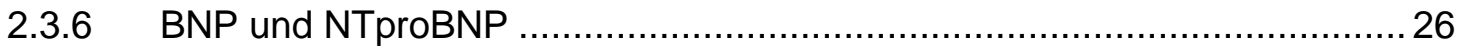

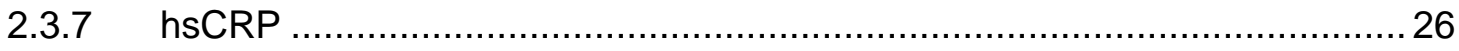

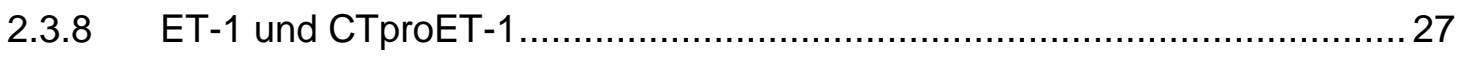

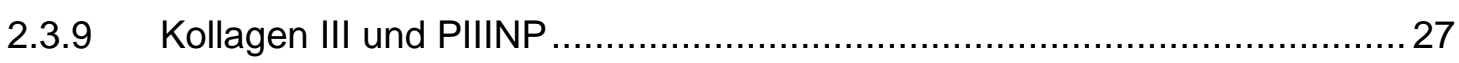

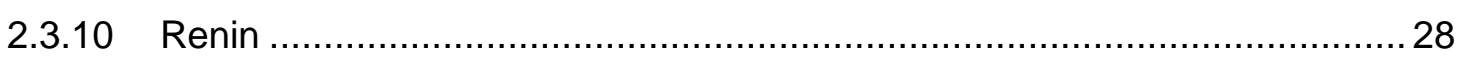




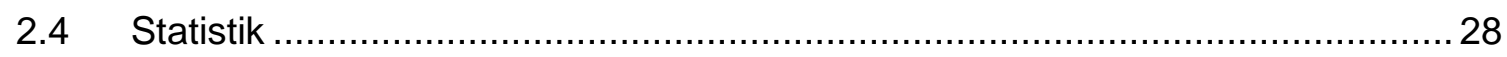

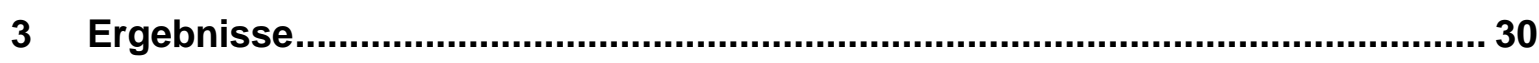

3.1 Deskriptive Statistik des Patientenkollektivs ............................................. 30

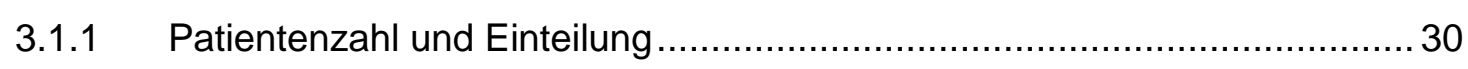

3.1.2 Klinische Parameter ...................................................................... 31

3.1.3 Kardiale Diagnose und Risikofaktoren................................................ 32

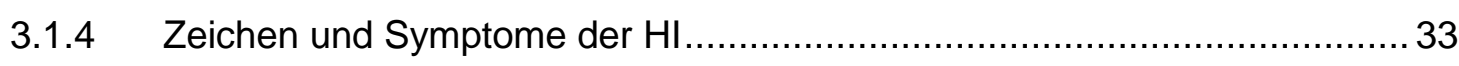

3.1.5 Allgemeine Labordiagnostik ......................................................... 33

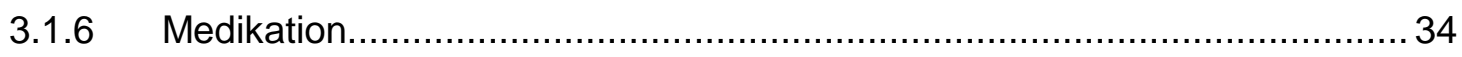

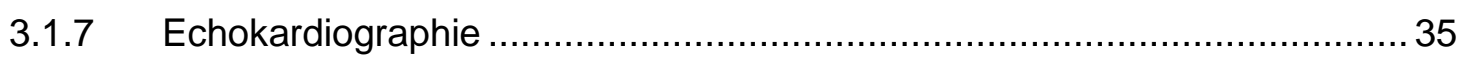

3.2 Analyse der prognostischen Wertigkeit .................................................... 35

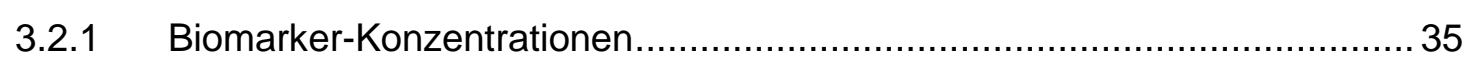

3.2.2 Kaplan-Meier-Analyse zur Inzidenz des kombinierten Endpunkts ............. 47

3.2.3 Univariate Cox-Regressionsmodelle aller Biomarker............................... 48

3.2.4 Cox-Regressionsmodelle für NTproBNP ............................................ 50

3.2.5 Multivariate Cox-Regressionsmodelle für NTproBNP, CTproET-1 und

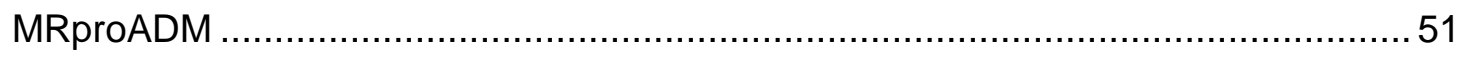

3.2.6 Multivariate Cox-Regressionsmodelle für NTproBNP, CTproET-1,

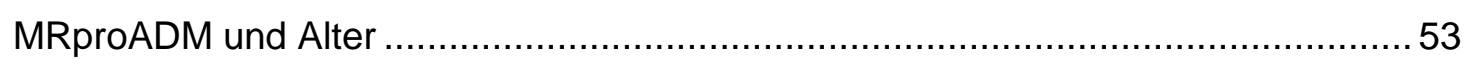

3.2.7 Korrelationsanalyse der Biomarker ................................................ 55

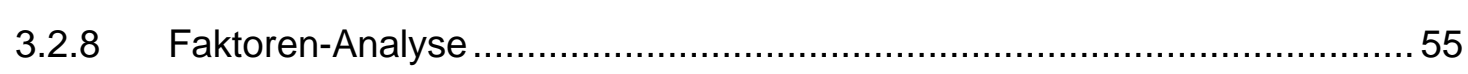

3.2.9 Finale multivariate Cox-Regressionsmodelle......................................... 56

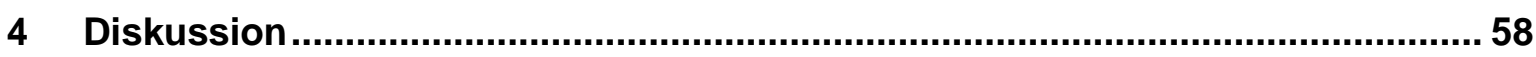

4.1 Schlussfolgerungen aus dem Patientenkollektiv ............................................ 58

4.2 Hindernisse beim Vergleich der prognostischen Wertigkeit .............................67

4.3 Vielversprechendes Potential von MRproADM .............................................. 68

4.4 Hohe Modulierbarkeit und fragwürdige Eignung von Aldosteron ...................... 71

4.5 Überlegenheit von MRproANP gegenüber NTproANP .................................. 73

4.6 Überschneidung prognostischer Informationen bei CTproAVP .......................... 76

4.7 Überlegene Prognosekraft von NTproBNP .............................................. 78

$4.8 \quad$ Unklare Datenlage zur Wertigkeit von hsCRP ........................................... 82

4.9 Scheitern von CTproET-1 an multivariaten Modellen ...................................... 85

4.10 Geringe prognostische Wertigkeit von PIIINP.......................................... 88

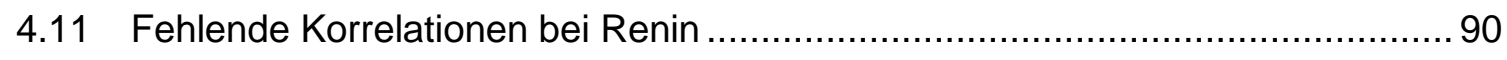

4.12 Überschneidung von prognostischen Informationen..................................... 92

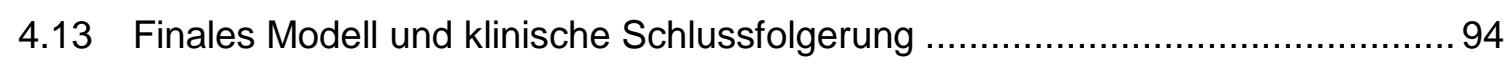

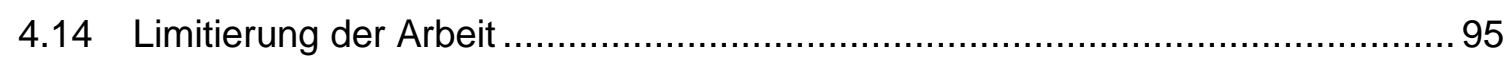




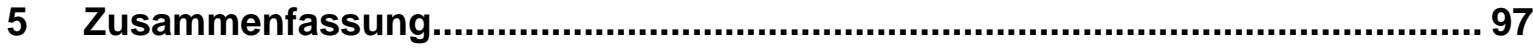

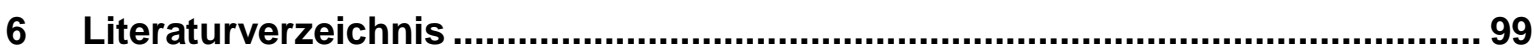




\section{Abkürzungsverzeichnis}

A Einstromgeschwindigkeit nach Vorhofkontraktion über der Mitralklappe

a' Geschwindigkeit der Bewegung des Mitralklappenanulus während der Vorhofkontraktion

ACE Angiotensin-converting enzyme

ADM Adrenomedullin

ANP atrial natriuretic peptide

ASS Acetylsalicylsäure

Avalsalva Einstromgeschwindigkeit über der Mitralklappe nach der Vorhofkontraktion während des Valsalva-Manövers

AVP Arginin-Vasopressin

A-Welle Geschwindigkeit der Füllung des linken Ventrikels durch den Vorhof

BigET-1 big endothelin-1

BMI body-mass-index

BNP brain natriuretic peptide

BSA body surface area

$\mathrm{Ca}^{2+} \quad$ Calcium-Ion

cGMP cyclisches Guanosinmonophosphat

$\mathrm{Cl} \quad$ confidence interval

CKD chronic kidney disease

COPD chronic obstructive pulmonary disease

CRP C-reaktives Protein

CTproAVP carboxy-terminal pro-arginin vasopressin

CTproET-1 carboxy-terminal pro-endothelin-1

CV cardiovascular

DD diastolische Dysfunktion

E maximale frühdiastolische Einstromgeschwindigkeit

e' maximale frühdiastolische Bewegung des Mitralklappenanulus

EDV elektronische Datenverarbeitung 


\begin{tabular}{|c|c|}
\hline $\begin{array}{l}\text { EF } \\
\text { (e)GFR }\end{array}$ & $\begin{array}{l}\text { Ejektionsfraktion } \\
\text { (estimated) glomerular filtration rate }\end{array}$ \\
\hline EKG & Elektrokardiogramm \\
\hline ESC & European Society of Cardiology \\
\hline ET-1 & Endothelin-1 \\
\hline E-Welle & Geschwindigkeit der passiven Füllung des linken Ventrikels \\
\hline EZM & extrazelluläre Matrix \\
\hline FS & fractional shortening \\
\hline HF & Herzfrequenz \\
\hline HFpEF & heart failure with preserved ejection fraction \\
\hline HFrEF & heart failure with reduced ejection fraction \\
\hline $\mathrm{HI}$ & Herzinsuffizienz \\
\hline $\mathrm{HR}$ & hazard ratio \\
\hline HRP & horseradish peroxidase \\
\hline hsCRP & highsensitive $C$-reactive protein \\
\hline IL-6 & Interleukin-6 \\
\hline IQR & interquartile range \\
\hline ir-ADM & immunoreactive adrenomedullin \\
\hline KHK & koronare Herzkrankheit \\
\hline $\mathrm{KNHI}$ & Kompetenznetz Herzinsuffizienz \\
\hline LA & linksatrial \\
\hline LAVI & left atrial volume index \\
\hline $\log$ & Logarithmus \\
\hline LV & linksventrikulär \\
\hline$L V D_{E D}$ & linksventrikulärer enddiastolischer Ventrikeldurchmesser \\
\hline LVEF & linksventrikuläre Ejektionsfraktion \\
\hline LVMI & linksventrikulärer Masse-Index \\
\hline LVVI & linksventrikulärer Volumen-Index \\
\hline MAb & monoclonal antibody \\
\hline
\end{tabular}


MMP Matrix-Metalloprotease

MRproADM mid-regional pro-adrenomedullin

MRproANP mid-regional pro-atrial natriuretic peptide

MW Mittelwert

$\mathrm{n}$

Anzahl

NO Stickstoffmonoxid

$\mathrm{N}$-terminal amino-terminal

NTproANP amino-terminal pro-atrial natriuretic peptide

NTproBNP amino-terminal pro-brain natriuretic peptide

NYHA New York Heart Association

$\mathrm{p}$ (-Wert) Signifikanz(-wert)

pAVK periphere arterielle Verschlusskrankheit

PIIINP procollagen III amino-terminal propeptide

PRA plasma-renin activity

PRC plasma-renin concentration

RAAS Renin-Angiotension-Aldosteron-System

RIA Radioimmunoassay

RR Riva-Rocci

SD standard deviation

TIMP tissue inhibitor of metalloproteinase

TMB 3,3',5,5'-Tetramethylbenzidin 


\section{Einheitenverzeichnis}

\begin{tabular}{|c|c|}
\hline$\mu g$ & Mikrogramm \\
\hline $\mathrm{cm}$ & Centimeter \\
\hline $\mathrm{dl}$ & Deziliter \\
\hline fmol & Femtomol \\
\hline g & Gramm \\
\hline h & Stunde \\
\hline IU & international unit \\
\hline $\mathrm{kg}$ & Kilogramm \\
\hline | & Liter \\
\hline $\mathrm{m}^{2}$ & Quadratmeter \\
\hline $\min$ & Minuten \\
\hline $\mathrm{ml}$ & Milliliter \\
\hline $\mathrm{mmHg}$ & Millimeter Quecksilbersäule \\
\hline $\mathrm{ms}$ & Millisekunde \\
\hline $\mathrm{mV}$ & Millivolt \\
\hline $\mathrm{ng}$ & Nanogramm \\
\hline $\mathrm{nm}$ & Nanometer \\
\hline $\mathrm{nmol}$ & Nanomol \\
\hline $\mathrm{pg}$ & Picogramm \\
\hline pmol & Picomol \\
\hline s & Sekunde \\
\hline
\end{tabular}




\section{Studienverzeichnis}

CHARM Candesartan in Heart Failure - Assessment of Reduction in Mortality and Morbidity

CHS Cardiovascular Health Study

DIAST-CHF Prävalenz und Verlauf der diastolischen Dysfunktion und der diastolischen Herzinsuffizienz

GISSI-HF The Gruppo Italiano per lo Studio della Sopravvivenza insufficienza cardiaca

I-PRESERVE Irbesartan in Patients with Heart Failure and preserved Ejection Fraction

PEP-CHF Perindopril in elderly People with chronic Heart Failure

Val-HeFT Valsartan Heart Failure Trial 


\section{Einleitung}

Die Herzinsuffizienz $(\mathrm{HI})$ stellt ein global größer werdendes Problem der Medizin dar. Insbesondere die Ausprägungsform mit erhaltener Ejektionsfraktion (EF), die mittlerweile ungefähr $50 \%$ der herzinsuffizienten Patienten ausmacht (Paulus et al. 2007), wird zunehmend problematischer, da bei anhaltend steigender Prävalenz bislang keine evidenzbasierte Therapieform bekannt ist (Borlaug und Paulus 2011). Eine unüberschaubare und stetig zunehmende Vielzahl von prognoserelevanten Faktoren sowie deren subjektive Interpretation und komplexe Zusammenführung zur Abschätzung der Prognose lassen den Wunsch nach einfachen, objektiven und zuverlässigen Hilfsmitteln größer werden. Biomarker erfüllen diese und weitere Kriterien, da es sich bei innen um Peptide/Proteine oder Fragmente handelt, die direkt oder indirekt mit der Pathophysiologie der zugrundeliegenden Erkrankung zusammenhängen. Mit dem technischen Fortschritt der letzten Jahrzehnte sind eine Vielzahl von im Blut zirkulierenden Molekülen identifiziert worden, die zur Verbesserung der Diagnose- und Prognosefindung beitragen können und zusätzlich helfen, die Pathophysiologie der HFpEF (heart failure with preserved ejection fraction) besser zu verstehen. Während die kardialen natriuretischen Peptide in dieser Hinsicht bislang als am besten untersucht gelten, existieren für andere Biomarker in Bezug auf die Prognoseabschätzung der diastolischen Dysfunktion (DD) und HFpEF nur wenige oder gar keine Daten.

\subsection{Definition}

Die HI kann als Anomalie der kardialen Strukturen oder Funktionen definiert werden, die dazu führt, dass das Herz nicht mehr in der Lage ist, die Gewebe des Körpers mit einer ausreichenden Menge an Sauerstoff zu versorgen. Aus klinischer Sicht handelt es sich um ein Syndrom, bei dem die Patienten typische Symptome wie Dyspnoe, Knöchelödeme oder reduzierte Leistungsfähigkeit und Anzeichen wie einen erhöhten Jugularvenendruck, pulmonale Rasselgeräusche oder einen verschobenen Herzspitzenstoß aufweisen, die auf Anomalien der kardialen Strukturen oder Funktionen zurückzuführen sind. Weitere Symptome und Zeichen können gemäß ESC-Guidelines (European Society of Cardiology) Orthopnoe, paroxysmale nächtliche Dyspnoe, nächtlicher Husten, hepatojugulärer Reflux, Aszites, Hepatomegalie, Tachykardie oder ein dritter Herzton sein (McMurray et al. 2012).

Es gab in der Vergangenheit diverse Versuche, die verschiedenen Ausprägungsformen der $\mathrm{HI}$ zu klassifizieren. Neben einer Einteilung in akute und chronische Formen existieren unter anderem Einteilungen anhand der Lokalisation in Linksherz-, Rechtsherz- und Globalinsuffizienz sowie des klinischen Schweregrads in NYHA-Stadien (New York Heart 
Association). Von einer Einteilung entsprechend der jeweiligen Dysfunktion in systolische bzw. diastolische $\mathrm{HI}$ wurde in der Literatur wieder Abstand genommen, da sie ungenau war und vermuten ließ, dass systolische und diastolische Dysfunktionen nicht gleichzeitig auftreten können. Erst später wurde bekannt, dass bei der diastolischen $\mathrm{HI}$ auch eine milde systolische Dysfunktion vorliegt und somit der Grundgedanke der Einteilung nicht korrekt war. Die momentan gängige Einteilung in HFrEF (heart failure with reduced ejection fraction) und HFpEF ist daher geeigneter (Sanderson 2007).

Die DD beschreibt lediglich eine kardiale Anomalie, nämlich das Unvermögen des Herzens, den Ventrikel bei angemessen niedrigen Drücken bis zum enddiastolischen Volumen zu füllen. Sie tritt im Gegensatz zur HI asymptomatisch auf (Zile 2003). Die HFrEF ist charakterisiert durch eine verminderte Kontraktilität und EF des Herzens. Während das Schlagvolumen durch eine Erhöhung des enddiastolischen Volumens, die der Dilatation des linken Ventrikels geschuldet ist, erhalten bleibt, kann das Herz nur noch einen verminderten Anteil (EF $<50 \%$ ) hiervon auswerfen. Bei Patienten mit HFpEF handelt es sich um eine größer werdende Gruppe von Erkrankten, die Symptome und Zeichen einer $\mathrm{HI}$ aufweisen, deren EF jedoch erhalten ist. Es kommt durch eine verminderte Dehnbarkeit des Herzens zu einem rascheren Druckanstieg in der Füllungsphase. Das enddiastolische Volumen wird zwar erreicht, jedoch vermindert sich das Schlagvolumen, wenngleich der Anteil des Blutes, der vom Herzen ausgeworfen wird, nahezu erhalten ( $E F \geq 50 \%$ ) bleibt (McMurray et al. 2012).

Zur Diagnose der HFpEF müssen laut McMurray et al. (2012) die folgenden vier Kriterien erfüllt sein: Das Vorhandensein von Symptomen (1) und Anzeichen (2) einer HI, wobei die EF in Abwesenheit einer linksventrikulären (LV)-Dilatation nicht oder nur leicht reduziert sein darf (3) und eine Anomalie (4) wie LV-Hypertrophie, linksatriale (LA)-Dilatation oder eine DD vorliegt. Letztere kann echokardiographisch und mithilfe der Bestimmung von NTproBNP (amino-terminal pro-brain natriuretic peptide) diagnostiziert werden. Ist während der echokardiographischen Untersuchung im Gewebedoppler ein Verhältnis von E/e' > 15 (maximale frühdiastolische Einstromgeschwindigkeit/Geschwindigkeit der Bewegung des Mitralklappenanulus während der passiven Füllung) festzustellen, so kann von einer DD ausgegangen werden. Im sogenannten Graubereich, der sich über $15>\mathrm{E} / \mathrm{e}^{\prime}>8$ erstreckt, muss zusätzlich eine erhöhte NTproBNP-Konzentration (>220 pg/ml) vorliegen, um von einer relevanten DD sprechen zu können (Paulus et al. 2007). 


\section{2 Ätiologie}

Bei den Risikofaktoren und assoziierten Vorerkrankungen der HFpEF handelt es sich zwar um dieselben wie bei HFrEF, allerdings unterscheiden sich die Prävalenzen der meisten Vorerkrankungen in charakteristischer Weise. Bei Patienten mit HFpEF handelt es sich vorrangig um ältere Personen, eher weiblichen Geschlechts mit tendenziell erhöhtem BMI (body-mass-index) und Adipositas (Owan et al. 2006). Bei den Vorerkrankungen liegt bei HFpEF laut Owan et al. (2006) eine höhere Prävalenz für Hypertonie (62\%) und Vorhofflimmern (41\%) und eine geringere Prävalenz für koronare Herzkrankheit (KHK) (52\%) und Erkrankungen der Herzklappen (2,6 \%) vor. McMurray et al. (2008) bestätigten diese Tendenzen und stellen weiterhin eine geringere Prävalenz für vorausgegangene Myokardinfarkte bei HFpEF fest. Eine LV-Hypertrophie tritt in ihrem Kollektiv bei $31 \%$ der Patienten auf. Nach Naughton (2003) stellt auch das obstruktive Schlafapnoesyndrom einen Risikofaktor für beide Formen der HI dar. Das Ätiologie-Profil von HFpEF weist im Gegensatz zu dem der HFrEF klare Unterschiede auf. Bei HFrEF ist das männliche Geschlecht bevorzugt, die Patienten sind jünger und weniger adipös. Bei den Vorerkrankungen sind die Prävalenzen für KHK und Klappenerkrankungen höher und solche für Hypertonie und Vorhofflimmern geringer. Die Prävalenz für Diabetes mellitus ist mit 33 - $34 \%$ bei beiden Ausprägungsformen gleich groß (Owan et al. 2006).

\subsection{Epidemiologie}

Im Allgemeinen betrifft die $\mathrm{HI}$ vor allem ältere Menschen und ist gekennzeichnet durch eine hohe Prävalenz und niedrige Überlebensraten. Die Prävalenz nimmt seit 30 Jahren stufenweise zu und deutet in Kombination mit einer älter werdenden Gesellschaft und häufiger auftretenden Komorbiditäten wie Adipositas und Diabetes mellitus darauf hin, dass die $\mathrm{HI}$ als Erkrankung auch in Zukunft an Bedeutung zunehmen wird. Die steigende Häufigkeit und Länge der durch $\mathrm{HI}$ verursachten Hospitalisationen stellen ebenso ein finanziell größer werdendes Problem für die Gesundheitssysteme dar (Guha und McDonagh 2013).

Die Vergleichbarkeit von Studien zur Epidemilogie der $\mathrm{HI}$ ist eingeschränkt, da innen durch wechselnde Definitionen keine einheitlichen Diagnosekriterien insbesondere hinsichtlich der EF zugrunde liegen. Während vor dem 40 . Lebensjahr nur $1 \%$ aller Menschen von einer Form der $\mathrm{HI}$ betroffen sind, so steigt die Anzahl der Betroffenen im Altersbereich ab 75 Jahren auf ca. $10 \%$ an (Jessup und Brozena 2003, Paulus et al. 2007). In der Framingham-Studie wurde eine mit dem Alter steigende Inzidenz von 3 / 1000 zu Beginn der Studie bis 91 / 1000 in der Patientengruppe $\geq 80$ Jahren nach 34 Jahren Beobachtungszeitraum festgestellt (Ho et al. 1993). Aktuellere Untersuchungen 
aus England mit einer Patientenzahl von 696.884 geben eine Inzidenz von 9,3 / 1000 pro Jahr an (de Giuli et al. 2005). Die Prävalenz liegt laut Davies et al. (2001) bei 1,8 - 3,5\%. Beim selben Kollektiv fanden Hobbs et al. (2007) eine Mortalitätsrate von $47 \%$ über fünf Jahre.

Für die DD wird eine Prävalenz von 3,1 \% angegeben, die mit dem Alter steigt und höher ist als die der systolischen Dysfunktion (Fischer et al. 2003). Die HFpEF betrifft inzwischen ungefähr 50 \% der herzinsuffizienten Patienten (Hogg et al. 2004, Owan et al. 2006). Männer sind paradoxerweise häufiger von der DD und Frauen häufiger von HFpEF betroffen (Hogg et al. 2004). Die Prävalenz der HFpEF hängt stark vom Alter ab und variiert in der Literatur zwischen 1,2\% in der Olmsted-Studie (Redfield et al. 2003) und $4,8 \%$ in einer Analyse der CHS (Cardiovascular Health Study) (Kitzman et al. 2001). Laut Borlaug et al. (2010) steigt die Prävalenz der HFpEF um 1\% pro Jahr im Vergleich zur HFrEF.

Bezüglich der Mortalität stellten Owan et al. (2006) eine etwas geringere Rate für HFpEF fest, was auch Metaanalysen der 'Meta-analysis Global Group in Chronic Heart Failure' (MAGGIC) bestätigen (Berry et al. 2012). Von Hobbs et al. (2007) wird sie beim oben genannten Kollektiv aus England mit $38 \%$ über fünf Jahre angegeben, was mit den Beobachtungen von Zile und Brutsaert (2002) übereinstimmt, die jährliche Mortalitätsraten von $10-15 \%$ für HFrEF, 5 - $8 \%$ für HFpEF und $1 \%$ in einer altersgleichen Kontrollgruppe feststellen.

\subsection{Pathophysiologie}

Die DD mit pathologischen Veränderungen der Relaxation, Füllung und Dehnbarkeit des linken Ventrikels wurde lange Zeit als einzige Ursache der HFpEF angesehen (Soufer et al. 1985, Sanderson et al. 1997). Zwar wurde sie als wichtiger Bestandteil der Pathophysiologie von HFpEF bestätigt (Zile et al. 2004) und inr negativer Einfluss auf die Herzleistung gezeigt (Westermann et al. 2008), jedoch ist sie nicht die einzige Ursache der Erkrankung und tritt beispielsweise im Kollektiv der 'I-PRESERVE'-Studie (Irbesartan in Patients with Heart Failure and preserved Ejection Fraction) nur bei $69 \%$ der Patienten auf (Zile et al. 2011b). Die Pathophysiologie ist vielmehr ein komplexes Zusammenspiel verschiedener Schädigungen im Bereich der systolischen, diastolischen und chronotropen Reservefunktion der Ventrikel und Störungen, die zu einer atrialen Dysfunktion, einer Versteifung der Ventrikel und Gefäße, einer Beeinträchtigung der systemischen Vasodilatation, einem pulmonalen Hypertonus, endothelialen Dysfunktionen und verschiedensten, peripheren Veränderungen führen. Charakteristisch für die HFpEF ist der erhöhte linksventrikuläre Füllungsdruck. Trotz einer erhaltenen EF liegt eine milde 
systolische Dysfunktion vor, deren Auswirkung auf die Reservefunktionen des Herzens vor allem unter Belastung deutlich wird (Borlaug 2014). Die früher als typisch für HFpEF angesehene linksventrikuläre Hypertrophie (Zile et al. 2001), die mit einer verringerten Dehnbarkeit einhergeht, ist ebenfalls nicht bei allen Patienten zu beobachten. So zeigen Zile et al. (2011b) erneut in der I-PRESERVE-Studie, dass ca. $41 \%$ der Patienten weder Hypertrophie noch konzentrisches Remodelling, sondern eine annährend normale Geometrie des linken Ventrikels aufweisen. Fast $2 / 3$ des Kollektivs zeigen allerdings eine Dilatation des linken Vorhofs, dessen Schweregrad wie die Hypertrophie mit einer erhöhten Mortalität einhergeht. Die Hypertrophie wird in relevanter Art und Weise durch das Renin-Angiotensin-Aldosteron-System (RAAS), Arginin-Vasopressin (AVP) und Endothelin-1 (ET-1) beeinflusst, welche auch an der gesteigerten Fibrose des Herzens und an endothelialen Dysfunktionen beteiligt sind (Ito et al. 1991, Schunkert et al. 1997, Tahara et al. 1998).

Der Druckabfall in der frühen Diastole wird im gesunden Herzen durch die Abspaltung der Myofilamente, den Calcium ${ }^{2+}\left(\mathrm{Ca}^{2+}\right)$-Reuptake und die passive elastische Rückstellung des Ventrikels herbeigeführt (Borlaug und Kass 2006). Dieser Druckabfall ist bei DD/HFpEF durch erhöhte Drücke im linken Vorhof und Ventrikel verlängert und die Relaxation somit verzögert (Wachter et al. 2009). Es kommt zu einer Verschiebung der Druck-Volumen-Kurve nach links und oben. Die normalerweise unter Belastung gesteigerte Saugfunktion des linken Ventrikels, die einen Hochdruck im linken Vorhof verhindern soll, ist verringert, sodass dieser hohe Drücke benötigt, um den Ventrikel zu füllen (Cheng et al. 1993). Bei gesunden Menschen finden $80 \%$ der Ventrikelfüllung passiv während der frühen Diastole statt, während die letzten $20 \%$ aktiv durch Kontraktion des Vorhofs ausgelöst werden. HFpEF-Patienten scheinen stärker von der aktiven Füllung durch den Vorhof abhängig zu sein (Phan et al. 2009b) und zeigen im Verlauf ein Fortschreiten der Dilatation und einen Verlust der Kontraktilitätreserven des Vorhofs, gerade unter Belastung (Tan et al. 2010). Das enddiastolische Volumen ist schließlich nicht oder nur unwesentlich verringert, es wird jedoch ein höherer Druck benötigt, um es zu erreichen. Dies führt zu Symptomen wie Dyspnoe, einem pulmonalen Hypertonus und fördert die Entwicklung einer rechtsventrikulären Dysfunktion sowie Vorhofflimmern (Borlaug 2014). Bei der Entstehung der DD spielen Veränderungen in der extrazellulären Matrix (EZM) und den Kardiomyozyten eine Rolle, die zu einer erhöhten Steifigkeit führen. Die Fibrose wird ebenfalls durch das RAAS und ET-1 beeinflusst (Weber und Brilla 1991, Guarda et al. 1993, Weber 2001), nimmt aber auch mit steigendem Alter sowie durch Hypertonie und Diabetes mellitus zu, was ebenfalls in einer erhöhten Steifigkeit von Ventrikeln und Gefäßen resultiert (Kawaguchi et al. 2003). In der EZM wird die Steifigkeit vorrangig durch die Menge und den Grad der Quervernetzung 
von Kollagen I (Borlaug und Paulus 2011) und Kollagen III beeinflusst. Eine Störung im Gleichgewicht von MMPs (Matrix-Metalloproteasen) und TIMPs (tissue inhibitor of metalloproteinase) kann zu einem verminderten Abbau des Kollagens und einer erhöhten Steifigkeit führen, was für HFpEF-Patienten mit Hypertonie (Ahmed et al. 2006) und Aortenstenose (Heymans et al. 2005) bereits gezeigt wurde. Die veränderten Konzentrationen von Fragmenten des Kollagen I und III, MMP-1 und TIMP-1 ermöglichen deren Nutzung als prädiktive Biomarker der HFpEF (González et al. 2008). Einen weiteren Beitrag zur erhöhten Steifigkeit leisten die Kardiomyozyten selbst, die dicker und weniger gestreckt sind als bei HFrEF. Die Steifigkeit der Kardiomyozyten wird vor allem vom Zytoskelettprotein Titin beeinflusst, welches bei HFpEF verstärkt in der unelastischeren Isoform vorliegt (van Heerebeek et al. 2006). Auch die Phosphorylierung durch cGMP (cyklisches Guanosinmonophosphat) verändert die Elastizität von Titin (Hidalgo und Granzier 2013). Bei HFpEF kommt es zu einer Hypophosphorylierung durch zu geringe Mengen an cGMP, die wiederum einem Anstieg des nitrosativen/oxidativen Stresses (van Heerebeek et al.2012) und der geringen Bioverfügbarkeit von Stickstoffmonoxid (NO) geschuldet sind. Auch Veränderungen in der $\mathrm{Ca}^{2+}$-Homöostase beeinflussen die Elastizität der Kardiomyozyten, da es durch eine NO-induzierte Sensitivitätsänderung der Myofilamente zu einer erleichterten Ablösung von $\mathrm{Ca}^{2+}$ und infolgedessen zu einer Erhöhung der Konzentration kommt (Paulus et al. 1994), die in einer geringer ausfallenden Relaxation während der Diastole resultiert. Dieser Energie verbrauchende Prozess kann zu einem Energiedefizit des Myokards führen, welches ebenfalls für die verlangsamte Relaxation verantwortlich sein kann (Phan et al. 2009a). Weiterhin korrelieren endotheliale Dysfunktionen mit der Stärke von Symptomen wie Dyspnoe und Erschöpfung. Durch multiple Komorbiditäten kommt es nach systemischer Inflammation zu mikrovaskulären Inflammationen, gefolgt von einer verringerten NOBioverfügbarkeit und einer daraus resultierenden erhöhten Steifigkeit der Kardiomyozyten durch hypophosphoryliertes Titin und Fibrose der EZM. Da diese Prozesse eine zentrale Rolle in der Pathophysiologie der HFpEF zu spielen scheinen (Paulus und Tschöpe 2013), versprechen Messungen entsprechender inflammatorischer Biomarker eine Verbesserung der Diagnose- und Prognosefindung sowie eine weitere Aufklärung der Pathophysiologie.

Die EF wird klinisch häufig zur Beurteilung der systolischen Funktion herangezogen, wobei sie laut Borlaug et al. (2009) eher die ventrikulo-arterielle Kopplung beschreibt. Bei hoher Nachlast kann die EF trotz physiologischer Kontraktilität verringert sein, oder sie kann unverändert sein, obwohl die Kontraktilität verringert ist, wenn die Nachlast gering ist. So ist zwar die EF bei HFpEF erhalten, trotzdem liegen Anomalien der systolischen Funktion vor (Yu et al. 2002), die jedoch deutlich geringer ausgeprägt sind als bei HFrEF 
(Fukuta und Little 2007) und unter Belastung deutlicher hervortreten (Tan et al. 2009). Die Erhöhung der EF unter Belastung ist bei HFpEF eingeschränkt (Borlaug et al. 2010) und führt durch ein zu hohes endsystolisches Volumen zu einer Verschlechterung der Saugfunktion des Ventrikels, was den Hochdruck im Vorhof fördert. Borlaug et al. (2010) beschreiben den Zusammenhang zwischen anormaler ventrikulo-arterieller Kopplung und verminderter Leistungsfähigkeit bei HFpEF, die weiterhin durch eine unzureichende systemische Vasodilatation eingeschränkt wird. In Kombination mit der verringerten chronotropen Reserve, d.h. der verringerten Möglichkeit die Herzfrequenz (HF) unter Belastung zu steigern, werden das Herzzeitvolumen und die Belastbarkeit stark eingeschränkt. Die Reduktion von kardiovaskulären (CV, cardiovascular), nämlich systolischen, diastolischen, chronotropen und vaskulären Reserven spielt eine wichtige Rolle bei HFpEF. Der kombinierte Verlust führt bei Patienten zu Symptomen, wobei die ausschlaggebenden Faktoren von Patient zu Patient variieren können (Borlaug et al. 2010).

Viele der genannten Prozesse treten auch mit voranschreitendem Alter auf, wenngleich der Schweregrad hier geringer ausfällt (Borlaug et al. 2010). So kommt es trotz gewöhnlicher Alterung ohne das Vorhandensein einer Hypertonie ebenso zu einer erhöhten Steifigkeit der Ventrikel (Fujimoto et al. 2012) und einer verlangsamten Relaxation (Carrick-Ranson et al. 2012). Adipositas beschleunigt die altersabhängige Versteifung insbesondere bei Frauen (Borlaug et al. 2013, Wohlfahrt et al. 2014) und erhöht nitrosativen/oxidativen Stress. Weiterhin verringern sich im Alter die kardialen Reserven, die bei der Anpassung unter Belastung benötigt werden (Fleg et al. 1985).

\subsection{Stellenwert von Biomarkern bei der Prognosefindung}

Obwohl die Prognoseabschätzung generell von hoher Wichtigkeit ist, um die Behandlung von Patienten zu individualisieren und sie hinsichtlich medizinischer Therapien oder späterer Pflege aufzuklären, sind Faktoren, die die Mortalität bei HFpEF zuverlässig vorhersagen können weitgehend unerforscht. Die ESC-Guidelines 2012 (McMurray et al. 2012) listen eine große Anzahl von Faktoren auf, die prognoserelevant sind. Zu diesen zählen neben demographischen Daten wie Alter, Geschlecht, NYHA-Klasse und Komorbiditäten auch Routinelaborwerte sowie Veränderungen im Elektrokardiogramm (EKG), der Echokardiographie und Ergometrie. Ein klares Schema zur Prognosefindung ist allerdings nicht vorhanden, und viele Variablen weisen eine geringe Spezifität auf. Zusätzlich herrscht eine große Inhomogenität in der Ausprägung von Symptomen und Überschneidungen mit anderen Erkrankungen. Die geringe Spezifität, deren subjektive Interpretation und komplexe Zusammenführung treiben die Suche nach objektiveren und 
besser geeigneten Hilfsmitteln voran. In den letzten Jahrzehnten wurde eine Vielzahl von zirkulierenden Molekülen identifiziert, die direkt mit der Pathophysiologie der HI zusammenhängen. Diese Biomarker tragen gleichzeitig zur Aufklärung der Pathophysiologie, Entwicklung neuer Therapieansätze und möglicherweise zur Verbesserung der Diagnose- und Prognosefindung bei. Masson et al. (2010a), Xue et al. (2013) und Lassus et al. (2013) zeigen beispielsweise eine Verbesserung von klinischen Risikomodellen zur Prognoseabschätzung bei HFrEF durch die Integration von Biomarkern. Durch definierte Grenzwerte stellen diese einzeln oder in Kombination praktische, schnelle, zuverlässige und objektive Hilfsmittel dar, die aufgrund ihrer minimalen Invasivität und hohen Spezifität Vorteile gegenüber anderen prognoserelevanten Faktoren bieten oder diese zumindest ergänzen.

Die vorliegende Arbeit untersucht die prognostische Wertigkeit von zehn verschiedenen Biomarkern hinsichtlich eines kombinierten Endpunkts aus Mortalität und CVHospitalisation im Kollektiv der 'DIAST-CHF'-Studie (Prävalenz und Verlauf der diastolischen Dysfunktion und der diastolischen Herzinsuffizienz) über einen Zeitraum von 5,2 Jahren. Die Biomarker stammen aus den Bereichen der neurohumoralen Regulation, des myokardialen Stresses, der Entzündung und des EZM-Remodellings und sind allesamt mit der Pathophysiologie der DD und HFpEF verbunden. Bis auf Aldosteron, hsCRP (highsensitive C-reactive protein) und Renin handelt es sich um Fragmente der eigentlich nachzuweisenden Peptide bzw. deren Vorstufen, da diese eine längere Halbwertszeit und höhere Stabilität aufweisen und folglich mit weniger Aufwand zu bestimmen sind. Zu den Markern zählen die Fragmente MRproANP (mid-regional proatrial natriuretic peptide), NTproANP (amino-terminal pro-atrial natriuretic peptide) und NTproBNP der entsprechenden kardialen natriuretischen Peptide, die Fragmente CTproAVP (carboxy-terminal pro-arginin vasopressin), CTproET-1 (carboxy-terminal proendothelin-1), MRproADM (mid-regional pro-adrenomedullin) sowie Renin und Aldosteron als weitere Vertreter der Neurohormone, der Entzündungsmarker hsCRP und das Fragment PIIINP (procollagen III amino-terminal propeptide) des proKollagen III als Indikator des Matrix-Remodellings.

\subsubsection{Neurohumorale Marker}

\subsubsection{Myokardialer Stress (ANP, BNP, ADM)}

Die kardialen natriuretischen Peptide gehören zu den bislang am besten untersuchten Biomarkern der $\mathrm{HI}$ und stellen mit BNP (brain natriuretic peptide) und NTproBNP den Goldstandard der Prognoseabschätzung dar. Ihre Gemeinsamkeit mit ADM (Adrenomedullin) besteht darin, dass die Sekretion unter anderem durch myokardialen 
Stress stimuliert wird. Während ANP (atrial natriuretic peptide) Anfang der Achtziger Jahre von de Bold et al. (1981) entdeckt wurde, konnten Sudoh et al. (1988) BNP sieben Jahre später zunächst im Gehirn von Schweinen nachweisen, was dem Peptid bis heute einen Teil seines Namens verleiht. ANP und BNP werden vorrangig in den Myozyten des Vorhofs bzw. des Ventrikels auf einen erhöhten Druck- bzw. Dehnungsreiz hin gebildet (Yasue et al. 1994). Ihre Wirkung ist weitestgehend identisch und besteht in einer gesteigerten Diurese, Natriurese, Vasodilatation, Hemmung des RAAS über eine Blockierung der Renin- und Aldosteron-Freisetzung sowie einer verbesserten Relaxation des Herzens in der Diastole (Cody et al. 1986, Marcus et al. 1996). ADM wurde zuerst von Kitamura et al. (1993) in Zellen eines Phäochromozytoms entdeckt und hat neben stark vasodilatorischen Eigenschaften ebenfalls natriuretische und diuretische Effekte (Ishiyama et al. 1993) sowie eine positiv inotrope Wirkung auf das Herz. Es wird im Endothel und unter anderem im insuffizienten Herzen gebildet (Sugo et al. 1994, Jougasaki et al. 1996). Die Sekretion von ADM wird ähnlich wie die von ANP und BNP durch einen erhöhten Druck im Ventrikel, mechanischen Stress aber auch durch Entzündung ausgelöst. Die Wirkungsmechanismen aller drei Peptide sind als kompensatorische Reaktionen auf den erhöhten Druck zu verstehen und senken Vorsowie Nachlast.

Diverse Studien konnten zeigen, dass die Konzentration von NTproBNP bei HFrEF und HFpEF im Vergleich zur Kontrollgruppe erhöht ist, wenngleich diese Erhöhung bei HFpEF geringer ausfällt (Tschöpe et al. 2005, McKelvie et al. 2010). Dies liegt am geringeren Wandstress, der aus einem verkleinerten linken Ventrikel und dickerem Myokard resultiert (Iwanaga et al. 2006). Die Höhe der NTproBNP-Konzentration korreliert mit dem Schweregrad der DD (Tschöpe et al. 2005) und hängt von weiteren Faktoren wie Geschlecht, Alter und diversen Komorbiditäten ab. Die Vermutung von Cleland et al. (2007) und McKelvie et al. (2010) zum Zusammenhang mit der Prognose bei HFpEF wird von mehreren Studien bestätigt (Grewal et al. 2008, Anand et al. 2011, Komajda et al. 2011, Cleland et al. 2012). Das Risiko für die Mortalität oder CV-Hospitalisation steigt mit der Konzentration von NTproBNP, also dem Schweregrad der $\mathrm{HI}$, und scheint zwischen HFrEF und HFpEF vergleichbar zu sein. Die prognostische Wertigkeit von NTproBNP ist als die Höchste unter den bisher bekannten Biomarkern einzustufen und dient auch in dieser Arbeit als Referenz für andere Marker.

ANP bzw. die beiden Fragmente MRproANP und NTproANP werden in Studien deutlich seltener bestimmt, da sich NTproBNP insgesamt durchgesetzt hat. Dass ANP bei HI in erhöhter Konzentration im Plasma zirkuliert, zeigten bereits Hartter et al. (1985). Bislang gibt es allerdings weder Studien, die sich mit der Prognosekraft eines der beiden Fragmente bei DD oder HFpEF beschäftigen, noch solche, die Angaben zur 
Konzentration in entsprechenden Kollektiven machen. NTproANP enthält zwar laut Selvais et al. (2000) und van Beneden et al. (2004) prognostische Informationen bei HFrEF, doch schneidet das Fragment insgesamt vergleichsweise schlecht ab und bleibt zum Beispiel hinter der Prognosekraft von ET-1 zurück. Für MRproANP zeigt sich hingegen ein anderes Bild. Im HFrEF-Kollektiv von Masson et al. (2010a) steigt die Mortalität mit der Konzentration von MRproANP kontinuierlich an und das Fragment stellt sich als guter prognostischer Faktor heraus. Es enthält zusätzliche und von BNP unabhängige, prognostische Valenz und verbessert ein Prognosemodell aus klinischen Risikofaktoren (Masson et al. 2010a). Diverse weitere Autoren sprechen bei HFrEF von einer Prognosekraft, die mindestens vergleichbar ist mit der von NTproBNP (Haehling et al. 2007, Moertl et al. 2009, Neuhold et al. 2010). Insbesondere die Untersuchung des Fragments MRproANP ist daher für die Prognosefindung bei DD und HFpEF vielversprechend.

Die Konzentration von ADM ist bei HI ebenfalls erhöht (Nishikimi et al. 1995). Dieses bestätigten auch Yu et al. (2001) sowohl für HFrEF als auch DD und HFpEF, was am restriktiven Füllungsmuster und der damit verbundenen Erhöhung des linksventrikulären Füllungsdrucks als Stimulus der Synthese liegt. Die Prognosekraft von ADM bzw. MRproADM bei DD und HFpEF ist allerdings unklar. Studien zur HFrEF zeigen jedoch eine hohe prognostische Valenz für das Fragment, sowohl bei akuter als auch bei chronischer HI. MRproADM korreliert laut Masson et al. (2010a) signifikant mit der Mortalität bei HFrEF und ist hierfür prädiktiv. Der kombinierte Endpunkt aus Tod und CVHospitalisation, der mit dem der vorliegenden Arbeit übereinstimmt, tritt in diesem Kollektiv mit steigender Konzentration von MRproADM signifikant häufiger auf. Dass MRproADM als prognostischer Faktor bei HFpEF von Interesse sein kann, zeigen Beobachtungen in HFrEF-Studien, in denen eine von der EF unabhängige (von Haehling et al. 2010) und insbesondere bei milder und non-ischämischer Ätiologie ausgeprägte Prognosekraft festgestellt wurde (Adlbrecht et al. 2009).

Im Gegensatz zu NTproBNP ist die prognostische Wertigkeit von MRproANP, NTproANP und MRproADM bei DD und HFpEF noch unklar. Diverse Studien zur HFrEF lassen allerdings vermuten, dass diese Marker auch bei DD und HFpEF positiv zur Prognosefindung beitragen könnten, was in dieser Arbeit untersucht werden soll.

\subsubsection{Weitere Neurohormone (Renin, Aldosteron, AVP, ET-1)}

Die $\mathrm{HI}$ ist neben der Ausschüttung von ANP, BNP und ADM auch mit der Aktivierung weiterer Neurohormone assoziiert. Sie alle haben gemeinsam, dass ihre Sekretion endokrin, parakrin oder autokrin stattfindet und Kompensationsmechanismen darstellen. 
Die hier untersuchten Neurohormone Aldosteron, AVP und ET-1 wirken vasokonstriktorisch und antagonistisch zu den kardialen natriuretischen Peptiden ANP und BNP, was auch indirekt für Renin gilt, welches das RAAS aktiviert. Sie alle tragen bei dauerhaft erhöhten Konzentrationen allerdings zur Verschlechterung der HI bei (Schrier und Abraham 1999).

Renin ist ein proteolytisches Schlüssel-Enzym in der Regulation des Blutdruckes und wurde in der humanen Form erstmals vollständig von Galen et al. (1979) aus einem juxtaglomerulären Tumor isoliert. Die Synthese erfolgt zunächst als Prorenin in den juxtaglomerulären Zellen der Niere, wo es in Vesikeln gespeichert und später durch Reize wie einen verringerten Blutdruck, eine verringerte Natriumkonzentration sowie die Aktivierung des sympatischen Nervensystems freigesetzt wird. Es aktiviert durch die Spaltung von Angiotensinogen zu Angiotensin I das RAAS, was zur Retention von Natrium und Wasser und einer Steigerung des Blutdrucks führt (Sealey et al. 1980). Die Aktivität des RAAS erhöht sich mit dem Schweregrad der HI (Schrier und Abraham 1999) mit dem Ziel die Perfusion der Organe aufrecht zu erhalten. Das stimulierte RAAS fördert nicht nur die myokardiale Fibrose, sondern auch die DD (Weber und Brilla 1991), die beide ihren Anteil an der Pathophysiologie der HFpEF haben. Eine direkte Hemmung von Renin mit Aliskiren zeigte im Tiermodell eine Reduktion der myokardialen Fibrose und Verbesserung der DD (Zhi et al. 2013). Da die Konzentration von Angiotensin II unverändert blieb, deuten diese Ergebnisse auf eine direkte Beteiligung von Renin oder Prorenin an der Fibrose hin. Die prognostische Wertigkeit von Renin bei DD und HFpEF ist allerdings unklar, da keinerlei Studien hierzu existieren. In Untersuchungen zur Prognosekraft bei HFrEF wird häufig die PRA (plasma-renin activity) statt der PRC (plasma-renin concentration) gemessen, obwohl Tsutamoto et al. (2007) für HFrEF feststellten, dass die PRC prognostisch wertvoller ist. Latini et al. (2004) zeigen zur chronischen HI mit reduzierter EF in einer Analyse der 'Val-HeFT'-Studie (Valsartan Heart Failure Trial), dass die PRA nicht prädiktiv für den kombinierten Endpunkt aus Mortalität und CV-Hospitalisation ist, allerdings für die reine Mortalität. Masson et al. (2010b) betrachten ein ähnlich großes Kollektiv und beschreiben signifikante Korrelationen sowohl für die Gesamtmortalität als auch für einen kombinierten Endpunkt aus Mortalität und Morbidität. Für die Einschätzung einer sehr langfristigen Prognose scheint die PRA laut Volpe et al. (2010) allerdings ungeeignet zu sein.

Aldosteron ist ein Steroidhormon dessen Synthese in der Nebennierenrinde unter anderem durch ein vermindertes Blutvolumen oder ausgehend von einem verminderten Blutdruck durch das RAAS bzw. Angiotensin II stimuliert wird. Es kann jedoch auch im Ventrikel des insuffizienten Herzen gebildet werden (Mizuno et al. 2001). Die Hauptfunktion von Aldosteron besteht in einer gesteigerten Retention von Natrium und 
Wasser in der Niere, was zusammen mit den Effekten von Angiotensin II zu einer Steigerung des Blutdrucks sowie Vor- und Nachlast führt. Es zeigte sich, dass erhöhte Plasmaspiegel von Aldosteron endotheliale Dysfunktionen, kardiale Hypertrophie und Fibrose fördern (Schunkert et al. 1997, Muscholl et al. 1998, Weber 2001). Weiterhin stimuliert es die Kollagen I und III Synthese in Fibroblasten (Robert et al. 1994) und moduliert MMPs und TIMPs (Deschamps und Spinale 2006), was zur erhöhten Steifigkeit der Ventrikel beiträgt und den Einfluss auf die Entwicklung und Progression der DD und HFpEF unterstreicht. Swedberg et al. (1990) zeigen, dass eine erhöhte Aldosteronkonzentration signifikant mit einer erhöhten Mortalität bei schwerer HI (NYHA IV) korreliert und dass diese durch Hemmung des RAAS mittels ACE-Hemmer (Angiotensin-converting enzyme-Hemmer) bei HFrEF entschieden gesenkt werden kann. Ähnliche Therapieansätze mit dem Aldosteron-Antagonisten Spironolacton schienen bei HFpEF schlüssig, führten jedoch nicht zu einer Senkung der Mortalität, wenngleich sich einige diastolische Parameter insbesondere bei Frauen verbesserten (Edelmann et al. 2012). Es wurde bislang nur eine Studie veröffentlicht, die sich mit der Prognosekraft von Aldosteron beschäftigt und dabei bedingt auf HFpEF eingeht. Güder et al. (2007) teilen ihr Kollektiv anhand der echokardiographisch festgelegten Verkürzungsfraktion (FS, fractional shortening) in systolische (FS < $24 \%$ ) und nicht-systolische $\mathrm{HI}(\mathrm{FS} \geq 24 \%)$ ein und sehen insgesamt einen signifikanten Zusammenhang zur Mortalität. Diverse HFrEF-Studien sind jedoch geteilter Meinung. So stufen Latini et al. (2004) die prognostische Wertigkeit von Aldosteron als sehr gering ein, zeigen aber, dass diese auch von einer Medikation mit ACE-Hemmern abhängt. Korrelationsnachweise von Cicoira et al. (2004), Tsutamoto et al. (2007) und Vergaro et al. (2011) scheitern an Adjustierungen in multivariaten CoxRegressionsmodellen, während Girerd et al. (2013) in der 'EVEREST'-Studie zur akuten $\mathrm{HI}$, einen Zusammenhang zwischen Baseline Aldosteron-Konzentrationen und der Mortalität bzw. erneuter Hospitalisation feststellen.

Arginin-Vasopressin ist ein Nonapeptid, welches im Hypothalamus synthetisiert und in der Hypophyse gespeichert wird. Seine Sekretion wird unter anderem durch eine Steigerung der Osmolarität und des kardialen Füllungsdruckes, ein abnehmendes Blutvolumen sowie durch Angiotensin II und ET-1 gefördert (Dunn et al. 1973, Yamamoto et al. 1992). Neben einer Retention von Wasser in der Niere wirkt AVP ebenfalls vasokonstriktorisch und steigert den Blutdruck (Singh Ranger 2002). Dies führt ebenso wie die direkte Induktion über V1a-Rezeptoren (arginin-vasopressin receptor 1A) zu einer Hypertrophie der Kardiomyozyten (Tahara et al. 1998). Goldsmith et al. (1983) stellten fest, dass die Konzentration von AVP bei HI erhöht ist, jedoch bleibt der auslösende Stimulus bislang unklar, da HI Patienten meist eine verringerte Osmolarität aufweisen. AVP trägt durch die Wasserretention auch zu einer verdünnenden Hyponatriämie bei, die bei HFpEF mit 
erhöhter Mortalität einhergeht (Bavishi et al. 2014). Angaben zur prognostischen Wertigkeit von AVP bzw. CTproAVP sind nur zur HFrEF vorhanden und nicht eindeutig. Während Stoiser et al. (2006), Neuhold et al. (2008) und Voors et al. (2009) in kleinen Kollektiven eine höhere prognostische Wertigkeit als die von NTproBNP feststellen, so schneidet CTproAVP in der Studie von Masson et al. (2010a) als schlechtester Biomarker ab. Oftmals besteht nur in hohen Konzentrationen eine prognostische Valenz, die zusätzlich mit dem Endpunkt variiert. Es zeigt sich die Tendenz, dass signifikante Zusammenhänge nach Adjustierung für NTproBNP verloren gehen.

ET-1 wurde von Yanagisawa et al. (1988) in aortalen Endothelzellen von Schweinen entdeckt und zählt zu den stärksten bisher bekannten Vasokonstriktoren. Die lange anhaltende Wirkung beruht auf einem erhöhten $\mathrm{Ca}^{2+}$-Einstrom in die glatten Muskelzellen der Gefäße, welcher über $\mathrm{ET}_{\mathrm{A}}$-Rezeptoren (endothelin A-receptor) vermittelt wird (Shah 2007). Es wirkt außerdem positiv inotrop, beeinflusst das Gleichgewicht des Salz- und Wasserhaushalts und stimuliert das RAAS (Moravec et al. 1989, Kennedy et al. 1993), was insgesamt zu einer Steigerung des Blutdrucks führt. Die positiv inotrope Wirkung ist am insuffizienten Herzen allerdings abgeschwächt (Pieske et al. 1999). Die Synthese von ET-1 wird unter anderem durch den Gefäßtonus und die in der Pathophysiologie der HI relevanten Stoffe Angiotensin II und AVP gefördert (Milner et al. 1990, Barton et al. 1997, Bakris et al. 1991). McMurray et al. (1992) fanden heraus, dass die Plasmakonzentration von ET-1 bei Patienten mit chronischer HI signifikant erhöht ist. Es wurde nachgewiesen, dass ET-1 die Hypertrophie von Kardiomyozyten (Ito et al. 1991) und die Synthese von Kollagen I und III stimuliert (Guarda et al. 1993), was zu einer erhöhten Steifigkeit des Herzens beiträgt, die bei HFpEF eine entscheidende Rolle spielt. Die prognostische Wertigkeit von ET-1 bzw. CTproET-1 bei herzinsuffizienten Patienten ist bislang nur in Zusammenhang mit einer reduzierten EF untersucht worden. Diverse Autoren sprechen dem Fragment CTproET-1 hier prädiktives Potential zu (Masson et al. 2010a, Neuhold et al. 2010, Jankowska et al. 2011). Masson et al. (2010a) zeigen allerdings für einen kombinierten Endpunkt und einen Konzentrationsbereich, der am ehesten einem HFpEFKollektiv entspricht, dass CTproET-1 prädiktiv ist, jedoch Adjustierungen im multivariaten Cox-Regressionsmodell nicht standhält. Deutlich höhere Konzentrationen korrelieren hingegen auch nach Adjustierung signifikant mit dem Endpunkt. Inwieweit diese Beobachtungen für DD und HFpEF relevant sind, soll in dieser Arbeit geklärt werden.

Für Renin, CTproAVP und CTproET-1 sind keine und für Aldosteron nur eine bedingt geeignete Studie bezüglich der Prognosekraft bei DD oder HFpEF vorhanden. Obwohl Aldosteron einen wichtigen Platz in der Pathophysiologie der HFpEF einnimmt, ist die Prognosekraft womöglich gering. CTproET-1 hingegen zeigt eine gute Prognosekraft bei HFrEF und scheint vielversprechend für HFpEF zu sein, da das aktive Peptid ebenfalls an 
Grundaspekten wie Hypertrophie und gesteigerter Fibrose des Myokards beteiligt ist. Bei HFrEF und nach Myokardinfarkten wird für CTproAVP in mehreren Studien eine hohe prognostische Wertigkeit festgestellt, was eine Eignung als prädiktiven Marker im Zusammenhang mit DD und HFpEF erhoffen lässt.

\subsubsection{Entzündungsmarker (hsCRP)}

Das C-reaktive Protein (CRP) zählt zu den Akute-Phase-Proteinen und den ersten Biomarkern, die in Verbindung mit der $\mathrm{HI}$ untersucht wurden (Elster et al. 1956). Es aktiviert in Entzündungsprozessen nicht nur das Komplementsystem, sondern opsoniert auch Antigene für die Phagozytose (Anker und von Haehling 2004). Seine Synthese wird in der Leber maßgeblich von IL-6 (Interleukin-6) auf einen Entzündungsreiz hin stimuliert (Castell et al. 1990). Es ist jedoch unklar, ob und welche Rolle dieser Mechanismus bei der HI spielt. Entzündungsmarker wie IL- 6 und TNF- $\alpha$ (Tumornekrosefaktor $\alpha$ ) sind bei mit HFpEF assoziierten Erkrankungen wie Diabetes mellitus oder Adipositas erhöht und induzieren sowohl Hypertrophie als auch kardiales Remodelling (Seta et al. 1996). Sie scheinen also eine nicht unwichtige Rolle in der Entwicklung der HFpEF zu spielen. Es ist allerdings ungewiss, ob CRP als Reaktion auf die pathologischen Vorgänge am Herzen gebildet wird oder sie direkt moduliert. CRP verringert weiterhin im Endothel die Freisetzung von NO (Venugopal et al. 2002) und erhöht die Synthese von ET-1 (Verma et al. 2002), was ebenfalls zur Progression beiträgt. In diversen Studien konnte gezeigt werden, dass die Konzentration von hsCRP bei HFpEF signifikant erhöht ist (Wisniacki et al. 2005, Michowitz et al. 2008, Okuyan et al. 2010). Bisher sind drei Studien publiziert worden, die die Prognosekraft von hsCRP bei HFpEF untersuchen. Sie kommen allerdings zu unterschiedlichen Ergebnissen. Michowitz et al. (2008) und Matsubara et al. (2014) sehen kein prädiktives Potential für kardiovaskuläre Ereignisse oder Mortalität, was auch für die HFrEF-Gruppe von Michowitz et al. (2008) gilt. Koller et al. (2014) hingegen zeigen in einem speziellen, von KHK geprägten HFpEF-Kollektiv, dass hsCRP ein starker prognostischer Faktor ist. Bei HFrEF wird hsCRP beispielsweise von Anand et al. (2005) und Lamblin et al. (2005) als unabhängiger Prädiktor der Mortalität eingestuft. Diese insgesamt widersprüchlichen Ergebnisse sollen in vorliegender Arbeit weiter untersucht werden.

\subsubsection{Matrix-Remodelling (Kollagen III)}

Das myokardiale Remodelling in Form von Hypertrophie, diffuser Fibrose und Versteifung des linken Ventrikels spielt eine zentrale Rolle in der Entwicklung der HFpEF (Borbély et al. 2009). Die Steifigkeit wird durch die Kardiomyozyten selbst und die Menge bzw. den 
Grad der Quervernetzungen von Kollagen I und III, die den Hauptteil des kardialen Kollagens in der EZM ausmachen, beeinflusst. Myokardiales Kollagen III dient der Strukturgebung und wird zunächst als proKollagen III in Fibroblasten synthetisiert. Nach Abgabe in die EZM wird es in mehreren Schritten prozessiert, wobei das Fragment PIIINP anfällt, welches als Marker für einen gesteigerten Kollagen-III-Umsatz genutzt werden kann (Jensen 1997). Eine Störung der Kollagen-Homöostase im Bereich der regulierenden Enzyme (MMPs, TIMPs) führt bei HFpEF zur Stimulierung der Synthese, Prozessierung und Quervernetzung, sowie einer Hemmung des Abbaus von Kollagen. Die dadurch voranschreitende Fibrose wirkt sich negativ auf die Dehnbarkeit und Relaxation des Herzens aus und trägt zur Entwicklung der DD und HFpEF bei. Im Tierversuch kommt es laut Baicu et al. (2012) bei Druckerhöhung zunächst zu einer LVHypertrophie, der eine Hypertrophie der Kardiomyozyten zu Grunde liegt. Erst nach einer bestimmten Zeit folgt die diffuse Fibrose des Herzens mit Erhöhung der Kollagenmarker im Blut und Verschlechterung der DD-Parameter. Mehrere Studien zeigen eine Erhöhung der PIIINP-Konzentration bei HFpEF-Patienten im Vergleich zur Kontrollgruppe (Barasch et al. 2009, Collier et al. 2011, Zile et al. 2011a). Mit der Prognosekraft bei HFpEF beschäftigen sich nur zwei Studien. Krum et al. (2011) finden einen Borderlinesignifikanten Zusammenhang zu einem kombinierten Endpunkt und stellen fest, dass PIIINP alleine betrachtet zwar signifikant mit erhöhter Mortalität einhergeht, im multivariaten Modell jedoch nicht mehr korreliert. Barasch et al. (2011) zeigen, dass PIIINP weder für HFrEF noch für HFpEF prädiktiv ist, jedoch für ein Gesamtkollektiv aus HFrEF-, HFpEF-, Risikopatienten und gesunden Probanden.

\subsection{Fragestellung}

Bislang existieren nur wenige Studien, die die Prognosekraft von Biomarkern bei DD und HFpEF untersuchen, was auch an der geringen Anzahl an HFpEF-Studien im Allgemeinen liegt. Die größte Aufmerksamkeit galt entsprechend der sehr guten Prognosekraft bei HFrEF dem kardialen natriuretischen Peptid BNP bzw. dem Fragment NTproBNP. Auch hsCRP und PIIINP wurden bereits bezüglich ihrer Prognosekraft untersucht, doch bleiben weiterhin viele Biomarker unbeachtet, die mit der Pathophysiologie der HFpEF zusammenhängen. Weiterhin betrachtet keine der bisher veröffentlichen HFpEF-Studien trotz möglicher Korrelationen mehrere Biomarker gleichzeitig. Nach den bisher verstandenen Mechanismen scheinen diverse Neurohormone und Marker für myokardialen Stress, Entzündung und Remodelling der EZM von besonderem Interesse zu sein. In dieser Arbeit wird die Prognosekraft von zehn potentiell relevanten Biomarkern, nämlich Aldosteron, CTproAVP, CTproET-1, hsCRP, MRproADM, MRproANP, NTproANP, NTproBNP, PIIINP und Renin untersucht, um 
Korrelationen untereinander und Zusammenhänge mit der Mortalität oder CVHospitalisationen aufzuzeigen und herauszufinden, ob und welche Marker positiv zur Prognosefindung bei DD und HFpEF beitragen können. 


\section{Material \& Methoden}

\subsection{Patientenkollektiv}

Die vorliegende Arbeit greift auf Patientendaten der Studie 'Prävalenz und Verlauf der diastolischen Dysfunktion und der diastolischen Herzinsuffizienz' (DIAST-CHF) zurück, die als Teilprojekt 7 (TP7, Diastolische Herzinsuffizienz) vom Kompetenznetz Herzinsuffizienz (KNHI, http://www.knhi.de) durchgeführt wurde. Dieses seit 2003 bestehende Netzwerk dient der interdisziplinären Erforschung von Mechanismen und Therapieformen der $\mathrm{HI}$ und wird vom Bundesministerium für Bildung und Forschung gefördert.

Bei der DIAST-CHF-Studie handelte es sich um eine prospektive, multizentrische ZweiKohortenstudie, an der neben dem Universitätsklinikum Göttingen auch Zentren in Berlin, Essen, Lübeck, Marburg und Würzburg beteiligt waren. Am Universitätsklinikum Göttingen wurden im Zeitraum vom 05.07.2004 bis 22.12.2006 Patienten eingeschlossen. Ein positives Votum der Ethik-Kommission der Medizinischen Fakultät der Georg-AugustUniversität Göttingen wurde vor Beginn der Studie unter der Antragsnummer 22/02/04 eingeholt.

Die Studie schloss Patienten im Alter zwischen 50 und 85 Jahren ein, die ihr schriftliches Einverständnis erklärt haben und mindestens einen Risikofaktor für das Auftreten einer DD zeigten oder bei denen bereits die Diagnose $\mathrm{HI}$ ärztlich gestellt und dokumentiert wurde. Zu den Risikofaktoren zählten arterielle Hypertonie, Diabetes mellitus, Schlafapnoesyndrom und Zeichen einer Arteriosklerose, die wiederrum definiert waren als symptomatische pAVK (periphere arterielle Verschlusskrankheit), angiographisch nachgewiesene KHK bzw. Karotisstenose und dem Zustand nach Apoplex oder Myokardinfarkt. Zu den Ausschlusskriterien zählten lediglich eine mangelnde Compliance, unzureichende Kommunikationsfähigkeit, geographische Hindernisse sowie Erkrankungen, die die Einwilligungsfähigkeit einschränkten.

Die Rekrutierung der Patienten erfolgte durch Suchanfragen nach oben genannten Risikofaktoren im Freitext oder anhand entsprechender ICD-Schlüssel (International Statistical Classification of Diseases and Related Health Problems) in der Praxis-EDV (elektronische Datenverarbeitung) von umliegenden Hausärzten und dem Basisdatensatz der Abteilung Allgemeinmedizin des Universitätsklinikums Göttingen. Die infrage kommenden Patienten wurden anschließend kontaktiert und über die geplante Studie informiert. Erst bei Rückmeldung durch den Patienten wurden diese für eine Erstuntersuchung eingeladen. 
Im Anschluss an die Erstuntersuchung erfolgte die Einteilung der Patienten in zwei Hauptgruppen. Alle Patienten, die keinerlei HI-Symptome, jedoch mindestens einen der genannten Risikofaktoren aufwiesen, wurden der Gruppe A zugeteilt. Patienten, bei denen mindestens ein Major- und zwei Minor-Kriterien nach Framingham (McKee et al. 1971) und damit eine klinisch manifeste $\mathrm{HI}$ vorlag oder bei bereits diagnostizierter $\mathrm{HI}$, wurden der Gruppe B zugeteilt. Für diese Arbeit wurde eine abweichende Gruppeneinteilung vorgenommen, die unter '3.1.1 Patientenzahl und Einteilung' (S. 30) näher erläutert wird.

\subsection{Basisuntersuchung}

Zu Beginn der Erstuntersuchung wurde der Patient erneut über die Studie aufgeklärt und sein Einverständnis zur Teilnahme eingeholt. $\mathrm{Zu}$ den anschließenden Untersuchungen zählten eine ausführliche Anamnese und klinische Untersuchung, ein Ruhe-EKG, eine echokardiographische Untersuchung, der 6-Minuten-Gehtest sowie eine Basis- und spezielle Labordiagnostik. Außerdem wurde der Patient gebeten einen psychosozialen Selbstbeurteilungsfragebogen auszufüllen.

\subsubsection{Anamnese}

Eine ausführliche Anamnese war bei jedem Patienten die Grundlage der weiteren Diagnostik. Zunächst wurden soziodemographische Daten wie Geschlecht, Geburtsdatum, ethnische Zugehörigkeit und die Anzahl der noch lebenden Angehörigen ermittelt. Anschließend wurde nach aktuellen Symptomen und Zeichen einer $\mathrm{HI}$ wie Belastungs- und Ruhedyspnoe, Orthopnoe, paroxysmaler nächtlicher Dyspnoe, nächtlichem Husten, Müdigkeit oder Leistungsschwäche sowie Nykturie gefragt. Die Erhebung dieser und weiterer Symptome ging mit der körperlichen Untersuchung (siehe '2.2.2 Körperliche Untersuchung' S. 19) einher.

Es folgten Angaben über die Häufigkeit von Haus- bzw. Facharztbesuchen sowie Krankenhaus- und Reha-Aufenthalten, die innerhalb der letzten zwölf Monate durch die HI ausgelöst wurden. Weiterhin wurden alle weiteren Krankenhausaufenthalte innerhalb der letzten zwölf Monate aufgenommen, denen nicht die HI zugrunde lag.

Als nächstes wurden kardiovaskuläre Risikofaktoren festgehalten, zu denen Diabetes mellitus, Hypertonie (bzw. Antihypertensiva-Therapie), Hyperlipidämie (bzw. Antilipidämika-Therapie), Hyperurikämie (bzw. Urikostatika-Therapie), das Schlafapnoesyndrom, ein Myokardinfarkt vor dem 60. Lebensjahr bei direkten Verwandten, Rauchen (Angabe der packyears) und Alkoholkonsum (Angabe in drinks per week) zählten. 
Es schloss sich die Erhebung bisheriger kardiovaskulärer Interventionen an, zu denen folgende Eingriffe gezählt wurden: koronare oder periphere Revaskularisationen, BypassOPs, sonstige Gefäßoperationen wie Thrombendarterektomien, Herzklappen-OPs, Implantation eines Schrittmachers oder Defibrillators sowie Herztransplantation und stattgefundene Reanimations- bzw. Defibrillationsversuche. Weitere, nicht aufgeführte kardiovaskuläre Interventionen wie eine Aneurysmektomie o.Ä. wurden unter 'andere kardiovaskuläre Interventionen' zusammengefasst.

Die Anamnese umfasste auch die Erhebung bisheriger kardialer Diagnosen, zu denen eine KHK, ein stattgefundener Myokardinfarkt, eine primäre Herzklappenerkrankung, angeborene sowie erworbene Herzfehler, Vorhofflimmern und Kardiomyopathien zählten. Nach aktuellen Nebendiagnosen wie pAVK (falls zutreffend mit Angabe des FontaineStadiums), cerebrovaskulären Erkrankungen (falls zutreffend mit Angabe der Ätiologie und genauen Diagnose), stattgefundenen Synkopen, COPD (chronic obstructive pulmonary disease), primärer pulmonaler Hypertonie, Depressionen, HIV-Infektionen (human immunodeficiency virus), Hepatitis B/C, Leberzirrhose und Malignomen wurde ebenfalls gefragt. Bei Frauen wurde zusätzlich, falls bereits geschehen, das Eintrittsjahr der Menopause festgehalten.

Zum Schluss erfolgte eine Dosis-genaue Aufstellung der Medikation, die in kardiovaskuläre Medikamente, Lipidsenker, Antikoagulantien, Antidiabetika, pulmonale Medikamente und sonstige Medikamente eingeteilt wurde. Bei Frauen wurde weiterführend die Einnahme oraler Kontrazeptiva und postmenopausaler Hormone erfragt.

\subsubsection{Körperliche Untersuchung}

Bei der körperlichen Untersuchung wurden zunächst Größe und Gewicht sowie Taillenund Hüftumfang des Patienten ermittelt. Nach fünf minütiger Ruhephase erfolgte die Messung des Blutdrucks und der Herzfrequenz am sitzenden Patienten.

Die weitere Untersuchung orientierte sich an den Major- und Minor-Kriterien der Framingham-Definition (McKee et al. 1971). Wie unter '2.2.1 Anamnese' (S. 18) erwähnt, wurden Symptome und Zeichen der HI zum Teil erfragt und desweiteren während der körperlichen Untersuchung festgestellt. Diese umfasste die Kontrolle auf periphere Ödeme, eine Halsvenenstauung, pulmonale Rasselgeräusche, hepatojugulären Reflux, einen vorhandenen dritten Herzton, Hepatomegalie und Aszites. Eine $\mathrm{HI}$ liegt nach genannter Definition vor, wenn mindestens ein Major- und zwei Minor-Kriterien zutreffen. Anschließend wurde das Jahr der HI-Erstdiagnose festgehalten und eine Einteilung in die NYHA-Klassifikation, Lokalisation und Funktion vorgenommen. 


\subsubsection{Elektrokardiogramm}

Zur Aufzeichnung der Herzaktionsströme wurde bei den Patienten ein 12-Kanal-EKG mit einer Vorschubgeschwindigkeit von $50 \mathrm{~mm} / \mathrm{s}$ aufgezeichnet. Bei klinisch stabilen Patienten war die Verwendung eines maximal drei Monate alten EKGs zulässig. Zu den Aufzeichnungen zählte zunächst die Standardableitung nach Einthoven, bei der es sich um eine bipolare Extremitätenableitung handelt, die Spannungsdifferenzen zwischen zwei Extremitäten misst (I, II, III). Die drei Elektroden wurden proximal der Handgelenke am jeweils rechten und linken Arm sowie oberhalb des linken Knöchels angelegt. Weiterhin wurden Ströme mittels unipolarer Extremitätenableitung nach Goldberger (aVR, aVL, aVF) aufgezeichnet, die als Vektoren betrachtet um $30^{\circ} \mathrm{zu}$ denen der EinthovenAbleitung verschoben sind und gemeinsam mit diesen zur Bestimmung des Lagetyps in der Frontalebene herangezogen werden können. Zuletzt erfolgte die unipolare, präkordale Ableitung nach Wilson (V1-6) und die Auswertung des EKGs beginnend mit der Bestimmung der Herzfrequenz, des Rhythmus (Sinus-Rhythmus, Vorhofflimmern, ggf. Kammerschrittmacher (VVI), Zweikammerschrittmacher (DDD), biventrikulärer Schrittmacherrhythmus) und der Leitungszeiten (PQ-Zeit, QRS-Dauer, QT-Zeit). Es wurde weiterhin auf Blockbilder wie den atrioventrikulären Block (Grad I, II, III), Links- sowie Rechtsschenkelblock und linksanteriorem sowie linksposteriorem Hemiblock gesucht. Weitere Auffälligkeiten wie kompletter R-Verlust, pathologische Q-Zacken und diskordante T-Negativierungen wurden ebenfalls notiert und zuletzt der Sokolow- und Lewis-Index als Hinweise auf eine Linksherzhypertrophie beurteilt. Der Sokolow-Index gilt als pathologisch wenn $\max \left(R_{V 5}, R_{V 6}\right)+\max \left(S_{V 1}, S_{V 2}\right)>3,5 m V$. Der Lewis-Index gilt bei $R_{I}+S_{I I I}-S_{I}-R_{\mid I I} \geq$ $1,6 \mathrm{mV}$ als pathologisch.

\subsubsection{Echokardiographie}

Als nicht-invasive Methode zur Untersuchung des Herzens wurde bei jedem Patienten eine transthorakale 2D-Echokardiographie in Linksseitenlage mit leicht erhöhtem Oberkörper durchgeführt. Die Untersuchung erfolgte mit dem 'Sonos 5500' (HewlettPackard, Andover, MA, USA). Eine anschließende Archivierung erfolgte auf gebräuchlichen Systemen/Medien des jeweiligen Studienzentrums (Videoband, handschriftliche Dokumentation, CD/DVD). Den Einstellungen und Messpunkten der Untersuchung lagen die 'Echokardiographie Richtlinien für den harmonisierten Datensatz' des KNHI in der Version vom 21.11.2003 zugrunde.

Zuerst erfolgte die Betrachtung des Herzens in der parasternal langen Achse. Mittels MMode wurden die Dimension der Aorta (in Klappenebene), der linksventrikuläre enddiastolische und endsystolische Ventrikeldurchmesser (LVDED bzW. LVDES), der 
linksatriale endsystolische Durchmesser ( $\left.L A_{E S(q u e r)}\right)$, die enddiastolische interventrikuläre Septumdicke (IVS $\mathrm{ED}_{\mathrm{D}}$ ) und die enddiastolische Hinterwanddicke (PW $\mathrm{ED}_{\mathrm{E}}$ ) ermittelt und notiert. Im apikalen Vierkammerblick erfolgte anschließend die Messung weiterer Parameter. So wurde zunächst die linksventrikuläre Ejektionsfraktion (LVEF) nach Simpson (biplan/monoplan) oder visuell bestimmt. Es folgte die Messung des linksventrikulären enddiastolischen und endsystolischen Volumens ( $L V V_{E D}$ bzw. LVV

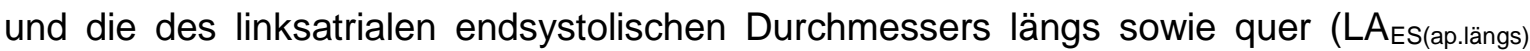
bzw. LA $\left.A_{E S(a p . q u e r)}\right)$. Weiterhin wurde das mögliche Vorliegen von Wandbewegungsstörungen, einer rechtsventrikulären Dilatation, einem Perikarderguss und einer gestauten Vena cava inferior dokumentiert.

Die vier Herzklappen wurden hinsichtlich Stenosen und Insuffizienzen untersucht und der Schweregrad (leicht, mittel, schwer, keine) notiert. Bei vorhandener Trikuspidalinsuffizienz wurde zusätzlich der Gradient über der Klappe in [mmHg] gemessen. Bei jeder Herzklappe wurde zusätzlich festgehalten, ob es sich um eine natürliche oder operierte Herzklappe handelt.

Um die diastolische Funktion beurteilen zu können, wurden weitere Einstellungen aufgezeichnet. Zunächst wurden im Mitralisdoppler die Geschwindigkeiten der passiven Füllung des linken Ventrikels (E-Welle) und der Füllung des Selbigen durch Vorhofkontraktion (A-Welle) in [cm/s] gemessen. Anschließend erfolgte die Messung der Dezelerationszeit und der isovolumetrischen Relaxationszeit in [ms] (Erbel et al. 2002). Zur Einschätzung der globalen systolischen und diastolischen Funktion wurde der TEIIndex (TEI = $[a-b] / b)$ bestimmt (Tei et al. 1995). Hierzu mussten zunächst der Abstand vom Ende der A-Welle bis zum Anfang der E-Welle (a) sowie die Ejektionszeit der Aorta (b) ermittelt werden. Im Gewebedoppler am lateralen Mitralanulus galt es die Geschwindigkeit der Bewegung des Mitralklappenanulus während der passiven Füllung (e') und der durch Vorhofkontraktion ausgelösten Füllung (a') in [cm/s] zu messen (Erbel et al. 2002). Zur Beurteilung des pulmonalvenösen Blutflusses wurden der Fluss während der Systole, Diastole und der atriale Rückfluss in [cm/s] gemessen. Zuletzt erfolgte die Messung der Flow-propagation-Time $(\mathrm{Vp})$ in $[\mathrm{cm} / \mathrm{s}]$ und die Einordnung der vorliegenden diastolischen (Dys-)Funktion in die ASE-Stadien (American Society of Echocardiography), wie bereits von Stahrenberg et al. (2010) für DIAST-CHF beschrieben:

- Grad 0 (normales Füllungsmuster): Von einem normalen linksventrikulären Einstrom und Pulmonalvenenfluss spricht man, wenn das Verhältnis von maximaler frühdiastolischer Einstromgeschwindigkeit (E) zur Einstromgeschwindigkeit nach Vorhofkontraktion $(A)$ gemessen über der Mitralklappe $(E / A) \geq 1$ ist und alle folgenden Kriterien erfüllt sind: 
1. Verhältnis zwischen maximaler frühdiastolischer Einstromgeschwindigkeit gemessen über der Mitralklappe (E) zur frühdiastolischen maximalen Geschwindigkeit des Mitralklappenanulus im Gewebedoppler (e') ist E / e' < 10

2. Verhältnis zwischen maximalem systolischen (S) und diastolischen pulmonalvenösen Fluss ist $S$ / $D \geq 1$

3. Verhältnis zwischen maximaler frühdiastolischer Einstromgeschwindigkeit gemessen über der Mitralklappe (E) zur Einstromgeschwindigkeit über der Mitralklappe nach der Vorhofkontraktion während des Valsalva-Manövers (A $A_{\text {Valsalva }}$ ) ist $E / A_{\text {Valsalva }} \geq 1$

- Grad I (verzögerte Relaxation): Ist das Verhältnis von $E$ / A $<1$, so handelt es sich um eine verzögerte Relaxation.

- Grad II (pseudonormale Füllung): Eine pseudonormale Füllung liegt vor, wenn das Verhältnis von $E$ / A im Bereich $\geq 1(E / A)<2$ liegt und eines der drei Kriterien zutrifft: $E / e^{\prime} \geq 10, S / D<1, E / A$ valsalva $<1$

- Grad III/IV (reversibles/irreversibles restriktives Füllungsmuster): Ein restriktives Füllungsmuster liegt vor, wenn das Verhältnis von $E / A \geq 2$ ist und eines dieser beiden Kritierien erfüllt ist: $E / e^{\prime} \geq 10 ; S / D<1$. Die Unterscheidung von reversiblem (Grad III) und irreversiblem (Grad IV) restriktivem Füllungsmuster erfolgt durch

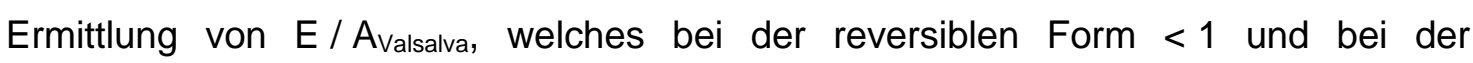
irreversiblen Form $\geq 1$ ist.

\subsubsection{6-Minuten-Gehtest}

Der 6-Minuten-Gehtest wurde durchgeführt, um die allgemeine Leistungsfähigkeit der Patienten zu objektivieren. Er gilt als nützliche und einfache Methode (Haass et al. 2010) zur Feststellung ebendieser (Boxer et al. 2010) und der Prognose bei Patienten mit chronischer $\mathrm{HI}$ (Guyatt et al. 1985). Es handelt sich um einen submaximalen Belastungstest, der bei Patienten mit HI-Symptomen sehr gut reproduzierbare Ergebnisse liefert (Demers et al. 2001) und mit der Mortalitätsrate bei Patienten mit chronischer HI korreliert (Arslan et al. 2007, Boxer et al. 2010, Ingle et al. 2014). Der Test hält sich an die von der 'American Thoracic Society' empfohlenen 'Guidelines for the Six-Minute Walk Test' (Crapo et al. 2002) und wurde während der Basisuntersuchung mit einem Mindestabstand von vier Stunden zu einer gegebenenfalls stattgefundenen kardiopulmonalen Belastungsuntersuchung auf einem Flur mit Meterskalierung und einer Länge von $100 \mathrm{~m}$ durchgeführt. Der Patient wurde zunächst instruiert und über den Zweck des Tests informiert. Nach Messung des Blutdrucks und der Herzfrequenz wurde er anschließend angewiesen innerhalb von sechs Minuten ohne zu rennen oder zu joggen 
die für inn größtmögliche Strecke zu Fuß zurückzulegen. Ein Fuß musste beim Gehen stets den Boden berühren. Die Geschwindigkeit legte der Patient selbst fest. Es war außerdem gestattet, dass der Patient sitzend oder stehend Pausen einlegte, währenddessen die Zeit jedoch nicht angehalten wurde. Um das Ergebnis nicht zu beeinflussen, war es dem Untersucher nicht gestattet, den Patienten beim Gehen zu begleiten. Er sagte dem Patienten lediglich nach drei und fünf Minuten die Zeit an und durfte inn verbal ermutigen. Nach Ablauf der sechs Minuten wurden erneut Blutdruck und HF gemessen, sowie die zurückgelegte Strecke, gerundet auf volle Meter, notiert. Bei vorzeitigem Abbruch wurden Zeit und Abbruchgrund (allgemeine Erschöpfung, Dyspnoe, Angina pectoris, Claudicatio, andere Gründe) festgehalten

\subsubsection{Basis-Labordiagnostik}

Bei jedem Patienten wurde eine Basis-Labordiagnostik durchgeführt, sofern es sich nicht um einen klinisch stabilen Patienten mit einem bereits vorhandenen, maximal drei Monate alten Laborbefund handelte, der alle geforderten Parameter abdeckte. Zur Diagnostik zählten zunächst die Bestimmung des Hämoglobin-Gehaltes, der Hämatokrit sowie die Anzahl von Leukozyten und Thrombozyten. Weiterhin wurden die eGFR (estimated glomerular filtration rate), die Elektrolyte Natrium und Kalium, der Kreatinin-Gehalt, das Gesamtcholesterin inkl. der Untergruppen LDL- (low density lipoprotein) und HDL- (high density lipoprotein) Cholesterol, Harnsäure, der Spiegel des basalen TSH (Thyreoideastimulierendes Hormon) und der $\mathrm{HbA}_{1 \mathrm{C}}$ (Hämoglobin-a1C) als Kenngröße des Blutzuckerspiegels der vergangenen acht bis zwölf Wochen (Nathan et al. 2007) bestimmt.

\subsection{Spezielle Labordiagnostik}

\subsubsection{Blutproben}

Neben der Blutentnahme für die Basis-Labordiagnostik wurde den Patienten außerdem Blut für eine spezielle Labordiagnostik entnommen. Die Entnahme erfolgte in nichtnüchternem Zustand des Patienten nach einer 30-minütigen Ruhephase in EDTARöhrchen (Ethylendiamintetraacetat). Diese wurden im Anschluss für zehn Minuten in einer 'Eppendorf Centrifuge Modell 5702R' zentrifugiert und der Plasmaüberstand abpipettiert. Bis zur Bestimmung der einzelnen Biomarker wurden die Proben bei $-80^{\circ} \mathrm{C}$ geblindet tiefgefroren, wobei die Kühlkette beim Transport stets eingehalten und ein unnötiges Auftauen vermieden wurde. 


\subsubsection{ADM und MRproADM}

Die Konzentrationsmessung des aktiven ADM ist unter anderem aufgrund der geringen Halbwertszeit von nur 22 Minuten (Meeran et al. 1997), der Bindung an Komplementfaktor H (Pio et al. 2001) und der Tendenz, an Oberflächen zu haften und somit bei einer Messung nicht zur Verfügung zu stehen (Lewis et al. 1998), nur schwer umsetzbar. Der von der Firma B.R.A.H.M.S GmbH (Hennigsdorf, Deutschland) gelieferte nichtkompetetive immunoluminometrische Assay namens 'SEVADIL LIA®' zielt daher auf das Vorläufermolekül proADM ab, welches wiederum aus präproADM entsteht. Die zwei polyklonalen Schaf-Antikörper des Tests binden an die mittlere Region von proADM (MRproADM), die von Aminosäure 45 bis 92 reicht. Zwar ist keine physiologische Wirkung von MRproADM bekannt (Gumusel et al. 1995), jedoch weist es eine höhere Stabilität und Halbwertszeit als ADM auf (Struck et al. 2004). Der Detection-Antikörper des Tests richtet sich gegen die Aminosäuren 69 -82, während der Capture-Antikörper an die Aminosäuren 83-92 von MRproADM bindet. Der Messbereich des Tests wird mit 0,12$0,25 \mathrm{nmol} / \mathrm{l}$, die untere Nachweisgrenze mit $0,08 \mathrm{nmol} / / \mathrm{l}$ und die Sensitivität mit $0,12 \mathrm{nmol} / \mathrm{l}$ angegeben (Morgenthaler et al. 2005).

\subsubsection{Aldosteron}

Zur quantitativen Bestimmung von Aldosteron wurde ein Enzymimmunoassay namens 'Aldosterone ELISA' der Firma IBL International GmbH (Hamburg, Deutschland) verwendet. Hierbei konkurriert eine bekannte Menge enzymmarkiertes HRP-Aldosteron (horseradish peroxidase-Aldosteron) mit der unbekannten Menge Aldosteron Probe $_{\text {um eine }}$ ebenfalls bekannte Menge polyklonaler Antikörper des Kaninchens, welche an eine Mikrotiterplatte gebunden sind (Schwartz et al. 1990). Je höher die Konzentration von Aldosteron $n_{\text {robe }}$ ist, desto seltener wird das enzymgebundene Aldosteron an die Antikörper binden und desto geringer wird die spätere enzymkatalysierte Farbreaktion mit 3,3',5,5'Tetramethylbenzidin (TMB) als Substrat ausfallen. Nach dem Auswaschen des nicht an Antikörper gebundenen Aldosterons, wird die Farbintensität bei $450 \mathrm{~nm}$ innerhalb von 20 Minuten nach Zugabe des Stopppuffers im Photometer ermittelt. Sie ist umgekehrt

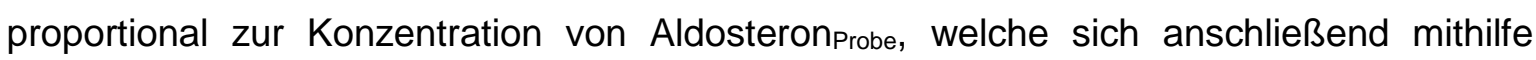
einer Standardkurve bestimmen lässt. Der Messbereich wird vom Hersteller mit 15 $1000 \mathrm{pg} / \mathrm{ml}$ bei einer Sensitivität von $10,0 \mathrm{pg} / \mathrm{ml}$ angegeben.

\subsubsection{ANP und MRproANP/NTproANP}

Auch bei ANP sind Halbwertszeit und Stabilität zu gering, um eine Messung des aktiven Peptids sinnvoll umzusetzen (Nelesen et al. 1992). Die beiden in dieser Arbeit 
verwendeten Tests zielen auf unterschiedliche Regionen (MRproANP, NTproANP) des Vorläuferhormons proANP ab, welches deutlich stabiler (Cleland et al. 1996) und daher besser geeignet ist als die Konzentrationsmessung von ANP (Buckley et al. 1999). Zur Bestimmung von MRproANP diente der nicht-kompetetive immunluminometrische Assay namens 'SERISTRA®' der Firma B.R.A.H.M.S GmbH (Hennigsdorf, Deutschland), bei dem die zwei enthaltenen Antikörper gegen die mittlere Region von proANP (MRproANP) gerichtet sind. Bei den Antikörpern handelt es sich um polyklonale Schaf-Antikörper. Der Capture-Antikörper ist gegen die Aminosäuren 73 - 90 von MRproANP gerichtet, während der Detection-Antikörper an die Aminosäuren 53 - 72 bindet (Morgenthaler et al. 2004). Nach Herauswaschen des ungebundenen Überstands erfolgt die Messung der Konzentration in einem Luminometer mit einer Sensitivität von 18 pmol/l und einer unteren Nachweisbarkeitsgrenze von 6,0 pmol// (Morgenthaler et al. 2004). Zur Bestimmung von NTproANP wurde der 'BI-20892 proANP' genannte Enzymimmunoassay der Firma Biomedica Medizinprodukte $\mathrm{GmbH}$ \& Co KG (Wien, Österreich) verwendet. Bei diesem Verfahren ist der polyklonale, vom Schaf stammende Capture-Antikörper gegen die Aminosäuren 16 - 23 von proANP gerichtet und an die Mikrotiterplatte gebunden. Der ebenfalls polyklonale Detection-Antikörper ist biotinyliert und bindet an die Aminosäuren 80 - 88 von proANP. Anschließend wird ein Konjugat aus Streptavidin und HRP hinzugegeben, welches an den biotinylierten Detection-Antikörper bindet und die Farbreaktion mit TMB katalysiert (Missbichler et al. 2001). Nach mehrfachem Auswaschen wird die Extinktion bei $450 \mathrm{~nm}$ im Photometer gemessen und die Konzentration mittels Standardkurven bestimmt. Der Messbereich wird vom Hersteller mit $0-5000 \mathrm{fmol} / \mathrm{ml}$ bei einer Sensitivität von $436 \mathrm{fmol} / \mathrm{ml}$ und einer unteren Detektionsgrenze von $50 \mathrm{fmol} / \mathrm{ml}$ angegeben.

\subsubsection{AVP und CTproAVP}

Eine direkte Konzentrationsmessung von AVP wird erschwert durch die geringe Halbwertszeit und Größe des Peptids und die Tatsache, dass es im Blut zu ungefähr $90 \%$ an Thrombozyten gebunden vorliegt (Preibisz et al. 1983). Der von der Firma B.R.A.H.M.S GmbH (Hennigsdorf, Deutschland) produzierte nicht-kompetetive immunoluminometrische Assay namens 'CT-proAVP LIA®' zielt auf das Carboxyterminale (C-terminale) Ende von proAVP (CTproAVP) ab. Aus dem im Hypothalamus synthetisierten Vorläufermolekül präproVasopressin entstehen durch Spaltung zu gleichen Teilen AVP, Neurophysin II und Copeptin (proAVP) (de Bree und Burchbach 1998). Da proAVP eine höhere Stabilität und Halbwertszeit aufweist (Struck et al. 2005a) und in gleicher Menge wie AVP entsteht, wird es stellvertretend für die Konzentration von AVP bestimmt. Bei dem Testverfahren kommen zwei polyklonale Schaf-Antikörper mit 
verschiedenen Epitopen zum Einsatz. Der Detection-Antikörper richtet sich gegen die Aminosäuren 149-164 von präproAVP, während der Capture-Antikörper an die Aminosäuren 132 - 147 bindet. Nach Herauswaschen des ungebundenen Überstands erfolgt die Messung mittels Luminometer innerhalb des angegebenen Messbereichs von 2,25 - $1215 \mathrm{pmol} / /$ bei einer unteren Nachweisgrenze von 1,7 pmol// und einer Sensitivität von 2,25 pmol/l (Morgenthaler et al. 2006).

\subsubsection{BNP und NTproBNP}

Aufgrund der geringen Stabilität von BNP (Cleland et al. 1996) gestaltet sich die Konzentrationsbestimmung des aktiven Peptids schwierig. Aus dem biologisch inaktiven Vorläuferhormon proBNP (108 Aminosäuren) entstehen durch Spaltung das aktive BNP (Aminosäuren 77 -108) und am amino-terminalen (N-terminalen) Ende das stabilere NTproBNP, welches sich besser als Marker eignet (Karl et al. 1999). Zur Messung der NTproBNP-Konzentration wurde der 'proBNP ELECSYS®' Test der Firma Roche Diagnostics GmbH (Mannheim, Deutschland) verwendet, bei dem es sich um einen nichtkompetetiven Elektrochemilumineszenz-Immunoassay handelt. Der Test enthält zwei polyklonale Antikörper, die verschiedene Epitope am NTproBNP Molekül besitzen. Dies erhöht die spätere Messgenauigkeit, da so kleinere Spaltprodukte nicht detektiert werden (Mueller et al. 2003). Der Capture-Antikörper ist biotinyliert und bindet an die Aminosäuren 1 - 21, während der zweite sogenannte Detection-Antikörper an die Aminosäuren 39 - 50 bindet (Collinson et al. 2004) und mit einem Ruthenium-Komplex markiert ist. Nach Zugabe von magnetischen, Streptavidin-beschichteten Mikropartikeln bindet der Antigen-Antikörperkomplex über Wechselwirkungen zwischen dem biotinylierten Antikörper und Streptavidin an die Partikel. Im Anschluss wird der Komplex in einer Messkammer durch Magnetismus an eine Elektrode fixiert, während die ungebundenen Substanzen ausgewaschen werden. Die eigentliche Konzentrationsmessung erfolgt im Anschluss mit Hilfe des Detection-Antikörpers nach Anlegen einer Spannung und dadurch induzierte Lumineszenz, die mittels Photomultiplier gemessen wird. Der Messbereich wird vom Hersteller mit 5 - 35.000 ng/l bei einer Sensitivität von 50 pg/ml angegeben.

\subsection{7 hsCRP}

Zur quantitativen Bestimmung von hsCRP wurde ein hochsensitiver Assay namens 'CRPHS' der Firma Roche Diagnostics GmbH (Mannheim, Deutschland) für 'COBAS INTEGRA®' Systeme verwendet, welcher auf einer immunologischen Agglutination (Price et al. 1987) beruht. Der Test eignet sich zum Nachweis sehr geringer CRPKonzentrationen (Cotton et al. 2001), deren Bestimmung zur Abschätzung des kardiovaskulären Risikos empfohlen wird (Pearson et al. 2003). Die zwei unterschiedlich 
reaktiven und damit zur Verstärkung der Trübung dienenden Latexpartikel sind mit monoklonalen Anti-CRP-Antikörpern der Maus beschichtet und agglutinieren unterschiedlich stark mit humanem CRP. Dies optimiert sowohl den Messbereich als auch die Sensitivität (Eda et al. 1998). Der Niederschlag wird anschließend turbidimetrisch bei $552 \mathrm{~nm}$ gemessen und kann laut Hersteller innerhalb eines Messbereichs von 0,1 $20 \mathrm{mg} / \mathrm{l}$ mit einer unteren Nachweisgrenze von $0,1 \mathrm{mg} / \mathrm{l}$ und einer Sensitivität von $0,3 \mathrm{mg} / \mathrm{l}$ bestimmt werden.

\subsubsection{ET-1 und CTproET-1}

Die Konzentrationsmessung von ET-1 wird nicht nur durch seine geringe Halbwertszeit (Weitzberg et al. 1991), sondern unter anderem auch durch die Tatsachen erschwert, dass es rasch an Plasmaproteine (Brunner et al. 1995) und lokale Gewebsrezeptoren bindet (Masaki 2004) und aufgrund einer hohen Clearance in der Lunge (Sirviö et al. 1990) nicht vollständig im Kreislauf zirkuliert. Der von der Firma B.R.A.H.M.S GmbH (Hennigsdorf, Deutschland) produzierte nicht-kompetetive immunoluminometrische Assay namens 'SEVACON LIA®' zielt daher auf das Vorläufermolekül proET-1 ab, dessen Halbwertszeit länger ist (Struck et al. 2005b). Die beiden polyklonalen Antikörper des Tests binden an das C-terminale Ende von proET-1 (CTproET-1). Der Capture-Antikörper richtet sich gegen die Aminosäuren 168 - 181 und der Detection-Antikörper gegen die Aminosäuren 200 - 212 des präproET-1 (Papassotiriou et al. 2006). Nach Herauswaschen des ungebundenen Überstands erfolgt die Messung der Konzentration innerhalb eines Messbereichs von $10-500 \mathrm{pmol} / \mathrm{l}$ mit einer unteren Nachweisbarkeitsgrenze von 0,4 pmol/l (Papassotiriou et al. 2006).

\subsubsection{Kollagen III und PIIINP}

Bei der Synthese von Kollagen III werden durch Abspaltung aus dem Vorläufermolekül proKollagen III ebenso diverse Propeptide freigesetzt, die sich an beiden Enden von proKollagen III befinden. Das so am N-terminalen Ende abgespaltene Propeptid PIIINP gilt somit als Hinweis auf einen erhöhten Umsatz von Kollagen III (Jensen 1997) und ist Ansatzpunkt des von der Firma Orion Diagnostica Oy (Espoo, Finnland) gelieferten kompetetiven Radioimmunoassays (RIA) (Risteli et al. 1988) namens 'UniQ PIIINP RIA'. Der Test ist nur für das intakte Propeptid und nicht für niedermolekulare Fragmente sensitiv. Gerade bei der Diagnosefindung von HFpEF und DD ist die Bestimmung von PIIINP hilfreich (Martos et al. 2009). Das Prinzip des Tests beruht darauf, dass eine bekannte Menge ${ }^{125}$-markiertes PIIINP (Tracer) mit einer unbekannten Menge PIIINP Probe um eine ebenfalls bekannte Menge PIIINP-Antikörper vom Kaninchen konkurriert. Je 
höher die Konzentration von PIIINP Probe, desto weniger Antikörper binden an das radioaktiv markierte PIIINP. Die Menge an radioaktiv markiertem PIIINP ist demnach umgekehrt proportional zur Menge von PIIINP Probe und wird nach Auswaschen der ungebundenen PIIINP-Moleküle für eine Minute im Gammacounter ermittelt. Anschließend erfolgt die Berechnung der PIIINP Probe-Konzentration anhand einer Standardkurve. Der Messbereich wird vom Hersteller mit $1-50 \mu \mathrm{g} / \mathrm{l}$ bei einer unteren Nachweisgrenze von $0,3 \mu \mathrm{g} / \mathrm{l}$ angegeben.

\subsubsection{Renin}

Die Konzentrationsmessung von Renin (PRC) kann aufgrund der günstigen Halbwertszeit von ungefähr 30 Minuten direkt erfolgen. Hierzu diente der von der Firma DiaSorin S.p.A (Saluggia, Italien) gelieferte nicht-kompetetive immunluminometrische Assay namens 'LIAISON® Direct Renin', bei dem ein an Magnetpartikel gebundener monoklonaler Antikörper der Maus zunächst als Capture-Antikörper (MAb 12-12, monoclonal antibody) dient, der sowohl für Renin als auch Prorenin spezifisch ist. Anschließend bindet der zweiten Antikörper, bei dem es sich um den monoklonalen Detection-Antikörper handelt (MAb 11-6), ausschließlich an Renin. Er ist zusätzlich mit einem Isoluminolderivat verbunden, sodass die Menge von Renin nach Herauswaschen des ungebundenen Überstands direkt proportional zum entstehenden Lichtsignal ist. Dieses wird in einem Photomultiplier bestimmt und kann laut Hersteller Konzentrationen mit einer Sensitivität von $1,96 \mu \mathrm{lU} / \mathrm{ml}$ bis zu $500 \mu \mathrm{lU} / \mathrm{ml}$ nachweisen.

\subsection{Statistik}

Die statistische Analyse der Daten erfolgte mit dem Programm 'IBM SPSS Statistics' in der Version 21.0.0.1 (IBM Corp. Armonk, New York, USA). Für die deskriptive Statistik wurde das Kollektiv anhand der Baseline NTproBNP-Konzentration in drei Gruppen eingeteilt ( $\leq 125 \mathrm{pg} / \mathrm{ml} ; 125<\ldots \leq 220 \mathrm{pg} / \mathrm{ml} ;>220 \mathrm{pg} / \mathrm{ml}$ ). Kategorische Variablen sind als ganzzahlige Werte mit aufgerundetem prozentualen Anteil am Gesamtkollektiv zu verstehen. Kontinuierliche Variablen werden als Mittelwert mit Standardabweichung angegeben. Um Unterschiede zwischen den NTproBNP-Untergruppen festzustellen, wurde der Uni-ANOVA Posthoc-Test angewendet. Das Signifikanzniveau beträgt $p=0,05$. Bei den Biomarker-Konzentrationen handelt es sich um Mittelwerte mit Angabe des IQR (interquartile range). In den anschließenden Cox-Regressionsmodellen wurden diese Konzentrationen aufgrund der teilweise starken Streuung logarithmiert. Die HRs (hazardratios) beziehen sich mit entsprechendem $95 \% \mathrm{Cl}$ (confidence interval) auf den Anstieg der Biomarker-Konzentration um den Betrag einer Standardabweichung. Nach der 
univariaten Cox-Regressionsanalyse erfolgte für signifikant mit dem Endpunkt korrelierende Biomarker eine Cox-Regressionsanalyse für NTproBNP. Hierbei wird bei gleichzeitiger Berücksichtigung des NTproBNP-Einflusses der Einfluss der einzelnen Biomarker auf die HR untersucht. Diejenigen Biomarker, die weiterhin eine signifikante Korrelation zum Endpunkt zeigten, wurden in multivariaten Cox-Regressionsmodellen analysiert, in denen nach den jeweils anderen Biomarkern und in einem weiteren Modell nach dem Alter der Patienten adjustiert wurde.

Um die Korrelationen der Biomarker untereinander zu verdeutlichen, wurde für solche, die im univariaten Cox-Regressionsmodell signifikant mit dem Endpunkt zusammenhingen, eine Korrelationsanalyse durchgeführt. Es stellten sich zwei Hauptfaktoren heraus, deren Aufladung durch die einzelnen Biomarker eine anschließende Faktoren-Analyse zeigt. Im finalen Regressionsmodell wurde der Zusammenhang zwischen den beiden Faktoren $A / B$ und dem kombinierten Endpunkt aus Mortalität und CV-Hospitalisation analysiert. Es erfolgte eine Adjustierung nach Alter, KHK, Diabetes mellitus, HI-Zeichen und Symptomen, Anämie, renaler Dysfunktion, LAVI (left atrial volume index) und E/e'.

Durch teilweise fehlende Daten der Nachbeobachtungsphase konnten bei den Regressionsanalysen nur maximal 1427 statt 1484 Patienten berücksichtigt werden (siehe '3.1.1 Patientenzahl und Einteilung' Tabelle 2, S. 31). Die größte Anzahl fehlender Daten wies NTproANP mit 748 validen Patienten auf. Auch in der Konzentrationsanalyse von NTproANP (siehe '3.2.1 Biomarker-Konzentrationen' S. 35) musste auf einen Teil des Kollektivs verzichtet werden, da lediglich 753 valide Datensätze vorlagen. 


\section{Ergebnisse}

Neben den bereits genannten Abkürzungen gelten in den nachstehenden Tabellen der statistischen Auswertung zur besseren Übersicht die hier aufgeführten Abkürzungen für body surface area (BSA), Logarithmus (Log), Mittelwert (MW), Anzahl (n), Signifikanz (p), Riva-Rocci (RR), standard deviation (SD).

\subsection{Deskriptive Statistik des Patientenkollektivs}

\subsubsection{Patientenzahl und Einteilung}

Für eine Gruppe von 1883 Patienten aus DIAST-CHF lagen Biomarker-Messungen vor. Hierunter befanden sich allerdings auch Datensätze, die keine Angaben zu Alter, Geschlecht, Paulus-Klassifikation, EF, LVVI (linksventrikulärer Volumen-Index) und NTproBNP beinhalteten. Nach Aussortieren dieser Datensätze und solcher Patienten, die eine $\mathrm{EF}<50 \%$ und einen LVVI $\geq 97 \mathrm{ml} / \mathrm{m}^{2}$ BSA aufwiesen, verblieben 1484 Patienten, die das Kollektiv dieser Arbeit bilden. Dieses wurde anhand der Baseline NTproBNPKonzentration in drei Untergruppen eingeteilt. Die erste Gruppe [1] mit einer NTproBNPKonzentration $\leq 125 \mathrm{pg} / \mathrm{ml}$ war mit 853 Patienten gleichzeitig die größte dieser Gruppen. Die zweite Gruppe [2] bestand aus 306 Patienten, die im NTproBNP-Konzentrationsbereich zwischen $125<\ldots \leq 220 \mathrm{pg} / \mathrm{ml}$ lagen. 325 Patienten bildeten mit einer NTproBNP-Konzentration $>220 \mathrm{pg} / \mathrm{ml}$ die dritte Gruppe [3]. Eine Übersicht zur Patientenzahl und der Einteilung in NTproBNP-Untergruppen liefern 'Abbildung 1' und 'Tabelle 1'.

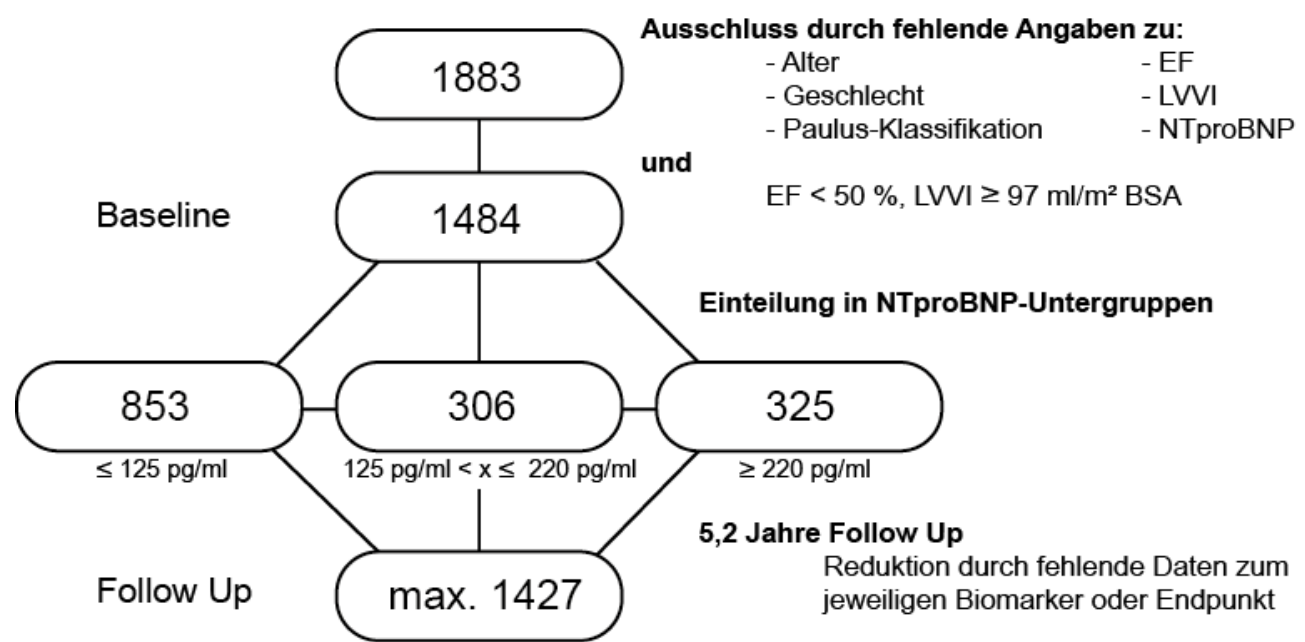

Abbildung 1 Bildung des Patientenkollektivs. Nach Ausschluss der Datensätze mit fehlenden Angaben zu Alter, Geschlecht, Paulus-Klassifikation, EF, LVVI, NTproBNP und Patienten mit $\mathrm{EF}<50 \%$ und LVVI $\geq 97 \mathrm{ml} / \mathrm{m}^{2} \mathrm{BSA}$ blieben 1484 Patienten für die Analysen übrig, die anhand der NTproBNP-Konzentration in drei Untergruppen eingeteilt wurden. Nach 5,2 Jahren Nachbeobachtungszeit lagen für maximal 1427 Patienten Daten für die Betrachtung in CoxRegressionsmodellen vor. 
Tabelle 1 Patientenzahl und Einteilung in drei Untergruppen anhand der Baseline NTproBNP Konzentration.

\begin{tabular}{|l|c|c|c|c|}
\hline \multirow{2}{*}{ Alle } & \multirow{2}{*}{ NTproBNP-Untergruppen [pg/ml] } \\
\cline { 3 - 5 } & & $\mathbf{1 2 5}$ & $\mathbf{1 2 5 < \ldots \leq 2 2 0}$ & $\mathbf{2 2 0}$ \\
\hline Patientenzahl & \multirow{2}{*}{1484} & 853 & 306 & 325 \\
\hline
\end{tabular}

Aufgrund fehlender Daten der Nachbeobachtungsphase bei einigen Patienten, konnten in den Cox-Regressionsmodellen maximal 1427 Patienten (NTproBNP) betrachtet werden. Die geringste Anzahl valider Daten lag bei NTproANP vor (siehe 'Tabelle 2').

Tabelle 2 Analysierte Patienten in Cox-Regressionsmodellen. Aufgrund unvollständiger oder fehlender Daten in der Nachbeobachtung reduzierte sich die Anzahl der untersuchten Patientenfälle in den Regressionsmodellen entsprechend der Tabelle.

\begin{tabular}{|l|c|}
\hline Biomarker & $\begin{array}{c}\text { Patientenzahl } \\
\text { Regressionsanalyse }\end{array}$ \\
\hline NTproBNP & 1427 \\
\hline Aldosteron & 1297 \\
\hline PIIINP & 1302 \\
\hline CTproAVP & 1201 \\
\hline CTproET-1 & 1201 \\
\hline MRproADM & 1201 \\
\hline MRproANP & 1201 \\
\hline NTproANP & 748 \\
\hline hsCRP & 1198 \\
\hline Renin & 1177 \\
\hline
\end{tabular}

\subsubsection{Klinische Parameter}

Die folgende 'Tabelle 3' zeigt allgemeine klinische Daten des Patientenkollektivs, die während der Anamnese und klinischen Erstuntersuchung erhoben wurden. Die Werte sind bis auf die Angabe zum Geschlecht als Mittelwert mit Standardabweichung zu verstehen. 
Tabelle 3 Daten der klinischen Untersuchung für das gesamte Kollektiv und die drei Untergruppen. Abkürzungen: $p<0,05(\alpha), p<0,01(\beta), p<0,001(\gamma)$ gegen NTproBNP $\leq 125$ sowie $p<0,05(\delta), p<0,01(\varepsilon), p<0,001(\eta)$ gegen NTproBNP $>220$.

\begin{tabular}{|l|c|c|c|c|c|}
\hline \multirow{2}{*}{} & \multirow{2}{*}{ Alle } & \multicolumn{2}{c|}{ NTproBNP-Untergruppen [pg/ml] } & \multirow{2}{*}{ p-Wert } \\
\cline { 2 - 5 } & $\mathbf{n}(\%)$ & $\mathbf{n}(\%)$ & $\mathbf{n}(\%)$ & $\mathbf{n}(\%)$ & \\
\hline weiblich & $757(51)$ & $405(48)$ & $179(59)^{\beta}$ & $173(53)$ & \multirow{2}{*}{0,003} \\
\hline Alter [Jahre] & MW (SD) & MW (SD) & MW (SD) & MW (SD) & \\
\hline BMI [kg/m²] & $66,8(8,1)$ & $64,2(7,1)$ & $69,0(7,9)^{\vee, n}$ & $71,2(8,0)^{\vee}$ & $<0,001$ \\
\hline RR systolisch [mmHg] & $29,1(4,8)$ & $29,4(4,8)$ & $28,6(4,5)^{\alpha}$ & $28,7(4,8)^{\alpha}$ & 0,008 \\
\hline RR diastolisch [mmHg] & $149(21)$ & $148(20)$ & $150(22)$ & $151(24)$ & 0,076 \\
\hline Pulsamplitude [mmHg] & $64(12)$ & $86(12)$ & $83(11)^{\vee}$ & $82(13)^{\vee}$ & $<0,001$ \\
\hline $\begin{array}{l}\text { Mittlerer arterieller Druck } \\
\text { [mmHg] }\end{array}$ & $106(13)$ & $106(13)$ & $105(13)$ & $105(14)$ & 0,123 \\
\hline Herzfrequenz [1/min] & $66(12)$ & $67(11)$ & $65(11)^{\vee}$ & $65(13)^{\alpha}$ & $<0,001$ \\
\hline
\end{tabular}

\subsubsection{Kardiale Diagnose und Risikofaktoren}

Die 'Tabelle 4' gibt Auskunft über die Verteilung von kardialen Diagnosen und Risikofaktoren im Kollektiv. Es handelt sich um ganzzahlige Werte mit aufgerundetem prozentualen Anteil am Gesamtkollektiv. Bei 175 von 1484 Patienten wurde bereits im Vorfeld eine $\mathrm{HI}$ diagnostiziert. Zu den Risikofaktoren zählten KHK, Hypertonie, Hyperlipidämie, Diabetes mellitus, das Schlafapnoesyndrom und Rauchen.

Tabelle 4 Kardiale Diagnose und Risikofaktoren, eingeteilt in Untergruppen und summiert zum Gesamtkollektiv. Abkürzungen: $p<0,05(\alpha), p<0,01(\beta), p<0,001(\gamma)$ gegen NTproBNP $\leq 125$ sowie $p<0,05(\delta), p<0,01(\varepsilon), p<0,001(\eta)$ gegen NTproBNP $>220$.

\begin{tabular}{|c|c|c|c|c|c|}
\hline & \multirow{2}{*}{ Alle } & \multicolumn{3}{|c|}{ NTproBNP-Untergruppen [pg/ml] } & \multirow{3}{*}{ p-Wert } \\
\hline & & $\leq 125$ & $125<x \leq 220$ & $>220$ & \\
\hline & n (\%) & n (\%) & $\mathrm{n}(\%)$ & $\mathrm{n}(\%)$ & \\
\hline Bereits diagnostizierte $\mathrm{HI}$ & $175(12)$ & $71(8)$ & $35(11)^{n}$ & $69(21)^{v}$ & $<0,001$ \\
\hline KHK & $292(20)$ & $113(13)$ & $59(19)^{\alpha, \eta}$ & $120(37)^{\vee}$ & $<0,001$ \\
\hline Hypertonie & $1327(89)$ & $741(87)$ & $283(93)^{\alpha}$ & $303(93)^{\beta}$ & 0,001 \\
\hline Hyperlipidämie & $664(45)$ & $375(44)$ & $127(42)$ & $162(50)$ & 0,085 \\
\hline Diabetes mellitus & $389(26)$ & $237(28)$ & $67(22)$ & $85(26)$ & 0,134 \\
\hline Schlafapnoesyndrom & $95(6)$ & $58(7)$ & $18(6)$ & $19(6)$ & 0,767 \\
\hline Raucher & $163(11)$ & $106(12)$ & $30(10)$ & $27(8)$ & 0,101 \\
\hline
\end{tabular}




\subsubsection{Zeichen und Symptome der HI}

Die 'Tabelle 5' gibt Auskunft über Zeichen und Symptome der $\mathrm{HI}$, zu denen Ruhe- und Belastungsdyspnoe, periphere Ödeme, pulmonale Rasselgeräusche, gestaute Halsvenen und hepatojugulärer Reflux zählten. $43 \%$ des gesamten Kollektivs wiesen Zeichen oder Symptome einer $\mathrm{HI}$ auf und litten somit unter HFpEF. Die Werte sind ganzzahlig mit Angaben zum aufgerundeten prozentualen Anteil am Gesamtkollektiv.

Tabelle 5 Zeichen und Symptome des Patientenkollektivs, eingeteilt in Untergruppen und summiert zum Gesamtkollektiv. Abkürzungen: $p<0,05$ ( $\alpha$ ), $p<0,01$ ( $\beta$ ), $p<0,001$ ( $(y)$ gegen NTproBNP $\leq 125$ sowie $p<0,05(\delta), p<0,01(\varepsilon), p<0,001(\eta)$ gegen NTproBNP $>220$.

\begin{tabular}{|l|c|c|c|c|c|}
\hline \multirow{2}{*}{ symptomatisch } & \multirow{2}{*}{ Alle } & \multicolumn{2}{|c|}{ NTproBNP-Untergruppen [pg/mL] } & \multirow{2}{*}{ p-Wert } \\
\cline { 2 - 5 } & $\mathbf{n}(\%)$ & $\mathbf{n}(\%)$ & $\mathbf{n}(\%)$ & $\mathbf{n}(\%)$ & \\
\hline Belastungsdyspnoe & $639(43)$ & $315(37)$ & $134(44)^{\alpha, \eta}$ & $190(59)^{\vee}$ & $<0,001$ \\
\hline Ruhedyspnoe & $481(32)$ & $227(27)$ & $103(34)^{\alpha, \varepsilon}$ & $151(47)^{\vee}$ & $<0,001$ \\
\hline Periphere Ödeme & $117(8)$ & $67(8)$ & $23(8)$ & $27(8)$ & 0,993 \\
\hline Pulmonale Rasselgeräusche & $23(2)$ & $6(1)$ & $7(2)^{\alpha}$ & $10(3)^{\beta}$ & 0,013 \\
\hline Gestaute Halsvenen & $18(1)$ & $7(1)$ & $3(1)$ & $8(3)$ & 0,083 \\
\hline Hepatojugulärer Reflux & $4(0,3)$ & $2(0,2)$ & 0 & $2(1)$ & 0,627 \\
\hline Framingham Kriterien & $37(3)$ & $8(1)$ & $8(3)^{\alpha, \delta}$ & $21(7)^{\vee}$ & $<0,001$ \\
\hline
\end{tabular}

\subsubsection{Allgemeine Labordiagnostik}

Die 'Tabelle 6' gibt Aufschluss über die Anzahl von Patienten mit Anämie oder renaler Dysfunktion anhand entsprechend ermittelter Laborwerte von Hämoglobin und eGFR.

Tabelle 6 Allgemeine Laborwerte des gesamten Patientenkollektivs und eingeteilt in Untergruppen. Abkürzungen: $p<0,05(\alpha), p<0,01(\beta), p<0,001(\gamma)$ gegen NTproBNP $\leq 125$ sowie $p<0,05(\delta), p<0,01(\varepsilon), p<0,001(\eta)$ gegen NTproBNP $>220$.

\begin{tabular}{|l|c|c|c|c|c|}
\hline \multirow{2}{*}{ Anämie } & \multirow{2}{*}{ Alle } & \multicolumn{2}{|c|}{ NTproBNP-Untergruppen [pg/mL] } & \multirow{2}{*}{-Wert } \\
\cline { 2 - 5 } & $\mathbf{n}(\%)$ & $\mathbf{n}(\%)$ & $\mathbf{n}(\%)$ & $\mathbf{n}(\%)$ & \\
\hline Renale Dysfunktion & $126(9)$ & $32(4)$ & $38(12)^{\vee}$ & $56(17)^{\vee}$ & $<0,001$ \\
\hline & $311(21)$ & $111(13)$ & $74(24)^{\vee, \eta}$ & $126(39)^{\vee}$ & $<0,001$ \\
\hline Hämoglobin [g/dl] & MW (SD) & MW (SD) & MW (SD) & MW (SD) & \\
\hline eGFR [ml/min/1.73m² BSA] & $14,1(1)$ & $14,3(1)$ & $13,8(1)^{\vee}$ & $13.6(1)^{\vee}$ & $<0,001$ \\
\hline & $73,2(18)$ & $76,7(17)$ & $70,7(17)^{\vee, \varepsilon}$ & $66,4(20)^{\vee}$ & $<0,001$ \\
\hline
\end{tabular}




\subsubsection{Medikation}

In der folgenden 'Tabelle 7' sind kardiovaskuläre Medikamente, Lipidsenker, Antikoagulantien sowie Antidiabetika aufgeführt, die von den Patienten regelmäßig eingenommen wurden. Die Werte sind ganzzahlig und die Angaben zum prozentualen Anteil am Gesamtkollektiv wurden auf ganze Zahlen gerundet.

Tabelle 7 Medikation des Patientenkollektivs, eingeteilt in Untergruppen und summiert zum Gesamtkollektiv. Abkürzungen: $p<0,05(\alpha), p<0,01(\beta), p<0,001(\gamma)$ gegen NTproBNP $\leq 125$ sowie $p<0,05(\delta), p<0,01(\varepsilon), p<0,001(\eta)$ gegen NTproBNP $>220$.

\begin{tabular}{|c|c|c|c|c|c|}
\hline & \multirow{3}{*}{$\begin{array}{c}\text { Alle } \\
\mathrm{n}(\%) \\
\end{array}$} & \multicolumn{3}{|c|}{ NTproBNP-Untergruppen [pg/mL] } & \multirow{3}{*}{ p-Wert } \\
\hline & & \multirow{2}{*}{$\begin{array}{l}\leq 125 \\
\mathrm{n}(\%) \\
\end{array}$} & \multirow{2}{*}{$\begin{array}{c}125<x \leq 220 \\
n(\%)\end{array}$} & \multirow{2}{*}{$\begin{array}{l}>220 \\
\mathrm{n}(\%) \\
\end{array}$} & \\
\hline & & & & & \\
\hline Irgendein Blutdrucksenker & $1255(85)$ & $683(80)$ & $270(88)^{\beta, \delta}$ & $302(93)^{r}$ & $<0,001$ \\
\hline Diuretika & $724(49)$ & $372(44)$ & $158(52)^{\alpha, \delta}$ & $194(60)^{r}$ & $<0,001$ \\
\hline Schleifendiuretika & $167(11)$ & $61(7)$ & $32(11)^{n}$ & $74(23)^{\vee}$ & $<0,001$ \\
\hline Thiazide & $616(42)$ & $333(39)$ & $140(46)^{\alpha}$ & $143(44)$ & 0,073 \\
\hline Kaliumsparende Diuretika & $80(5)$ & $40(5)$ & $16(5)$ & $24(7)$ & 0,190 \\
\hline Aldosteron-Antagonisten & $19(1)$ & $7(1)$ & $3(1)$ & $9(3)^{\alpha}$ & 0,038 \\
\hline Andere Blutdrucksenker & $1210(82)$ & $652(76)$ & $264(86)^{\vee}$ & $294(91)^{\vee}$ & $<0,001$ \\
\hline ACE-Hemmer & $657(44)$ & $345(40)$ & $142(46)$ & $170(52)^{\mathrm{r}}$ & 0,001 \\
\hline Angiotensin-I-Antagonisten & $264(18)$ & $145(17)$ & $55(18)$ & $64(20)$ & 0,556 \\
\hline Betablocker & $727(49)$ & $336(39)$ & $172(56)^{\vee, \varepsilon}$ & $219(67)^{\mathrm{V}}$ & $<0,001$ \\
\hline Calcium-Antagonisten & $318(21)$ & $167(20)$ & $71(23)$ & $80(25)$ & 0,119 \\
\hline Insulin & $144(10)$ & $83(10)$ & $22(7)$ & $39(12)$ & 0,128 \\
\hline Orale Antidiabetika & $227(15)$ & $138(16)$ & $43(14)$ & $46(14)$ & 0,548 \\
\hline $\begin{array}{l}\text { Thrombozytenaggregations- } \\
\text { hemmer }\end{array}$ & $541(37)$ & $250(29)$ & $136(44)^{r}$ & $155(48)^{r}$ & $<0,001$ \\
\hline Gerinnungshemmer & $84(5,7)$ & $18(2)$ & $7(2)^{n}$ & $59(18)^{\mathrm{r}}$ & $<0,001$ \\
\hline Statine & $447(30)$ & $224(26)$ & $89(29)^{n}$ & $134(41)^{\mathrm{r}}$ & $<0,001$ \\
\hline
\end{tabular}




\subsubsection{Echokardiographie}

Die echokardiographisch erhobenen Parameter zeigt folgende 'Tabelle 8'. Die Werte sind als Mittelwert mit Standardabweichung angegeben und in die bereits erwähnten NTproBNP-Untergruppen eingeteilt. Zur besseren Übersicht ist der linksventrikuläre Masse-Index als LVMI abgekürzt.

Tabelle 8 Echokardiographische Parameter des gesamten Patientenkollektivs und eingeteilt in Untergruppen. Abkürzungen: $p<0,05(\alpha), p<0,01(\beta), p<0,001(\gamma)$ gegen NTproBNP $\leq 125$ sowie $p<0,05(\delta), p<0,01(\varepsilon), p<0,001(\eta)$ gegen NTproBNP $>220$.

\begin{tabular}{|c|c|c|c|c|c|}
\hline & \multirow{3}{*}{$\begin{array}{c}\text { Alle } \\
\text { MW (SD) }\end{array}$} & \multicolumn{3}{|c|}{ NTproBNP-Untergruppen [pg/mL] } & \multirow{3}{*}{ p-Wert } \\
\hline & & \multirow{2}{*}{$\frac{\leq 125}{M W(S D)}$} & \multirow{2}{*}{$\begin{array}{c}125<x \leq 220 \\
M W(S D)\end{array}$} & \multirow{2}{*}{$\begin{array}{c}>220 \\
\text { MW (SD) }\end{array}$} & \\
\hline & & & & & \\
\hline LVEF [\%] & $61,3(6,4)$ & $61,7(6,2)$ & $61,4(6,4)$ & $60,5(6,9)^{\beta}$ & 0,015 \\
\hline $\mathrm{LVD}_{\mathrm{ED}}[\mathrm{mm}]$ & $48,9(5,7)$ & $48,7(5,7)$ & $49,0(5,5)$ & $49,3(5,6)$ & 0,332 \\
\hline LVVI $\left[\mathrm{ml} / \mathrm{m}^{2} \mathrm{BSA}\right]$ & $48,5(13,0)$ & $48,2(12,9)$ & $48,3(12,2)$ & $49,4(14,2)$ & 0,364 \\
\hline Septumdicke [mm] & $12,3(1,9)$ & $12,2(1,8)$ & $12,2(2,0)^{\delta}$ & $12,5(2,1)^{\alpha}$ & 0,048 \\
\hline Hinterwanddicke [mm] & $11,4(1,7)$ & $11,3(1,6)$ & $11,3(1,7)$ & $11,5(1,7)$ & 0,106 \\
\hline LAVI $\left[\mathrm{ml} / \mathrm{m}^{2} \mathrm{BSA}\right]$ & $25,0(8,9)$ & $22,6(6,5)$ & $25,7(8,2)^{\mathrm{r}, n}$ & $31,6(12,1)^{\mathrm{v}}$ & $<0,001$ \\
\hline LVMI $\left[\mathrm{g} / \mathrm{m}^{2} \mathrm{BSA}\right]$ & $85,1(46,5)$ & $82,2(45,3)$ & $84,8(45,9)^{\delta}$ & $92,8(49,4)^{\beta}$ & 0,003 \\
\hline $\begin{array}{l}\text { Mitralisdoppler E-Welle } \\
{[\mathrm{cm} / \mathrm{s}]}\end{array}$ & $73,1(19,7)$ & $69,3(16,5)$ & $74,6(19,7)^{\vee, n}$ & $81,6(24,1)^{v}$ & $<0,001$ \\
\hline $\begin{array}{l}\text { Mitralisdoppler A-Welle } \\
{[\mathrm{cm} / \mathrm{s}]}\end{array}$ & $81,0(19,5)$ & $80,2(17,8)$ & $81,7(20,4)$ & $82,7(23,4)$ & 0,137 \\
\hline $\begin{array}{l}\text { Gewebedoppler e'-Welle } \\
\text { (lateral + medial) / } 2 \text { [cm/s] }\end{array}$ & $7,0(2,1)$ & $7,1(2,1)$ & $6,9(2,1)$ & $6,9(2,1)$ & 0,169 \\
\hline $\begin{array}{l}\text { Gewebedoppler a'-Welle } \\
\text { (lateral + medial) / } 2[\mathrm{~cm} / \mathrm{s}]\end{array}$ & $10,3(2,4)$ & $10,6(2,2)$ & $10,2(2,5)^{\alpha, n}$ & $9,3(2,5)^{\vee}$ & $<0,001$ \\
\hline$E / e^{\prime}$ & $11,2(4,2)$ & $10,5(3,7)$ & $11,6(4,1)^{\gamma, \varepsilon}$ & $12,7(5,0)^{\vee}$ & $<0,001$ \\
\hline
\end{tabular}

\subsection{Analyse der prognostischen Wertigkeit}

\subsubsection{Biomarker-Konzentrationen}

Folgende 'Tabelle 9' gibt Aufschluss über die Baseline-Konzentrationen der zehn erhobenen Biomarker. Die Werte verstehen sich als Mittelwert mit Angabe des Interquartilenabstandes. 'Abbildung 2-11' veranschaulichen diese Verteilung in BoxplotGrafiken. Aufgrund der teilweise starken Streuung der Werte, wurden diese in logarithmierter Form aufgetragen. Werte, die zwischen $1,5 \leq x \leq 3$ Interquartilweiten von der Box entfernt liegen (Ausreißer), sind mit einem 'o' markiert, während Extremwerte (> 3 
Interquartilweiten) durch ein "*' gekennzeichnet sind. Signifikante Unterschiede zwischen den Gruppen sind mit folgenden Abkürzungen versehen: $p<0,05(\alpha), p<0,01$ ( $\beta$ ),

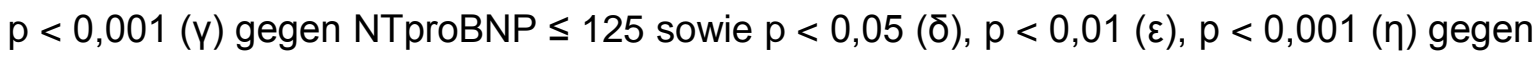
NTproBNP > 220. Der p-Wert gibt die Signifikanz des gruppenübergreifenden Trends an.

Tabelle 9 Biomarker Konzentrationen des gesamten Patientenkollektivs und eingeteilt in Untergruppen. Abkürzungen: $p<0,05(\alpha), p<0,01(\beta), p<0,001(\gamma)$ gegen NTproBNP $\leq 125$ sowie $p<0,05(\delta), p<0,01(\varepsilon), p<0,001(\eta)$ gegen NTproBNP $>220$.

\begin{tabular}{|c|c|c|c|c|c|}
\hline & \multirow{3}{*}{$\begin{array}{c}\text { Alle } \\
\text { MW (IQR) }\end{array}$} & \multicolumn{3}{|c|}{ NTproBNP-Untergruppen $[\mathrm{pg} / \mathrm{mL}]$} & \multirow{3}{*}{ p-Wert } \\
\hline & & \multirow{2}{*}{$\begin{array}{c}\leq 125 \\
M W(I Q R)\end{array}$} & \multirow{2}{*}{\begin{tabular}{|c|}
$125<x \leq 220$ \\
$M W($ IQR $)$ \\
\end{tabular}} & \multirow{2}{*}{$\begin{array}{c}>220 \\
M W(I Q R)\end{array}$} & \\
\hline & & & & & \\
\hline $\begin{array}{l}\text { NTproBNP } \\
{[p g / m l]}\end{array}$ & $\begin{array}{c}103 \\
(52-200)\end{array}$ & $\begin{array}{c}58 \\
(36-83)\end{array}$ & $\begin{array}{c}159 \\
(142-187)\end{array}$ & $\begin{array}{c}444 \\
(296-784)\end{array}$ & - \\
\hline $\begin{array}{l}\text { Aldosteron } \\
{[\mathrm{pg} / \mathrm{ml}]}\end{array}$ & $\begin{array}{c}70,3 \\
(55,5-91,8)\end{array}$ & $\begin{array}{c}71,1 \\
(56,0-91,2)\end{array}$ & $\begin{array}{c}68,0 \\
(53,9-87,3)\end{array}$ & $\begin{array}{c}69,7 \\
(56,2-91,6)\end{array}$ & 0,673 \\
\hline $\begin{array}{l}\text { PIIINP } \\
{[\mu \mathrm{g} / \mathrm{l}]}\end{array}$ & $\begin{array}{c}3,28 \\
(2,78-3,91)\end{array}$ & $\begin{array}{c}3,10 \\
(2,66-3,65)\end{array}$ & $\begin{array}{c}3,33 \\
(2,76-3,88)^{\varepsilon}\end{array}$ & $\begin{array}{c}3,56 \\
(3,07-4,23)^{\vee}\end{array}$ & $<0,001$ \\
\hline $\begin{array}{l}\text { CTproAVP } \\
\text { [pmol//] }\end{array}$ & $\begin{array}{c}3,94 \\
(2,45-7,12)\end{array}$ & $\begin{array}{c}3,76 \\
(2,36-6,32)\end{array}$ & $\begin{array}{c}3,56 \\
(2,41-7,41)^{\delta}\end{array}$ & $\begin{array}{c}4,38 \\
(2,52-8,91)^{\vee}\end{array}$ & 0,002 \\
\hline $\begin{array}{l}\text { CTproET-1 } \\
\text { [pmol//] }\end{array}$ & $\begin{array}{c}54,9 \\
(47,3-63,5)\end{array}$ & $\begin{array}{c}51,9 \\
(45,5-59,6)\end{array}$ & $\begin{array}{c}58,8 \\
(49,5-67,6)^{\vee, n}\end{array}$ & $\begin{array}{c}62,4 \\
(55,0-74,7)^{\vee}\end{array}$ & $<0,001$ \\
\hline $\begin{array}{l}\text { MRproADM } \\
\text { [nmol//] }\end{array}$ & $\begin{array}{c}0,574 \\
(0,490-0,692)\end{array}$ & $\begin{array}{c}0,525 \\
(0,451-0,619)\end{array}$ & $\begin{array}{c}0,580 \\
(0,516-0,719) \text { r,n }\end{array}$ & $\begin{array}{c}0,700 \\
(0,590-0,852)^{\vee}\end{array}$ & $<0,001$ \\
\hline $\begin{array}{l}\text { MRproANP } \\
\text { [pmol//] }\end{array}$ & $\begin{array}{c}88,3 \\
(62,3-126)\end{array}$ & $\begin{array}{c}68,4 \\
(51,6-89,1)\end{array}$ & $\begin{array}{c}107 \\
(86,7-134)^{\vee, n}\end{array}$ & $\begin{array}{c}154 \\
(122-200)^{\vee}\end{array}$ & $<0,001$ \\
\hline $\begin{array}{l}\text { NTproANP } \\
\text { [pmol/l] }\end{array}$ & $\begin{array}{c}3925 \\
(3175-4843)\end{array}$ & $\begin{array}{c}3402 \\
(2895-4073)\end{array}$ & $\begin{array}{c}4302 \\
(3737-5293)^{v, n}\end{array}$ & $\begin{array}{c}5394 \\
(4543-6669)^{\vee}\end{array}$ & $<0,001$ \\
\hline $\begin{array}{l}\mathrm{hsCRP} \\
{[\mathrm{mg} / \mathrm{l}]}\end{array}$ & $\begin{array}{c}1,80 \\
(0,89-3,86)\end{array}$ & $\begin{array}{c}1,54 \\
(0,79-3,35)\end{array}$ & $\begin{array}{c}1,63 \\
(0,880-3,68)^{\delta}\end{array}$ & $\begin{array}{c}2,40 \\
(1,13-4,74)^{\vee}\end{array}$ & 0,002 \\
\hline $\begin{array}{l}\text { Renin } \\
{[\mu \mathrm{IU} / \mathrm{ml}]}\end{array}$ & $\begin{array}{c}17,1 \\
(7,30-54,7)\end{array}$ & $\begin{array}{c}18,6 \\
(9,30-50,1)\end{array}$ & $\begin{array}{c}13,3 \\
(6,13-39,6)^{r}\end{array}$ & $\begin{array}{c}12,0 \\
\left(4,88^{-35,8)^{\vee}}\right.\end{array}$ & $<0,001$ \\
\hline
\end{tabular}




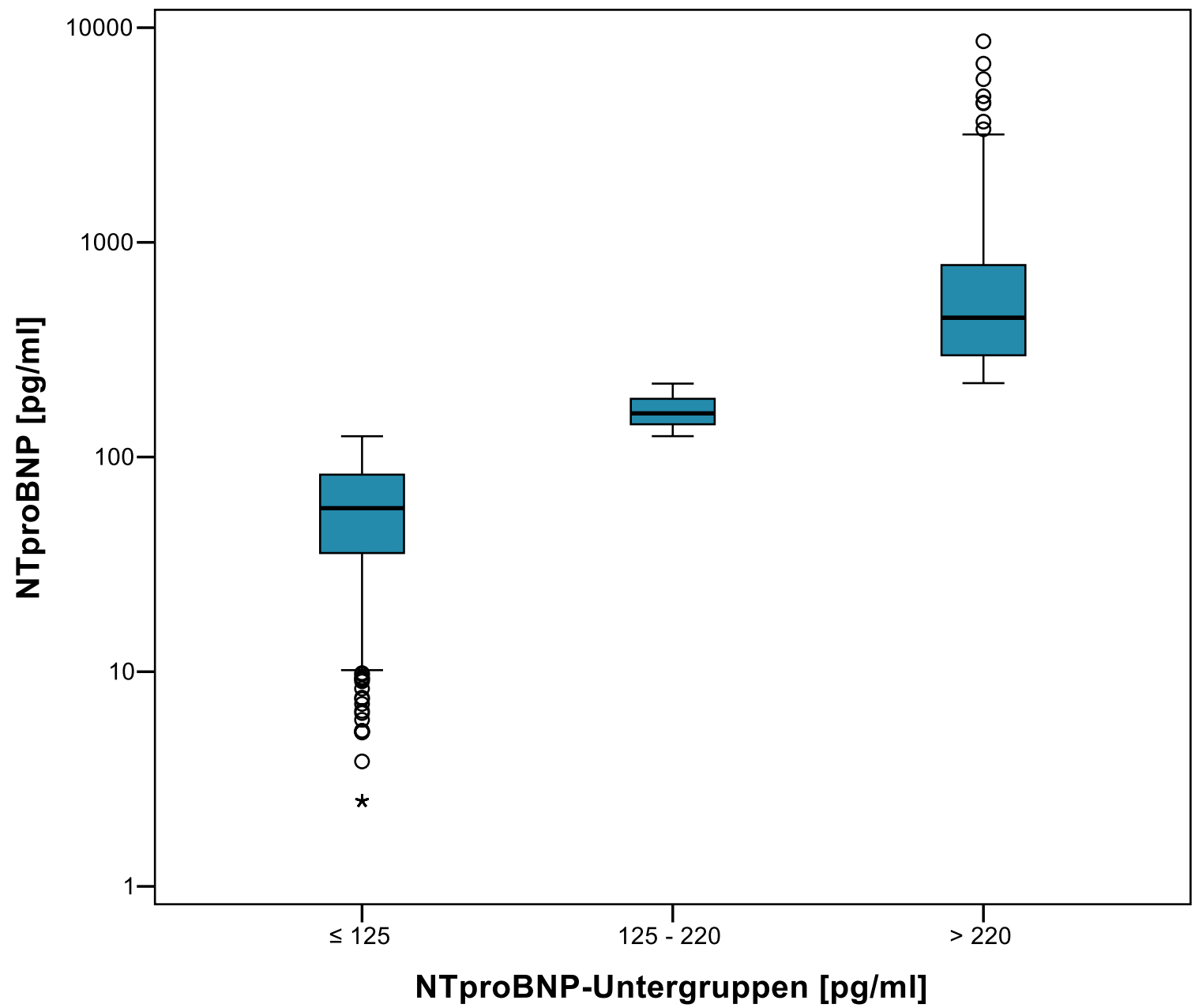

Abbildung 2 Verteilung der NTproBNP-Konzentration. Diese Abbildung zeigt die Verteilung der gemessenen NTproBNP-Konzentrationen (Ordinate) innerhalb der drei Untergruppen (Abszisse) in logarithmierter Darstellung. Die Boxen demonstrieren den jeweiligen IQR, während der MW als schwarzer Balken hervorgehoben ist. Abkürzungen: $0=$ Ausreißer, ${ }^{*}=$ Extremwert. 


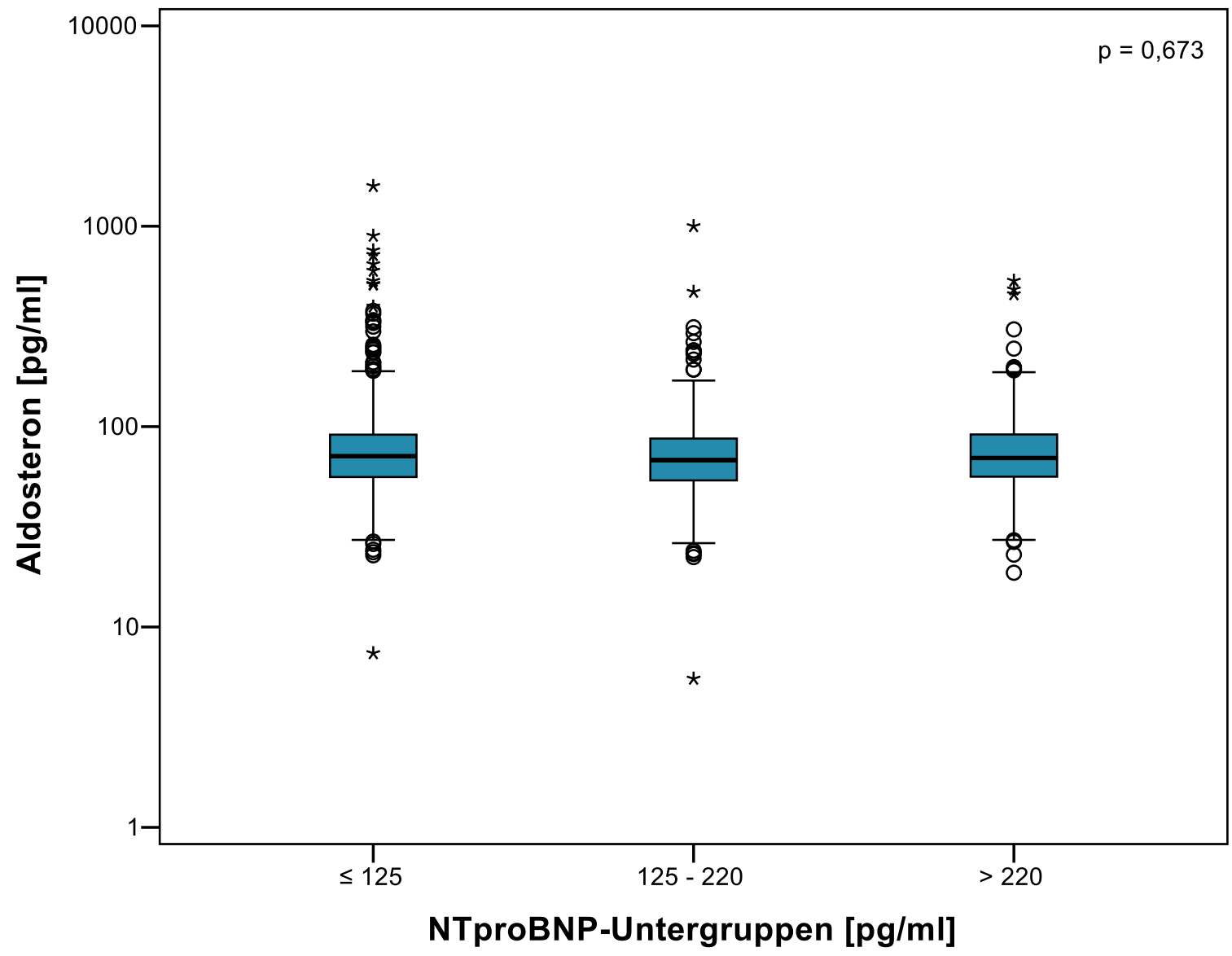

Abbildung 3 Verteilung der Aldosteron-Konzentration. Dargestellt ist die Verteilung der gemessenen Aldosteron-Konzentrationen (Ordinate) entsprechend der drei Untergruppen (Abszisse). Die Boxplots geben den jeweiligen IQR und MW bei logaritmierter Auftragung an. Abkürzungen: $0=$ Ausreißer, ${ }^{*}=$ Extremwert, $p=$ gruppen-übergreifender Trend. 


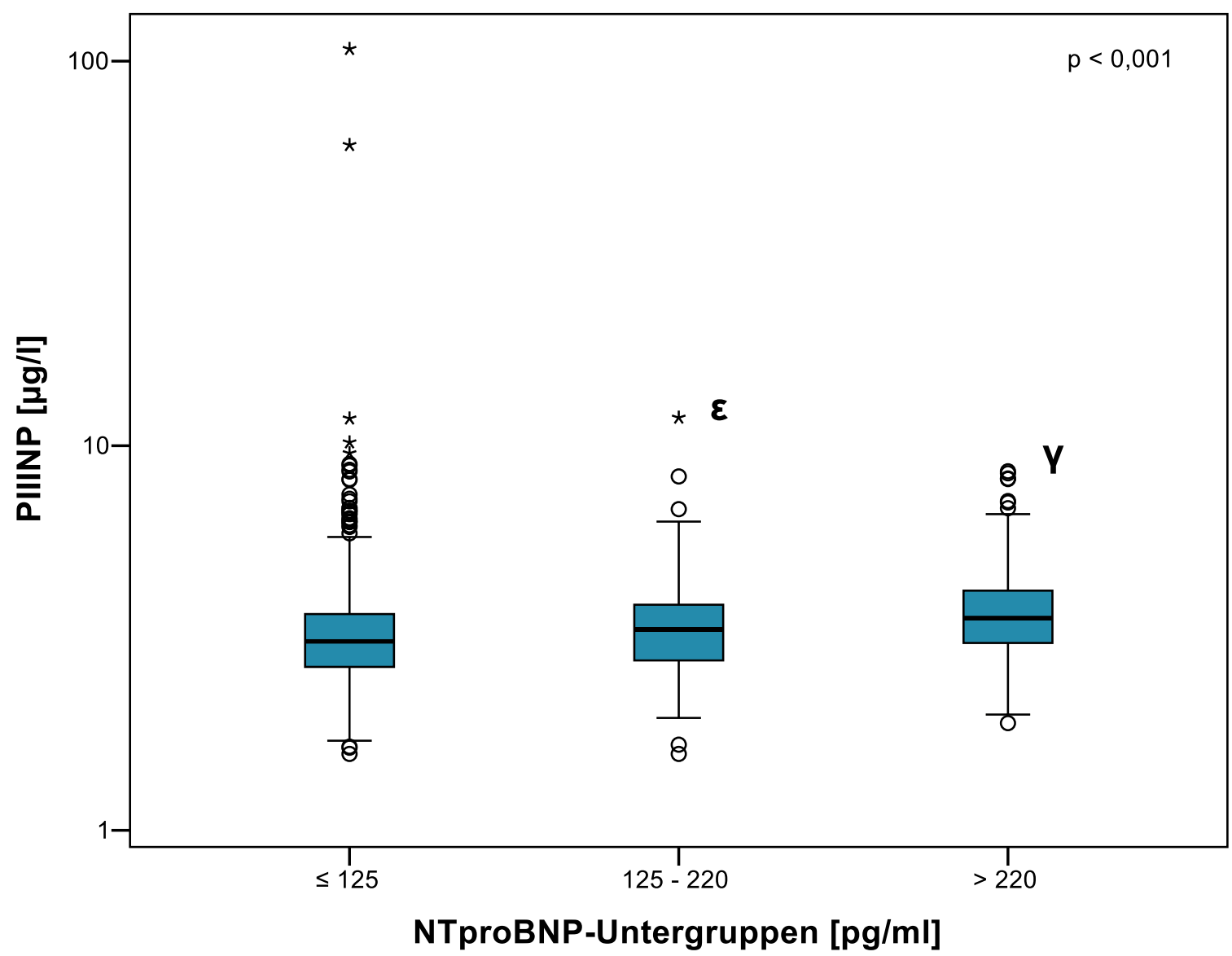

Abbildung 4 Verteilung der PIIINP-Konzentration. Die PIIINP-Konzentrationen (Ordinate) sind in dieser Abbildung entsprechend der Untergruppen (Abszisse) in logarithmierter Form dargestellt. Zusätzlich sind IQR und $M W$ in den Boxplots abgebildet. Abkürzungen: $Y=(p<0,001)$ gegen NTproBNP $\leq 125$ sowie $\varepsilon=(p<0,01)$ gegen NTproBNP $>220$. $0=$ Ausreißer, ${ }^{*}=$ Extremwert, $\mathrm{p}=$ gruppenübergreifender Trend. 


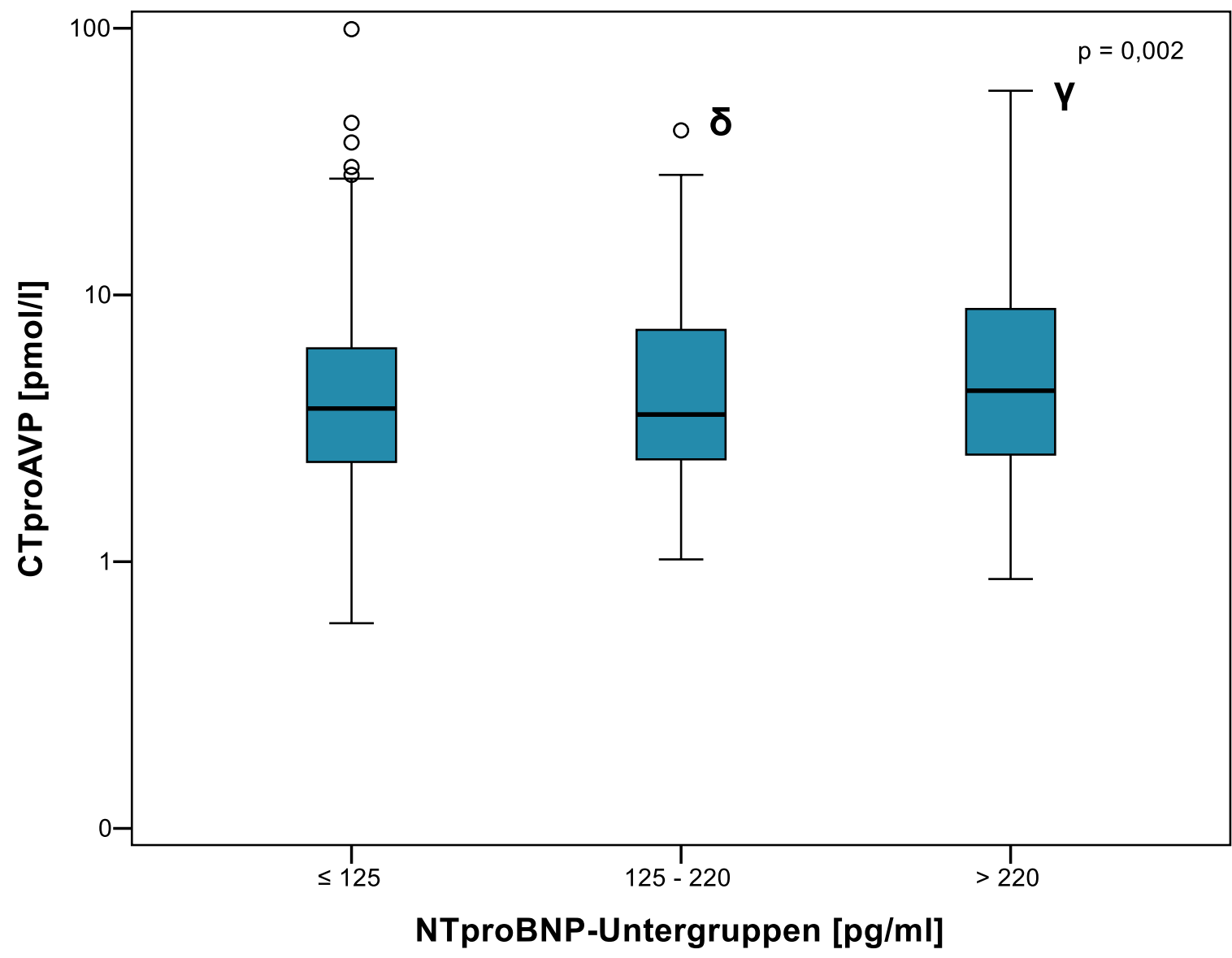

Abbildung 5 Verteilung der CTproAVP-Konzentration. Veranschaulicht sind die jeweils in den Untergruppen ermittelten CTproAVP-Konzentrationen (Ordinate) in Form von Boxplot-Diagrammen mit entsprechendem IQR und MW bei logarithmierter Auftragung. Abkürzungen: $Y=(p<0,001)$ gegen NTproBNP $\leq 125$ sowie $\delta=(p<0,05)$ gegen NTproBNP $>220$. $0=$ Ausreißer, $*=$ Extremwert, $p=$ gruppenübergreifender Trend. 


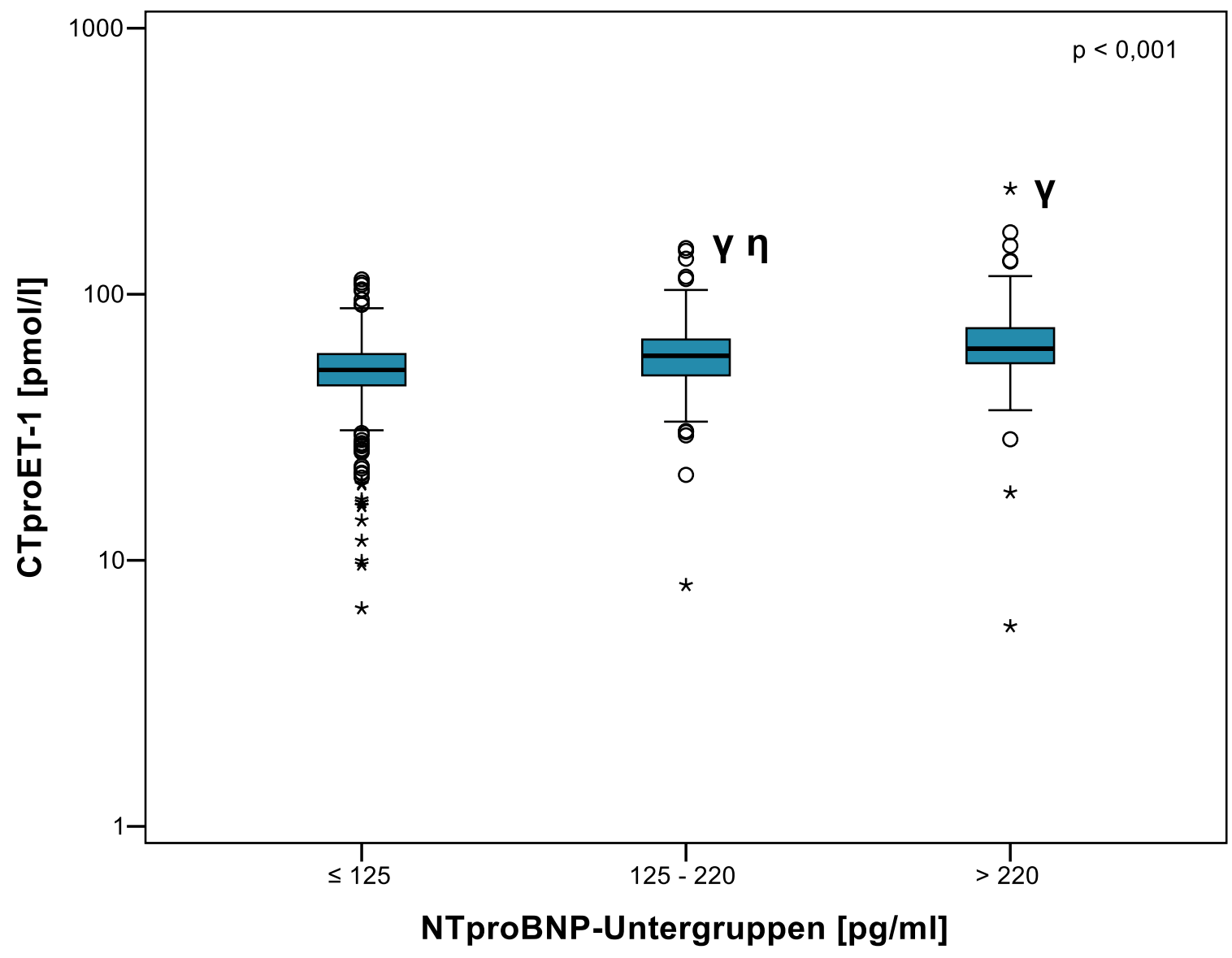

Abbildung 6 Verteilung der CTproET-1-Konzentration. Diese Abbildung verdeutlicht die gemessenen ET-1-Konzentrationen (Ordinate), die mithilfe von Boxplots in logarithmierter Form gezeigt sind. Die Boxen geben den jeweiligen IQR und MW an. Abkürzungen: $\gamma=(p<0,001)$ gegen NTproBNP $\leq 125$ sowie $\eta=(p<0,001)$ gegen NTproBNP $>220$. $0=$ Ausreißer, ${ }^{*}=$ Extremwert, $\mathrm{p}=$ gruppenübergreifender Trend. 


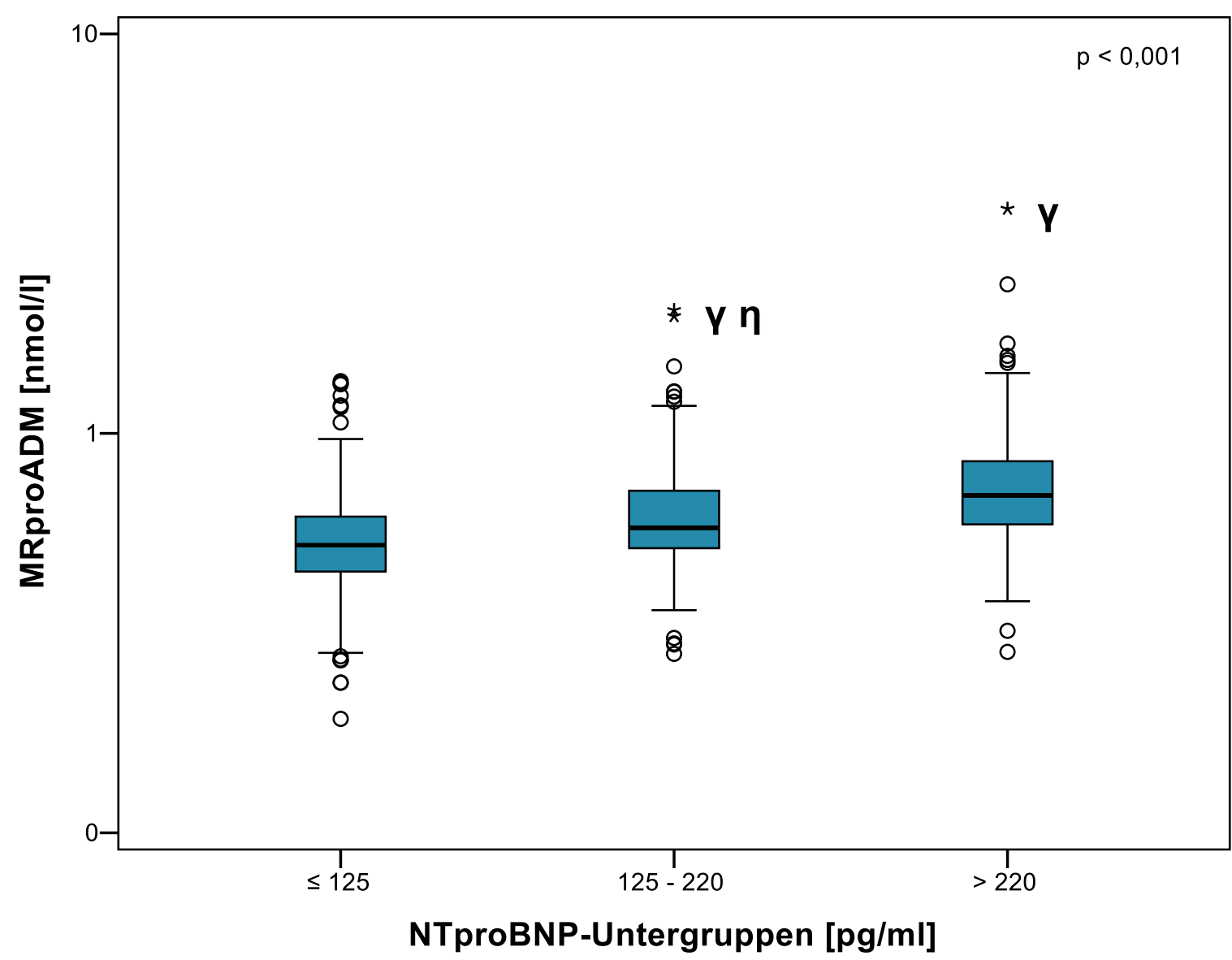

Abbildung 7 Verteilung der MRproADM-Konzentration. Die festgestellten MRproADMKonzentrationen (Ordinate) sind in dieser Abbildung in logarithmierter Form dargestellt. Die Boxplots markieren IQR und MW. Abkürzungen: $\gamma=(p<0,001)$ gegen NTproBNP $\leq 125$ sowie $\eta=(p<0,001)$ gegen NTproBNP $>220.0=$ Ausreißer, ${ }^{*}=$ Extremwert, $p=$ gruppenübergreifender Trend. 


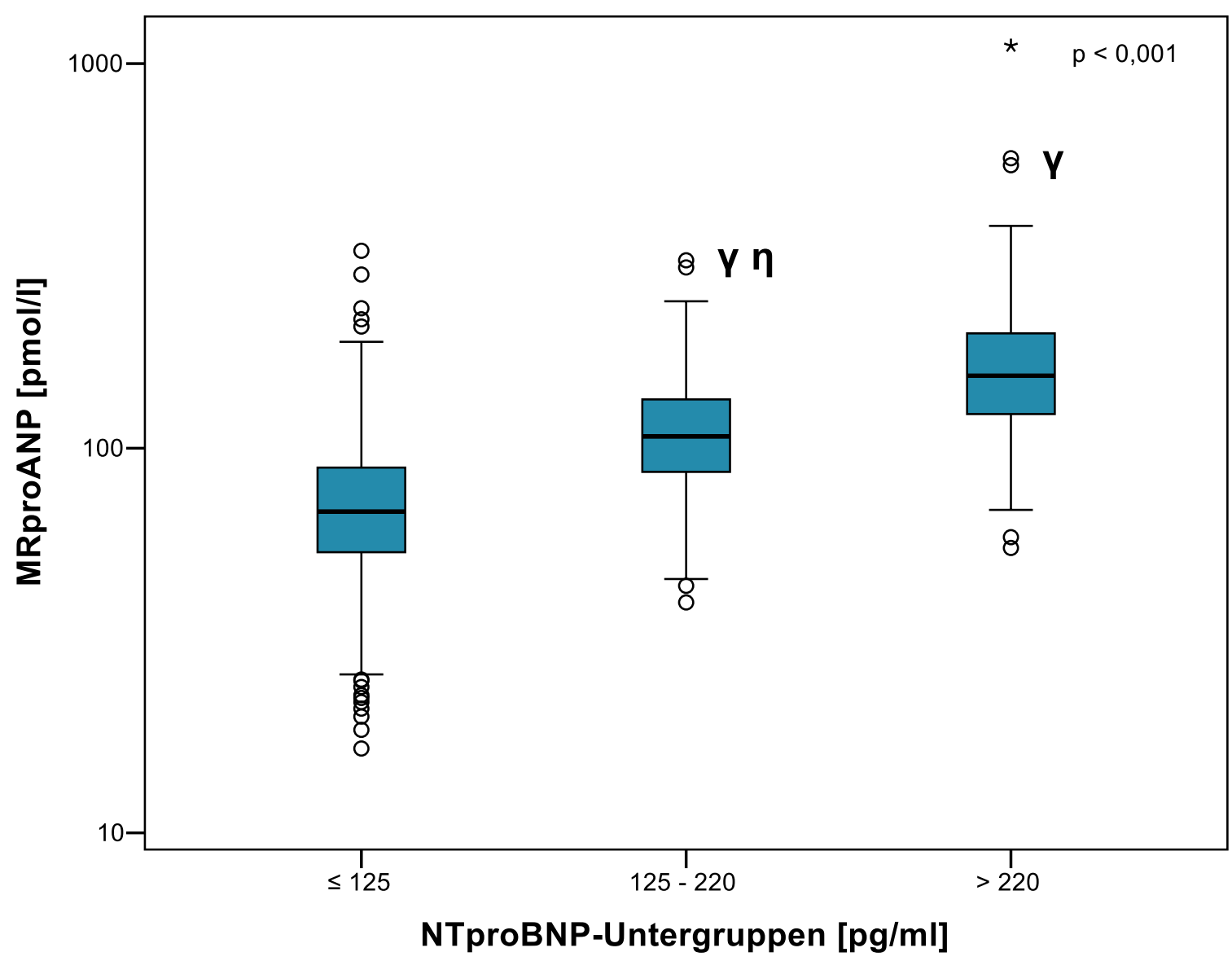

Abbildung 8 Verteilung der MRproANP-Konzentration. Veranschaulicht sind die Verteilung der gemessenen MRproANP-Konzentrationen (Ordinate) innerhalb der drei Untergruppen (Abszisse). Es handelt sich um logarithmiert dargestellte Boxplots mit Angabe von IQR und MW. Abkürzungen: $\gamma=(p<0,001)$ gegen NTproBNP $\leq 125$ sowie $\eta=(p<0,001)$ gegen NTproBNP $>$ 220. $0=$ Ausreißer, ${ }^{*}=$ Extremwert, $p=$ gruppenübergreifender Trend. 


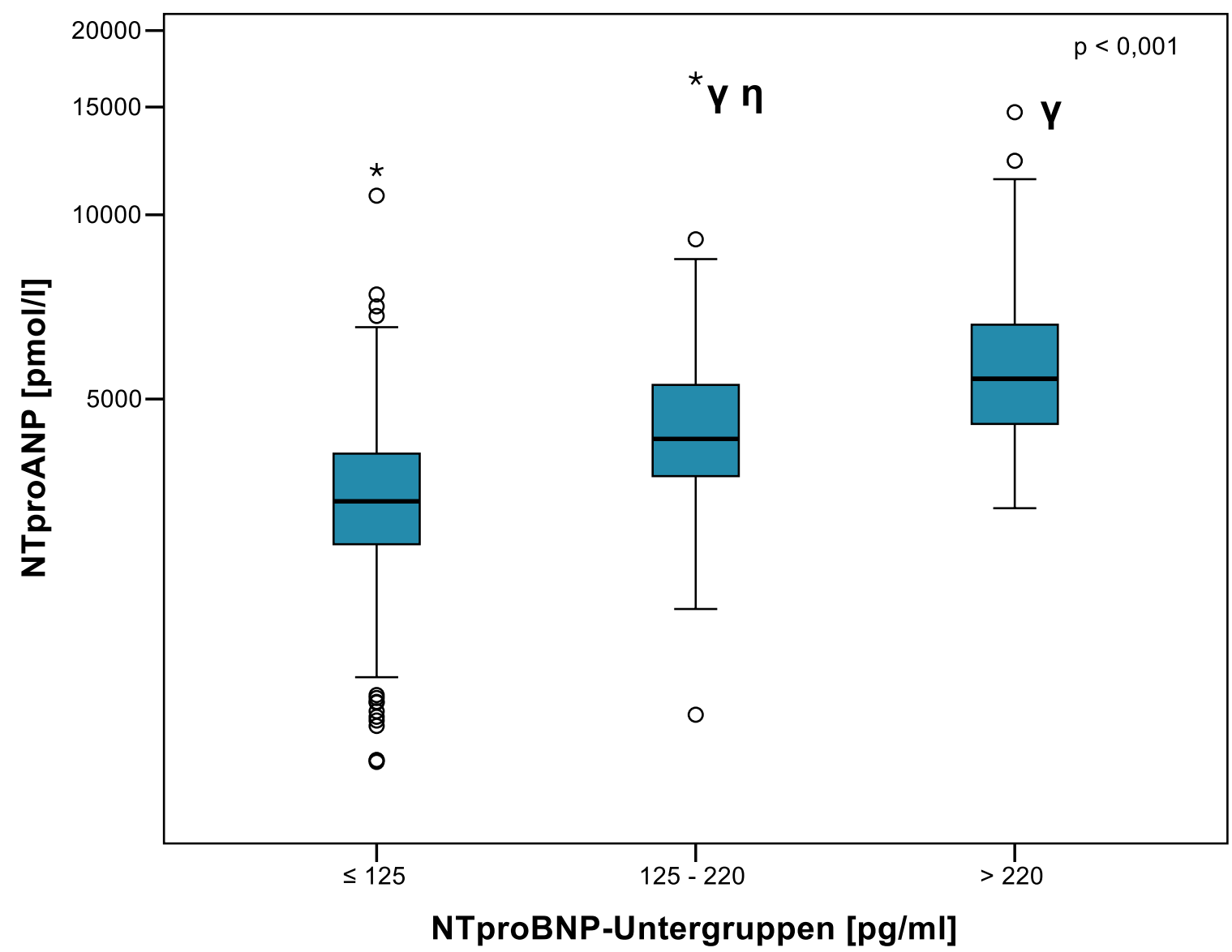

Abbildung 9 Verteilung der NTproANP-Konzentration. Die ermittelten NTproANPKonzentrationen (Ordinate) werden in dieser Abbildung für die drei Untergruppen (Abszisse) gezeigt. Die logarithmiert aufgetragenen Boxen geben den jeweiligen IQR und MW an. Abkürzungen: $\gamma=(p<0,001)$ gegen NTproBNP $\leq 125$ sowie $\eta=(p<0,001)$ gegen NTproBNP $>$ 220. $o=$ Ausreißer, ${ }^{*}=$ Extremwert, $p=$ gruppenübergreifender Trend. 


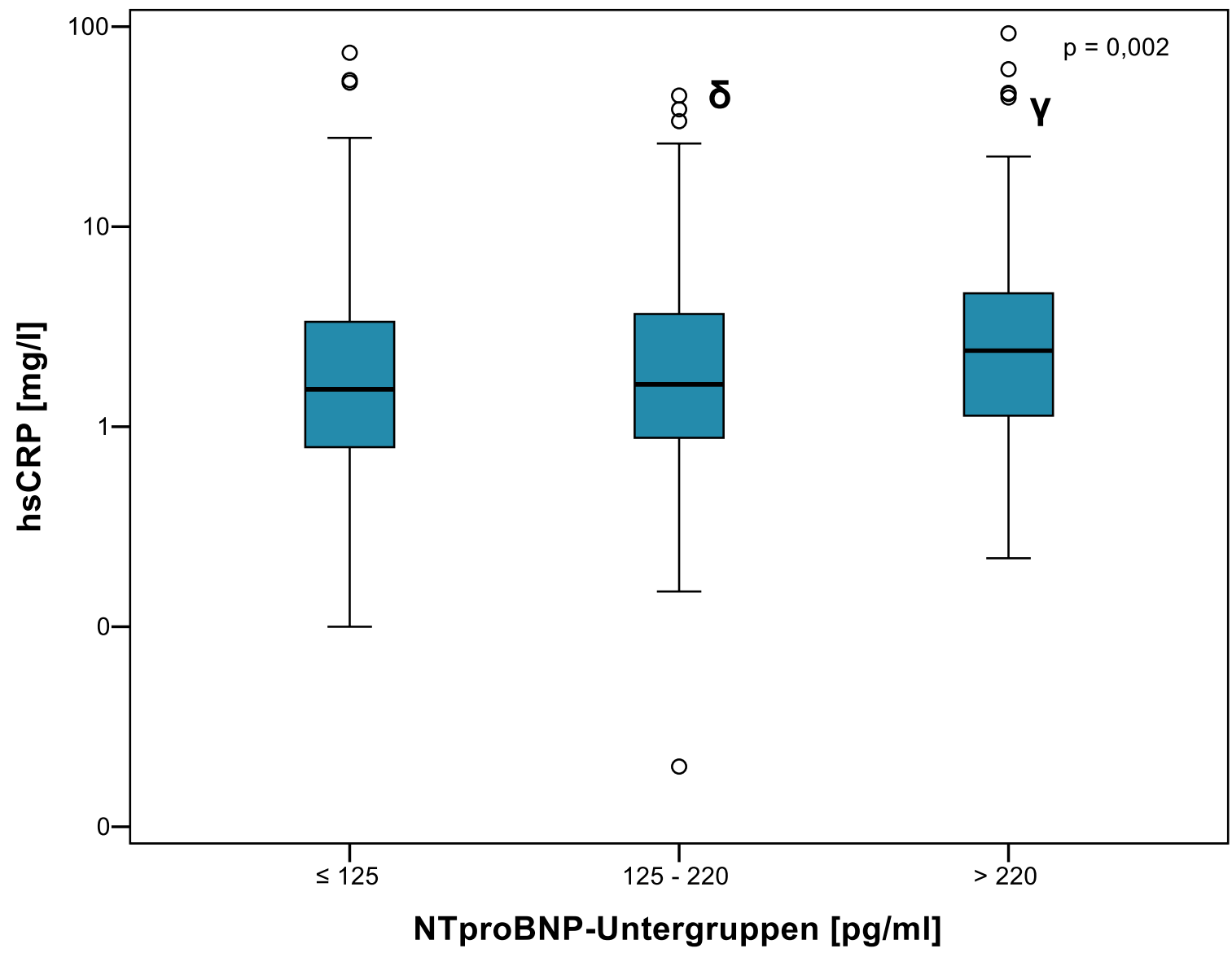

Abbildung 10 Verteilung der hsCRP-Konzentration. Diese Abbildung demonstriert die gemessenen hsCRP-Konzentrationen (Ordinate) in den Untergruppen (Abszisse). Die logarithmierte Darstellung gibt mit den Boxplots den jeweiligen IQR und MW an. Abkürzungen: $Y=(p<0,001)$ gegen NTproBNP $\leq 125$ sowie $\delta=(p<0,05)$ gegen NTproBNP $>220$. $0=$ Ausreißer, ${ }^{*}=$ Extremwert, $p=$ gruppenübergreifender Trend. 


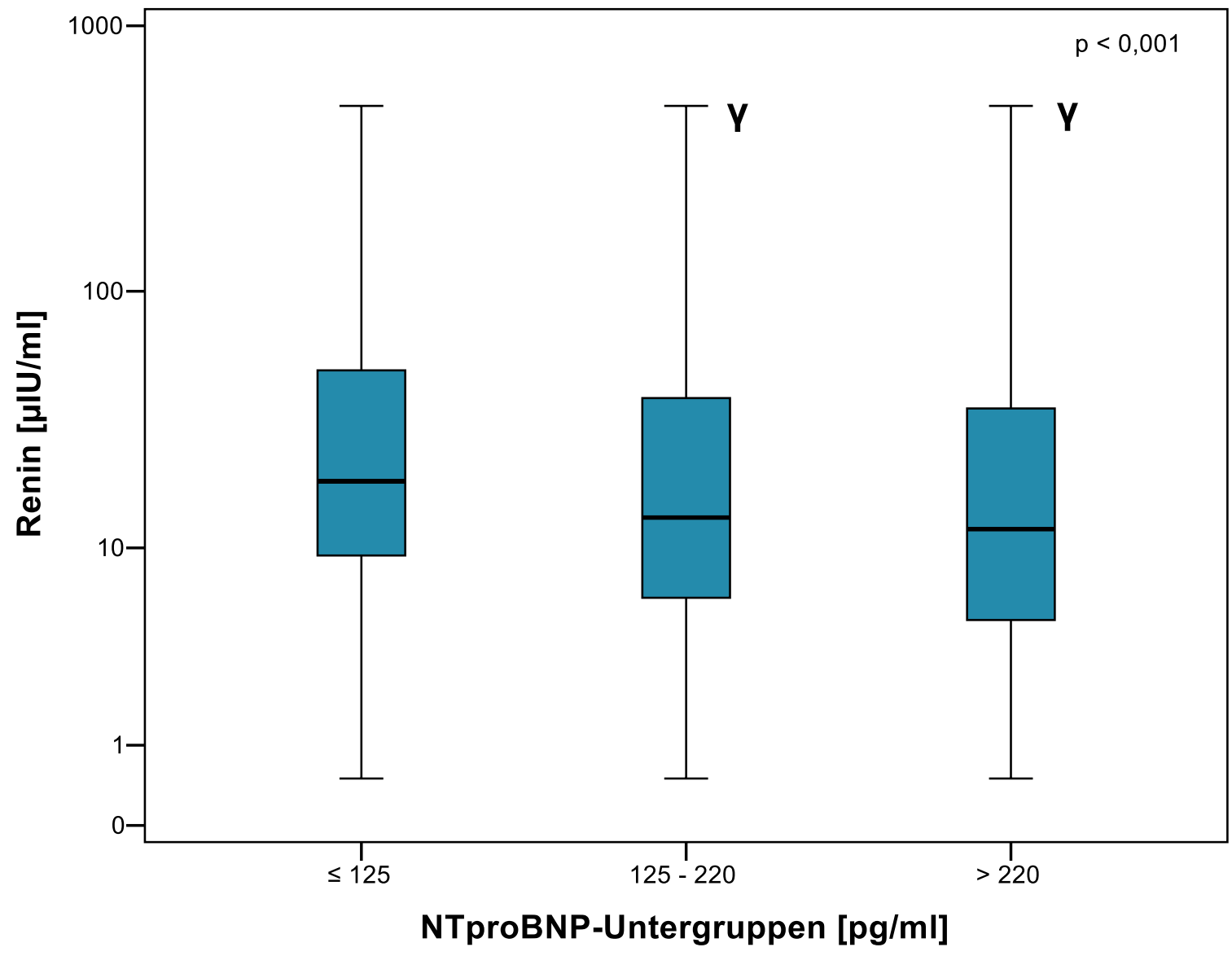

Abbildung 11 Verteilung der Renin-Konzentration. Die Boxplot-Diagramme geben die jeweils festgestellten Renin-Konzentrationen mit IQR und MW an, die auf der Ordinate in logarithmierter Form aufgetragen sind. Abkürzungen: $Y=(p<0,001)$ gegen NTproBNP $\leq 125,0=$ Ausreißer, * $=$ Extremwert, $p=$ gruppenübergreifender Trend. 


\subsubsection{Kaplan-Meier-Analyse zur Inzidenz des kombinierten}

\section{Endpunkts}

In 'Abbildung 12' veranschaulicht die Umkehr der überlicherweise monoton fallenden Überlebensfunktion nach Kaplan-Meier (1-Überlebensfunktion) die Wahrscheinlichkeit für das Auftreten des kombinierten Endpunkts aus Mortalität und CV-Hospitalisation in den drei NTproBNP-Untergruppen. Auf der Ordinate ist die Inzidenzrate, auf der Abszisse der Nachbeobachtungszeitraum von ca. sechs Jahren abgebildet. Patienten der dritten Untergruppe, d.h. solche mit NTproBNP-Konzentrationen $>220 \mathrm{pg} / \mathrm{ml}$ wiesen über die Zeit das größte Risiko für Mortalität und CV-Hospitalisation auf, während die der ersten Untergruppe $(\leq 125 \mathrm{pg} / \mathrm{ml})$ das geringste Risiko zeigten. Die Unterschiede zwischen den drei Untergruppen sind nach dem LogRank-Test hochsignifikant $(p<0,001)$. Da, wie bereits erwähnt, von 57 Patienten keine Nachbeobachtungsdaten zu NTproBNP vorlagen, konnten in der Analyse maximal 1427 Patienten berücksichtigt werden.

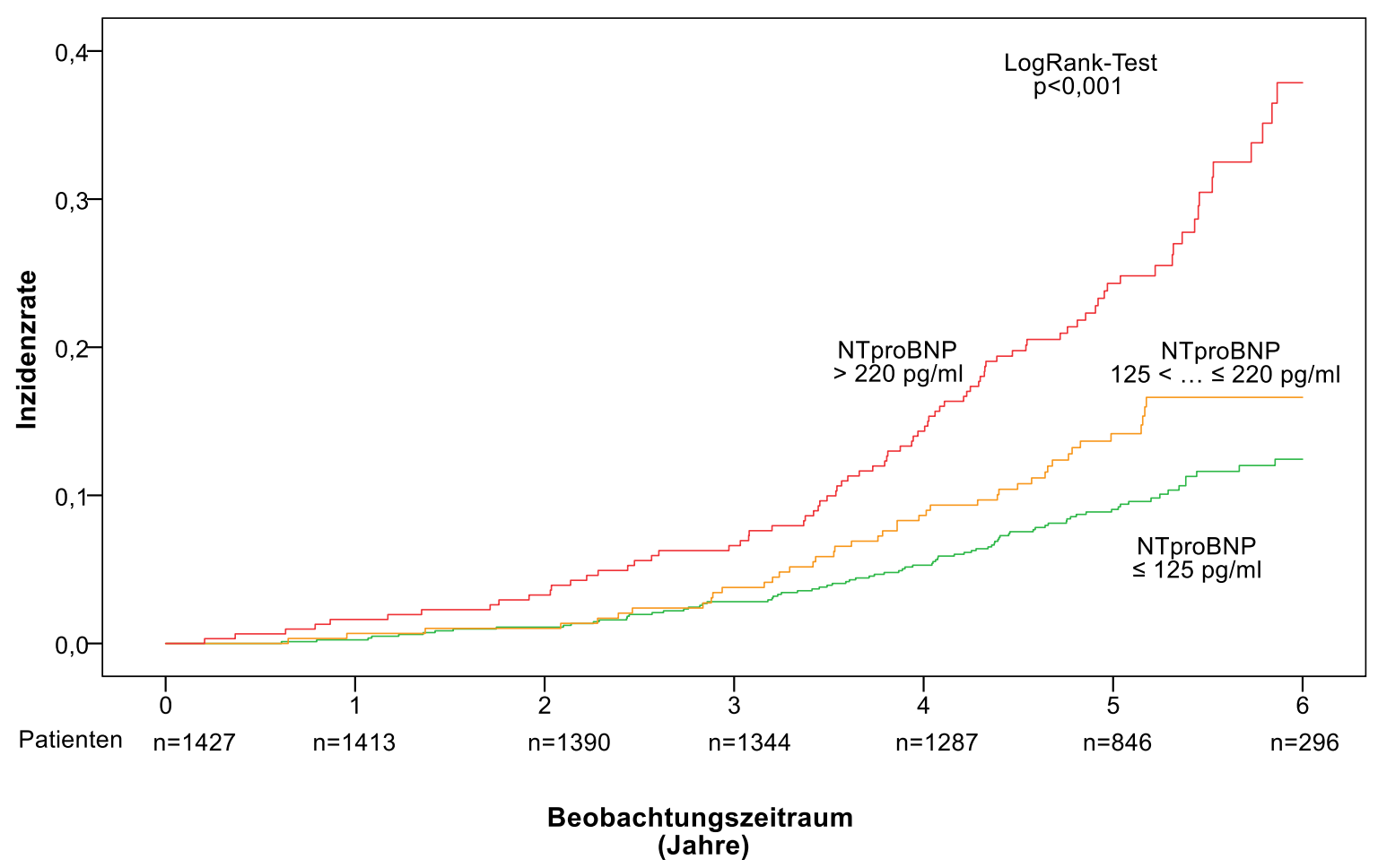

Abbildung 12 Kaplan-Meier-Analyse zur Inzidenz des kombinierten Endpunkts. Für jede der drei NTproBNP-Untergruppen wird hier der Zusammenhang zwischen dem Nachbeobachtungszeitraum von ungefähr sechs Jahren (Abszisse) und der Wahrscheinlichkeit für das Eintreten des kombinierten Endpunkts aus Mortalität und CV-Hospitalisation der Studie (Ordinate) dargestellt. Die Unterschiede zwischen den drei Untergruppen sind nach dem LogRank-Test hochsignifikant $(p<0,001)$. 


\subsubsection{Univariate Cox-Regressionsmodelle aller Biomarker}

Für jeden der zehn Biomarker wurde ein Cox-Regressionsmodell erstellt, welches den Zusammenhang zum kombinierten Endpunkt aus Mortalität und CV-Hospitalisation herstellt und das jeweilige Risiko für die Konzentrationserhöhung eines Biomarkers angibt. Da die Konzentrationen der Biomarker nicht normalverteilt waren, wurden sie logarithmiert und die HRs beziehen sich auf die Konzentrationserhöhung um eine SD. 'Tabelle 10' zeigt die Ergebnisse der Regressionsmodelle. Für Aldosteron, hsCRP und Renin konnte kein signifikanter Zusammenhang hergestellt werden. Eine übersichtliche graphische Darstellung erfolgt in 'Abbildung 13'.

Tabelle 10 Univariate Cox-Regressionsmodelle für alle zehn Biomarker. Sie zeigen den Zusammenhang zum kombinierten Endpunkt aus Mortalität und CV-Hospitalisation. Da die Konzentrationen der Biomarker nicht normalverteilt waren, wurden sie logarithmiert. Die HRs beziehen sich entsprechend auf die Erhöhung der Konzentration um eine SD.

\begin{tabular}{|l|c|c|}
\hline Biomarker & HR (95 \% Cl) & p-Wert \\
\hline logNTproBNP & $1,66(1,46-1,89)$ & $<0,001$ \\
\hline $\log$ Aldosteron & $1,02(0,88-1,19)$ & 0,753 \\
\hline $\log$ PIIINP & $1,18(1,05-1,33)$ & 0,005 \\
\hline $\log$ CTproAVP & $1,23(1,06-1,43)$ & $<0,001$ \\
\hline $\log$ CTproET-1 & $1,69(1,43-2,00)$ & $<0,001$ \\
\hline $\log$ MRproADM & $1,62(1,41-1,87)$ & $<0,001$ \\
\hline $\log$ MRproANP & $1,53(1,31-1,79)$ & 0,594 \\
\hline $\operatorname{loghsCRP}$ & $1,04(0,89-1,22)$ & 0,019 \\
\hline $\operatorname{logNTproANP}$ & $1,24(1,04-1,48)$ & 0,256 \\
\hline $\log$ Renin & $1,09(0,94-1,28)$ & 0.008 \\
\hline
\end{tabular}




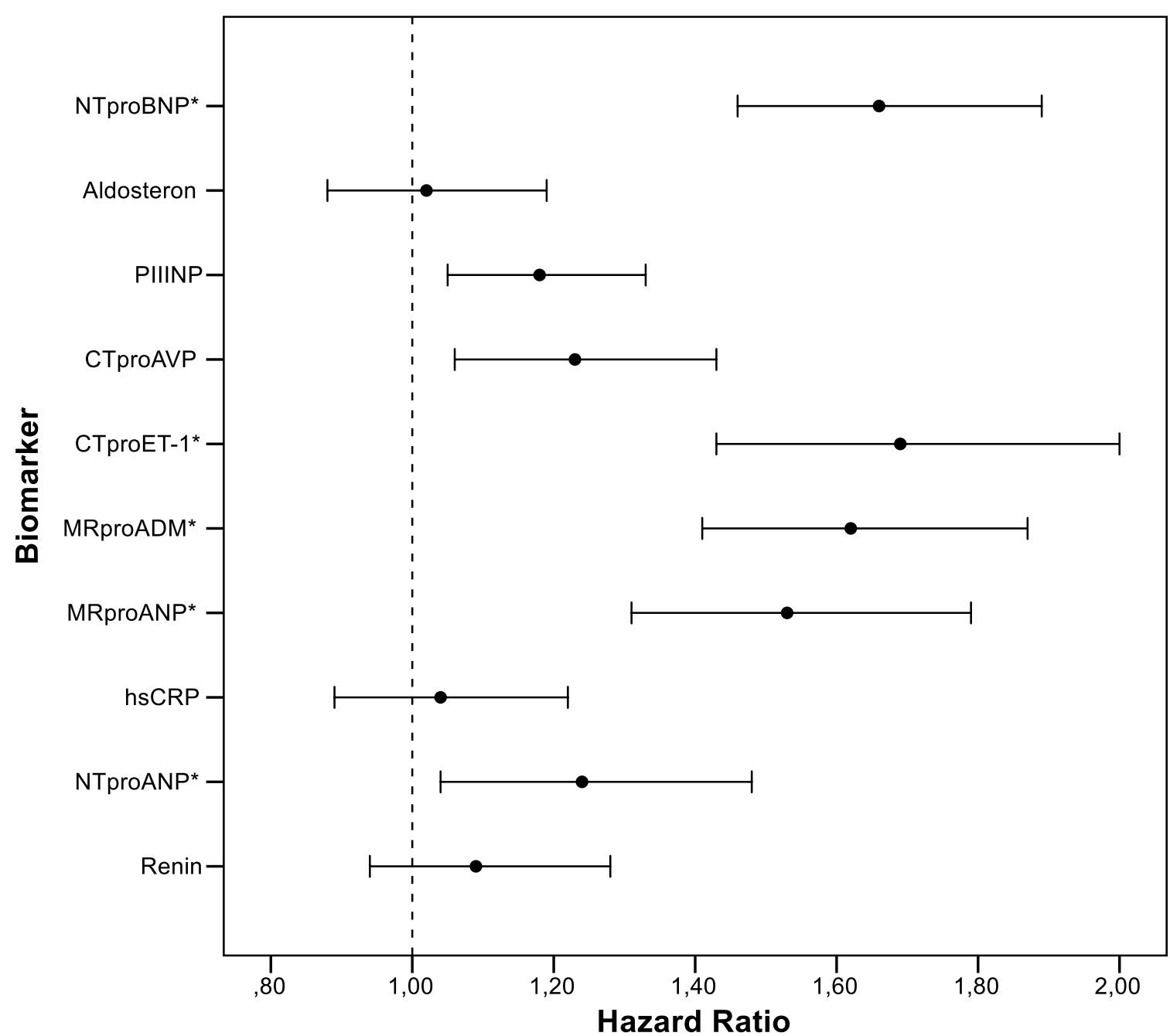

Abbildung 13 Forest-Plot zu univariaten Cox-Regressionsmodellen. Diese Abbildung zeigt anschaulich die Ergebnisse der univariaten Cox-Regressionsmodelle aller zehn Biomarker. Auf der Ordinate sind die einzelnen Biomarker dargestellt, während die Abszisse die HR in Bezug auf die Konzentrationserhöhung der jeweiligen Biomarker mit Angabe der Konfidenzintervalle angibt. Signifikante Korrelationen sind mit "*' gekennzeichnet. 


\subsubsection{Cox-Regressionsmodelle für NTproBNP}

Diejenigen Biomarker, die im vorausgegangenen Regressionsmodell signifikant mit dem Endpunkt korrelierten, wurden in weiteren Cox-Regressionsmodellen für NTproBNP getestet. Diese Analyse untersucht den Einfluss der Biomarker auf die HR, wenn gleichzeitig der Einfluss von NTproBNP berücksichtigt wird. Je höher der Einfluss von NTproBNP, desto stärker reduziert sich in diesem Regressionsmodell die HR. Die Konzentrationen der Biomarker wurden wie zuvor logarithmiert und die HRs beziehen sich auf die Konzentrationserhöhung um eine SD. Nur für CTproET-1 und MRproADM konnte eine signifikante Korrelation gezeigt werden. Die Ergebnisse sind in 'Tabelle 11' und 'Abbildung 14' als Forest-Plot dargestellt.

Tabelle 11 Cox-Regressionsmodelle für NTproBNP für die im univariaten Regressionsmodell signifikant korrelierenden Biomarker. Die Konzentrationen sind wie zuvor logarithmiert und die HRs beziehen sich auf die Erhöhung der Konzentration um eine SD.

\begin{tabular}{|l|c|c|}
\hline Biomarker & HR (95 \% Cl) & p-Wert \\
\hline logPIIINP & $1,14(1,00-1,31)$ & 0,056 \\
\hline logNTproBNP & $1,67(1,43-1,96)$ & $<0,001$ \\
\hline $\log$ CTproAVP & $1,15(0,99-1,34)$ & $<0,001$ \\
\hline $\operatorname{logNTproBNP}$ & $1,62(1,38-1,92)$ & $<0,001$ \\
\hline $\log$ CTproET-1 & $1,45(1,21-1,74)$ & $<0,001$ \\
\hline $\operatorname{logNTproBNP}$ & $1,45(1,21-1,73)$ & $<0,001$ \\
\hline $\log$ MRproADM & $1,42(1,21-1,67)$ & $<0,001$ \\
\hline $\operatorname{logNTproBNP}$ & $1,39(1,16-1,68)$ & 0,256 \\
\hline $\log$ MRproANP & $1,15(0,90-1,47)$ & 0,003 \\
\hline $\operatorname{logNTproBNP}$ & $1,49(1,15-1,93)$ & 0,847 \\
\hline $\operatorname{logNTproANP}$ & $1,02(0,81-1,30)$ & 0,011 \\
\hline $\operatorname{logNTproBNP}$ & $1,41(1,08-1,85)$ & \\
\hline
\end{tabular}




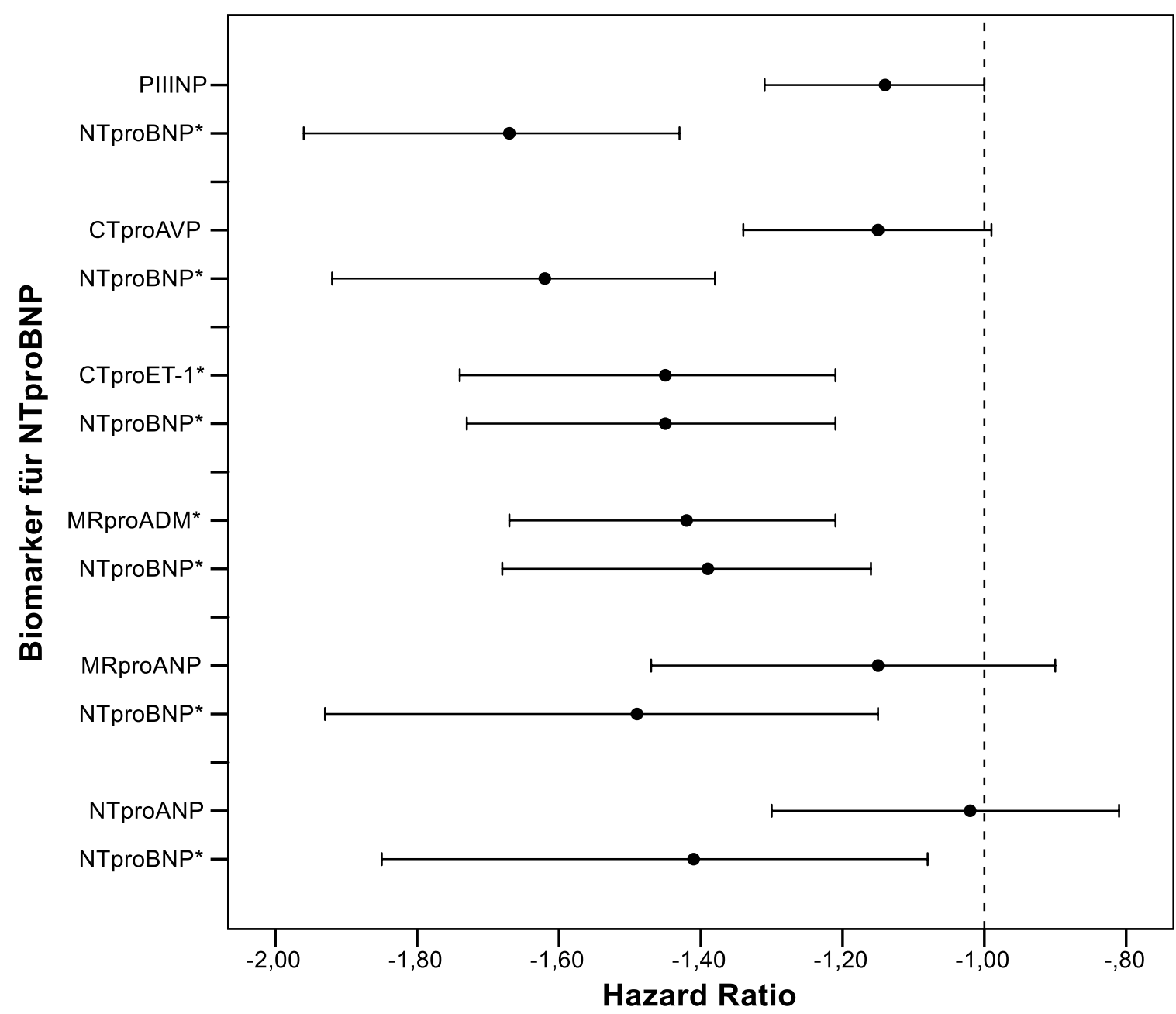

Abbildung 14 Forest-Plot zu Cox-Regressionsmodellen für NTproBNP. Diese Abbildung zeigt anschaulich die Ergebnisse der Cox-Regressionsmodelle für NTproBNP. Auf der Ordinate sind paarweise mit NTproBNP die zuvor signifikant korrelierenden Biomarker dargestellt, während die Abszisse die HRs mit entsprechendem Konfidenzintervall angibt. Signifikante Korrelationen sind mit '*' gekennzeichnet.

\subsubsection{Multivariate Cox-Regressionsmodelle für NTproBNP, CTproET-1 und MRproADM}

In der vorausgegangenen Analyse konnte nur für CTproET-1 und MRproADM ein signifikanter Zusammenhang zu Mortalität und CV-Hospitalisationen hergestellt werden. Für diese und NTproBNP wurden anschließend multivariate Cox-Regressionsmodelle erstellt, in denen nach den beiden jeweils anderen Biomarkern adjustiert wurde. Es zeigt sich, dass eine signifikante Korrelation nur für NTproBNP (HR 1,39; $95 \%$ Cl, 1,15 - 1,66; $\mathrm{p}=0,001)$ und MRproADM (HR 1,26; $95 \% \mathrm{Cl}, 1,00-1,59 ; \mathrm{p}=0,049)$ bestehen bleibt. Die Konzentrationen der Biomarker wurden ebenfalls logarithmiert und die HRs beziehen sich auf die Konzentrationserhöhung um eine SD. Die Ergebnisse der multivariaten Regressionsmodelle zeigen 'Tabelle 12' und 'Abbildung 15'. 
Tabelle 12 Multivariate Cox-Regressionsmodelle für NTproBNP und die beiden im Test für NTproBNP weiterhin signifikant mit dem kombinierten Endpunkt korrelierenden Biomarker CTproET-1 und MRproADM. In diesen Modellen werden die drei Biomarker gegeneinander adjustiert. Die Konzentrationen der Biomarker wurden logarithmiert, die HRs beziehen sich auf die Erhöhung der Konzentration um eine SD.

\begin{tabular}{|l|c|c|}
\hline Biomarker & HR $(95 \%$ Cl) & p-Wert \\
\hline logNTproBNP & $1,39(1,15-1,66)$ & 0,001 \\
\hline logCTproET-1 & $1,20(0,93-1,55)$ & 0,155 \\
\hline logMRproADM & $1,26(1,00-1,59)$ & 0,049 \\
\hline
\end{tabular}

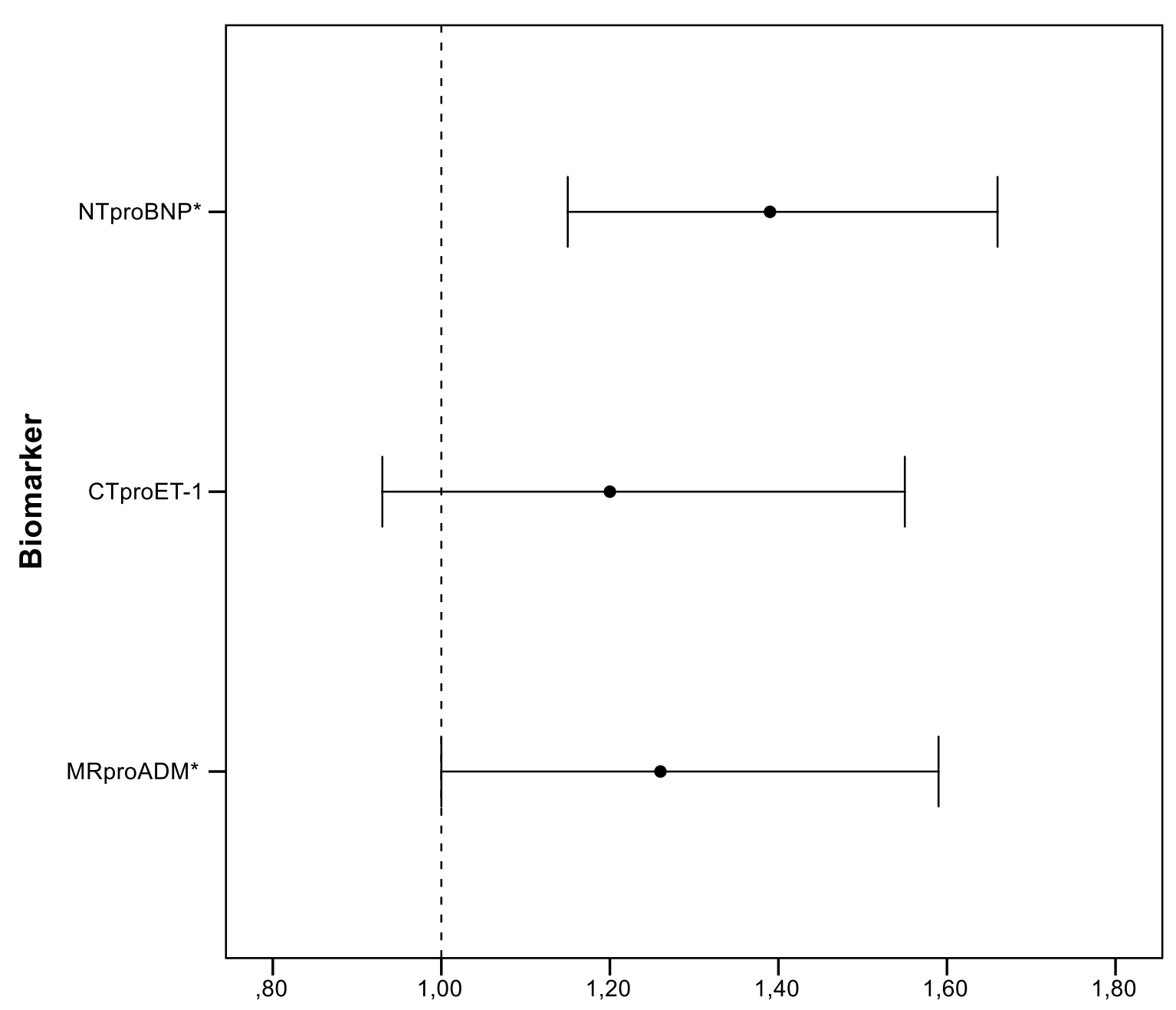

Hazard Ratio

Abbildung 15 Forest-Plot zu multivariaten Cox-Regressionsmodellen. Die Ergebnisse der multivariaten Cox-Regressionsmodelle von NTproBNP, CTproET-1 und MRproADM werden in dieser Abbildung veranschaulicht. Auf der Ordinate sind die einzelnen Biomarker dargestellt, während die Abszisse die HRs mit dazugehörigem Konfidenzintervall zeigt. Signifikante Korrelationen sind mit '*' gekennzeichnet. 


\subsubsection{Multivariate Cox-Regressionsmodelle für NTproBNP, CTproET-1, MRproADM und Alter}

Im Vergleich zur ersten multivariaten Regressionsanalyse aus '3.2.5 Multivariate CoxRegressionsmodelle für NTproBNP, CTproET-1 und MRproADM' (S. 51) wird in diesem Modell die zusätzliche Variable 'Alter +10 Jahre' eingeführt und nach dieser adjustiert. Das Alter der Patienten korreliert selbstverständlich auch mit der Mortalität bzw. CVHospitalisationen. Für eine Erhöhung des Alters um zehn Jahre besteht in dieser Analyse eine signifikante Korrelation ( $\mathrm{HR} 1,47 ; 95 \% \mathrm{Cl}, 1,17-1,84 ; \mathrm{p}=0,001)$. Durch die zusätzliche Adjustierung verlieren CTproET-1 und MRproADM allerdings ihren signifikanten Zusammenhang zum Endpunkt. Die Konzentrationen der Biomarker wurden auch hier logarithmiert und die HRs beziehen sich wie zuvor auf die Konzentrationserhöhung um eine SD. Die Ergebnisse der multivariaten Regressionsmodelle zeigen 'Tabelle 13' und 'Abbildung 16'.

Tabelle 13 Multivariate Cox-Regressionsmodelle für das Alter, NTproBNP und die beiden im Test für NTproBNP weiterhin signifikant mit dem kombinierten Endpunkt korrelierenden Biomarker CTproET-1 und MRproADM. In diesem Modell werden die drei Biomarker gegeneinander und das Alter adjustiert. Die Konzentrationen der Biomarker wurden logarithmiert. Die HRs beziehen sich beim Alter auf eine Erhöhung um zehn Jahre, bei den Biomarkern auf eine Erhöhung der Konzentration um eine SD.

\begin{tabular}{|l|c|c|}
\hline Biomarker & HR $(95 \%$ Cl) & p-Wert \\
\hline logNTproBNP & $1,28(1,05-1,55)$ & 0,014 \\
\hline logCTproET-1 & $1,18(0,91-1,52)$ & 0,212 \\
\hline logMRproADM & $1,18(0,93-1,50)$ & 0,172 \\
\hline Alter $(+10$ Jahre $)$ & $1,47(1,17-1,84)$ & 0,001 \\
\hline
\end{tabular}




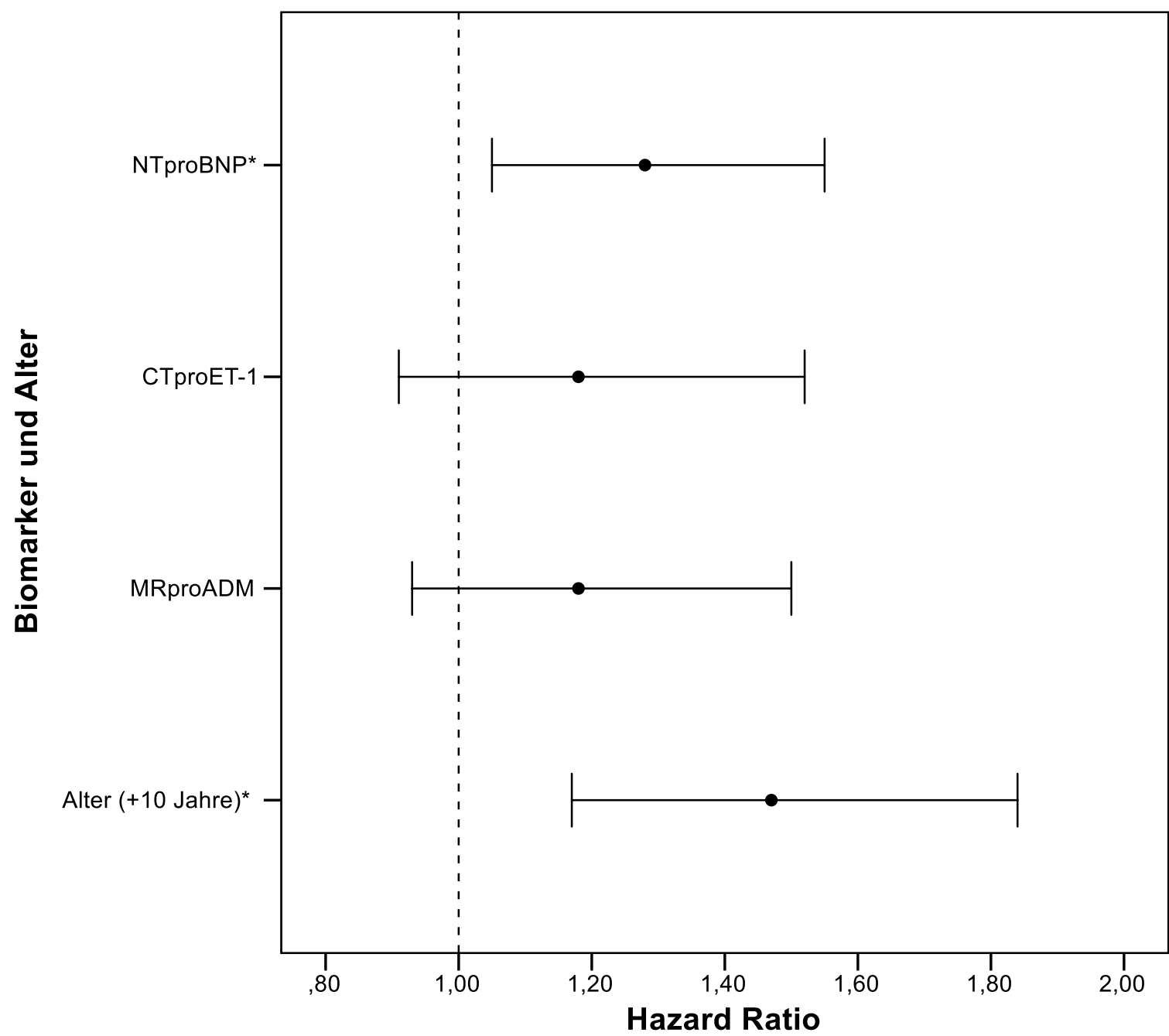

Abbildung 16 Forest-Plot zu multivariaten Cox-Regressionsmodellen mit Altersbetrachtung. Dargestellt sind die Ergebnisse der multivariaten Cox-Regressionsmodelle von NTproBNP, CTproET-1 und MRproADM und der Erhöhung des Patientenalters um zehn Jahre. Auf der Ordinate sind die einzelnen Biomarker und die Variable 'Alter' veranschaulicht, während die Abszisse die HR für die Konzentrationserhöhung der Biomarker bzw. die Erhöhung des Alters um zehn Jahre angibt. Die HRs sind jeweils mit entsprechendem $95 \% \mathrm{Cl}$ aufgetragen. Signifikante Korrelationen sind mit '*' gekennzeichnet. 


\subsubsection{Korrelationsanalyse der Biomarker}

Die zuvor durchgeführten Analysen deuten auf Korrelationen der Biomarker untereinander hin, da signifikante Zusammenhänge zum Endpunkt nach Adjustierung für andere Biomarker in multivariaten Regressionsmodellen verloren gingen. Aus diesem Grund wurde eine Korrelationsanalyse durchgeführt, die die Überschneidungen der Informationen darstellt. Die Ergebnisse sind in 'Tabelle 14' ersichtlich. Es wurden nur diejenigen Biomarker berücksichtigt, die bereits im univariaten Cox-Regressionsmodell signifikante Zusammenhänge zeigten, d.h. Aldosteron, hsCRP und Renin wurden nicht betrachtet. NTproANP wurde aufgrund der geringen Anzahl valider Daten ebenfalls nicht einbezogen.

Tabelle 14 Korrelationsanalyse derjenigen Biomarker, die im univariaten CoxRegressionsmodell einen signifikanten Zusammenhang zum kombinierten Endpunkt zeigten. Die linke Spalte wurde nach dem Alter adjustiert. In dieser Tabelle gelten folgende Fußnoten: $p<0,05$ $(\alpha) ; p<0,01(\beta) ; p<0,001(y)$.

\begin{tabular}{|c|c|c|c|c|c|c|}
\hline (n) & NTproBNP & PIIINP & CTproET-1 & CTproAVP & MRproADM & MRproANP \\
\hline NTproBNP & & $0,15^{\vee}$ & $0,33 \gamma$ & $0,09^{\beta}$ & $0,44 v$ & $0,77 v$ \\
\hline PIIINP & $0,10 \mathrm{r}$ & & $0,20 r$ & $0,10^{\beta}$ & $0,20 r$ & $0,14 r$ \\
\hline CTproET-1 & $0,23 \mathrm{r}$ & $0,17 \gamma$ & & $0,22^{Y}$ & $0,73^{\vee}$ & $0,43^{v}$ \\
\hline CTproAVP & 0,06 & $0,08^{\beta}$ & $0,20 \mathrm{r}$ & & $0,31 \mathrm{r}$ & $0,10^{\beta}$ \\
\hline MRproADM & $0,33 r$ & $0,16^{r}$ & $0,69 r$ & $0,30 r$ & & $0,53 \mathrm{r}$ \\
\hline MRproANP & $0,71 \mathrm{r}$ & $0,09^{\beta}$ & $0,34 r$ & $0,07^{\alpha}$ & $0,43 v$ & \\
\hline
\end{tabular}

\subsubsection{Faktoren-Analyse}

Die Korrelationsanalyse zeigt, dass diverse Biomarker überschneidende Informationen bereitstellen. In Kombination mit den Ergebnissen der vorherigen Regressionsmodelle schien es daher sinnvoll, zwei getrennte Gruppen bzw. Faktoren (A/B) statt einzelner Biomarker zu betrachten. 'Faktor $A$ ' wird zum Großteil aus den Informationen von NTproBNP und MRproANP gebildet, während 'Faktor B' maßgeblich von CTproAVP und fast zu gleichen Anteilen von PIIINP, CTproET-1 und MRproADM bestimmt wird. Wie zuvor finden Aldosteron, hsCRP, Renin und NTproANP aus genannten Gründen keine Berücksichtigung. Die Ergebnisse der Faktoren-Analyse liefert 'Tabelle 15'. 
Tabelle 15 Faktoren-Analyse der zuvor in der Korrelationsanalyse untersuchten Biomarker und ihr Beitrag zu Faktor A und Faktor B.

\begin{tabular}{|l|c|c|}
\hline & Faktor A & Faktor B \\
\hline NTproBNP & 0,474 & $-0,206$ \\
\hline PIIINP & $-0,067$ & 0,310 \\
\hline CTproET-1 & 0,103 & 0,340 \\
\hline CTproAVP & $-0,258$ & 0,591 \\
\hline MRproADM & 0,143 & 0,333 \\
\hline MRproANP & 0,462 & $-0,151$ \\
\hline
\end{tabular}

\subsubsection{Finale multivariate Cox-Regressionsmodelle}

Anstatt den Zusammenhang zwischen den Biomarkern und dem kombinierten Endpunkt einzeln zu betrachten, erfolgt nun die Betrachtung der Faktoren $A$ und $B$ in zwei multivariaten Cox-Regressionsmodellen. In diesen wurde nach Alter, KHK, Diabetes mellitus, HI-Symptomen, Anämie, renale Dysfunktion, LAVI und E/e' korrigiert. Für beide Faktoren besteht ein signifikanter Zusammenhang zur Mortalität und CV-Hospitalisation. Die Ergebnisse der finalen multivariaten Regressionsmodelle zeigen 'Tabelle 16' und 'Abbildung 17'.

Tabelle 16 Finale multivariate Cox-Regressionsmodelle für die Faktoren $A$ und $B$ der Faktoren-Analyse. In diesem Modell wurde nach Alter, KHK, Diabetes mellitus, HI-Symptome und Zeichen, Anämie, renale Dysfunktion, LAVI und E/e' adjustiert. Die HRs beziehen sich entsprechend auf die Zunahme eines Faktors um eine SD.

\begin{tabular}{|l|c|c|}
\hline & HR (95\% Cl) & p-Wert \\
\hline Faktor A & $1,31(1,07-1,59)$ & 0,007 \\
\hline Faktor B & $1,23(1,03-1,46)$ & 0,02 \\
\hline
\end{tabular}




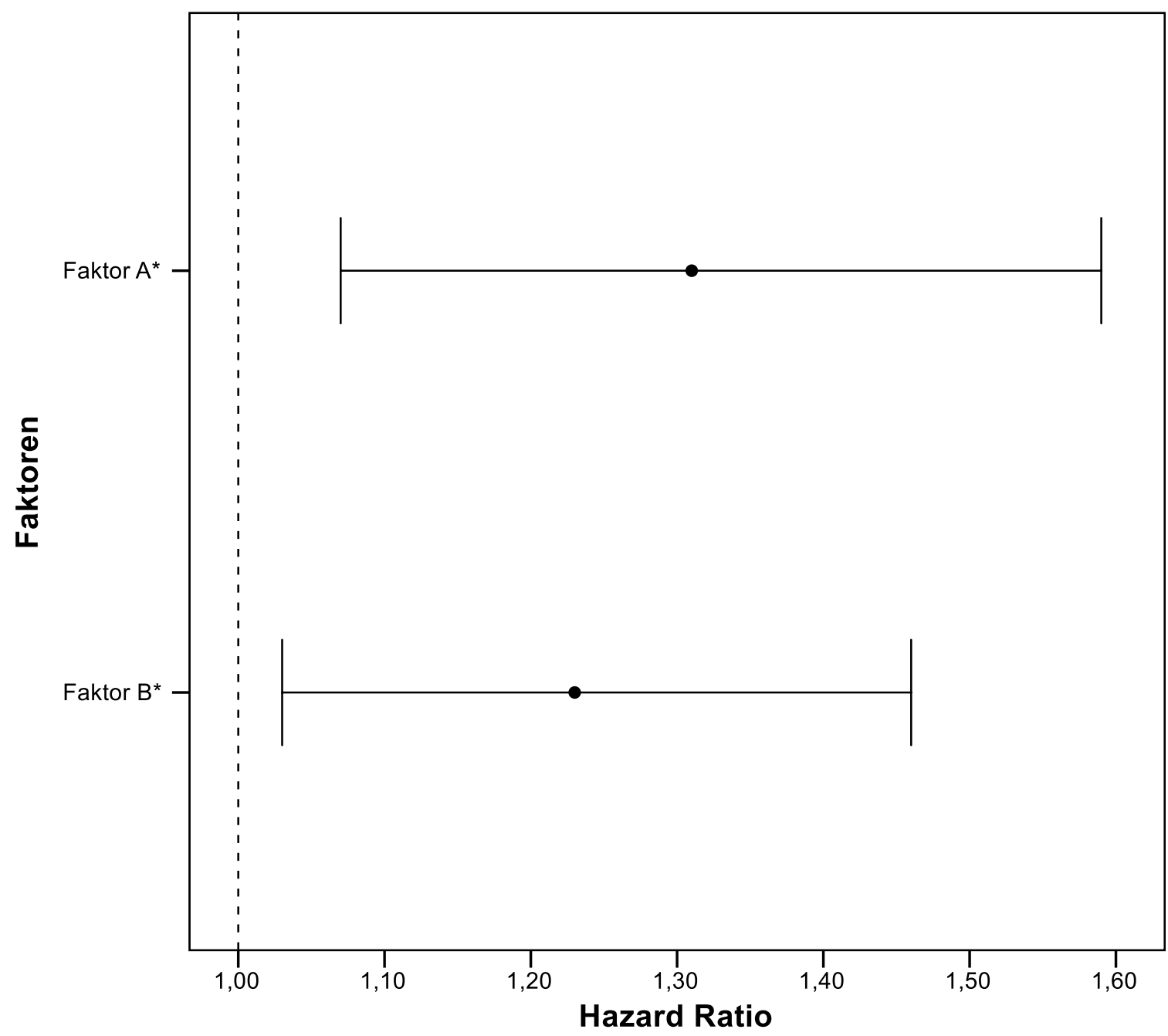

Abbildung 17 Forest-Plot zu finalem Cox-Regressionsmodell. Diese Abbildung zeigt die Ergebnisse des finalen Cox-Regressionsmodells. Auf der Ordinate sind die beiden Faktoren A und $B$ dargestellt, während die Abszisse die HR zeigt. Die HR für den jeweiligen Faktor ist mit entsprechendem Konfidenzintervall aufgetragen. Signifikante Korrelationen sind mit '*' gekennzeichnet. 


\section{Diskussion}

Die bisher vorhandenen Möglichkeiten zur Prognoseabschätzung bei DD und HFpEF sind begrenzt. Zwar gibt es eine Vielzahl prognoserelevanter Faktoren, doch ist kein klares Schema für die Prognosefindung vorhanden, und die subjektive Interpretation und Zusammenführung dieser Faktoren ist oftmals von geringer Präzision. Die Objektivität von Biomarkern kann folglich für die Prognosefindung von großem Nutzen sein. Entsprechende Studien sind allerdings rar und beziehen sich zum Großteil auf das natriuretische Peptid BNP (van Veldhuisen et al. 2013, Izumiya et al. 2014) oder das entsprechende Fragment NTproBNP (Grewal et al. 2008, Anand et al. 2011, Komajda et al. 2011, Cleland et al. 2012). Viele weitere Biomarker, die pathophysiologisch mit DD und HFpEF zusammenhängen, blieben bislang ungeachtet.

Daher untersucht die vorliegende Arbeit die Prognosekraft von zehn verschiedenen Biomarkern aus unterschiedlichen Bereichen der Pathophysiologie von DD und HFpEF in einem Kollektiv der DIAST-CHF-Studie. Sie stammten aus der neurohumoralen Regulation (Aldosteron, CTproAVP, CTproET-1, MRproADM, Renin), dem myokardialen Stress (MRproANP, NTproANP, NTproBNP), der Entzündung (hsCRP) und dem EZMRemodelling (PIIINP). Es galt herauszufinden, ob Zusammenhänge zwischen den einzelnen Biomarkern und dem kombinierten Endpunkt aus Mortalität und CVHospitalisation über eine Nachbeobachtungsphase von 5,2 Jahren bestehen und, ob bestimmte Biomarker geeignet sind, um diesen Endpunkt zuverlässig vorherzusagen. Dieses Kapitel widmet sich der Bewertung und Interpretation der festgestellten Ergebnisse und zieht Vergleiche zu bisher gewonnenen Erkenntnissen der klinischen Forschung. Aus Mangel an HFpEF-Studien erfolgt auch eine Einordnung der Ergebnisse in vergleichbare HFrEF-Studien.

\subsection{Schlussfolgerungen aus dem Patientenkollektiv}

Die zugrundeliegenden Patientendaten stammen aus der prospektiven, multizentrischen Zwei-Kohortenstudie DIAST-CHF ('Prävalenz und Verlauf der diastolischen Dysfunktion und der diastolischen Herzinsuffiziens'). Die Rekrutierung der Patienten erfolgte über den Basisdatensatz der Abteilung Allgemeinmedizin des Universitätsklinikums Göttingen und die Praxis-EDV von umliegenden Hausärzten. Zum Einschluss in die Studie mussten die Patienten zwischen 50 - 85 Jahren alt sein und mindestens einen Risikofaktor für die Entwicklung einer DD aufweisen oder eine ärztlich gestellte HI-Diagnose erhalten haben. Es handelt sich somit um ein nicht-vorselektiertes Risikokollektiv, in dem sowohl HFpEFals auch symptomlose Patienten mit Risikofaktoren und erhaltener EF $\geq 50 \%$ vertreten 
sind. Diese Arbeit betrachtet eine Gruppe von insgesamt 1484 Patienten über einen Zeitraum von 5,2 Jahren, die anhand der Baseline-Konzentration von NTproBNP in drei Untergruppen eingeteilt wurden ( $\leq 125 \mathrm{pg} / \mathrm{ml}$ [1]; $125<\ldots \leq 220 \mathrm{pg} / \mathrm{ml}$ [2]; > $220 \mathrm{pg} / \mathrm{ml}$ [3]). Dies ermöglicht die genauere Betrachtung von Prävalenzen und Zusammenhängen einzelner Variablen bei unterschiedlich hoher NTproBNP-Konzentration.

Die Vergleichbarkeit zu anderen Studien wird unter anderem erschwert durch die unterschiedlichen Studiendesigns, Diagnose- und Einschlusskritierien sowie heterogenen Populationen. Dies liegt einerseits am Risikokollektiv von DIAST-CHF, welches vorranging von DD geprägt ist und kein reines HFpEF-Kollektiv darstellt, andererseits an den oftmals divergierenden Werten zur EF und dem Schweregrad der HI. So haben Koller et al. (2014) ihre Patienten bei anstehender Koronarangiographie eingeschlossen, während die drei auf I-PRESERVE basierenden Studien (Anand et al. 2011, Komajda et al. 2011, Krum et al. 2011) sowie Michowitz et al. (2008), Grewal et al. (2008) und Cleland et al. (2012) eine vorherige Hospitalisation aufgrund einer HI voraussetzten. Insbesondere die Cut-Off-Werte für das Vorhandensein einer erhaltenen EF schwanken zwischen 40 $55 \%$, was dazu führt, dass bei entsprechenden Studien auch Patienten mit bereits eingeschränkter Pumpfunktion eingeschlossen wurden und das HFpEF-Kollektiv verfälschen. Ebenfalls problematisch ist die geringe Anzahl an Patienten in den meisten Studien, da die Aussagekraft bei kleinen Kollektiven geringer ist und hinterfragt werden muss. Die Studien mit der größten Patientenzahl beziehen sich allesamt auf die bisher größte HFpEF-Studie I-PRESERVE, in der ein Therapieansatz mit dem Angiotensin-1Antagonisten Irbesartan überprüft wurde. Komajda et al. (2011) betrachten durch eine spezielle Kalkulation die gesamte Kohorte mit 4128 Patienten, während Anand et al. (2011) mit 3480 und Krum et al. (2011) mit 313 Patienten aufgrund fehlender BaselineMessungen von Biomarkern (NTproBNP, PIIINP) auf kleinere Patientengruppen zurückgreifen mussten. Die Einschlusskriterien dieser drei Substudien sind identisch und setzen ein Alter > 60 Jahren, eine EF $\geq 45 \%$ und eine NYHA-Klasse II - IV voraus. Weiterhin mussten die Patienten innerhalb der letzten sechs Monate aufgrund der HI hospitalisiert worden sein oder den NYHA-Klassen III - IV angehören und zusätzlich entsprechend klare Anzeichen einer HFpEF aufweisen. Im Gegensatz zur DIAST-CHF-Studie gab es eine Vielzahl an Ausschlusskriterien wie schwere, die Lebenszeit deutlich verkürzende Erkrankungen, unkontrollierte Arrhythmien, ein schlecht eingestellter Blutdruck etc., sodass es sich um ein selektiertes Kollektiv handelt. Alle Autoren betrachten die Patienten über eine Nachbeobachtungszeit von durchschnittlich 49,5 Monaten.

Die nächstgrößeren Kollektive untersuchten Koller et al. (2014) und Matsubara et al. (2014) mit 459 bzw. 360 Patienten, beide zur Prognosekraft von hsCRP. Zwar wurde die HFpEF-Diagnose in diesen Studien nach den Vorgaben von Paulus et al. (2007) gestellt, 
trotzdem wählten die Autoren unterschiedliche Cut-Off-Werte für die EF. Koller et al. (2014) schlossen symptomatische Patienten mit einer $E F \geq 45 \%$ ein, die zur Koronarangiographie erschienen. Aufgrund der Betrachtung von hsCRP wurden Patienten mit akuten/chronischen Infektionen, Autoimmunerkrankungen und malignen Tumoren ausgeschlossen. Als Vergleichsgruppe dient eine 522 Patienten zählende HFrEF-Gruppe, die ebenfalls über den langen Zeitraum von 9,7 Jahren (median) beobachtet wurde. Matsubara et al. (2014) betrachten eine deutlich kürzere Nachbeobachtungsphase von durchschnittlich 30 Monaten und schlossen klinisch stabile Patienten (NYHA-Klasse II IV) mit einer $E F \geq 50 \%$ und vorhandener DD ein.

Cleland et al. (2012) greifen auf ein aus 375 Patienten bestehendes Kollektiv von 'PEPCHF' (Perindopril in elderly People with chronic Heart Failure) zurück. Diese Medikamentenstudie untersuchte die Wirkung von Perindopril bei älteren Patienten mit HFpEF und hatte strenge Einschlusskriterien. Es wurden nur symptomatische Patienten $\geq 70$ Jahre mit einer $E F \geq 40 \%$ und vorhandener DD eingeschlossen, die bereits eine Diuretika-Medikation erhalten und innerhalb der letzten sechs Monate aufgrund einer $\mathrm{HI}$ hospitalisiert wurden. Zum Ausschluss führte unter anderem eine Medikation mit ACEHemmern, kaliumsparenden Diuretika, Kaliumpräparaten, ein systolischer Blutdruck $<100 \mathrm{mmHg}$ und schwere Herzklappenerkrankungen.

Die übrigen Studien betrachten mit maximal 181 Patienten - ohne gegebenenfalls vorhandene Kontrollgruppen - deutlich kleinere Kollektive. Grewal et al. (2008) beziehen ihre Daten aus der Substudie 'CHARM Echocardiographic Substudy' der Medikamentenstudie 'CHARM-Preserved' (Candesartan in Heart Failure - Assessment of Reduction in Mortality and Morbidity), die die HFpEF-Therapie mit Candesartan untersuchte. Die Einschlusskriterien gleichen der Hauptstudie und setzten ein Alter > 18 Jahren, eine EF $\geq 40 \%$ und NYHA-Klasse II-IV voraus. Ebenso lag bei allen Patienten eine vorausgegangene Hospitalisation aus kardialen Gründen vor. Zum Ausschluss führte die Medikation mit einem Angiotensin-Antagonisten, ACE-Hemmer (nur zu Beginn der Studie) und moderate bis schwere Herzklappeninsuffizienzen. Der kombinierte Endpunkt aus Tod, Hospitalisierung, Myokardinfarkt und Apoplex wurde über einen Zeitraum von 524 Tagen (median) verfolgt.

Barasch et al. (2011) nutzten zur Untersuchung der Prognosekraft von PIIINP Daten der prospektiven, bevölkerungsbezogenen, epidemiologischen 'CHS'-Studie (Cardiovascular Health Study), die Zusammenhänge zwischen Risikofaktoren und dem Überleben bei älteren Patienten zwischen 65-100 Jahren untersuchte. Sie betrachten in den Hauptgruppen nur Patienten mit diagnostizierter $\mathrm{HI}$ und somit einen Bruchteil des CHSKollektivs. Insgesamt kommen sie auf 175 HFpEF-Patienten mit einer EF $\geq 55 \%$ sowie 
146 HFrEF- und 280 Risikopatienten ohne HI. Der Nachbeobachtungszeitraum betrug $12 \pm 4$ Jahre.

Mit 77 HFpEF-Patienten betrachteten Michowitz et al. (2008) ein kleines Kollektiv zur Prognosekraft von hsCRP über 34,1 $\pm 11,2$ Monate und verglichen Ihre Ergebnisse mit einer 217 Patienten starken HFrEF- und einer aus 7701 gesunden Probanden bestehenden Kontrollgruppe. Die Einschlusskriterien waren weniger streng als bei bereits genannten Studien. Die Patienten mussten eine EF $\geq 45 \%$ aufweisen, der NYHA-Klasse II - IV angehören und durften innerhalb der letzten drei Monate an keiner akuten Dekompensation oder zur Einschlussuntersuchung an einer hochgradigen Herzklappenerkrankung leiden.

Nur bedingt vergleichbare Daten liefern Güder et al. (2007) aus einer prospektiven Kohortenstudie zur Prognosekraft von Aldosteron über eine Beobachtungsphase von 803 Tage (median). Die Patienten wurden nach der echokardiographisch erhobenen FS in systolische HI (FS < 24 \%, 171 Patienten) und diastolische HI (FS $\geq 24 \%, 123$ Patienten) eingeteilt. Zum Einschluss in die Studie mussten die Patienten Symptome zeigen, jedoch durfte keine Corticosteroid-Medikation vorliegen, um die ebenfalls analysierte Prognosekraft von Cortisol nicht zu beeinflussen.

Insgesamt erscheinen die Studien aufgrund stark variierender Einschlusskriterien, Beobachtungszeiträume und Patientenzahlen sehr heterogen. Viele Untersuchungen unterscheiden sich zwar in der EF, halten sich jedoch an aktuelle Richtlinien zur Diagnose der HFpEF. Das I-PRESERVE-Kollektiv hat aufgrund der großen Patientenzahl eine hohe Aussagekraft, wurde in nahezu voller Zahl aber nur für die Prognosekraft von NTproBNP genutzt. Die Rekrutierung von Patienten bei bevorstehender Koronarangiographie, wie sie bei Koller et al. (2014) stattgefunden hat, selektiert eine bestimmte Gruppe von Patienten, die vorrangig an KHK erkrankt ist. Ebenfalls schwierig ist die Beurteilung von Daten, die nachträglich anhand der EF eingeteilt wurden und deren genauen Diagnosegrundlagen für HFpEF unklar sind. Trotz diverser Hindernisse lassen sich jedoch Parallelen und Tendenzen in den Kollektiven erkennen, die in der deskriptiven Statistik näher beschrieben werden.

Das Patientenkollektiv der vorliegenden Arbeit beinhaltet insgesamt 757 Frauen und 727 Männer, was einer nahezu ausgeglichenen Verteilung von 51:49\% entspricht. Die Gruppe mit der geringsten NTproBNP-Konzentration beinhaltet weniger Frauen (48\%), während sie in der mittleren und höchsten Gruppe stärker vertreten sind (59: 41 \% bzw. $53: 47 \%$ ). Das mittlere Alter der Studienteilnehmer beträgt 66,8 $\pm 8,1$ Jahre und steigt mit der NTproBNP-Konzentration an. Ursächlich für diese Beobachtungen sind die generell bei Frauen und steigendem Alter festzustellenden, erhöhten NTproBNP. 
Konzentrationen. Insgesamt ist das Kollektiv dieser Arbeit jünger als in übrigen Studien, was unter anderem an den unterschiedlich festgelegten Einschlusskriterien, der Art der Rekrutierung und am Design der jeweiligen Studie liegt. Barasch et al. (2011) und Cleland et al. (2012) untersuchten generell ältere Patienten (> 65 bzw. > 70 Jahre), sodass ihr Altersschnitt mit 73 - 78 Jahren (je nach Untergruppe) und $75 \pm 5$ Jahren entsprechend hoch ist. Beide zeigen mit 51 - 59\% (Cleland et al. 2012) und $55 \%$ (Barasch et al. 2011) eine leichte Überzahl des weiblichen Geschlechts. Die I-PRESERVE-Studie schloss Patienten > 60 Jahre ein, was sich in den drei Substudien in einem ebenfalls erhöhten Altersschnitt von $\sim 72$ Jahren wiederspiegelt (Komajda et al. 2011, Krum et al. 2011, Anand et al. 2011). Anand et al. (2011) zeigen wie die vorliegende Arbeit ein mit der NTproBNP-Konzentration steigendes Durchschnittsalter (70 \pm 6,5 bzw. 74 \pm 7,7 Jahre in der Placebogruppe). Mit $\sim 60 \%$ sind in zwei der drei I-PRESERVE-Studien mehr Frauen als Männer vertreten (Komajda et al. 2011, Krum et al. 2011). Lediglich Anand et al. (2011) weichen von dieser Verteilung ab und geben für die Gruppe mit geringer NTproBNP-Konzentration einen höheren (63 - 65,7\%; Placebo-, Medikamentengruppe) und für hohe Konzentrationen einen geringeren Frauenanteil (53,3-59\%; Medikamenten-, Placebo-Gruppe) an. Mit steigender NTproBNP-Konzentration sinkt somit im Gegensatz zu vorliegender Arbeit der Anteil von Frauen. Güder et al. (2007) und Matsubara et al. (2014) haben mit 43,9\% bzw. $44 \%$ einen praktisch identischen Frauenanteil in ihren Kollektiven, jedoch sind die Patienten von Matsubara et al. (2014) im Schnitt etwas älter $(70,5 \pm 9,9$ vs. 67,2 Jahre), was am insgesamt hohen Altersdurchschnitt in Japan, dem Studienort von Matsubara et al. (2014) liegen kann. Ein ähnliches Kollektiv untersuchten Michowitz et al. (2008) mit einem Durchschnittsalter von $71 \pm 11,2$ und einem geringfügig höheren Frauenanteil (53\% und $52 \%$ ), der die allgemeine Ätiologie der HFpEF und dem erhöhten Risiko mit steigendem Alter und weiblichem Geschlecht gut wiederspiegelt. Die Patientengruppe von Grewal et al. (2008) ist vergleichsweise jung, was am niedrigen Cut-Off der EF (40\%) und entsprechend höherem Anteil an HFrEF-Patienten liegen könnte. Sie teilten anhand des Schweregrades der DD in normal/milde bzw. moderat/schwere Formen ein und fanden ein höheres Alter mit steigendem Schweregrad der DD (65 \pm 12 bzw. $70 \pm 10$ Jahre). Der Frauenanteil ist in beiden Gruppen gleich groß und beträgt nicht-repräsentative $35 \%$, was wiederum dem höheren HFrEF-Anteil und der umgekehrten Ätiologie geschuldet sein kann. Der ebenfalls geringe Anteil an Frauen und das geringe mittlere Alter von 67,9 Jahren bei Koller et al. (2014) lässt sich durch die Rekrutierungsform bei bevorstehender Koronarangiographie und den Prävalenzen des männlichen Geschlechts und geringerem Alter bei KHK erklären. Entsprechend tritt in diesem Kollektiv die KHK als Vorerkrankung mit 75,6\% deutlich häufiger auf als in übrigen Studien. 
Die Adipositas stellt einen kardiovaskulären Risikofaktor dar, weshalb Angaben zum BMI und insbesondere Werte $\geq 30 \mathrm{~kg} / \mathrm{m}^{2}$ für eine genaue Beschreibung des Kollektivs von Interesse sind. Im Kollektiv dieser Arbeit liegt der BMI wie in den meisten anderen Studien knapp unterhalb dieses Grenzwertes bei $29,1 \pm 4,8 \mathrm{~kg} / \mathrm{m}^{2}$. Vergleichbare bzw. leicht geringere Werte, die mit $26-28 \mathrm{~kg} / \mathrm{m}^{2}$ ebenfalls unterhalb des Grenzwertes liegen, stellten Güder et al. (2007), Cleland et al. (2012) und Koller et al. (2014) fest. Auffällig sind die besonders niedrigen Werte von Matsubara et al. (2014) mit 24,4 $\pm 3,5 \mathrm{~kg} / \mathrm{m}^{2}$, die wie der hohe Altersschnitt durch den Studienort Japan zu erklären sind. Wie Finucane et al. (2011) zeigen, ist der BMI in Japan generell niedriger als in der EU und den USA. In der großen Kohorte von I-PRESERVE stellten Komajda et al. (2011) einen genau am Grenzwert liegenden Median von $30 \pm 5 \mathrm{~kg} / \mathrm{m}^{2}$ fest, was mit dem höheren Alter des Kollektivs zusammenhängen kann. Grewal et al. (2008) und Anand et al. (2011) liegen je nach Patientengruppe mit 28,8 - 30,2 kg/m² teilweise oberhalb des Grenzwertes. Lediglich Michowitz et al. (2008), Barasch et al. (2011) und Krum et al. (2011) machen keine Angaben zum BMI.

Der durchschnittlich ermittelte Blutdruck beträgt in dieser Arbeit $149 \pm 21$ / $84 \pm 12 \mathrm{mmHg}$ bei einer HF von $66 \pm 12$ /min, was sich mit dem hohen Anteil an Hypertonikern (89\%) deckt. Beides lässt sich durch das vorliegende Risikokollektiv, die Einschlusskriterien von Patienten mit mindestens einem Risikofaktor, der generell hohen Prävalenz für Hypertonie und die nicht vorhandenen Ausschlusskriterien bezüglich des Blutdrucks erklären. Ähnlich hohe Werte sind nur im Kollektiv von Koller et al. (2014) mit 147 / 82 mmHg und einer HF von 67 /min festzustellen, die mit der Selektion der Patienten bei Koronarangiographie und dem hohen Anteil an Rauchern (59,9\%) zusammenhängen könnte. Die drei IPRESERVE-Studien liegen bei ungefähr $136 / 79 \mathrm{mmHg}$ und einer HF von $71 / \mathrm{min}$ (Anand et al. 2011, Komajda et al. 2011, Krum et al. 2011). Grewal et al. (2008) und Cleland et al. (2012) machen nur Angaben zum systolischen Druck, (130 - $140 \mathrm{mmHg}$ ), während Grewal et al. (2008) zusätzlich eine HF von 67 - 68 /min feststellten. Güder et al. (2007), Michowitz et al. (2008), Barasch et al. (2011) und Matsubara et al. (2014) machen keinerlei Angaben zu Blutdruck oder HF.

Insgesamt sind die Vorerkrankungen in den zu vergleichenden Studien sehr heterogen. Trotzdem stellt sich die Hypertonie als Hauptrisikofaktor in allen Studien heraus, wenngleich die Anteile der Erkrankten oftmals geringer sind, wie in dieser Arbeit. Dies liegt erneut am Einschluss der Patienten mit mindestens einem Risikofaktor und der generell hohen Prävalenz für Hypertonie. Die Verteilung von Diabetes mellitus unterliegt geographischen Schwankungen, befindet sich aber bis auf Ausnahmen ungefähr im Bereich der von Owan et al. (2006) angegebenen Prävalenz von 33\%. Diverse Studien schlossen Patienten nur nach vorausgegangener Hospitalisation ein und weisen daher 
deutlich häufiger Zwischenfälle wie Myokardinfarkt und Apoplex in der Anamnese auf. Neben Hypertonie (89 \%) zählt im Kollektiv dieser Arbeit die Hyperlipidämie (45 \%) zu den häufigsten kardiovaskulären Risikofaktoren. Die Anteile an Patienten mit Hypertonie steigen, nicht aber bei Hyperlipidämie, von der ersten bis zur dritten NTproBNPUntergruppe signifikant an. Ähnlich hohe Werte, allerdings bezogen auf die HypertonieVergangenheit, zeigen zwei der drei I-PRESERVE-Studien mit 88 - $91 \%$, da Anand et al. (2011) keine Angaben machen. Über eine Hyperlipidämie wird in allen drei Studien keine Auskunft gegeben, sodass Diabetes mellitus (27 - $35 \%$ ) und Vorhofflimmern (29\%) zumindest bei Komajda et al. (2011) und Krum et al. (2011) die nächsthäufigen Risikofaktoren darstellen. Anand et al. (2011) geben je nach Untergruppe Prävalenzen von bis zu 47,7 \% für Vorhofflimmern und 30,9 \% für Diabetes mellitus an. Güder et al. (2007), Michowitz et al. (2008) und Barasch et al. (2011) zeigen für die häufigsten beiden Risikofaktoren Ähnlichkeit zur DIAST-CHF-Studie, wobei insgesamt weniger Patienten unter Hypertonie und mehr unter Hyperlipidämie leiden. Im Kollektiv von Michowitz et al. (2008) weisen verhältnismäßig viele Patienten eine chronische Niereninsuffizienz $(49,3 \%)$ und KHK in der Vergangenheit (50,6\%) auf, was sich auch in der HFrEFKontrollgruppe wiederspiegelt. Bei diesen Patienten erfolgte im Gegensatz zur DIASTCHF-Studie allerdings eine wesentlich genauere Abklärung der KHK mittels Koronarangiographie. Ebenso können sich das erhöhte Durchschnittsalter und die damit verbundene Multimorbidität auf die breite Verteilung von Vorerkrankungen auswirken. Auch Grewal et al. (2008), Koller et al. (2014) und Matsubara et al. (2014) zeigen Kollektive mit Hypertonie als häufigste Vorerkrankung (60-76,1\%), jedoch ebenso auffallend hohe Prävalenzen für KHK (66,7-82\%). Bei Koller et al. (2014) ist dies wiederum durch die Art der Patienten-Rekrutierung bei Koronarangiographie zu erklären. Matsubara et al. (2014) zeigen wie Güder et al. (2007) und Michowitz et al. (2008) einen erhöhten Anteil an Diabetikern (47,5 \%), der deutlich oberhalb der von Owan et al. (2006) angegebenen Prävalenz liegt. Ein Grund hierfür könnte erneut der Studienort Japan sein, wo in den vergangenen Jahren eine rapide Zunahme an Typ 2-Diabetikern verzeichnet wurde (Neville et al. 2009). Cleland et al. (2012) geben für Hypertonie (68-78\%) und Diabetes mellitus (14-26\%) vergleichbare Werte an, zeigen in ihrem Kollektiv aber erhöhte Prävalenzen für Vorhofflimmern (3-53\%) und einen vorausgegangenen Myokardinfarkt (17-31\%), was durch die Art der Rekrutierung nach kardialer Hospitalisation zu erklären ist.

Unter Symptomen einer HI leiden in der DIAST-CHF Studie $43 \%$ der Patienten. Die häufigsten Vertreter sind dabei Belastungsdyspnoe (32\%) gefolgt von peripheren Ödemen (20\%) und Ruhedyspnoe (8\%). Eine steigende NTproBNP-Konzentration korreliert mit dem Anstieg von Symptomen (37\% [1], $44 \%$ [2], $59 \%$ [3]), insbesondere 
bei Belastungsdyspnoe und peripheren Ödemen. Statt einer genauen Aufschlüsselung der Symptome, geben alle Autoren bis auf Barasch et al. (2011), die gänzlich auf Angaben verzichten, die Anteile der NYHA-Klassen an. Die Verteilung ist entsprechend stark von den Einschlusskriterien abhängig, da die Mehrheit der Studien Patienten mit NYHA-Klasse II-IV betrachten. Die DIAST-CHF Studie hingegen schloss auch asymptomatische Probanden (NYHA I) ein, während dekompensierte Patienten (NYHA IV) nicht teilnehmen durften. Mit $60 \%$ gehören die Patienten von Grewal et al. (2008) mehrheitlich der NYHA-Klasse II an. Auch die Kollektive von Koller et al. (2014) und Cleland et al. (2012) bestehen zum Großteil (75,7\% bzw. 64-77\%) aus Patienten mit NYHA I-II, während die patientenstarken Kollektive der I-PRESERVE-Studie eine Häufung der NYHA-Klasse III aufweisen (Anand et al. 2011, Komajda et al. 2011, Krum et al. 2011). Michowitz et al. (2008) geben eine mittlere NYHA-Klasse von 2,69 0,66 an und liegen damit zwischen beiden Gruppen. Ähnliche Verteilungen zeigen auch die Kollektive von Güder et al. (2007) und Matsubara et al. (2014) mit 78,1 \% bzw. 71,9\% NYHA II - III.

Entsprechend der hohen Prävalenz für Hypertonie im Kollektiv dieser Arbeit liegt bei $85 \%$ der Patienten eine blutdrucksenkende Medikation vor, wobei jeweils $49 \%$ auf $\beta$-Blocker und Diuretika entfallen, deren größten Anteil die Thiazide (42\%) ausmachen. ACEHemmer werden von $44 \%$, ASS (Acetylsalicylsäure) von $37 \%$ und Statine von $30 \%$ der Patienten eingenommen, was sich mit der hohen Prävalenz für Hyperlipidämie im Kollektiv deckt. Insgesamt zählen $\beta$-Blocker, ACE-Hemmer, Diuretika, ASS und Statine zu den am häufigsten eingenommenen kardiovaskulären Medikamenten. Bezüglich der Einnahme von $\beta$-Blockern ähneln die Kollektive von Krum et al. (2011) und Matsubara et al. (2014) mit 50,6 - 53 \% der DIAST-CHF-Studie. Die Einnahme von ACE-Hemmern ist bei Krum et al. (2011) mit $40 \%$ ebenfalls vergleichbar, während die anderen Kollektive teilweise deutlich abweichen, was an der allgemein variierenden Verschreibungspraxis und den nicht vorhandenen Therapierichtlinien liegt. So fallen auch in der Gruppe der Diuretika große Varianzen auf, die von 22,2 \% (Matsubara et al. 2014) bis 88 \% (Anand et al. 2011) reichen. Auffallend ist auch der ausschließlich in den Studien von Krum et al. (2011), Anand et al. (2011), Cleland et al. (2012) und Matsubara et al. (2014) festgestellte Anteil an Calcium-Antagonisten (23 - 62,2\%), welcher im Kollektiv der DIAST-CHF Studie mit $21 \%$ deutlich geringer ist. Die auf I-PRESERVE basierende Studie von Anand et al. (2011) unterscheidet sich in einer geringeren Einnahme von ACE-Hemmern (22 - $29 \%$ vs. $40 \%$ ) und einer höheren Einnahme von $\beta$-Blockern (56- $64 \%$ vs. $53 \%$ ) von der deutlich kleineren, aber ebenfalls aus I-PRESERVE stammenden Patientengruppe von Krum et al. (2011). Die Einnahme von Diuretika (Anand et al. 2011, Krum et al. 2011) und ASS (Anand et al. 2011) ist insgesamt höher als bei DIAST-CHF. Komajda et al. (2011) 
machen keinerlei Angaben zur Medikation, werden aber aufgrund des Kollektivs ungefähr mit den Angaben von Anand et al. (2011) übereinstimmen. Güder et al. (2007), Michowitz et al. (2008) und Grewal et al. (2008) zeigen ähnliche Medikationsprofile wie DIAST-CHF, jedoch nimmt ein deutlich höherer Patientenanteil die jeweiligen Medikamente ein. Bei Cleland et al. (2012) musste eine Diuretika-Medikation vorliegen und Patienten, die ACEHemmer einnahmen, wurden ausgeschlossen. Durch die Einteilung nach NTproBNPKonzentration in Quartilen kommt es zusätzlich zu einer sehr großen Streuung der Medikation, bei der ASS, Schleifendiuretika, Thiazide, $\beta$-Blocker und Nitrate am häufigsten eingenommen werden. Barasch et al. (2011) verzichten gänzlich auf Angaben zur Medikation.

Ein Großteil der chronisch herzinsuffizienten Patienten entwickelt eine eingeschränkte Nierenfunktion, die wiederum das kardiovaskuläre Risiko erhöht. Beides zusammen erhöht das Mortalitätsrisiko deutlich (Smith et al. 2006). Zur Abklärung einer eingeschränkten Nierenfunktion sind Angaben zur GFR bzw. eGFR von Interesse. In den meisten Studien liegt die geschätzte eGFR bei ungefähr $70 \mathrm{ml} / \mathrm{min} / 1,73 \mathrm{~m}^{2}$, was nach Stellungnahme der 'Kidney Disease Outcomes Quality Initiative' (KDOQI) (Eckardt et al. 2009) einer leicht eingeschränkten Nierenfunktion bzw. CKD-Stadium II (chronic kidney disease) entspricht. Auch das Kollektiv dieser Arbeit zeigt mit einer durchschnittlichen eGFR von 73,2 $\pm 18 \mathrm{ml} / \mathrm{min} / 1,73 \mathrm{~m}^{2}$ eine leicht eingeschränkte Nierenfunktion, deren Anteil am Gesamtkollektiv nochmals gesondert mit $21 \%$ angegeben wird. In den Untergruppen lässt sich mit steigender NTproBNP-Konzentration zwar eine sinkende eGFR und eine deutliche Zunahme der renalen Dysfunktion feststellen, jedoch befinden sich alle eGFR-Mittelwerte innerhalb des CKD-Stadiums II. Ähnliche Größenordnungen zeigen die drei auf I-PRESERVE basierenden Studien (Anand et al. 2011, Komajda et al. 2011, Krum et al. 2011) sowie Güder et al. (2007) mit Mittelwerten zwischen 67 $78 \mathrm{ml} / \mathrm{min} / 1,73 \mathrm{~m}^{2}$. Anand et al. (2011) zeigen wie diese Arbeit einen Zusammenhang zwischen steigender NTproBNP-Konzentration und sinkender eGFR. Unterhalb dieser Werte liegt das Kollektiv von Matsubara et al. (2014) mit 63,3 $\pm 17,4 \mathrm{ml} / \mathrm{min} / 1,73 \mathrm{~m}^{2}$. Einzig die Patienten von Koller et al. (2014) weichen mit eGFR-Werten von $85,0 \mathrm{ml} / \mathrm{min} / 1,73 \mathrm{~m}^{2}$ deutlich vom Durchschnitt ab, was am vergleichsweise jungen und von KHK geprägten Kollektiv liegen kann. Michowitz et al. (2008), Grewal et al. (2008), Barasch et al. (2011) und Cleland et al. (2012) verzichten auf Angaben zur (e)GFR und lassen folglich keinen Vergleich zu.

In der DIAST-CHF-Studie wurde eine Vielzahl von echokardiographischen Parametern erhoben, während die meisten anderen Studien sich auf die Angabe der EF beschränken oder gar keine Angaben diesbezüglich machen (Michowitz et al. 2008, Barasch et al.2011). Güder et al. (2007) teilen ihr Kollektiv anhand der FS ein und verzichten 
ebenfalls auf die Angabe einer EF. Trotz unterschiedlicher Cut-Off-Werte ist die EF von Anand et al. (2011), Komajda et al. (2011), Krum et al. (2011), Cleland et al. (2012) und Matsubara et al. (2014) mit 57,6-65\% vergleichbar zur vorliegenden Arbeit $(61,3 \pm 6,4 \%)$. Grewal et al. (2008) liegen je nach Gruppe (54 $\pm 7 \%-57 \pm 8 \%$ ) leicht unterhalb dieses Wertes, befinden sich jedoch noch oberhalb des Cut-Offs aktueller Richtlinien ( $\geq 50 \%$ ) von McMurray et al. (2012). Koller et al. (2014) geben statt eines Durchschnitts an, dass $70,3 \%$ der Patienten eine EF > $55 \%$ zeigen und $29,7 \%$ im Bereich von 45 - $55 \%$ liegen. Weitere echokardiographische Parameter, die für HFpEF von Interesse sind, geben Matsubara et al. (2014) mit E/e' $(15,5)$ an. Diese liegen oberhalb des bei DIAST-CHF festgestellten Wertes von 11,2 $\pm 4,2$, was genau wie die deutlich geringeren LVMI-Werte in DIAST-CHF $\left(85,1 \pm 46,5 \mathrm{~g} / \mathrm{m}^{2}\right.$ vs. $\left.153,5 \mathrm{~g} / \mathrm{m}^{2}\right)$ durch das Risikokollektiv dieser Arbeit zu erklären ist. Das Vorhandensein einer Myokardhypertrophie geben zwei der drei I-PRESERVE-Studien mit 29 - 31 \% (Anand et al. 2011, Komajda et al. 2011) an. Die Patienten von Cleland et al. (2012) zeigen im Vergleich zu dieser Arbeit echokardiographische Parallelen mit geringfügig höheren Septum- und Hinterwanddicken, jedoch geringeren enddiastolischen, linksventrikulären Durchmessern (LVDED).

\subsection{Hindernisse beim Vergleich der prognostischen Wertigkeit}

Generell ist ein Vergleich der Biomarker zwischen verschiedenen Studien schwierig, da unter anderem das Studiendesign, die Kollektive, Endpunkte und Beobachtungszeiträume stark variieren. Die unterschiedlich starke Ausprägung der $\mathrm{HI}$ im Kollektiv und die meist mit zunehmendem Schweregrad verbundene Konzentrationserhöhung der Biomarker können zu unterschiedlichen Ergebnissen ihrer Prognosekraft führen. Neuhold et al. (2010) gehen beispielsweise bei dekompensierten HFrEF-Patienten davon aus, dass es durch die medikamentöse Intervention zu einem Reset der Biomarker kommt und ihre Prognosekraft für einen bestimmten Zeitraum ungewiss ist. Vor allem in MultimarkerStudien kann es aus oben genannten Gründen zu variierenden Aussagen kommen, was den Zusammenhang zur Mortalität einzelner Biomarker angeht. Ein weiteres Hindernis bei Interpretation und Vergleich der HRs stellen die unterschiedlichen Faktoren dar, nach denen in multivariaten Cox-Regressionsmodellen adjustiert wurde. Eine Betrachtung multivariater Modelle ist allerdings nötig, um andere Einflussfaktoren auszuschließen und eine möglichst bereinigte Prognosekraft des jeweiligen Biomarkers zu erhalten. 


\subsection{Vielversprechendes Potential von MRproADM}

Die Konzentration von MRproADM im gesamten Kollektiv dieser Arbeit beträgt 0,574 $\mathrm{nmol} / \mathrm{l}$ (median) und wurde mit einem immunoluminometrischen Verfahren der Firma B.R.A.H.M.S GmbH (Hennigsdorf, Deutschland) ermittelt. Morgenthaler et al. (2005) publizieren für diese Methode in einer gesunden Probandengruppe eine durchschnittliche Konzentration von 0,33 nmol/l und in einer Gruppe mit kardiovaskulären Erkrankungen $0,56 \mathrm{nmol} / \mathrm{l}$. In vorliegender Arbeit zeigt sich in den ersten beiden NTproBNP-Gruppen eine hierzu vergleichbare Konzentration von 0,525 nmol/l [1] und $0,580 \mathrm{nmol} / /$ [2]. Gruppe [3] liegt mit $0,700 \mathrm{nmol} / \mathrm{l}$ etwas über diesen Werten. Insgesamt zeigt sich ein signifikanter Anstieg mit steigender NTproBNP-Konzentration.

Yu et al. (2001) zeigen in einem sehr kleinen Kollektiv aus 31 Patienten mit DD und EF $\geq 50 \%$, dass die Konzentration des aktiven Proteins ADM mit dem Schweregrad der DD und insbesondere mit einem restriktiven Füllungsmuster ansteigt. Die ADMKonzentration in der HFrEF-Kontrollgruppen von Yu et al. (2001) war höher (57,0 pmol/l) als bei HFpEF (33,4 pmol/l) und der Kontrollgruppe (6,9 pmol/l), was allgemein auch bei den meisten anderen Biomarkern beobachtet wird. Trotz des kleinen Kollektivs und der Untersuchung des aktiven Peptids, was einen Vergleich der Konzentrationen hinfällig macht, sind die Ergebnisse dieser Arbeit von Relevanz, da das Fragment MRproADM in äquivalenter Menge zu ADM entsteht. Aus Mangel an DD- und HFpEF-Studien zur Konzentration von MRproADM ist lediglich eine Einordnung in Studien zur akuten bzw. chronischen $\mathrm{HI}$ mit reduzierter EF möglich. Wie bereits von Yu et al. (2001) beobachtet, sind die Konzentrationen bei HFrEF allerdings höher als bei HFpEF. Masson et al. (2010a) stellen in ihrem HFrEF-Kollektiv fest, dass Zusammenhänge zwischen einer steigenden MRproADM-Konzentration und dem weiblichen Geschlecht, steigendem Alter, der Zunahme von Symptomen, verringerter GFR sowie verringerter EF bestehen. Für die akute $\mathrm{HI}$ werden Konzentrationen im Bereich von 0,79-1,37 nmol/l angegeben (Gegenhuber et al. 2007, Maisel et al. 2010, Shah et al. 2012), die nochmals höher sind als die Konzentrationen $(0,64-0,96 \mathrm{nmol} / \mathrm{l})$ bei chronischer $\mathrm{HI}$ (Neuhold et al. 2010, Adlbrecht et al. 2009, Masson et al. 2010a, von Haehling et al. 2010). Obwohl die Ätiologien von HFrEF und HFpEF unterschiedlich sind, zeigt das Kollektiv von von Haehling et al. (2010) bezüglich der Konzentration (0,64 nmol/l) Ähnlichkeit zum Kollektiv der DIAST-CHF-Studie.

Im ersten univariaten Cox-Regressionsmodell besteht ein signifikanter Zusammenhang zwischen den logarithmierten Werten von MRproADM und dem kombinierten Endpunkt aus Mortalität und CV-Hospitalisation. Mit einer HR von 1,62 (95\% Cl; 1,41-1,87; $p<0,001$ ) liegen die logarithmierten Werten von MRproADM nur knapp hinter denen von 
CTproET-1 (HR 1,69) und NTproBNP (HR 1,66), d.h. das Risiko für Mortalität und CVHospitalisation bei Erhöhung der Konzentration um eine SD ist vergleichbar. Der Zusammenhang zwischen MRproADM und dem Endpunkt bleibt auch im Regressionsmodell für NTproBNP signifikant und reduziert die HR auf $1,42(95 \% \mathrm{Cl}$; $1,21$ - 1,67; $p<0,001)$, da bei gleichzeitiger Berücksichtigung des NTproBNP-Einflusses das Risiko durch ebendiesen Einfluss sinkt. MRproADM wurde anschließend in ein multivariates Cox-Regressionsmodell integriert, in dem eine Adjustierung gegen die jeweils anderen, ebenfalls noch signifikant mit dem Endpunkt korrelierenden Biomarker (NTproBNP und CTproET-1) erfolgte. Die HR für logarithmierte Werte von MRproADM reduzierte sich durch überschneidende Informationen auf 1,26 $(95 \% \mathrm{Cl} ; 1,00$ - 1,59; $p=0,049)$. Wird das Regressionsmodell zusätzlich nach dem Alter der Patienten korrigiert, geht der signifikante Zusammenhang zum Endpunkt schließlich verloren (HR 1,18; $95 \% \mathrm{Cl} ; 0,93-1,50 ; p=0,172)$.

Die Prognosekraft von MRproADM bei DD und HFpEF wurde bislang in keiner Studie untersucht. Die vorhandenen Studien zur HFrEF stellen jedoch weitestgehend fest, dass MRproADM signifikant mit der Mortalität korreliert und hierfür prädiktiv ist (Adlbrecht et al. 2009, Neuhold et al. 2010, Maisel et al. 2010, Masson et al. 2010a, von Haehling et al. 2010, Shah et al. 2012, Xue et al. 2013). Bei akut destabilisierter HI wird in mehreren Studien von einer mit NTproBNP vergleichbaren (Gegenhuber et al. 2007) oder sogar höheren Prognosekraft gesprochen (Maisel et al. 2010, Shah et al. 2012), wobei diese Studien nur kurze Nachbeobachtungsintervalle (90 Tage bis ein Jahr) betrachten und die Vergleichbarkeit aufgrund der Kollektive und der deutlich abweichenden Ätiologie, Pathophysiologie und Dauer beider Erkrankungen sehr begrenzt ist. Zur chronischen $\mathrm{HI}$ zeigen Pousset et al. (2000) bereits früh Korrelationen zwischen ir-ADM (immunoreactive adrenomedullin) und der Mortalität, obwohl die von innen verwendete RIA-Messmethode unzuverlässig und inzwischen überholt ist, da sie das aktive Peptid nicht detektiert, wenn es an Komplementfaktor $\mathrm{H}$ gebunden ist (Bełtowski und Jamroz 2004). Unter den Studien zur HFrEF, die große Kollektive und geeignet lange Nachbeobachtungszeiten betrachten, stellen sich Adlbrecht et al. (2009), Masson et al. (2010a), von Haehling et al. (2010) und Xue et al. (2013) heraus.

Das größte vergleichbare HFrEF-Kollektiv untersuchen Masson et al. (2010a) in einer Multimarkerstudie mit 1237 Patienten über 3,9 Jahre (median) und einer MRproADMKonzentration von $0,75 \mathrm{nmol} / \mathrm{l}$ (median), die wie erwartet geringfügig höher ist, wie in vorliegender Arbeit. Zwar geben sie an, dass 11,5\% ihrer Patienten eine EF $\geq 40 \%$ aufweisen, getrennte Daten werden jedoch leider nicht angegeben. Wie in vorliegender Arbeit wurden die Baseline-Messungen der Biomarker (MRproADM, MRproANP, CTproET-1, CTproAVP) mit identischen Verfahren der Firmen B.R.A.H.M.S GmbH 
(Hennigsdorf, Deutschland) und Roche Diagnostics GmbH (Mannheim, Deutschland) durchgeführt. Es zeigte sich, dass alle Marker prognostisch relevant waren und unabhängig von BNP mit der Mortalität korrelierten. Der kombinierte Endpunkt aus Tod und CV-Hospitalisation trat mit steigender Konzentration von MRproADM signifikant häufiger auf. Im univariaten Cox-Regressionsmodell wird für MRproADM eine im Vergleich etwas geringere $\mathrm{HR}$ von $1,31(95 \% \mathrm{Cl} ; 1,09-1,58 ; \mathrm{p}=0,0039)$ angegeben, die sich auf den am ehesten mit dem Kollektiv der DIAST-CHF-Studie vergleichbaren Konzentrationsbereich von 0,63 - 0,87 nmol// bezieht. Im multivariaten Modell wurde nach demographischen, klinischen und echokardiographischen Variablen adjustiert, die selbst signifikant mit der Mortalität korrelieren. Ein signifikanter Zusammenhang zum kombinierten Endpunkt besteht ausschließlich im Konzentrationsbereich von 0,88$3,97 \mathrm{pmol} / \mathrm{l}$, der wenig vergleichbar erscheint. Von Haehling et al. (2010) zeigen in ihrem von NYHA II und III geprägten (83\%) HFrEF-Kollektiv die am besten vergleichbare, da niedrigste MRproADM-Konzentration von 0,64 nmol/l (median), betrachten jedoch eine kurze Nachbeobachtungsphase von nur einem Jahr. MRproADM stellte sich als prognostischer Faktor der Mortalität heraus, welcher unabhängig von NTproBNP und der EF ist, was eine interessante Beobachtung für HFpEF darstellt, die Masson et al. (2010a) jedoch nicht teilen. Sie logarithmieren die Biomarker-Konzentrationen in den uni- und multivariaten Cox-Regressionsmodellen zwar wie in vorliegender Arbeit, jedoch bezieht sich die HR auf den Anstieg um eine IQR, was zu deutlich höheren Risiken führt (HR 2,67 und HR 1,82). Adlbrecht et al. (2009) betrachten 786 Patienten über zwei Jahre und zeigen gerade bei milder und non-ischämischer HI, dass MRproADM ein prognostischer Faktor ist. Im univariaten Cox-Regressionsmodell berechnen sie ein ähnliches Risiko wie Masson et al. (2010a), welches aber im Vergleich zu vorliegender Arbeit etwas geringer ist (HR 1,41; $95 \% \mathrm{Cl} ; 1,3-1,54 ; \mathrm{p}<0,001$ ). Die logarithmierte, schrittweise Regressionsanalyse zeigt, dass MRproADM ein unabhängiger Prädiktor der Mortalität ist (HR 1,74; $95 \% \mathrm{Cl} ; 1,41-2,22 ; \mathrm{p}<0,001$ ) und bei schwächeren Ausprägungsformen und non-ischämischer $\mathrm{HI}$ sogar höhere Prognosekraft besitzt als BNP. Die aktuellste Studie zur Thematik veröffentlichen Xue et al. (2013). Sie stimmen mit vorausgegangenen Studien überein und zeigen, dass MRproADM auch bei sechs Jahren Beobachtungszeit die Mortalität von $\mathrm{HI}$ - und Risikopatienten vorhersagen kann. Ihre Berechnung zeigt, dass MRproADM Risikomodelle wie den Framingham-Risk-Score und ein klinisches Risikomodell verbessert und dass Biomarker für die zukünftige Prognosefindung hilfreich sein können.

Die Feststellung von Adlbrecht et al. (2009), dass MRproADM gerade bei milder und nonischämischer HI prädiktiv ist und die Aussagen von Pousset et al. (2000) und von von Haehling (2010), dass die Prognosekraft von ir-ADM bzw. MRproADM unabhängig von 
der EF ist, geben trotz nicht vorhandener HFpEF-Studien einen Hinweis darauf, dass ADM/MRproADM prognostische Wertigkeit bei HFpEF besitzt. Dass die Prognosekraft in vorliegender Arbeit hinter der von NTproBNP zurückbleibt, war zu erwarten und wurde auch von Adlbrecht et al. (2009) für HFrEF festgestellt. Die schrittweisen Regressionsmodelle dieser Arbeit zeigen, dass MRproADM prognostisches Potential hat und erhöhte Konzentrationen mit der Mortalität bzw. CV-Hospitalisationen korrelieren, obwohl ein signifikanter Zusammenhang im multivariaten Regressionsmodell schließlich verloren geht. Ein Grund hierfür sind die Korrelationen der Marker untereinander und die Adjustierung nach ähnlichen prognostischen Informationen. Dieses Problem wird für MRproADM und weitere Marker unter '4.12 Überschneidung von prognostischen Informationen' (S. 92) diskutiert.

\subsection{Hohe Modulierbarkeit und fragwürdige Eignung von Aldosteron}

Zur Bestimmung von Aldosteron wurde ein Enzymimmunoassay der Firma IBL International $\mathrm{GmbH}$ (Hamburg, Deutschland) verwendet. Im Mittel beträgt die Konzentration im Kollektiv dieser Arbeit $70,3 \mathrm{pg} / \mathrm{ml}$. Die Untergruppen zeigen mit $71,1 \mathrm{pg} / \mathrm{ml}$ [1], $68,0 \mathrm{pg} / \mathrm{ml}$ [2] und $69,7 \mathrm{pg} / \mathrm{ml}$ [3] leichte Unterschiede, die jedoch nicht signifikant sind. Im univariaten Cox-Regressionsmodell zeigt sich für logarithmierte Werte von Aldosteron eine nicht signifikante und sehr geringe HR von 1,02 (95 \% Cl; 0,88 - 1,19; $p=0,753)$. Erhöhte Aldosteron-Konzentrationen scheinen in diesem Kollektiv nicht mit einem erhöhten Risiko für Mortalität und CV-Hospitalisation einherzugehen, weshalb eine weitere Untersuchung in adjustierten Regressionsmodellen und der Korrelationsanalyse nicht stattfand.

Güder et al. (2007) und Bishu et al. (2012) machen die Beobachtung, dass die Konzentration von Aldosteron bei HFrEF und HFpEF zwar insgesamt erhöht ist, aber auf nahezu gleichem Niveau liegt. Bishu et al. (2012) erklären dies mit der häufigeren Einnahme von RAAS-Antagonisten bei HFrEF-Patienten, die die eigentlich höhere Aldosteron-Konzentration auf das selten durch Medikamente reduzierte Level von HFpEFPatienten senken soll. Dieser Aspekt spielt auch bei der Konzentration von Renin eine Rolle, dessen prognostische Valenz unter '4.11 Fehlende Korrelationen bei Renin' (S. Fehler! Textmarke nicht definiert.) diskutiert wird. Im DIAST-CHF Kollektiv nehmen $44 \%$ der Patienten einen ACE-Hemmer, $18 \%$ einen Angiotensin-1-Antagonisten und $1 \%$ einen Aldosteron-Antagonisten ein. Verglichen mit der HFrEF-Gruppe von Bishu et al. (2012) sind diese Werte tatsächlich geringer. Güder et al. (2007) geben für die Gruppe mit nicht-systolischer $\mathrm{HI}$ eine Aldosteron-Konzentration von $95 \mathrm{pg} / \mathrm{ml}$ an, die sich noch im 
Normbereich befindet und deutlich geringer ist als die am Grenzwert liegende Konzentration $(153,4 \mathrm{pg} / \mathrm{ml})$ von Bishu et al. (2012). Dies liegt zum einen an der Medikation mit RAAS-Hemmern und am Kollektiv, bei dem es sich um akut dekompensierte HFpEF-Patienten handelt. Beide Studien nutzten statt eines Enzymimmunoassays die aufwändigeren aber vergleichbaren RIA-Methoden von DiaSorin S.p.A (Saluggia, Italien) und DPC Biermann (Bad Nauheim, Deutschland). Trotz der eigentlich nicht gravierenden Konzentrationsunterschiede von Aldosteron liegen vergleichbare HFrEF-Studien (Latini et al. 2004, Cicoira et al. 2004, Tsutamoto et al. 2007, Volpe et al. 2010, Vergaro et al. 2011) zur chronischen HI mit $83,3-145 \mathrm{pg} / \mathrm{ml}$ insgesamt oberhalb des bei DIAST-CHF festgestellten Medianwertes von 70,3 pg/ml. Ursächlich sind auch hier die unterschiedlichen Kollektive und Medikationen zwischen HFrEF- und HFpEF-Patienten.

Im Gegensatz zu vorliegender Arbeit fanden Güder et al. (2007) signifikante Zusammenhänge zwischen einer erhöhten Aldosteron-Konzentration und der Mortalität. Wie bereits beschrieben, teilten sie ihr Kollektiv anhand der echokardiographisch erhobenen FS ein, die sich analog zur EF berechnet jedoch statt der linksventrikulären, enddiastolischen und endsystolischen Volumina die entsprechenden Durchmesser zur Berechnung heranzieht. Ihre Bedeutung ist mehr oder weniger gleich, umrechnen lassen sich die Werte jedoch nicht, sodass die EF der Patienten von Güder et al. (2007) unklar bleibt, was bei Vergleichen berücksichtigt werden muss. Im multivariaten CoxRegressionsmodell, in dem ebenfalls nach signifikant mit der Mortalität zusammenhängenden Variablen wie Alter, Geschlecht, NYHA-Klasse, NTproBNP etc. adjustiert wurde, ergibt sich ein im Vergleich zu dieser Arbeit höheres Risiko (HR 1,29; $95 \% \mathrm{Cl} ; 1,05-1,61 \mathrm{p}=0,025)$ für die Erhöhung der Konzentration um eine SD. Trotz ihrer vorher durchgeführten Einteilung, werden die HRs leider nur für das gesamte Kollektiv angegeben. Die Zusammenhänge zwischen erhöhter Aldosteron-Konzentration und erhöhter Mortalität sollen zwischen den beiden Gruppen jedoch identisch gewesen sein. Ein Vergleich ihrer Daten wird durch den unterschiedlichen Endpunkt, der keine CVHospitalisationen beinhaltet und die unterschiedliche Adjustierung im multivariaten CoxRegressionsmodell zusätzlich erschwert. Die Aussagen dieser Studie sollten auch aufgrund des kleinen Kollektivs sowie der unklaren Diagnosekriterien für die Gruppe der nicht-systolischen $\mathrm{HI}$ nur als Anhaltspunkt dienen.

HFrEF-Studien kommen zu unterschiedlichen Aussagen, was die Prognosekraft von Aldosteron angeht. Während Swedberg et al. (1990) zur schweren, chronischen HI und Girerd et al. (2013) zur akuten HI signifikante Zusammenhänge zur Mortalität sehen, so finden Cicoira et al. (2004), Latini et al. (2004), Tsutamoto et al. (2007) und Vergaro et al. (2011) allesamt lediglich Korrelationen in univariaten und nicht in multivariaten Cox- 
Regressionsmodellen. Bei Cicoira et al. (2004) besteht ein Zusammenhang weiterhin nur, wenn Aldosteron als kategorische Variable ins Modell integriert wird. Latini et al. (2004) sprechen insgesamt von einer sehr schwachen Prognosekraft und Volpe et al. (2010) fanden bei einem langen Nachbeobachtungszeitraum von 15 Jahren keinerlei Zusammenhänge zur Mortalität. Da die Konzentration stark durch Medikamente moduliert werden kann und ACE-Hemmer die Prognosekraft von Aldosteron zumindest in einem HFrEF-Kollektiv beeinflussen (Latini et al. 2004), muss hinterfragt werden, ob dieser Biomarker überhaupt zur Prognoseabschätzung geeignet sein kann. Insgesamt, so zeigen auch die Daten vorliegender Arbeit, scheint Aldosteron bei DD und HFpEF kein relevanter Prognosemarker zu sein, da kein signifikanter Zusammenhang zur Mortalität und CVHospitalisationen besteht. Um diese Aussage zu unterstützen bedarf es jedoch weiterer Forschung an großen, nach aktuellen Richtlinien diagnostizierten DD- und HFpEFKollektiven.

\section{5 Überlegenheit von MRproANP gegenüber NTproANP}

Obwohl ANP zu den gut untersuchten natriuretischen Peptiden zählt, betrachtet keine Studie die Konzentration oder Prognosekraft der Fragmente MRproANP bzw. NTproANP bei DD und HFpEF. In vorliegender Arbeit wurden die Fragmente mit jeweiligen Verfahren der Firmen B.R.A.H.M.S GmbH (Hennigsdorf, Deutschland) und Biomedica Medizinprodukte $\mathrm{GmbH}$ \& Co KG (Wien, Österreich) bestimmt. Der Mittelwert der MRproANP-Konzentration im gesamten Kollektiv beträgt $88,3 \mathrm{pmol} / \mathrm{l}$. Diese steigt signifikant mit der NTproBNP-Konzentration von Gruppe [1] 68,4 pmol// über $107 \mathrm{pmol} / /$ [2] auf $154 \mathrm{pmol} / \mathrm{l}$ [3] an, was sich durch den gleichen Sekretionsmechanismus erklärt. Die Konzentration von NTproANP liegt insgesamt bei $3925 \mathrm{pmol} / \mathrm{l}$ und in den jeweiligen Untergruppen bei $3402 \mathrm{pmol} / \mathrm{l}$ [3], $4302 \mathrm{pmol} / \mathrm{l}$ [3] und $5394 \mathrm{pmol} / \mathrm{l}$ [3]. Auch hier ist ein signifikanter Anstieg mit steigender NTproBNP-Konzentration zu beobachten.

Die meisten HFrEF-Studien ermitteln die Konzentration des Fragments MRproANP, da dieses Fragment eine höhere Halbwertszeit besitzt und die Nachweismethode im Gegensatz zu der von NTproANP weniger anfällig ist. Durch enzymatischen Abbau des $\mathrm{N}$-terminalen Endes entzieht sich das Fragment NTproANP der Bindung durch den Antikörper und kann somit nicht mehr nachgewiesen werden. Die Bindung von Antikörpern am N-terminalen Ende ist daher oft unvollständig und führt zu fehlerhaften Messergebnissen (Ala-Kopsala et al. 2004). Selvais et al. (2000) und van Beneden et al. (2004) betrachten das selten bestimmte Fragment NTproANP bei chronischer $\mathrm{HI}$ mit identischer RIA-Messmethode und geben Konzentrationen an, die nach dem Schweregrad der HI oder dem Überleben aufgeteilt wurden (581 - 1647 pg/ml bzw. 537 - 
1903 pg/ml). Zusätzlich messen van Beneden et al. (2004) die NTproANP-Konzentration mit dem in dieser Arbeit verwendeten Enzymimmunoassay der Biomedica Medizinprodukte GmbH \& Co KG (Wien, Österreich). Da ihre Ergebnisse allerdings nicht von der Bestimmungsmethode abhängig waren, wurden für die weiteren Analysen die Ergebnisse der RIA-Methode verwendet. Beide Autoren stellen fest, dass NTproANP mit dem Schweregrad der $\mathrm{HI}$ steigt, was sich durch eine gesteigerte Sekretion infolge der erhöhten Druckbelastung erklärt. Die Konzentration von MRproANP ist bei HFrEF aus selbigem Grund deutlich höher als im Kollektiv dieser Arbeit und korreliert laut Masson et al. (2010a) und von Haehling et al. (2007) des Weiteren positiv mit dem Alter und einer verschlechterten Nierenfunktion. Beim weiblichen Geschlecht und einem erhöhten BMI sinkt hingegen die Konzentration von ANP (Moertl et al. 2009, Masson et al. 2010a). Morgenthaler et al. (2004) geben für eine gesunde Kontrollgruppe einen MRproANPReferenzwert von $45 \mathrm{pmol} / \mathrm{l}$ an, während Studien zur chronischen $\mathrm{HI}$ mit reduzierter EF zwischen 206 - 380 pmol/l (von Haehling et al. 2007, Moertl et al. 2009, Neuhold et al. 2010, Masson et al. 2010a) und solche zur akuten HI im Bereich von 306 - 420,3 pmol/l (Gegenhuber et al. 2007, Miller et al. 2011, Shah et al. 2012) liegen. Der Mittelwert der DIAST-CHF-Studie ist somit zwischen der Konzentration gesunder Probanden und chronisch herzinsuffizienter Patienten mit reduzierter EF anzusiedeln.

In dieser Arbeit konnte im univariaten Cox-Regressionsmodell ein hochsignifikanter Zusammenhang zwischen dem kombinierten Endpunkt und den logarithmierten Werten von MRproANP (HR 1,53; $95 \% \mathrm{Cl} ; 1,31-1,79 ; \mathrm{p}<0,001)$ und ein signifikanter Zusammenhang zu denen von NTproANP (HR 1,24; $95 \% \mathrm{Cl} ; 1,04-1,48 ; p=0,019$ ) festgestellt werden. Für das Regressionsmodell von NTproANP konnte aufgrund unvollständiger Daten nur auf 748 Patienten zurückgegriffen werden. Im Regressionsmodell für NTproBNP geht die signifikante Korrelation bei beiden Markern verloren $(p=0,256$ und $p=0,847)$, sodass sie in den folgenden multivariaten Regressionsmodellen nicht mehr berücksichtigt wurden. Zu erklären ist der Verlust des signifikanten Zusammenhangs durch die stark überschneidenden Informationen, die NTproBNP und NT/MRproANP liefern. MRproANP wurde in der Korrelations- und Hauptkomponentenanalyse sowie im finalen, multivariaten Cox-Regressionsmodell berücksichtigt, wie unter '4.12 Überschneidung von prognostischen Informationen' (S. 92) und '4.13 Finales Modell und klinische Schlussfolgerung' (S. 94) nachzulesen.

Wie bereits erwähnt, befasste sich bislang keine Studie mit der Prognosekraft beider ANP-Fragmente bei DD und HFpEF. Selvais et al. (2000) und van Beneden et al. (2004) betrachten NTproANP in chronisch herzinsuffizienten Kollektiven mit ähnlichem Schweregrad und annähernd gleicher aber wenig aussagekräftiger Größe (109 bzw. 87 Patienten). Selvais et al. (2000) finden signifikante Zusammenhänge zur kardialen 
Mortalität in uni- und multivariaten Cox-Regressionsmodellen, doch schneidet beispielsweise ET-1 deutlich besser ab als in der Studie von van Beneden et al. (2004). Im multivariaten Modell können van Beneden et al. (2004) keine signifikante Korrelation zum Überleben feststellen, während ET-1 beiden natriuretischen Peptiden (NTproANP, NTproBNP) bei schwerer HI (NYHA-III und IV) überlegen ist. Zu erklären ist dies durch das sehr kleine (47 Patienten) und spezielle Kollektiv und die Tatsache, dass das Fragment NTproANP weniger geeignet ist als beispielsweise MRproANP. Korrelationen zwischen Biomarkern und der Mortalität sind bei höherem Schweregrad einer Erkrankung ebenso einfacher herzustellen, sodass stellenweise Biomarker eine höhere Prognosekraft zeigen als bereits etablierte Marker wie NTproBNP.

Masson et al. (2010a) betrachten wie auch für CTproET-1, MRproADM und CTproAVP das größte HFrEF-Kollektiv. Die Mortalität steigt bei innen signifikant mit der Konzentration von MRproANP an und das Fragment stellt sich als stärkster Prädiktor der Mortalität und des identischen kombinierten Endpunkts heraus. Im Vergleich mit der ersten Tertile (5 - $149 \mathrm{pmol} / \mathrm{l})$ zeigen die zweite (150 - $280 \mathrm{pmol} / \mathrm{l})$ und dritte Tertile (281 $1340 \mathrm{pmol} / \mathrm{l}$ ) zu beiden Endpunkten in uni- sowie multivariaten Cox-Regressions-modellen signifikante Zusammenhänge. Für den kombinierten Endpunkt und den Konzentrationsbereich der zweiten Tertile, der am ehesten dem vorliegender Arbeit entspricht, allerdings bereits deutlich höher ist, ergibt sich ein geringfügig höheres Risiko im univariaten ( $\mathrm{HR}$ 1,63; $95 \% \mathrm{Cl} ; 1,36$ - 1,96; $\mathrm{p}>0,0001)$ und im multivariaten CoxModell (HR 1,47; $95 \% \mathrm{Cl} ; 1,20-1,80 ; \mathrm{p}=0,0002)$. MRproANP war zusätzlich der einzige Marker, dessen Konzentrationsänderung über drei Monate prädiktiv für die Mortalität war und ein Prognosemodell aus klinischen Faktoren und NTproBNP verbesserte.

Weitere Studien zur chronischen HI mit reduzierter EF bestätigen die gute Prognosekraft von MRproANP bei vergleichsweise kurzem Beobachtungszeitraum von 24 bzw. 28 Monaten (von Haehling et al. 2007, Neuhold et al. 2010) sowie langer Beobachtungszeit von 68 Monaten (Moertl et al. 2009). Von Haehling et al. (2007) stufen die Prognosekraft als gleichwertig zu NTproBNP ein und Moertl et al. (2009) sprechen sogar von einer höheren Wertigkeit. Dies soll an der längeren Halbwertszeit und höheren Stabilität von MRproANP und dem enzymatischen Abbau des N-terminalen Endes von NTproBNP liegen, dem auch NTproANP unterworfen ist (Ala-Kopsala et al. 2004). Moertl et al. (2009) errechnen nach Logarithmierung der Werte im univariaten Cox-Regressionsmodell ein etwas höheres Risiko für die Mortalität (HR 2,01; $95 \% \mathrm{Cl} ; 1,78-2,26 ; \mathrm{p}<0,0001$ ). Im multivariaten Modell wurde nach diversen klinischen Parametern und den Biomarkern MRproANP, BNP und NTproBNP adjustiert. Lediglich für MRproANP blieb ein signifikanter Zusammenhang zur Mortalität bestehen ( $\mathrm{HR}$ 1,72; $95 \% \mathrm{Cl} ; 1,27$ - 2,33; $p=0,0004)$. 
Insgesamt ist die Bestimmungsmethode von MRproANP der von NTproANP überlegen. Aufgrund des N-terminalen Abbaus und der Fehleranfälligkeit, scheint NTproANP kein für die Prognosefindung geeigneter Biomarker zu sein, was auch ein Vergleich der univariaten Cox-Regressionsmodelle von NTproANP und MRproANP dieser Arbeit zeigt. MRproANP stellte sich in der Vergangenheit in weiten Bereichen der $\mathrm{HI}$ als hilfreich und prognostisch wertvoll heraus, was auch Studien zur akuten HI (Gegenhuber et al. 2007, Miller et al. 2011, Shah et al. 2012) und die univariate Cox-Regressionsanalyse dieser Arbeit zeigen. Dass für die logarithmierten Werte von MRproANP im nachfolgenden multivariaten Modell kein signifikanter Zusammenhang besteht, liegt wie bei MRproADM an der Korrelation der Marker untereinander, da MRproANP und NTproBNP zu den kardial gesehen zentralen Biomarkern zählen. Die Diskussion dieses offenbar gewichtigen Problems bei der Betrachtung mehrerer Biomarker erfolgt unter '4.12 Überschneidung von prognostischen Informationen' (S. 92).

\section{6 Überschneidung prognostischer Informationen bei CTproAVP}

Die Konzentrationsbestimmung von CTproAVP erfolgte in vorliegender Arbeit mit einem Verfahren der Firma B.R.A.H.M.S GmbH (Hennigsdorf, Deutschland). Für das gesamte Kollektiv ergab sich eine Konzentration von 3,94 pmol/l. Die niedrigste Konzentration findet sich in Untergruppe [2] mit 3,56 pmol/l. Gruppe [1] zeigt eine durchschnittliche Konzentration von 3,76 pmol// und Gruppe [3] 4,38 pmol/l. Der Unterschied zwischen den Gruppen ist signifikant $(p=0,002)$. CTproAVP war bislang nicht Gegenstand von Untersuchungen zur Konzentration und Prognosekraft bei DD und HFpEF, sodass auch bei diesem Biomarker nur Vergleiche zu HFrEF-Studien gezogen werden können. Entsprechend der Patientenverteilung und der großen Anzahl an Patienten mit Risikofaktoren ohne manifeste $\mathrm{HI}$ sind die Konzentrationen im Kollektiv der DIAST-CHFStudie eher gering.

Bei gesunden Probanden wird eine Median-Konzentration von 3,7 - 4,2 pmol/I und eine Höchstkonzentration von 11,25 - 16,4pmol/l (97. Perzentile) festgestellt (Morgenthaler et al. 2006, Potocki et al. 2010). Die Patienten dieser Arbeit liegen somit nahezu vollständig im Konzentrationsbereich von gesunden Patienten. Vergleichbar niedrige Konzentrationen sind in keiner HFrEF-Studie zu finden. Die Konzentration von CTproAVP korreliert bei HFrEF mit steigendem Alter und sinkender GFR (Neuhold et al. 2008, Voors et al. 2009, Masson et al. 2010a, Balling et al. 2012). Zusätzlich steigen die Werte mit dem Schweregrad der $\mathrm{HI}$ und sind beim männlichen Geschlecht höher (Morgenthaler et al. 2006, Masson et al. 2010a, Balling et al. 2012). Die geringste CTproAVP-Konzentration 
$(13,8 \mathrm{pmol} / \mathrm{l})$ wird in der bereits mehrfach erwähnten Multimarker-Studie von Masson et al. (2010a) ermittelt, die erneut die Studie mit den meisten Patienten darstellt. Neuhold et al. (2008) messen für die Gruppe der Überlebenden und Balling et al. (2012) für das gesamte HFrEF-Kollektiv jeweils $\sim 15$ pmol/l. Weitere Studien, die sich mit der Prognosekraft von CTproAVP bei akuter und chronischer $\mathrm{HI}$ beschäftigen, stellen mit durchschnittlich 21 $55,2 \mathrm{pmol} / \mathrm{l}$ deutlich höhere Konzentrationen fest (Stoiser et al. 2006, Gegenhuber et al. 2007, Neuhold et al. 2010, Maisel et al. 2011, Miller et al. 2011).

Diese Arbeit zeigt im univariaten Cox-Regressionsmodell einen signifikanten Zusammenhang zwischen den logarithmierten Werten von CTproAVP und dem kombinierten Endpunkt. Die errechnete HR beträgt 1,23 (95\% Cl; 1,06-1,43; $p=0,008)$. Betrachtet man den Zusammenhang zum Endpunkt bei gleichzeitiger Berücksichtigung des Einflusses von NTproBNP auf den selbigen, so geht der signifikante Zusammenhang verloren $(p=0,064)$, sodass auf eine Integration in die beiden folgenden multivariaten Regressionsmodelle verzichtet wurde. CTproAVP wird allerdings in der Korrelations- und Hauptkomponentenanalyse sowie im finalen Regressionsmodell berücksichtigt, da das Problem der Korrelation untereinander wahrscheinlich auch bei diesem Marker zu statistischen Problemen führte.

Masson et al. (2010a) zeigen zwar, dass CTproAVP prognostische Informationen enthält, jedoch der schlechteste Prädiktor unter den getesteten Biomarkern (MRproANP, MRproADM, CTproET-1 und CTproAVP) ist. Für den mit dieser Arbeit übereinstimmenden kombinierten Endpunkt aus Mortalität und CV-Hospitalisation ergibt sich nur im univariaten Cox-Modell und hier ausschließlich in der höchsten Tertile (19,2 - 228 pmol/l) ein signifikanter Zusammenhang ( $\mathrm{HR} 1,63 ; 95 \% \mathrm{Cl} ; 1,37-1,92 ; \mathrm{p}<0,0001)$. Die in vorliegender Arbeit festgestellte mittlere Konzentration von 3,94 pmol/l stellt nur einen Bruchteil des unteren Wertes dar. Entsprechend ist das Risiko im univariaten Regressionsmodell dieser Arbeit deutlich geringer (HR 1,23). Neuhold et al. (2010) und Balling et al. (2012) kommen in deutlich kleineren Kollektiven zu ähnlichen Zusammenhängen. Neuhold et al. (2010) finden in einem schrittweisen CoxRegressionsmodell, in dem nicht nach NTproBNP adjustiert wird, einen signifikanten Zusammenhang zur Gesamtmortalität (HR 1,92; $95 \% \mathrm{Cl}, 1,233-3,007 ; \mathrm{p}=0,004$ ). Diesen bestätigen Balling et al. (2012) in ihrem Kollektiv, wenn Patienten der höchsten Tertile $(>22,5 \mathrm{pmol} / \mathrm{l})$ mit solchen der ersten beiden Tertilen $(<22,5 \mathrm{pmol} / \mathrm{l})$ verglichen werden. Die Signifikanz geht in ihrem multivariaten Modell erst verloren, wenn nach NTproBNP adjustiert wird. Zum kombinierten Endpunkt aus Mortalität und CVHospitalisation bestehen bei innen interessanterweise signifikante Zusammenhänge im uni- (HR 1,50; $95 \% \mathrm{Cl} ; 1,2-1,9 ; \mathrm{p}<0,05)$ und auch nach Adjustierung für NTproBNP im multivariaten Cox-Regressionsmodell (HR 1,40; $95 \% \mathrm{Cl} ; 1,1$ - 1,9; $\mathrm{p}<0,05)$. 
Frühere Studien von Stoiser et al. (2006) und Neuhold et al. (2008) zur chronischen HI mit reduzierter EF stufen die prognostische Wertigkeit von CTproAVP höher ein als die von BNP/NTproBNP. Gleiches fanden Voors et al. (2009) für Patienten heraus, die nach einem Myokardinfarkt eine HI entwickelten. Gegenhuber et al. (2007) und erneut Neuhold et al. (2010) zeigen in einem akut destabilisierten und in dem bereits beschriebenen Kollektiv eine mit BNP vergleichbare prognostische Wertigkeit. Viele HFrEF-Studien sehen CTproAVP nur in hohen Konzentrationen als prädiktiv bei akuter HI (Gegenhuber et al. 2007, Maisel et al. 2011) sowie chronischer HI (Masson et al. 2010a, Balling et al. 2012). Bei Masson et al. (2010a) gehen signifikante Zusammenhänge nach NTproBNPAdjustierung verloren. Möglicherweise verzichteten Neuhold et al. (2010) aus diesem Grund auf eine Adjustierung, um signifikante Zusammenhänge in ihrem Kollektiv zu publizieren. Insgesamt scheint CTproAVP bei DD/HFpEF mit der Mortalität zu korrelieren, enthält aber offenbar mit anderen Biomarkern überschneidende prognostische Informationen, die einen signifikanten Zusammenhang nach Adjustierung in multivariaten Modellen verschwinden lassen. Da die Konzentration von CTproAVP im Kollektiv nahezu der von gesunden Probanden entsprach und sich bis zur Adjustierung für NTproBNP trotzdem signifikante Zusammenhänge zeigten, sollte das mögliche prognostische Potential dieses Biomarkers noch nicht abgeschrieben werden.

\section{7 Überlegene Prognosekraft von NTproBNP}

BNP und NTproBNP stellen den Goldstandard zur Prognoseabschätzung bei HFrEF und HFpEF dar und sind gleichzeitig die am besten erforschten Biomarker. In dieser Arbeit wurde die Konzentration des Fragments NTproBNP mit einem Verfahren der Firma Roche Diagnostics $\mathrm{GmbH}$ (Mannheim, Deutschland) bestimmt. Diese beträgt im gesamten Kollektiv im Mittel $103 \mathrm{pg} / \mathrm{ml}$. Anhand der NTproBNP-Konzentrationen erfolgte die Einteilung des Kollektivs in drei Untergruppen, für die sich entsprechend steigende Mittelwerte von $58 \mathrm{pg} / \mathrm{ml}$ [1], $159 \mathrm{pg} / \mathrm{ml}$ [2] und $444 \mathrm{pg} / \mathrm{ml}$ [3] ergeben. Vergleiche zu gesunden Kontrollgruppen von Tschöpe et al. (2005) und Dong et al. (2006) zeigen, dass die Konzentration von Gruppe [1] nur leicht oberhalb der von gesunden Probanden liegt ( 52 - $53 \mathrm{pg} / \mathrm{ml})$. Zile et al. (2011a) stellen bei gesunden Probanden $(87,4 \mathrm{pg} / \mathrm{ml})$ und in der HFpEF-Gruppe $(214,2 \mathrm{pg} / \mathrm{ml})$ insgesamt etwas höhere Werte fest. Zu beachten ist, dass über die Hälfte der Patienten der DIAST-CHF-Studie NTproBNP-Konzentrationen $\leq 125 \mathrm{pg} / \mathrm{ml}$ aufweisen, was den Mittelwert entsprechend senkt. Eine Kontrollgruppe aus Patienten mit kardiovaskulären Risikofaktoren zeigten eine NTproBNP-Konzentration von $128 \mathrm{pg} / \mathrm{ml}$ (Barasch et al. 2009). 
Das große Kollektiv der I-PRESERVE-Studie diente McKelvie et al. (2010), Anand et al. (2011) und Komajda et al. (2011) in unterschiedlichem Ausmaß zur Ermittlung der NTproBNP-Konzentration bei HFpEF-Patienten, was der Grund dafür ist, dass ihre Angaben mit 339 - 341 pg/ml nahezu identisch sind. Die in diesen Studien festgestellten Mittelwerte sind deutlich höher, was vor allem durch das Kollektiv dieser Arbeit zu erklären ist, welches auch Patienten ohne manifeste $\mathrm{HI}$ beinhaltet. Hinzu kommt die in anderen Studien oftmals vorausgegangene Hospitalisation der Patienten. Anand et al. (2011) räumen außerdem ein, dass ihre Konzentrationen stark verzerrt sind $(0$ $28670 \mathrm{pg} / \mathrm{ml}$ ), was zu einer Erhöhung des Medians führt. Erhöhte NTproBNPKonzentrationen korrelieren laut McKelvie et al. (2010) bei HFpEF mit steigendem Alter, steigender NYHA-Klasse, Diabetes mellitus, COPD, Vorhofflimmern, sinkender eGFR und der Einnahme von ACE-Hemmern und $\beta$-Blockern. Am bedeutendsten sind die Korrelationen mit dem enddiastolischen Wandstress und den linksventrikulären Füllungsdrücken (Iwanaga et al. 2006, Tschöpe et al. 2005). Bei hypertensiver Vorgeschichte, $\mathrm{RR}>130 / 80 \mathrm{mmHg}$ und einem $\mathrm{BMI} \geq 30 \mathrm{~kg} / \mathrm{m}^{2}$ sind die Konzentrationen von NTproBNP hingegen verringert. Weiterhin gibt es geographische Unterschiede (McKelvie et al. 2010). Grewal et al. (2008) liegen mit $376 \pm 638 \mathrm{pg} / \mathrm{ml}$ bzw. $1419 \pm 3423 \mathrm{pg} / \mathrm{ml}$ je nach Schweregrad der DD nochmals oberhalb der I-PRESERVEWerte. Sie betrachten allerdings ein deutlich kleineres Kollektiv mit teilweise schwerer DD und höheren Prävalenzen für KHK, Vorhofflimmern sowie vorausgegangene Myokardinfarkte und schlossen keine Patienten der NYHA-Klasse I ein. Cleland et al. (2012) untersuchen zwar die Prognosekraft von NTproBNP bei HFpEF, die durchschnittliche Konzentration von 409 pg/ml geht jedoch aus einer früheren Publikation hervor (Cleland et al. 2007). Dieser deutlich erhöhte Wert ist durch das hohe Einschlussalter ( $\geq 70$ Jahre) und die vorausgegangene Hospitalisation zu erklären. Insgesamt ist die Konzentration von NTproBNP bei den Patienten der DIAST-CHF-Studie im Vergleich zu anderen Prognosestudien geringer, was an der ungleichen Verteilung der Patienten, den Einschlusskriterien sowie den oben genannten Einflussfaktoren von McKelvie et al. (2010), Iwanaga et al. (2006) und Tschöpe et al. (2005) liegt. Weitere Studien zur DD und HFpEF betrachten nicht das Fragment NTproBNP, sondern das aktive Peptid BNP. Ihre Daten sind zwar nicht direkt vergleichbar, zeigen jedoch oftmals übereinstimmende Zusammenhänge auf. Während Collier et al. (2011) ausschließlich HFpEF-Patienten betrachten, so differenzieren Martos et al. (2007) und Izumiya et al. (2014) auch zwischen isolierter DD und HFpEF. Sie alle zeigen deutlich erhöhte BNPKonzentrationen bei HFpEF. Die Untersuchungen von Martos et al. (2007) belegen zusätzlich eine mit dem Schweregrad der DD ansteigende BNP-Konzentration. 
Wie unter anderem McKelvie et al. (2010) und Anand et al. (2011) feststellen, sind die NTproBNP-Konzentrationen bei HFpEF deutlich geringer als bei HFrEF, was auch beispielhafte Vergleiche mit Studien zur chronischen HI (von Haehling et al. 2007, Moertl et al. 2009, Voors et al. 2009, von Haehling et al. 2010, Vergaro et al. 2011, Szymanski et al. 2011, D'Amato et al. 2013, Lok et al. 2013) und zur akuten HI (Maisel et al. 2010, Maisel et al. 2011, Shah et al. 2012, Park et al. 2014) zeigen. Zu erklären ist die geringere Konzentration bei HFpEF durch das kleinere linksventrikuläre Volumen und die höhere Wanddicke des linken Ventrikels, was zu einem geringeren enddiastolischen Wandstress führt, der den Stimulus für die Sekretion von BNP darstellt (Iwanaga et al. 2006).

Die Analyse der logarithmierten Werte von NTproBNP im univariaten CoxRegressionsmodell zeigt in dieser Arbeit einen hochsignifikanten Zusammenhang zum kombinierten Endpunkt aus Mortalität und CV-Hospitalisation. Das Risiko für Mortalität und CV-Hospitalisation ist etwas geringer (HR 1,66; $95 \% \mathrm{Cl} ; 1,46-1,89 ; \mathrm{p}<0,001$ ) als das von CTproET-1. NTproBNP diente unter '3.2.4 Cox-Regressionsmodelle für NTproBNP' (S.50) aufgrund seiner bekannten Überlegenheit als Korrekturvariable. Wie auch für CTproET-1 und MRproADM erfolgte anschließend eine Betrachtung in Regressionsmodellen mit gegenseitiger Adjustierung, in dem sich eine reduzierte HR von 1,39 (95 \% Cl; 1,15 - 1,66; $p<0,001)$ für NTproBNP ergibt. Eine zusätzliche Adjustierung nach dem Alter verringerte das Risiko nochmals (HR 1,28; $95 \% \mathrm{Cl} ; 1,05-1,55$; $p=0,014)$. Der Zusammenhang bleibt jedoch im Gegensatz zu CTproET-1 und MRproADM signifikant.

Erste genauere Hinweise zur Prognosekraft von NTproBNP bei HFpEF stammen aus einem Kommentar von Cleland et al. (2007), jedoch veröffentlichten sie die vollständigen Ergebnisse erst 2012. Somit liefern Grewal et al. (2008) die erste vollständige Publikation und zeigen, dass NTproBNP ein starker Prädiktor für kardiovaskuläre Ereignisse in einem HFpEF-Kollektiv ist. Im Gegensatz zu dieser Arbeit betrachten Grewal et al. (2008) allerdings ein sehr viel kleineres Kollektiv über einen deutlich kürzeren Zeitraum. Zur Errechnung des Risikos wurden zwei Cut-Off-Werte, nämlich $>300$ pg/ml und $>600$ pg/ml verwendet. Für beide Werte ergeben sich im uni- und multivariaten CoxRegressionsmodell signifikante Zusammenhänge zum Endpunkt. Der eher dem Mittelwert dieser Arbeit entsprechende Cut-Off von $>300 \mathrm{pg} / \mathrm{ml}$, der allerdings bereits deutlich höher ist als der Mittelwert im DIAST-CHF-Kollektiv, zeigte im univariaten Modell eine HR von $7,2(95 \% \mathrm{Cl} ; 1,7-31,7 ; \mathrm{p}=0,008)$ und im multivariaten Modell, in dem nach diversen klinischen Parametern adjustiert wurde, eine HR von 5,8 (95\% Cl; 1,3 - 26,4; $\mathrm{p}=0,02)$. In der Patientengruppe mit moderater/schwerer DD und NTproBNP-Konzentrationen $>300$ pg/ml traten die meisten Endpunkte auf. Das vergleichsweise hohe Risiko ist durch 
die hohen Cut-Off-Werte, die erhöhten Konzentrationen von BNP und NTproBNP im gesamten Kollektiv und die geringe Größe der Untersuchungsgruppe zu erklären.

McKelvie et al. (2010) betrachten zunächst die Konzentration von NTproBNP und deren Einflussfaktoren im HFpEF-Kollektiv von I-PRESERVE. Sie vermuten, dass erhöhte NTproBNP-Konzentrationen mit erhöhter Mortalität einhergehen, doch wird dieser Zusammenhang bei I-PRESERVE erst von Anand et al. (2011) und Komajda et al. (2011) gezeigt. Selbiges zeigt sich in dieser Arbeit unter '3.2.2 Kaplan-Meier-Kurven zur Inzidenzrate entsprechend des NTproBNP-Levels' (S. 47). Anand et al. (2011) untersuchen nur die prognostische Wertigkeit von NTproBNP, während Komajda et al. (2011) insgesamt 58 Faktoren betrachten. Anand et al. (2011) berechnen im univariaten Cox-Regressionsmodell für den mit dieser Arbeit identischen Endpunkt nach Logarithmierung der NTproBNP-Konzentration eine HR von 1,76 (95\% Cl; 1,68 - 1,85; $\mathrm{p}<0,001)$. In der multivariaten Analyse werden ohne nähere Erläuterung 220 Patienten ausgeschlossen und es ergibt sich eine HR von 1,46 (95\% Cl; 1,37 - 1,57; $\mathrm{p}<0,001)$. Bei Komajda et al. (2011) ist NTproBNP der stärkste prognostische Faktor für den kombinierten Endpunkt. Sie geben nach Logarithmierung ein insgesamt etwas geringeres Risiko in der univariaten (HR 1,59; $95 \% \mathrm{Cl} ; 1,525$ - 1,661; $\mathrm{p}<0,0001$ ) und multivariaten (HR 1,25; $95 \% \mathrm{Cl} ; 1,201-1,304 ; \mathrm{p}<0,0001$ ) Regressionsanalyse an. Die Unterschiede zu Anand et al. (2011) kommen durch verschiedene Adjustierungen und die Modellbildung von Komajda et al. (2011) zustande. Diese betrachten zwar die gesamte I-PRESERVEKohorte (4128 Patienten), allerdings lagen nur bei 2563 Patienten vollständige Daten bezüglich aller 58 Parameter vor, sodass die fehlenden Daten durch regressionsbasierte Kalkulation nach Bildung und Anpassung der Cox-Regressionsmodelle auf die gesamte Kohorte hochgerechnet wurden. Es stellen sich vor und nach dieser Prozedur laut der Autoren nur marginale Unterschiede zwischen der Gruppe mit vollständigen Daten (2563 Patienten) und dem gesamten Kollektiv (4128 Patienten) mit nachträglich kalkulierten Daten heraus, sodass man sich für letzteres Modell entschied. Anand et al. (2011) berichten, dass bei 3480 der 4128 Patienten NTproBNP-Konzentrationen vorlagen. Aus den Daten von Komajda et al. (2011) geht nicht hervor, ob für die Modelle Daten von 2563 oder tatsächlich 3480 Patienten verwendet wurden. Verlässlicher scheinen die HRs von Anand et al. (2011) zu sein, obwohl Komajda et al. (2011) ihre kalkulierten Daten mehrfach auf signifikante Unterschiede in den Modellen prüften. Die vorliegende Arbeit liegt mit der univariaten HR $(1,66)$ exakt zwischen der von Anand et al. (2011) und Komajda et al. (2011), während die multivariate HR $(1,28)$ eher der von Komajda et al. (2011) entspricht. Die geringen Differenzen sind durch die unterschiedlichen Kollektive und Adjustierungen zu erklären, zeigen jedoch übereinstimmend die hohe prognostische Wertigkeit von NTproBNP bei HFpEF. Auch zu HFrEF-Kollektiven mit ähnlichem 
Schweregrad sind die HRs der logarithmierten Cox-Regressionsmodelle trotz zwei- bis viermal so hoher Konzentration vergleichbar (Masson et al. 2008, Cleland et al. 2009, Moertl et al. 2009), was auf ähnliche prognostische Valenz schließen lässt.

Cleland et al. (2012) bestätigen NTproBNP als starken prognostischen Faktor bei HFpEF, finden jedoch mit einer $\mathrm{HR}$ von 2,70 (95\% Cl; 1,34 - 5,43; $\mathrm{p}=0,005)$ in der univariaten und einer $\mathrm{HR}$ von 2,68 (95 \% Cl; 1,3 - 5,52; $\mathrm{p}=0,007)$ in der multivariaten Regression ein deutlich höheres Risiko für den identischen Endpunkt. Zu erklären ist diese Beobachtung dadurch, dass sich das Risiko im univariaten Modell auf den Konzentrationsbereich $409,4-1035,9 \mathrm{pg} / \mathrm{ml}$ und im multivariaten Modell auf Konzentrationen $\geq 1036 \mathrm{pg} / \mathrm{ml}$ bezieht, da in niedrigeren Bereichen jeweils keine signifikanten Zusammenhänge gefunden wurden. Dies wiederum liegt gegebenenfalls am kleinen Kollektiv und dem kurzen Beobachtungszeitraum von nur einem Jahr. Wie zuvor beschrieben lassen sich in Extremkonzentrationen einfacher signifikante Zusammenhänge zur Mortalität herstellen. Entsprechend der erhöhten Konzentration ist auch das Risiko für den Endpunkt deutlich höher, allerdings wenig vergleichbar mit dem Kollektiv dieser Arbeit.

Die prognostische Wertigkeit des Biomarkers NTproBNP ist unbestritten, was abermals Studien zu akut dekompensierten bzw. hospitalisierten Patienten mit HFpEF (Kirk et al. 2004, Bettencourt et al. 2007) zeigen oder solche, die sich auf das aktive Peptid BNP bei HFpEF-Patienten beziehen (Fonarow et al. 2007, Valle et al. 2005, van Veldhuisen et al. 2013, Izumiya et al. 2014). Die durchweg hohe Prognosekraft und Überlegenheit gegenüber anderen klinischen Mitteln ist unter anderem dadurch zu erklären, dass BNP sowie das stabile Fragment NTproBNP diverse prognostische Informationen wie beispielsweise die kardiale und renale Funktion, den Herzrhythmus sowie erhöhte Füllungsdrücke unterschiedlicher Genese (DD, Ischämie, LV-Dysfunktion) beinhalten und widerspiegeln. Das Risiko für die Mortalität oder CV-Hospitalisation steigt mit der Konzentration von NTproBNP, was auch die Analyse '3.2.2 Kaplan-Meier-Kurven zur Inzidenzrate entsprechend des NTproBNP-Levels' (S. 47) zeigt. Die Daten dieser Arbeit fügen sich in solche von vergleichbaren Studien und zeigen ebenso Ähnlichkeit zum Risiko bei HFrEF. NTproBNP bestätigt sich zunächst einzeln betrachtet als Biomarker der Wahl bei DD und HFpEF und scheint eine vergleichbare Prognosekraft wie bei HFrEF zu besitzen.

\subsection{Unklare Datenlage zur Wertigkeit von hsCRP}

Die Rolle von hsCRP in der Pathophysiologie von DD und HFpEF ist nicht vollständig geklärt, und bereits durchgeführte Studien zur Prognosekraft kommen zu unterschiedlichen Ergebnissen. In vorliegender Arbeit wurde die Konzentration von 
hsCRP mit einem hochsensitiven Assay der Firma Roche Diagnostics GmbH (Mannheim, Deutschland) ermittelt. In der gesamten Studienpopulation von DIAST-CHF beträgt die mittlere Konzentration $1,80 \mathrm{mg} / \mathrm{l}$. Die hsCRP-Konzentration steigt mit der NTproBNPKonzentration signifikant von 1,54 mg/l in Gruppe [1] über 1,63 mg/l [2] auf 2,40 mg/l in Gruppe [3] an.

In einem gesunden Kollektiv beträgt die hsCRP-Konzentration im Mittel 1,6 $\pm 3,4 \mathrm{mg} / \mathrm{l}$ für Frauen und $1 \pm 2,7 \mathrm{mg} / \mathrm{l}$ für Männer (Rogowski et al. 2004). Diverse Studien belegen eine Erhöhung der hsCRP-Konzentration bei HFpEF (Wisniacki et al. 2005, Michowitz et al. 2008, Okuyan et al. 2010, Koller et al. 2014), während Matsubara et al. (2011) dies infrage stellen, da sie in ihrem sehr kleinen Kollektiv zwar signifikant höhere Werte bei $\operatorname{HFrEF}(1,15 \mathrm{mg} / \mathrm{l})$, jedoch nicht bei HFpEF $(0,9 \mathrm{mg} / \mathrm{l})$ im Vergleich zur Kontrollgruppe $(0,7 \mathrm{mg} / \mathrm{l})$ feststellen. $\mathrm{Zu}$ beachten sind allerdings die insgesamt niedrigen Konzentrationen von hsCRP im gesamten Kollektiv dieser Studie. So weisen die gesunden Kontrollprobanden von Wisniacki et al. (2005) und Okuyan et al. (2010) mit $1,5 \mathrm{mg} / \mathrm{l}$ und 1,94 mg/l bereits höhere Konzentrationen auf als die an HFrEF erkrankten Patienten von Matsubara et al. (2011), welche ebenso keinen Zusammenhang zwischen erhöhten hsCRP-Werten und dem Vorhandensein einer DD und HFpEF sehen. Auch diese Aussage muss kritisch betrachtet werden, da Michowitz et al. (2008) und Koller et al. (2014) für HFpEF sowie Tang et al. (2008) für DD (allerdings in Kombination mit $\mathrm{HFrEF}$ ), in größeren Kollektiven signifikante Zusammenhänge zwischen hsCRP und dem Schweregrad der jeweiligen Erkrankung feststellten. Die beiden größten HFpEF-Kollektive betrachten Koller et al. (2014) und Matsubara et al. (2014). Ihre Angaben zur Konzentration unterscheiden sich jedoch deutlich und betragen $3,88 \mathrm{mg} / \mathrm{l}$ (Koller et al. 2014) und $0,8 \mathrm{mg} / \mathrm{l}$ (Matsubara et al. 2014), was erneut durch die unterschiedlichen Kollektive, die Rekrutierungsform und Vorerkrankungen zu erklären ist. Deutlich höhere Werte (7,45 - 9,5 mg/l) zeigen die Patienten von Michowitz et al. (2008) und Okuyan et al. (2010), wobei es sich bei letztgenannten um hospitalisierte Patienten handelt. Wisniacki et al. (2005) liegen mit 4,5 mg/l, gemessen bei einem Kollektiv aus lediglich 25 Patienten, zwischen den genannten Studien. Laut Michowitz et al. (2008) gibt es keine signifikanten Konzentrationsunterschiede zu HFrEF-Patienten, was beispielhafte Vergleiche zu HFrEFKollektiven (1,96 - 12,9 mg/l median) bestätigen (Yin et al. 2004, Anand et al. 2005, Lamblin et al. 2005, Windram et al. 2007, Tang et al. 2008, Radauceanu et al. 2008, Park et al. 2014). Izumiya et al. (2014) geben für ihre HFpEF-Patienten Konzentrationen an $(0,06-0,07 \mathrm{mg} / \mathrm{l})$, die um mindestens eine Zehnerpotenz von denen anderer Studien abweichen und machen keinerlei Angaben zur verwendeten Messmethode. Diese Werte sind nicht repräsentativ und vergleichbar, da derart niedrige Konzentrationen aufgrund 
einer unteren Nachweisbarkeitsgrenze von $0,1 \mathrm{mg} / \mathrm{l}$ jedenfalls nicht mit dem in dieser Arbeit verwendeten hochsensitiven Assay ermittelt werden können.

Im univariaten Cox-Regressionsmodell stellt sich für logarithmierte Werte von hsCRP im DIAST-CHF-Kollektiv ein sehr geringes Risiko für den kombinierten Endpunkt heraus (HR $1,04 ; 95 \% \mathrm{Cl} ; 0,89-1,22 ; \mathrm{p}=0,594)$. Der Zusammenhang zur Mortalität und CVHospitalisation ist nicht signifikant. hsCRP scheint zumindest in dieser Arbeit keinen relevanten Zusammenhang zum Enpunkt aufzuweisen, weshalb von einer Integration in weitere statistische Modelle abgesehen wurde.

Michowitz et al. (2008) und Matsubara et al. (2014) sind sich einig, dass hsCRP kein prädiktiver Faktor bei HFpEF ist. Beide Autoren finden wie in vorliegender Arbeit keinen signifikanten Zusammenhang in univariaten Modellen. Während Matsubara et al. (2014) daher auf ein multivariates Cox-Regressionsmodell verzichten, berechnen Michowitz et al. (2008) dieses und finden verständlicherweise auch hier keinen signifikanten Zusammenhang zur Mortalität. Neben der Vermutung, dass hsCRP möglicherweise kein prädiktives Potential bei HFpEF besitzt, könnte allerdings auch das mit 77 Patienten sehr kleine Kollektiv von Michowitz et al. (2008) schuld an der nicht-signifikanten Korrelation sein. Einzig Koller et al. (2014) sehen hsCRP als starken prognostischen Faktor der Mortalität an. Nach Logarithmierung der hsCRP-Konzentration zeigt die univariate CoxRegressionsanalyse für einen Anstieg der Konzentration um eine SD bei der Gesamtmortalität eine HR von 1,28 $(95 \% \mathrm{Cl} ; 1,12-1,49 ; \mathrm{p}=0,001)$ und bei der CVMortalität eine HR von $1,38(95 \% \mathrm{Cl} ; 1,15-2,40 ; p>0,001)$. In der anschließenden multivariaten Regression wird nach mehreren Faktoren wie NTproBNP, Alter, Geschlecht, NYHA-Klasse, KHK und weiteren Risikofaktoren adjustiert. Es ergeben sich für die Gesamtmortalität (HR 1,20; $95 \% \mathrm{Cl} ; 1,02-1,40 ; \mathrm{p}=0,018)$ und die CV-Mortalität (HR 1,32; $95 \% \mathrm{Cl} ; 1,08$ - 1,62; $\mathrm{p}=0$,005) jeweils leicht reduzierte Risiken. Das höchste Risiko der CV-Mortalität (HR 8,32) bestand bei Patienten, die gleichzeitig hohe NTproBNP- und hsCRP-Konzentrationen aufwiesen. Dass ihre Ergebnisse im Gegensatz zu denen anderer HFpEF-Studien Signifikanz zeigen, könnte am selektierten Kollektiv dieser Arbeit liegen, welches zu 75,6 \% an KHK leidet. Die Inflammation spielt bei KHK eine zentrale Rolle (Libby et al. 2002). Ihr Kollektiv zeigt im Vergleich zu ätiologischen Untersuchungen von Owan et al. (2006) eine deutlich höhere Prävalenz für KHK, die eher dem Profil von HFrEF entspricht. Es handelt sich bei Koller et al. (2014) somit um eine nichtrepräsentative Gruppe von HFpEF-Patienten, die von der gewöhnlichen Ätiologie abweichen. Allerdings bestätigen sie signifikante Zusammenhänge zwischen hsCRP und KHK und adjustieren im multivariaten Cox-Regressionsmodell hiernach. Des Weiteren geben sie an, dass hsCRP bei Patienten ohne KHK sogar prädiktiver war. Insgesamt sollten die Ergebnisse dieses speziellen Kollektivs jedoch mit Vorsicht interpretiert und 
nicht als allgemeingültig für HFpEF angesehen werden. Die Daten von Michowitz et al. (2008), Matsubara et al. (2014) und dieser Arbeit zeigen, dass kein signifikanter Zusammenhang zwischen hsCRP und der Mortalität bzw. einem kombinierten Endpunkt besteht. Die hsCRP-Konzentration wird durch diverse Erkrankungen moduliert und der Marker scheint insgesamt zu unspezifisch, um klare Aussagen zur Prognose bei HFpEF treffen zu können. HFrEF-Studien sehen hsCRP hingegen mehrheitlich als prognostisch relevant an (Yin et al. 2004, Anand et al. 2005, Windram et al. 2007, Tang et al. 2008, Lok et al. 2013, Park et al. 2014, Li et al. 2014), was aber auch mit der unterschiedlichen Ätiologie der Erkrankungen zusammenhängen kann. So zeigen Lamblin et al. (2005), dass hsCRP eher bei ischämischer statt non-ischämischer HI prädiktiv war. Der Ansatz von Matsubara et al. (2014) daher bei HFpEF das für vaskuläre und kardiale Inflammation spezifischere Protein Pentraxin-3 (PTX-3) zu betrachten, für das im Gegensatz zu hsCRP signifikante Zusammenhänge zur Mortalität festgestellt wurden, erscheint sinnvoll. Trotzdem sollte hsCRP in weiteren Studien mit großen, nicht-selektierten HFpEFKollektiven untersucht werden, um oben genannte Tendenzen zu bestätigen, da die patophysiologische Beteiligung des Proteins unbestritten ist.

\subsection{Scheitern von CTproET-1 an multivariaten Modellen}

Die Bestimmung der Konzentration von CTproET-1 erfolgte mit einem Assay der Firma B.R.A.H.M.S GmbH (Hennigsdorf, Deutschland). Es ergab sich im gesamten Kollektiv eine mittlere Konzentration von 54,9 pmol// mit einem signifikanten Anstieg von Gruppe [1] bis [3]. Während die Konzentration von CTproET-1 in Gruppe [1] bei 51,9 pmol/l liegt, beträgt der Mittelwert in Gruppe [2] bereits 58,8 pmol// und in Gruppe [3] schließlich $62,4 \mathrm{pmol} / \mathrm{l}$. Sowohl die prognostische Wertigkeit als auch die Konzentration von CTproET-1 bei DD und HFpEF sind aufgrund nicht vorhandener Studien unklar.

Für eine Gruppe gesunder Probanden ermitteln Papassotiriou et al. (2006) eine durchschnittliche Konzentration von $44,3 \mathrm{pmol} / \mathrm{l}$. Ihre Angaben zu chronisch herzinsuffizienten Patienten (104pmol/l) ist etwas höher als solche $(63,6-85,57 \mathrm{pmol} / \mathrm{l})$ in diversen HFrEF-Studien (Adlbrecht et al. 2009, Neuhold et al. 2010, Masson et al. 2010a, Jankowska et al. 2011). Alle Autoren greifen auf die Messmethode der Firma B.R.A.H.M.S $\mathrm{GmbH}$ (Hennigsdorf, Deutschland) zurück. Die Daten der DIAST-CHF-Studie lassen vermuten, dass die Konzentration von CTproET-1 bei DD und HFpEF zwischen der von gesunden Probanden und HFrEF-Patienten liegt. Die Konzentration von CTproET-1 bei HFrEF steigt mit dem Auftreten von Symptomen (Adlbrecht et al. 2009, Masson et al. 2010a, Jankowska et al. 2011), was auch für das Kollektiv dieser Arbeit zu gelten scheint, wenn beide Variablen in den Untergruppen betrachtet und verglichen werden. Vor allem 
ältere Studien messen die Konzentration des aktiven Peptids ET-1 (3,5 - 10 pg/ml) mittels RIA (Pousset et al. 1997, Isnard et al. 2000, Pousset et al. 2000, Latini et al. 2004, van Beneden et al. 2004). Ein Vergleich zwischen diesen beiden Markern/Methoden ist aufgrund der kürzeren Halbwertszeit, der Bindung an Plasmaproteine und Rezeptoren sowie der hohen pulmonalen Clearance des aktiven Peptids nicht sinnvoll.

Um den Zusammenhang zwischen CTproET-1 und dem Endpunkt zu ermitteln, wurde wie bei den Biomarkern zuvor ein univariates Cox-Regressionsmodell analysiert. Hier stellte sich nach Logarithmierung der Konzentration ein hochsignifikanter Zusammenhang mit einer HR von 1,69 (95\% Cl; 1,43-2,00; $\mathrm{p}<0,001)$ heraus. Im anschließenden CoxRegressionsmodell für NTproBNP blieb die signifikante Korrelation erhalten und verringerte sich aufgrund der Korrektur geringfügig (HR 1,45; $95 \% \mathrm{Cl} ; 1,21$ - 1,74; $p<0,001)$. Das multivariate Cox-Regressionsmodell, in dem zunächst nach NTproBNP und MRproADM adjustiert wurde, zeigt ebenso wie das Modell mit zusätzlicher Korrektur des Alters keinen signifikanten Zusammenhang mehr $(p=0,155$ und $p=0,212)$, was auch hier durch überschneidende prognostische Informationen zu erklären ist. Für CTproET-1 erfolgte daher ebenso eine Korrelations- sowie Hauptkomponentenanalyse und die Integration ins finale Regressionsmodell, deren Diskussionen in den folgenden Kapiteln nachzulesen sind.

Adlbrecht et al. (2009), Neuhold et al. (2010), Masson et al. (2010a) und Jankowska et al. (2011) untersuchten die Prognosekraft von CTproET-1 bei chronischer HI mit reduzierter EF und kommen zu unterschiedlichen Ergebnissen. Erneut betrachten Masson et al. (2010a) in 'GISSI-HF' (The Gruppo Italiano per lo Studio della Sopravvivenza insufficienza cardiaca) das größte Kollektiv. CTproET-1 zeigt keinen signifikanten Unterschied in der Prognosekraft verglichen mit MRproANP, NTproBNP und MRproADM. Die Mortalitätsrate steigt mit der Konzentration aller vier Marker signifikant an $(p<0,0001)$, was auch für das Auftreten des kombinierten Endpunkts gilt. Im univariaten Regressionsmodell errechnete sich für den Konzentrationsbereich von 70 - 94 pmol/l, der dem dieser Arbeit am meisten ähnelt, ein im Vergleich etwas geringeres Risiko (HR 1,27; $95 \% \mathrm{Cl} ; 1,06$ - 1,53; $p=0,0115)$. Im multivariaten Modell, in dem wie zuvor erläutert nach diversen Faktoren adjustiert wird, die ebenfalls signifikant $(p<0,05)$ mit der Mortalität korrelieren, besteht ein signifikanter Zusammenhang nur noch im höchsten Konzentrationsbereich von 95 $375 \mathrm{pmol} / \mathrm{l}(\mathrm{p}=0,0007)$ und nicht mehr im vergleichbaren Bereich von $70-94 \mathrm{pmol} / \mathrm{l}$ ( $p=0,6498)$. Im nächstgrößeren Kollektiv stellen Adlbrecht et al. (2009) ähnlich wie Masson et al. (2010a) fest, dass die Mortalität bei erhöhter CTproET-1 Konzentration oberhalb des Medians von 77,4 pmol// signifikant ansteigt $(p<0,001)$. Die univariate CoxRegression zeigt hier eine nahezu identische HR von 1,29 (95\% Cl; 1,22-1,44; $\mathrm{p}<0,001)$. Im schrittweisen Cox-Regressionsmodell ergibt sich für CTproET-1 jedoch ein 
negativ prädiktives Potential bezüglich der Mortalität (HR 1,00; $95 \% \mathrm{Cl} ; 0,99$ - 1,00; $p=0,008$ ). Dies liegt wahrscheinlich an Interaktionen zwischen den Variablen im multivariaten Modell, da nach Integration aller Biomarker dieser Studie (MRproADM, CTproET-1, BNP) in das finale Regressionsmodell lediglich ein signifikanter Zusammenhang für MRproADM bestehen blieb. Ähnliche Probleme traten in dieser Arbeit auf, weshalb weitere, bereits erwähnte Analysen durchgeführt wurden.

Die Studie von Jankowska et al. (2011) zeigt trotz des HFrEF-Kollektivs, der Betrachtung einer kurzen Nachbeobachtungsphase und des nicht-kombinierten Endpunkts der CVMortalität eine gute Vergleichbarkeit, da die Median-Konzentration von 63,6 pmol/l ähnlich ist und in den Regressionsmodellen logarithmierte Werte betrachtet werden. Insgesamt sind die von innen berechneten HRs im univariaten (HR 2,41;95\% Cl; 1,87-3,1; $\mathrm{p}<0,0001$ ) und multivariaten Modell (HR 1,42; $95 \% \mathrm{Cl} ; 1,04-1,95 ; \mathrm{p}=0,03$ ) etwas höher, was auf ein höheres Risiko bei HFrEF im Vergleich zu DD und HFpEF hindeutet.

Weitere Studien betrachten vergleichsweise kleine Kollektive und das aktive Peptid ET-1 statt CTproET-1. Sie finden sowohl in univariaten als auch in multivariaten Regressionsmodellen signifikante Zusammenhänge zur Mortalität (Pousset et al. 1997, Pousset et al. 2000, Selvais et al. 2000, van Beneden et al. 2004). Isnard et al. (2000) und Latini et al. (2004) beobachten hingegen nur in univariaten Modellen signifikante Korrelationen. Dies liegt bei Latini et al. (2004) jedoch daran, dass gleichzeitig nach ET-1 und BigET-1 (big endothelin-1) adjustiert wird, was zum Zusammenbruch des statistischen Modells führte. Die Studie von Li et al. (2014) ist aufgrund diverser Unterschiede, wie der Betrachtung von gerade hospitalisierten Patienten und BigET-1 statt CTproET-1, wenig vergleichbar aber erwähnenswert, da sie mit der dilatativen Kardiomyopathie eine ähnliche Erkrankung mit lediglich unterschiedlicher Ursache betrachten. Wie in dieser Arbeit und in diversen oben genannten Studien zur HFrEF, so geht auch bei ihnen der signifikante Zusammenhang zur Mortalität im multivariaten Modell verloren. Die Tatsache, dass in einigen Studien und auch in dieser Arbeit der Zusammenhang zum Endpunkt nach Adjustierung für NTproBNP keine Signifikanz mehr zeigt, lässt vermuten, dass CTproET-1 zwar prognostische Informationen beinhaltet, diese jedoch große Ähnlichkeit zu denen anderer Biomarker aufweisen. In einigen HFrEFStudien besteht ein Zusammenhang in multivariaten Modellen nur in sehr hohen Konzentrationsbereichen, die jedoch bei HFpEF unrealistisch scheinen. 


\subsection{Geringe prognostische Wertigkeit von PIIINP}

Kollagen III spielt eine zentrale Rolle in der Pathophysiologie der DD und HFpEF, da es am Remodelling und der Versteifung der Ventrikel beteiligt ist. Die Konzentration des Fragmentes PIIINP wurde mit einem Radioimmunoassay der Firma Orion Diagnostica Oy (Espoo, Finnland) bestimmt. Im gesamten Kollektiv beträgt die Konzentration im Mittel $3,28 \mu \mathrm{g} / \mathrm{l}$ und steigt von 3,10 $\mu \mathrm{g} / \mathrm{l}$ in Gruppe [1] bis 3,56 $\mu \mathrm{g} / \mathrm{l}$ in Gruppe [3] signifikant an. Je höher die NTproBNP-Konzentration, desto höher ist auch die PIIINP-Konzentration. Barasch et al. (2009) stellen für gesunde Probanden eine PIIINP-Konzentration von 3,1 $\mu \mathrm{g} / \mathrm{l}$ fest. In einer Patientengruppe mit kardiovaskulären Risikofaktoren ermitteln sie 3,8 $\mu \mathrm{g} / \mathrm{l}$, während Collier et al. (2011) bei asymptomatischen Hypertonikern 3,1 $\mathrm{g} / \mathrm{l}$ messen. Die in der DIAST-CHF-Studie festgestellten Konzentrationen befinden sich genau zwischen den beschriebenen Werten.

Mehrere Studien befassten sich in der Vergangenheit mit der PIIINP-Konzentration bei HFpEF-Patienten. Sie betrachteten zwar alle deutlich kleinere Kollektive, stellen jedoch übereinstimmend fest, dass die Konzentration von PIIINP im Vergleich zu gesunden Probanden signifikant erhöht ist (Martos et al. 2007, Barasch et al. 2009, Collier et al. 2011, Zile et al. 2011a). Die PIIINP-Konzentration korreliert mit dem Schweregrad der DD und steigt bei gleichzeitigem Vorliegen von DD und HFpEF nochmals deutlich an (Martos et al. 2007). Rossi et al. (2004) und Cicoira et al. (2004) bestätigen eine Korrelation zwischen DD und der Konzentration von PIIINP, allerdings bei dilatativer Kardiomyopathie bzw. chronischer HI mit reduzierter EF. Insgesamt sind die Konzentrationen von PIIINP in vergleichbaren DD- und HFpEF-Studien höher, was am Kollektiv und der ungleichen Gruppenverteilung dieser Arbeit liegt. Martos et al. (2007) stellen je nach Schweregrad der DD (Stadium 0-IV) Konzentrationen zwischen 3,6-6,5 $\mu \mathrm{g} / \mathrm{l}$ fest. Bei gleichzeitiger HFpEF kommen sie auf Werte von 4,2 - 7,5 $\mu \mathrm{g} / \mathrm{l}$, ohne HFpEF auf 4,0 - 4,3 $\mu \mathrm{g} / \mathrm{l}$. In den Kollektiven von Barasch et al. (2009) und Collier et al. (2011) werden mit 4,2 - 4,6 $\mu \mathrm{g} / \mathrm{l}$ vergleichbare Werte ermittelt. Zile et al. (2011a) und Bishu et al. (2012) zeigen die höchsten Konzentrationen für HFpEF-Kollektive $(9,1-10,3 \mu \mathrm{g} / \mathrm{l})$, allerdings auch in ihrer HFrEF- bzw. gesunden Kontrollgruppe. Bishu et al. (2012) vergleichen ihre Ergebnisse mit HFrEF-Patienten und stellten für beide Gruppen zwar erhöhte, aber nicht signifikant unterschiedliche Konzentrationen fest, was bereits Barasch et al. (2009) beobachteten. Die insgesamt deutlich höheren PIIINP-Konzentrationen von Bishu et al. (2012) sind durch die Einschlusskriterien und die daraus resultierende Selektion von Patienten mit höherem Schweregrad zu erklären. Vergleiche zu HFrEF-Studien von Klappacher et al. (1995), Zannad et al. (2000), Cicoira et al. (2004), Radauceanu et al. (2008), Ho et al. (2009) und Chang et al. (2014) zeigen nämlich Konzentrationen, die denen der bereits 
genannten HFpEF-Studien ähneln, jedoch nicht an solche von Bishu et al. (2012) heranreichen. Bei Zile et al. (2011a) zeigt sich bereits in der gesunden Kontrollgruppe eine nahezu doppelt so hohe PIIINP-Konzentrationen $(7,2 \mu \mathrm{g} / \mathrm{l})$ wie in den HFpEFGruppen der beiden Studien zur Prognosekraft (Barasch et al. 2011, Krum et al. 2011), die wiederum fast identische Konzentrationen (4,2 - 4,3 $\mu \mathrm{g} / \mathrm{l})$ messen und eine adäquate Vergleichbarkeit zu den Werten dieser Arbeit zeigen.

Im univariaten Cox-Regressionsmodell konnte in vorliegender Arbeit ein signifikanter Zusammenhang zwischen den logarithmierten Werten von PIIINP und dem kombinierten Endpunkt aus Mortalität und CV-Hospitalisation festgestellt werden (HR 1,18; $95 \% \mathrm{Cl}$; $1,05$ - 1,33; $p=0,005)$. Im anschließenden Regressionsmodell für NTproBNP ging die signifikante Korrelation jedoch verloren $(p=0,056)$, weshalb auf eine Betrachtung in den beiden multivariaten Cox-Regressionsmodellen verzichtet wurde. Eine Integration in die Korrelations- und Hauptkomponentenanalyse sowie das finale Regressionsmodell fand allerdings trotzdem statt.

Zusammenhänge zwischen PIIINP und der Mortalität bei HFpEF werden von beiden in der Vergangenheit durchgeführten Studien tendenziell negativ bewertet. Krum et al. (2011) können in ihrem reduzierten I-PRESERVE-Kollektiv im univariaten CoxRegressionsmodell nur eine Borderline-Signifikanz für den identischen, kombinierten Endpunkt feststellen (HR 2,47; $95 \% \mathrm{Cl} ; 0,97$ - 6,33; $\mathrm{p}=$ 0,059). Für die Gesamtmortalität ( $\mathrm{HR} 2,85 ; 95 \% \mathrm{Cl} ; 1,52-5,36 ; \mathrm{p}=0,001)$ und den kombinierten Endpunkt aus HIMortalität und HI-Hospitalisation (HR 5,91; $95 \% \mathrm{Cl}$; 2,94 - 11,88; $\mathrm{p}=0,0001$ ) bestehen hingegen signifikante Zusammenhänge. Die HRs beziehen sich auf eine Erhöhung der PIIINP-Konzentration um $10 \mu \mathrm{g} / \mathrm{l}$ und sind entsprechend hoch und schlecht mit den Angaben vorliegender Arbeit zu vergleichen. In multivariaten Cox-Regressionsmodellen kann für keinen Endpunkt ein Zusammenhang hergestellt werden ( $p=0,156-0,998)$. Ursächlich hierfür könnte allerdings auch die vehemente Adjustierung nach 19 bzw. 20 (+NTproBNP) Variablen bei einem gleichzeitig sehr kleinen Kollektiv sein. Weiterhin spielt die Tatsache, dass PIIINP nicht nur bei HI, sondern auch bei Knochen- und Lebererkrankungen erhöht ist, eine Rolle. Diese Patienten wurden von Krum et al. (2011) bewusst nicht ausgeschlossen, zeigen jedoch ebenso erhöhte PIIINP-Konzentrationen. Bei Barasch et al. (2011) war PIIINP lediglich prädiktiv für verschiedene Endpunkte (Gesamt- und CV-Mortalität, Myokardinfarkt, HI-Hospitalisation sowie HI-Vorfall in der Risiko- bzw. gesunden Patientengruppe), wenn ein gemischtes Kollektiv aus HFpEF-, HFrEF-, Risikopatienten und gesunden Probanden untersucht wurde oder jeweils die Risikopatienten und gesunden Probanden getrennt voneinander. Wurden die HFrEF- und HFpEF-Patienten einzeln betrachtet, so konnten keinerlei signifikante Zusammenhänge zu oben genannten Endpunkten gefunden werden. 
Ganz im Gegensatz hierzu stellten diverse HFrEF-Studien Korrelationen zwischen der PIIINP-Konzentration und der Mortalität bzw. Prognose fest (Klappacher et al. 1995, Zannad et al. 2000, Cicoira et al. 2004, Rossi et al. 2004, Radauceanu et al. 2008, Ho et al. 2009, Chang et al. 2014). Von besonderem Interesse sind die Studien von Cicoira et al. (2004) zur HFrEF mit DD bzw. Klappacher et al. (1995) und Rossi et al. (2004) zur dilatativen Kardiomyopathie, die PIIINP allesamt als prädiktiv bezüglich der Mortalität ansehen. Sie beziehen sich mit der DD auf einen Hauptaspekt der HFpEF und mit der dilatativen Kardiomyopathie auf eine ähnliche Erkrankung. Darüber hinaus korreliert eine erhöhte PIIINP-Konzentration mit einer schlechteren Prognose, unabhängig von der EF (Rossi et al. 2004) bzw. der linksventrikulären Funktion (Cicoira et al. 2004). Trotz gewisser Parallelen sollten diese Ergebnisse jedoch nicht direkt auf HFpEF übertragen werden.

Insgesamt deuten die Resultate von Krum et al. (2011), Barasch et al. (2011) trotz des pathophysiologischen Zusammenhangs zur DD und HFpEF darauf hin, dass PIIINP für den kombinierten Endpunkt aus Mortalität und CV-Hospitalisation nicht prädiktiv ist. Einzeln betrachtet besteht nach dem univariaten Regressionsmodell dieser Arbeit ein signifikanter Zusammenhang zum Endpunkt, der jedoch nach Adjustierung verloren geht. Trotz geringer Überschneidungen mit anderen Biomarkern in der Korrelationsanalyse (siehe '3.2.7 Korrelationsanalyse der Biomarker' S. 55) scheint PIIINP anfällig für Adjustierungen zu sein. Um diese Auffälligkeit zu klären, sollte der Zusammenhang von PIIINP und der Mortalität in weiteren DD- und HFpEF-Kollektiven näher untersucht werden.

\subsection{Fehlende Korrelationen bei Renin}

Statt der direkten Konzentration von Renin (PRC) wird oftmals die Aktivität (PRA) bestimmt. Wie Tsutamoto et al. (2007) allerdings herausfanden, ist die Prognosekraft der PRC bei HFrEF höher als die der PRA, obwohl beide Methoden in Abwesenheit einer Renin-Inhibition äquivalente Informationen liefern (Campbell et al. 2009). In vorliegender Arbeit wurde die direkte Renin-Konzentration mit einem Assay der Firma DiaSorin S.p.A (Saluggia, Italien) ermittelt. Hierbei ergibt sich für das gesamte Kollektiv der Arbeit eine PRC von 17,1 $\mu \mathrm{lU} / \mathrm{ml}$. Mit steigender NTproBNP-Konzentration fällt diese von $18,6 \mu \mathrm{lU} / \mathrm{ml}$ in Gruppe [1] über 13,3 $\mu \mathrm{lU} / \mathrm{ml}$ [2] auf 12,0 $\mu \mathrm{lU} / \mathrm{ml}$ in Gruppe [3] ab.

Keine HFpEF-Studie ermittelt die direkte Konzentration von Renin und einzig Bishu et al. (2012) messen die PRA in einem beschränkt vergleichbaren, sehr kleinen und akut dekompensierten HFpEF-Kollektiv. Es ergab sich eine Aktivität von $2,2 \mathrm{ng} / \mathrm{ml} / \mathrm{h}$. Sie stellen außerdem fest, dass die PRA bei HFrEF und HFpEF zwar insgesamt erhöht ist, 
sich zwischen den beiden Gruppen jedoch nicht signifikant unterscheidet. Erklärbar ist diese Beobachtung durch den höheren Blutdruck in ihrem Kollektiv, der die PRA verringert und die Tatsache, dass HFpEF-Patienten seltener ACE-Hemmer und Angiotensin-Antagonisten einnehmen, die durch fehlende negative Rückkopplung die PRA erhöhen (Swedberg et al. 1990, Francis et al. 1993). Eine Medikation mit $\beta$-Blockern, die in der DIAST-CHF-Studie $49 \%$ der Patienten erhalten, senkt hingegen die PRA (Bühler et al. 1972) durch Abschwächung der adrenergen Stimulation (Hsueh et al. 1985). Bishu et al. (2012) vermuten, dass die PRA bei HFpEF aus oben genannten Gründen relativ gesehen sogar stärker erhöht ist als bei HFrEF. Entsprechend ihrer Erkenntnis sollten in HFrEF-Studien ähnliche Aktivitäten festzustellen sein, was jedoch nur begrenzt zutrifft. Volpe et al. (2010) und Vergaro et al. (2011) zeigen in HFrEF-Kollektiven noch eine vergleichsweise niedrige PRA von 2,6 ng/ml/h und 1,59 ng/ml/h. Latini et al. (2004) und Masson et al. (2010b) liegen mit 5,26 ng/ml/h bereits deutlich über diesen Werten, was dadurch zu erklären ist, dass ihre Patienten entgegen aktueller Indikationen und Richtlinien seltener $\beta$-Blocker (35,8\%) und Spironolacton einnehmen. Im Kollektiv von Vergaro et al. (2011) werden hingegen deutlich häufiger $\beta$-Blocker (82 \%) eingenommen, die sich wie bereits erwähnt auf die Konzentration von Renin auswirken. Tsutamoto et al. (2007) messen bei chronischer HI eine nochmals höhere PRA von 11,3 ng/ml/h.

Bereits das univariate Cox-Regressionsmodell zeigt in vorliegender Arbeit keinen signifikanten Zusammenhang zwischen den logarithmierten Werten von Renin und dem kombinierten Endpunkt (HR 1,09; $95 \% \mathrm{Cl}$; 0,94 - 1,28; $\mathrm{p}=1,256$ ), weshalb auf weitere Analysen verzichtet wurde.

Derzeit existiert keine HFpEF-Studien, die sich mit der Prognosekraft von Renin beschäftigt. Viele HFrEF-Studien, allerdings zur PRA und nicht zur PRC, zeigen auch nach Adjustierung in multivariaten Cox-Regressionsmodellen signifikante Zusammenhänge zur Mortalität. Die größten Kollektive hierzu untersuchen Latini et al. (2004) und Masson et al. (2010b) mit jeweils knapp 4300 Patienten. Zwar ist die PRA nach Latini et al. (2004) nicht der Beste, aber ein guter prognostischer Faktor, der allerdings nicht für den kombinierten Endpunkt aus Mortalität/Morbidität, sondern lediglich für die Mortalität prädiktiv war (multivariate $\mathrm{HR} \mathrm{1,27} \mathrm{für}>5,26 \mathrm{ng} / \mathrm{ml} / \mathrm{h}$ ). Sie stellen wie Masson et al. (2010b) fest, dass die Prognosekraft der PRA unabhängig von einer Medikation mit ACE-Hemmern ist, obwohl diese die PRA erhöht. Die Korrelation zur Mortalität bleiben bei Masson et al. (2010b) und Vergaro et al. (2011) im univariaten (HR 1,14; 95 \% Cl; 1,09 - 1,19; p > 0,0001 bzw. HR 1,293; $95 \% \mathrm{Cl} ; 1,194-1,401 ; p<0,001)$ sowie im multivariaten Cox-Regressionsmodell (HR 1,12; $95 \% \mathrm{Cl} ; 1,06-1,20 ; p<0,0001$ bzw. HR 1,201; $95 \%$ Cl; 1,024 - 1,408; $p=0,024)$ erhalten. Dies gilt bei Masson et al. (2010b) anders als bei Latini et al. (2004) auch für den kombinierten Endpunkt aus 
Mortalität/Morbidität (jeweils $p<0,0001$ ), was allerdings auch an den unterschiedlich festgelegten Ereignissen liegen kann, die zum Endpunkt zählen. Tsutamoto et al. (2007) finden nur im univariaten Modell einen signifikanten Zusammenhang zwischen PRA und der Mortalität $(p=0,0002)$, sehen aber die direkte Reninbestimmung als geeignetere Methode an, da ihre Prognosekraft überlegen ist. Zur Ermittlung einer sehr langfristigen Prognose, allerdings ebenfalls bei HFrEF, scheint die PRA nach Untersuchungen von Volpe et al. (2010) nicht geeignet zu sein. Sie fanden wahrscheinlich bedingt durch ihr kleines Kollektiv (106 Patienten) und den extrem langen Beobachtungszeitraum von 15 Jahren keine signifikanten Korrelationen $(p=0,08)$.

Insgesamt besteht bei einer erhöhten PRA in HFrEF-Kollektiven ein gesteigertes Mortalitätsrisiko. Eine Vergleichbarkeit der Studien ist nicht nur aufgrund der unterschiedlichen Bestimmungsmethoden von Renin erschwert, sondern auch durch die unterschiedliche Medikation der Patienten. Die Prognosekraft soll laut Latini et al. (2004), Masson et al. (2010b) und Vergaro et al. (2011) allerdings nicht durch die Einnahme von ACE-Hemmern beeinflusst werden. Ob dies auch für die PRC bei HFpEF gilt, ist jedoch ebenso unklar, wie die Prognosekraft selbst. Bis auf Volpe et al. (2010), die die sehr langfristige Prognosekraft der PRA untersuchen, können verschiedene Autoren Zusammenhänge zwischen PRA und der Mortalität herstellen, die jedoch nach Adjustierung in multivariaten Modellen nicht immer signifikant bleiben. Für eine genauere Einschätzung sollten weitere Untersuchungen zur PRC an DD- und HFpEF-Kollektiven durchgeführt werden.

\subsection{2 Überschneidung von prognostischen Informationen}

Sowohl im Cox-Regressionsmodell für NTproBNP als auch im multivariaten Regressionsmodell der logarithmierten Werte von NTproBNP, CTproET-1 und MRproADM wird deutlich, dass signifikante Zusammenhänge zum Endpunkt nach einer Adjustierung für andere Biomarker schlussendlich verloren gehen. Lediglich für NTproBNP besteht im multivariaten Cox-Regressionsmodell weiterhin eine signifikante Korrelation $(p=0,014)$, obwohl einzeln betrachtet auch CTproAVP, CTproET-1, MRproANP, MRproADM, NTproANP und PIIINP signifikant mit dem Endpunkt der Studie zusammenhängen. In einer schrittweisen Regressionsanalyse (Daten nicht gezeigt) stellte sich heraus, dass es Zufall ist, welcher Biomarker im Modell bleibt und schließlich signifikant mit dem Endpunkt korreliert. Erklärbar sind diese Beobachtungen dadurch, dass die Biomarker keine unabhängigen, sondern teilweise überschneidende, biologische bzw. prognostische Informationen enthalten. Die Korrektur der Regressionsmodelle nach ähnlichen Informationen führt insbesondere bei prognostisch schwächeren Biomarkern 
dazu, dass die übrigen Informationen nicht mehr ausreichen, um einen signifikanten Zusammenhang zum kombinierten Endpunkt herzustellen. Um mögliche Korrelationen und Überschneidungen der untersuchten Biomarker festzustellen, wurde eine Korrelations-analyse durchgeführt (siehe '3.2.7 Korrelationsanalyse der Biomarker', S. 55). Dass das oben genannte Problem in anderen Studien nur selten oder gar nicht thematisiert wird, liegt an der Tatsache, dass insgesamt nur wenige Multimarker-Studien zur Prognosekraft existieren und eine Adjustierung aufgrund fehlender oder unvollständiger Daten nicht durchgeführt werden kann. Lediglich Masson et al. (2010a) können für einige Biomarker vergleichbare Daten aus einer Korrelationsanalyse liefern.

Die beiden natriuretischen Peptide ANP und BNP zeigen viele Gemeinsamkeiten wie beispielsweise einen sehr ähnlichen Sekretionsmechanismus und nahezu identische Funktion. Sie stellen zentrale Biomarker des Herzens dar und die Fragmente ihrer Propeptide NTproBNP und MRproANP korrelieren entsprechend stark miteinander $(0,71$ bzw. 0,77). Ebenfalls hoch ist die Korrelation zu MRproADM (0,33 bzw. 0,44), die sich möglicherweise durch ähnliche Sekretionsmechanismen bzw. Sekretionsstimuli und überschneidende Funktionen erklären lässt. Masson et al. (2010a) zeigen insgesamt stärkere Korrelationen, aber ähnliche Verhältnisse für NTproBNP und MRproANP $(0,83)$. Bei innen korreliert CTproET-1 $(0,56)$ im Vergleich zu MRproADM $(0,52)$ minimal stärker mit NTproBNP. Diese Beobachtungen zeigen mit der Korrelationsanalyse dieser Arbeit, dass CTproET-1 und MRproADM aufgrund der Überschneidungen mit NTproBNP höhere prognostische Wertigkeit besitzen als andere Biomarker, die es nicht bis in multivariate Regressionsmodelle für NTproBNP geschafft haben. Ebenso zeigt sich mit der hohen Korrelation zu NTproBNP der Grund, warum beide Biomarker einer Korrektur für NTproBNP bzw. 'NTproBNP und Alter' nicht mehr standhielten. PIIINP korreliert in vorliegender Arbeit zwar ebenfalls signifikant mit NTproBNP, allerdings ist dieser Zusammenhang schwach $(0,10$ bzw. 0,15$)$ und die Überschneidung von prognostischen Informationen gering. Beide Marker hängen zwar pathophysiologisch mit der HFpEF und dem Endpunkt der Studie zusammen, sprechen jedoch gänzlich verschiedene biologische Aspekte an. PIIINP stellt als Vertreter des Kollagen-III-Stoffwechsels andere prognostische Informationen zur Verfügung, was wahrscheinlich auch für den Entzündungsmarker hsCRP gelten würde, der sich allerdings bereits im univariaten CoxRegressionsmodell als offenbar ungeeigneter Faktor herausstellte. PIIINP zeigt auch zu anderen Biomarkern wie CTproET-1 $(0,17$ bzw. 0,20) und MRproADM (0,16 bzw. 0,20) nur schwache Korrelationen. Die beiden letztgenannten Biomarker korrelieren hingegen stark miteinander (0,69 bzw. 0,73), was auch Masson et al. (2010a) bestätigen $(0,72)$. Insgesamt lassen sich NTproBNP und MRproANP als kardial gesehen zentrale und PIIINP, CTproET-1, CTproAVP und MRproADM als periphere Biomarker der DD/HFpEF 
verstehen. In der anschließenden Hauptkomponentenanalyse werden zwei in sich ähnliche aber untereinander wenig überschneidende, prognostische Informationskomplexe aufgefasst und der prognostische Beitrag der einzelnen Biomarker in ebendiese dargestellt. Demzufolge wird Faktor A maßgeblich von NTproBNP $(0,474)$ und MRproANP $(0,462)$ bestimmt, die nach der durchgeführten Korrelationsanalyse stark miteinander korrelieren. MRproADM $(0,143)$ und CTproET-1 $(0,103)$ tragen auch Informationen zu diesem Faktor bei, wenngleich das Ausmaß deutlich gering ist. Faktor B wird umgekehrt zu fast gleichen Anteilen aus den Informationen von CTproAVP $(0,591)$, CTproET-1 $(0,340)$ und MRproADM $(0,333)$ gebildet. PIIINP leistet aus oben genannten Gründen einen etwas geringeren Beitrag (0,310).

\subsection{Finales Modell und klinische Schlussfolgerung}

Die vorausgegangenen Analysen zeigen, dass es insgesamt sinnvoll erscheint, nicht den Zusammenhang jedes Biomarkers einzeln, sondern den Zusammenhang zwischen Faktoren zum kombinierten Endpunkt aus Mortalität und CV-Hospitalisation zu betrachten, damit überschneidende Informationen der Biomarker das Regressionsmodell nicht zerstören. Diese Problematik besteht bei der Betrachtung von Faktoren nicht mehr, da Biomarker mit ähnlichen Informationen entsprechend stark zum selben Faktor beitragen und sich nicht gegenseitig behindern. Das finale Cox-Regressionsmodell greift ebenfalls auf logarithmierte Biomarker-Konzentrationen zurück. Es wird schließlich nach Alter, KHK, Diabetes mellitus, HI-Symptomen und Zeichen, Anämie, renaler Dysfunktion, LAVI und E/e' adjustiert, was den Zusammenhang unabhängig von entsprechenden Variablen macht. Die HRs sind daher unabhängig vom Vorliegen einer HI und gelten für das gesamte Kollektiv der DIAST-CHF-Studie also auch für Patienten mit Risikofaktoren ohne HFpEF. Für Faktor A ist das Risiko etwas höher (HR 1,31; 95 \% Cl; 1,07 - 1,59; $p=0,007)$ als für Faktor B (HR 1,23; $95 \% C l ; 1,03-1,46 ; p=0,02)$. Das bedeutet, dass bei einer Konzentrationserhöhung der zentralen Biomarker NTproBNP und MRproANP ein höheres Risiko für Mortalität und CV-Hospitalisation vorliegt als bei einer Erhöhung der peripheren Biomarker CTproAVP, MRproADM, CTproET-1 oder PIIINP, was auch den pathophysiologisch näheren Zusammenhang von NTproBNP und MRproANP unterstreicht. Da bislang keine Multimarker-Studien zur Prognosekraft bei DD und HFpEF exisiterien, lassen sich die Ergebnisse dieses Modells leider nicht mit anderen Studien vergleichen.

Insgesamt zeigt diese Arbeit, dass im Kollektiv der DIAST-CHF-Studie bei allen Biomarkern außer Aldosteron, hsCRP und Renin einzeln betrachtet ein signifikanter Zusammenhang zu Mortalität und CV-Hospitalisation bestand und dass es starke 
Korrelationen der Biomarker untereinander gibt. NTproBNP, CTproET-1, MRproADM und MRproANP korrelieren hochsignifikant $(p>0,001)$ und PIIINP $(p=0,005)$ und CTproAVP $(p=0,008)$ jeweils signifikant im univariaten Cox-Regressionsmodell. Das $\mathrm{N}$-terminale Fragment von proANP sollte aufgrund des beschriebenen Abbaus und der Überlegenheit von MRproANP nicht bestimmt werden. Es zeigt sich weiterhin, dass eine Erhöhung der zentralen Biomarker NTproBNP und MRproANP das Risiko stärker erhöht als eine Erhöhung der peripheren Biomarker CTproAVP, CTproET-1, MRproADM und PIIINP. Im klinischen Alltag macht es aus praktikablen und wirtschaftlichen Gründen wenig Sinn, alle hier untersuchten Biomarker zur Prognoseabschätzung zu bestimmen. Bei der Bestimmung eines einzelnen Biomarkers eignet sich wie zu erwarten NTproBNP. Werden mehrere Biomarker ermittelt, so ist eine Bestimmung der zentralen Peptide NTproBNP und MRproANP sinnvoll. Um diese Aussage zu bestätigen, sollten weitere MultimarkerStudien an möglichst großen Kollektiven durchgeführt werden.

\subsection{Limitierung der Arbeit}

Diese Arbeit ist nach dem derzeitigen Wissensstand die erste, die sich gleichzeitig mit der Prognosekraft mehrerer Biomarker in einem Kollektiv aus HFpEF- und Risikopatienten befasst. Das Kollektiv kann trotz stellenweiser Reduktion in den Regressionsmodellen durch fehlende Daten der Nachbeobachtungsphase als vergleichsweise große Untersuchungsgruppe angesehen werden und wird lediglich von den I-PRESERVESubstudien von Anand et al. (2011) und Komajda et al. (2011) zur Prognosekraft von NTproBNP übertroffen. Viele der weiteren Biomarker wurden bislang in keiner Studie betrachtet.

Die Art der Rekrutierung für DIAST-CHF kann als Vor- und Nachteil gesehen werden. Da die Patienten nicht aufgrund von HI-Symptomen zur Erstuntersuchung eingeladen, sondern anhand von Risikofaktoren ausgewählt wurden, handelt es sich zwar um ein breit gefächertes Kollektiv, welches dem klinischen Alltag entspricht, allerdings werden somit auch Patienten ohne $\mathrm{HI}$ und Symptome (NYHA-Klasse I) eingeschlossen, was in vergleichbaren Studien oftmals als Ausschlusskriterium gilt. Dadurch kommt es in dieser Arbeit zu einer ungleichen Verteilung innerhalb der NTproBNP-Untergruppen. So macht Gruppe [1] ungefähr $57 \%$ des Kollektivs aus und nur $37 \%$ von innen leiden unter Symptomen.

Bei der Diagnostizierung der DD wurde zwar auf generell akzeptierte, echokardiographische Verfahren zurückgegriffen, invasive Methoden gelten aber weiterhin als Goldstandard zur Diagnose der DD (Zile et al. 2004). Eine Verwendung ist jedoch aus ethischen, finanziellen und praktikablen Gründen gerade bei größeren Studien nicht 
sinnvoll. Die Diagnose einer HI wurde bei DIAST-CHF anhand der Framingham-Kriterien gestellt (McKee et al. 1971). Insgesamt weichen die Diagnosegrundlagen wie bei vielen HFpEF-Studien von aktuellen Empfehlungen von Paulus et al. (2007) und den ESCGuidelines 2012 (McMurray et al. 2012) ab, was an der unklaren Situation insgesamt und den sich häufig ändernden Richtlinien liegt. Eine Vergleichbarkeit der Studien wird hierdurch fast immer erschwert.

Ein weiterer limitierender Faktor mit dem sich auch die übrigen Studien auseinandersetzen müssen, ist die Tatsache, dass einige Biomarker-Konzentrationen nicht nur durch die $\mathrm{HI}$ beeinflusst, sondern auch durch Komorbiditäten und temporäre Erkrankungen moduliert werden. Komorbiditäten wie Diabetes mellitus spielen insbesondere in der Pathophysiologie der HFpEF eine Rolle und können möglicherweise die Prognosekraft diverser Biomarker stark beeinflussen. Ein Ausschluss von Patienten mit bestimmten Vorerkrankungen bzw. striktere Einschlusskriterien führen jedoch zu einem vorselektieren und nicht-repräsentativen Kollektiv, welches ebenso unerwünscht ist.

Für zukünftige Studien ist nicht nur ein geeignet großes Kollektiv, sondern auch die korrekte Diagnostizierung von DD und HFpEF nach möglichst aktuellen Richtlinien von großer Wichtigkeit. Die Betrachtung von Mehrfachmessungen im Nachbeobachtungszeitraum statt einer einmaligen Baseline-Messung, die sich bei Masson et al. (2010a) für MRproANP in einem HFrEF-Kollektiv als überlegen herausstellte, ist ein interessanter Aspekt, der auch bei DD und HFpEF zu prognostisch höherwertigen Informationen führen könnte. 


\section{Zusammenfassung}

Die $\mathrm{HI}$ stellt ein global größer werdendes Problem der Medizin dar. Insbesondere die Ausprägungsform mit erhaltener Ejektionsfraktion (HFpEF) macht mittlerweile ungefähr $50 \%$ der herzinsuffizienten Patienten aus.

Obwohl die Prognoseabschätzung generell von hoher Wichtigkeit ist, um die Behandlung von Patienten $\mathrm{zu}$ individualisieren und sie hinsichtlich medizinischer Therapien oder späterer Pflege aufzuklären, sind Faktoren, die mit der Mortalität bei DD und HFpEF korrelieren und diese im Umkehrschluss realistisch vorhersagen können, weitgehend unerforscht und allgemeine Richtlinien zur Prognosefindung existieren nicht. Die Objektivität von Biomarkern kann hier von großem Nutzen sein. Entsprechende Studien sind allerdings rar und beziehen sich zum Großteil auf das Fragment NTproBNP, dessen prognostische Wertigkeit bereits für HFrEF unbestritten ist. Die vorliegende Arbeit untersucht daher die Prognosekraft von zehn verschiedenen Biomarkern aus unterschiedlichen Bereichen der Pathophysiologie von DD und HFpEF in einem Kollektiv der prospektiven multizentrischen Zwei-Kohortenstudie 'DIAST-CHF' über einen Nachbeobachtungszeitraum von 5,2 Jahren, um Zusammenhänge mit dem kombinierten Endpunkt aus Mortalität und CV-Hospitalisation aufzuzeigen und herauszufinden, ob und welche Biomarker, einzeln oder in Kombination, positiv zur Prognosefindung beitragen können.

Das Kollektiv dieser Arbeit besteht aus 1484 Patienten, die anhand der BaselineNTproBNP-Konzentration in drei Untergruppen eingeteilt wurden. Es liegt ein durchschnittliches Alter von 66,8 Jahren und mit $51 \%$ eine leichte Überzahl des weiblichen Geschlechts vor.

Die mittleren Konzentrationen der Biomarker betragen im gesamten Kollektiv: Aldosteron 70,3 pg/ml, CTproAVP 3,94 pmol/l, CTproET-1 54,9 nmol/l, hsCRP 1,80 mg/l, MRproADM 0,574 nmol/l, MRproANP 88,3 pmol/l, NTproANP 3925 pmol/l, NTproBNP 103 pg/ml, PIIINP 3,28 $\mu \mathrm{g} / \mathrm{l}$ und Plasma-Renin 17,1 $\mu \mathrm{lU} / \mathrm{ml}$. Aufgrund der teilweise starken Streuung der Konzentrationen, wurden diese für die Cox-Regressionsmodelle logarithmiert.

In univariaten Cox-Regressionsmodellen zeigen sich für logNTproBNP (HR 1,66), logCTproET-1 (HR 1,69), logMRproADM (HR 1,62) und logMRproANP (HR 1,53) jeweils hochsignifikante $(p<0,001)$ und für logNTproANP (HR 1,24; $p=0,019)$, logPIIINP (HR $1,18 ; p=0,005)$ und logCTproAVP (HR 1,23; $p=0,008)$ signifikante Korrelationen zum Endpunkt. Für Aldosteron, hsCRP und Renin besteht in diesem Kollektiv kein signifikanter Zusammenhang zur Mortalität und CV-Hospitalisationen $(p=0,256-0,753)$. Sie wurden daher in weiteren Analysen nicht betrachtet. Im nachfolgenden Regressionsmodell wurde 
der Zusammenhang zwischen den zuvor signifikant korrelierenden Biomarkern und dem Endpunkt bei gleichzeitiger Berücksichtigung des Einflusses von NTproBNP auf ebendiesen untersucht. Nur CTproET-1 (HR 1,45; $p<0,001$ ) und MRproADM (HR 1,42; $p<0,001)$ zeigen weiterhin signifikante Zusammenhänge und werden in multivariaten Cox-Regressionsmodellen mit gegenseitiger Adjustierung analysiert. Dieser Adjustierung halten nur logNTproBNP (HR 1,39; $p=0,001$ ) und logMRproADM (HR 1,26; $p=0,049$ ) stand, wobei nach zusätzlicher Korrektur für das Alter der Patienten lediglich für logNTproBNP ein signifikanter Zusammenhang zum kombinierten Endpunkt bestehen bleibt (HR 1,28; $p=0,014)$. Der Grund für diese Beobachtung liegt in der Korrelation der Biomarker untereinander und der Tatsache, dass sie überschneidende prognostische Informationen bereitstellen. Die Korrektur der Regressionsmodelle nach ähnlichen Informationen führt dazu, dass die übrigen Informationen nicht mehr ausreichen, um einen signifikanten Zusammenhang herzustellen. Es ist daher sinnvoll nicht den Zusammenhang jedes Biomarkers einzeln, sondern den Zusammenhang zwischen Faktoren mit überschneidenden Informationen und dem Endpunkt zu betrachten. Im finalen Regressionsmodell wird daher der Zusammenhang zweier Faktoren A und B zum kombinierten Endpunkt untersucht. Faktor $A$ wird vorrangig aus den Informationen der kardial-zentralen Biomarker NTproBNP und MRproANP gebildet, während sich Faktor B aus den peripheren Biomarkern CTproAVP, CTproET-1, MRproADM und PIIINP zusammensetzt. Beide Faktoren korrelieren trotz multivariater Adjustierung signifikant mit dem Endpunkt. Ist die Konzentration der zentralen Biomarker erhöht, besteht ein höheres Risiko (Faktor A: HR 1,31; $95 \% \mathrm{Cl} ; 1,07-1,59 ; \mathrm{p}=0,007$ ) für Mortalität und CVHospitalisation als bei Erhöhung der Konzentration peripherer Biomarker (Faktor B: HR $1,23 ; 95 \% \mathrm{Cl} ; 1,03-1,46 ; \mathrm{p}=0,02)$.

Diese Arbeit zeigt, dass in einem Kollektiv aus HFpEF- und Risikopatienten alle betrachteten Biomarker außer hsCRP, Aldosteron und Renin einzeln betrachtet mit dem kombinierten Endpunkt zusammenhängen und dass es starke Korrelationen der Biomarker untereinander gibt. Eine Erhöhung der zentralen Biomarker NTproBNP und MRproANP erhöht das Risiko stärker als die Erhöhung der peripheren Biomarker. Zur Prognoseabschätzung eignet sich bei der Bestimmung eines einzelnen Biomarkers aufgrund seiner unerreichten Wertigkeit und Unabhängigkeit NTproBNP. Werden mehrere Biomarker bestimmt, macht es Sinn, die zentralen Peptide NTproBNP und MRproANP zu ermitteln. Um diese Aussagen zu bestätigen, sollten weitere Multimarker-Studien an möglichst großen und nach aktuellen Richtlinien diagnostizierten DD- und HFpEFKollektiven durchgeführt werden. 


\section{Literaturverzeichnis}

Adlbrecht C, Hülsmann M, Strunk G, Berger R, Mörtl D, Struck J, Morgenthaler NG, Bergmann A, Jakowitsch J, Maurer G (2009): Prognostic value of plasma midregional proadrenomedullin and C-terminal-pro-endothelin-1 in chronic heart failure outpatients. Eur $\mathrm{J}$ Heart Fail 11, 361-366

Ahmed SH, Clark LL, Pennington WR, Webb CS, Bonnema DD, Leonardi AH, McClure CD, Spinale FG, Zile MR (2006): Matrix metalloproteinases/tissue inhibitors of metalloproteinases: relationship between changes in proteolytic determinants of matrix composition and structural, functional, and clinical manifestations of hypertensive heart disease. Circulation 113, 2089-2096

Ala-Kopsala M, Magga J, Peuhkurinen K, Leipälä J, Ruskoaho H, Leppäluoto J, Vuolteenaho O (2004): Molecular heterogeneity has a major impact on the measurement of circulating $\mathrm{N}$-terminal fragments of $\mathrm{A}$ - and $\mathrm{B}$-type natriuretic peptides. Clin Chem $\underline{50}$, 1576-1588

Anand IS, Latini R, Florea VG, Kuskowski MA, Rector T, Masson S, Signorini S, Mocarelli P, Hester A, Glazer R (2005): C-reactive protein in heart failure: prognostic value and the effect of valsartan. Circulation 112, 1428-1434

Anand IS, Rector TS, Cleland JG, Kuskowski M, McKelvie RS, Persson H, McMurray JJ, Zile MR, Komajda M, Massie BM (2011): Prognostic value of baseline plasma aminoterminal pro-brain natriuretic peptide and its interactions with irbesartan treatment effects in patients with heart failure and preserved ejection fraction: findings from the IPRESERVE trial. Circ Heart Fail $\underline{4}$, 569-577

Anker SD, von Haehling S (2004): Inflammatory mediators in chronic heart failure: an overview. Heart $\underline{90}, 464-470$

Arslan S, Erol MK, Gundogdu F, Sevimli S, Aksakal E, Senocak H, Alp N (2007): Prognostic value of 6-minute walk test in stable outpatients with heart failure. Tex Heart Inst J 34, 166-169

Baicu CF, Li J, Zhang Y, Kasiganesan H, Cooper G, Zile MR, Bradshaw AD (2012): Time course of right ventricular pressure-overload induced myocardial fibrosis: relationship to changes in fibroblast postsynthetic procollagen processing. Am $\mathrm{J}$ Physiol Heart Circ Physiol $\underline{303}, \mathrm{H} 1128-1134$ 
Bakris GL, Fairbanks R, Traish AM (1991): Arginine vasopressin stimulates human mesangial cell production of endothelin. J Clin Invest $\underline{87}, 1158-1164$

Balling L, Kistorp C, Schou M, Egstrup M, Gustafsson I, Goetze JP, Hildebrandt P, Gustafsson F (2012): Plasma copeptin levels and prediction of outcome in heart failure outpatients: relation to hyponatremia and loop diuretic doses. J Card Fail 18, 351-358

Barasch E, Gottdiener JS, Aurigemma G, Kitzman DW, Han J, Kop WJ, Tracy RP (2009): Association between elevated fibrosis markers and heart failure in the elderly: the cardiovascular health study. Circ Heart Fail 2 , 303-310

Barasch E, Gottdiener JS, Aurigemma G, Kitzman DW, Han J, Kop WJ, Tracy RP (2011): The relationship between serum markers of collagen turnover and cardiovascular outcome in the elderly: the Cardiovascular Health Study. Circ Heart Fail $\underline{4}$, 733-739

Barton M, Shaw S, d'Uscio LV, Moreau P, Lüscher TF (1997): Angiotensin II increases vascular and renal endothelin-1 and functional endothelin converting enzyme activity in vivo: role of ETA receptors for endothelin regulation. Biochem Biophys Res Commun $\underline{238}$, 861-865

Bavishi C, Ather S, Bambhroliya A, Jneid H, Virani SS, Bozkurt B, Deswal A (2014): Prognostic significance of hyponatremia among ambulatory patients with heart failure and preserved and reduced ejection fractions. Am J Cardiol 113, 1834-1838

Bełtowski J, Jamroz A (2004): Adrenomedullin--what do we know 10 years since its discovery? Pol J Pharmacol $\underline{56}, 5-27$

Berry C, Doughty RN, Granger C, Køber L, Massie B, McAlister F, McMurray J, Pocock S, Poppe K, Swedberg K (2012): The survival of patients with heart failure with preserved or reduced left ventricular ejection fraction: an individual patient data meta-analysis. Eur Heart J $\underline{33}, 1750-1757$

Bettencourt P, Azevedo A, Fonseca L, Araújo JP, Ferreira S, Almeida R, RochaGoncalves F, Ferreira A (2007): Prognosis of decompensated heart failure patients with preserved systolic function is predicted by NT-proBNP variations during hospitalization. Int J Cardiol 117, 75-79

Bishu K, Deswal A, Chen HH, LeWinter MM, Lewis GD, Semigran MJ, Borlaug BA, McNulty S, Hernandez AF, Braunwald E (2012): Biomarkers in acutely decompensated heart failure with preserved or reduced ejection fraction. Am Heart J $\underline{164}, 763-770$ 
Borbély A, Papp Z, Edes I, Paulus WJ (2009): Molecular determinants of heart failure with normal left ventricular ejection fraction. Pharmacol Rep $\underline{61}, 139-145$

Borlaug BA (2014): The pathophysiology of heart failure with preserved ejection fraction. Nature reviews. Cardiology $11,507-515$

Borlaug BA, Kass DA (2006): Mechanisms of diastolic dysfunction in heart failure. Trends Cardiovasc Med 16, 273-279

Borlaug BA, Paulus WJ (2011): Heart failure with preserved ejection fraction: pathophysiology, diagnosis, and treatment. Eur Heart J $\underline{32}, 670-679$

Borlaug BA, Lam, Carolyn S P, Roger VL, Rodeheffer RJ, Redfield MM (2009): Contractility and ventricular systolic stiffening in hypertensive heart disease insights into the pathogenesis of heart failure with preserved ejection fraction. J Am Coll Cardiol $\underline{54}$, 410-418

Borlaug BA, Olson TP, Lam, Carolyn S P, Flood KS, Lerman A, Johnson BD, Redfield MM (2010): Global cardiovascular reserve dysfunction in heart failure with preserved ejection fraction. J Am Coll Cardiol $\underline{56}$, 845-854

Borlaug BA, Redfield MM, Melenovsky V, Kane GC, Karon BL, Jacobsen SJ, Rodeheffer RJ (2013): Longitudinal changes in left ventricular stiffness: a community-based study. Circ Heart Fail $\underline{6}$, 944-952

Boxer R, Kleppinger A, Ahmad A, Annis K, Hager D, Kenny A (2010): The 6-minute walk is associated with frailty and predicts mortality in older adults with heart failure. Congest Heart Fail 16, 208-213

Brunner F, Stessel H, Watzinger N, Löffler BM, Opie LH (1995): Binding of endothelin to plasma proteins and tissue receptors: effects on endothelin determination, vasoactivity, and tissue kinetics. FEBS Lett $\underline{373}, 97-101$

Buckley MG, Marcus NJ, Yacoub MH (1999): Cardiac peptide stability, aprotinin and room temperature: importance for assessing cardiac function in clinical practice. Clin Sci (Lond) 97, 689-695

Bühler FR, Laragh JH, Baer L, Vaughan ED, Brunner HR (1972): Propranolol inhibition of renin secretion. A specific approach to diagnosis and treatment of renin-dependent hypertensive diseases. N Engl J Med 287, 1209-1214 
Campbell DJ, Nussberger J, Stowasser M, Danser AH, Morganti A, Frandsen E, Ménard J (2009): Activity assays and immunoassays for plasma Renin and prorenin: information provided and precautions necessary for accurate measurement. Clin Chem 55, 867-877

Carrick-Ranson G, Hastings JL, Bhella PS, Shibata S, Fujimoto N, Palmer MD, Boyd K, Levine BD (2012): Effect of healthy aging on left ventricular relaxation and diastolic suction. Am J Physiol Heart Circ Physiol 303, H315-322

Castell JV, Gómez-Lechón MJ, David M, Fabra R, Trullenque R, Heinrich PC (1990): Acute-phase response of human hepatocytes: regulation of acute-phase protein synthesis by interleukin-6. Hepatology $\underline{12}, 1179-1186$

Chang Y, Chen A, Wu X, Hsu T, Liu LD, Chen Y, Wu Y, Lin H, Hsu R, Lee C (2014): Comparison the prognostic value of galectin-3 and serum markers of cardiac extracellular matrix turnover in patients with chronic systolic heart failure. Int J Med Sci 11, 1098-1106

Cheng CP, Noda T, Nozawa T, Little WC (1993): Effect of heart failure on the mechanism of exercise-induced augmentation of mitral valve flow. Circ Res $\underline{72}, 795-806$

Cicoira M, Rossi A, Bonapace S, Zanolla L, Golia G, Franceschini L, Caruso B, Marino PN, Zardini P (2004): Independent and additional prognostic value of aminoterminal propeptide of type III procollagen circulating levels in patients with chronic heart failure. $J$ Card Fail $\underline{10}, 403-411$

Cleland JG, Ward S, Dutka D, Habib F, Impallomeni M, Morton IJ (1996): Stability of plasma concentrations of $\mathrm{N}$ and $\mathrm{C}$ terminal atrial natriuretic peptides at room temperature. Heart $\underline{75}, 410-413$

Cleland JG, Taylor J, Tendera M (2007): Prognosis in heart failure with a normal ejection fraction. N Engl J Med 357, 829-830

Cleland JG, McMurray JJ, Kjekshus J, Cornel JH, Dunselman P, Fonseca C, Hjalmarson A, Korewicki J, Lindberg M, Ranjith N (2009): Plasma concentration of amino-terminal probrain natriuretic peptide in chronic heart failure: prediction of cardiovascular events and interaction with the effects of rosuvastatin: a report from CORONA (Controlled Rosuvastatin Multinational Trial in Heart Failure). J Am Coll Cardiol 54, 1850-1859

Cleland JG, Taylor J, Freemantle N, Goode KM, Rigby AS, Tendera M (2012): Relationship between plasma concentrations of $\mathrm{N}$-terminal pro brain natriuretic peptide and the characteristics and outcome of patients with a clinical diagnosis of diastolic heart failure: a report from the PEP-CHF study. Eur J Heart Fail 14, 487-494 
Cody RJ, Atlas SA, Laragh JH, Kubo SH, Covit AB, Ryman KS, Shaknovich A, Pondolfino K, Clark M, Camargo MJ (1986): Atrial natriuretic factor in normal subjects and heart failure patients. Plasma levels and renal, hormonal, and hemodynamic responses to peptide infusion. J Clin Invest $\underline{78}, 1362-1374$

Collier P, Watson CJ, Voon V, Phelan D, Jan A, Mak G, Martos R, Baugh JA, Ledwidge MT, McDonald KM (2011): Can emerging biomarkers of myocardial remodelling identify asymptomatic hypertensive patients at risk for diastolic dysfunction and diastolic heart failure? Eur J Heart Fail 13, 1087-1095

Collinson PO, Barnes SC, Gaze DC, Galasko G, Lahiri A, Senior R (2004): Analytical performance of the $\mathrm{N}$ terminal pro $\mathrm{B}$ type natriuretic peptide (NT-proBNP) assay on the Elecsys 1010 and 2010 analysers. Eur J Heart Fail $\underline{6}$, 365-368

Cotton F, Thiry P, Hsaïn AB, Boeynaems JM (2001): Analyzer transfer of a broad range high-sensitivity C-reactive protein immunoassay. Clin Lab 47, 405-409

Crapo RO, Casaburi R, Coates AL, Enright PL, Macintyre NR, McKay RT, Johnson D, Wanger JS, Zeballos RJ (2002): ATS statement guidelines for the six-minute walk test. ATS statement: guidelines for the six-minute walk test. Am J Respir Crit Care Med $\underline{166}$, $111-117$

D'Amato R, Tomberli B, Castelli G, Spoladore R, Girolami F, Fornaro A, Caldini A, Torricelli F, Camici P, Gensini GF (2013): Prognostic value of N-terminal pro-brain natriuretic Peptide in outpatients with hypertrophic cardiomyopathy. Am J Cardiol $\underline{112}$, 1190-1196

Davies M, Hobbs F, Davis R, Kenkre J, Roalfe AK, Hare R, Wosornu D, Lancashire RJ (2001): Prevalence of left-ventricular systolic dysfunction and heart failure in the Echocardiographic Heart of England Screening study: a population based study. Lancet $\underline{358}, 439-444$

De Bold AJ, Borenstein HB, Veress AT, Sonnenberg H (1981): A rapid and potent natriuretic response to intravenous injection of atrial myocardial extract in rats. Life Sci $\underline{28}$, 89-94

De Bree FM, Burbach JP (1998): Structure-function relationships of the vasopressin prohormone domains. Cell Mol Neurobiol $\underline{18}, 173-191$ 
De Giuli F, Khaw K, Cowie MR, Sutton GC, Ferrari R, Poole-Wilson PA (2005): Incidence and outcome of persons with a clinical diagnosis of heart failure in a general practice population of 696,884 in the United Kingdom. Eur J Heart Fail ㄱ, 295-302

Demers C, McKelvie RS, Negassa A, Yusuf S (2001): Reliability, validity, and responsiveness of the six-minute walk test in patients with heart failure. Am Heart $\mathrm{J} \underline{142}$, 698-703

Deschamps AM, Spinale FG (2006): Pathways of matrix metalloproteinase induction in heart failure: bioactive molecules and transcriptional regulation. Cardiovasc Res $\underline{69}$, 666676

Dong SJ, de las Fuentes L, Brown AL, Waggoner AD, Ewald GA, Dávila-Román VG (2006): N-terminal pro B-type natriuretic peptide levels: correlation with echocardiographically determined left ventricular diastolic function in an ambulatory cohort. J Am Soc Echocardiogr 19, 1017-1025

Dunn FL, Brennan TJ, Nelson AE, Robertson GL (1973): The role of blood osmolality and volume in regulating vasopressin secretion in the rat. J Clin Invest $\underline{52}, 3212-3219$

Eckardt K, Berns JS, Rocco MV, Kasiske BL (2009): Definition and classification of CKD: the debate should be about patient prognosis--a position statement from KDOQI and KDIGO. Am J Kidney Dis $\underline{53}$, 915-920

Eda S, Kaufmann J, Roos W, Pohl S (1998): Development of a new microparticleenhanced turbidimetric assay for C-reactive protein with superior features in analytical sensitivity and dynamic range. J Clin Lab Anal $\underline{12}, 137-144$

Edelmann F, Tomaschitz A, Wachter R, Gelbrich G, Knoke M, Düngen H, Pilz S, Binder L, Stahrenberg R, Schmidt A (2012): Serum aldosterone and its relationship to left ventricular structure and geometry in patients with preserved left ventricular ejection fraction. Eur Heart J $\underline{33}, 203-212$

Elster SK, Braunwald E, Wood HF (1956): A study of C-reactive protein in the serum of patients with congestive heart failure. Am Heart J $\underline{51}, 533-541$

Erbel R, Neumann T, Zeidan Z, Bartel T, Buck T (2002): Echokardiographische Diagnostik der diastolischen Herzinsuffizienz. Herz 27, 99-106

Finucane MM, Stevens GA, Cowan MJ, Danaei G, Lin JK, Paciorek CJ, Singh GM, Gutierrez HR, Lu Y, Bahalim AN (2011): National, regional, and global trends in body- 
mass index since 1980: systematic analysis of health examination surveys and epidemiological studies with 960 country-years and 9.1 million participants. Lancet $\underline{377}$, $557-567$

Fischer M, Baessler A, Hense HW, Hengstenberg C, Muscholl M, Holmer S, Döring A, Broeckel U, Riegger G, Schunkert H (2003): Prevalence of left ventricular diastolic dysfunction in the community. Results from a Doppler echocardiographic-based survey of a population sample. Eur Heart J $\underline{24}, 320-328$

Fleg JL, O'Connor F, Gerstenblith G, Becker LC, Clulow J, Schulman SP, Lakatta EG (1995): Impact of age on the cardiovascular response to dynamic upright exercise in healthy men and women. J Appl Physiol $\underline{78}$, 890-900

Fonarow GC, Peacock WF, Phillips CO, Givertz MM, Lopatin M (2007): Admission B-type natriuretic peptide levels and in-hospital mortality in acute decompensated heart failure. $J$ Am Coll Cardiol $\underline{49}, 1943-1950$

Francis GS, Cohn JN, Johnson G, Rector TS, Goldman S, Simon A (1993): Plasma norepinephrine, plasma renin activity, and congestive heart failure. Relations to survival and the effects of therapy in V-HeFT II. The V-HeFT VA Cooperative Studies Group. Circulation $\underline{87}$, V140-48

Fujimoto N, Hastings JL, Bhella PS, Shibata S, Gandhi NK, Carrick-Ranson G, Palmer D, Levine BD (2012): Effect of ageing on left ventricular compliance and distensibility in healthy sedentary humans. J Physiol (Lond) $\underline{590}, 1871-1880$

Fukuta H, Little WC (2007): Contribution of systolic and diastolic abnormalities to heart failure with a normal and a reduced ejection fraction. Prog Cardiovasc Dis $\underline{49}$, 229-240

Galen FX, Devaux C, Guyenne T, Menard J, Corvol P (1979): Multiple forms of human renin. Purification and characterization. J Biol Chem 254, 4848-4855

Gegenhuber A, Struck J, Dieplinger B, Poelz W, Pacher R, Morgenthaler NG, Bergmann A, Haltmayer M, Mueller T (2007): Comparative evaluation of B-type natriuretic peptide, mid-regional pro-A-type natriuretic peptide, mid-regional pro-adrenomedullin, and Copeptin to predict 1-year mortality in patients with acute destabilized heart failure. J Card Fail $\underline{13}, 42-49$

Girerd N, Pang PS, Swedberg K, Fought A, Kwasny MJ, Subacius H, Konstam MA, Maggioni A, Gheorghiade M, Zannad F (2013): Serum aldosterone is associated with 
mortality and re-hospitalization in patients with reduced ejection fraction hospitalized for acute heart failure: analysis from the EVEREST trial. Eur J Heart Fail 15, 1228-1235

Goldsmith SR, Francis GS, Cowley AW, Levine TB, Cohn JN (1983): Increased plasma arginine vasopressin levels in patients with congestive heart failure. J Am Coll Cardiol 1 , 1385-1390

González A, López B, Querejeta R, Zubillaga E, Echeverría T, Díez J (2010): Filling pressures and collagen metabolism in hypertensive patients with heart failure and normal ejection fraction. Hypertension $\underline{55}, 1418-1424$

Grewal J, McKelvie RS, Persson H, Tait P, Carlsson J, Swedberg K, Ostergren J, Lonn E (2008): Usefulness of $\mathrm{N}$-terminal pro-brain natriuretic Peptide and brain natriuretic peptide to predict cardiovascular outcomes in patients with heart failure and preserved left ventricular ejection fraction. Am J Cardiol 102, 733-737

Guarda E, Katwa LC, Myers PR, Tyagi SC, Weber KT (1993): Effects of endothelins on collagen turnover in cardiac fibroblasts. Cardiovasc Res $\underline{27}, 2130-2134$

Güder G, Bauersachs J, Frantz S, Weismann D, Allolio B, Ertl G, Angermann CE, Störk S (2007): Complementary and incremental mortality risk prediction by cortisol and aldosterone in chronic heart failure. Circulation $\underline{115}, 1754-1761$

Guha K, McDonagh T (2013): Heart failure epidemiology: European perspective. Curr Cardiol Rev $\underline{9}, 123-127$

Gumusel B, Chang JK, Hyman A, Lippton H (1995): Adrenotensin: an ADM gene product with the opposite effects of ADM. Life Sci $\underline{57}$, PL87-90

Guyatt GH, Sullivan MJ, Thompson PJ, Fallen EL, Pugsley SO, Taylor DW, Berman LB (1985): The 6-minute walk: a new measure of exercise capacity in patients with chronic heart failure. Can Med Assoc J 132, 919-923

Haass M, Zugck C, Kübler W (2000): Der 6-Minuten-Gehtest: Eine kostengünstige Alternative zur Spiroergometrie bei Patienten mit chronischer Herzinsuffizienz? Z Kardiol $\underline{89}, 72-80$

Hartter E, Weissel M, Stummvoll HK, Woloszczuk W, Punzengruber C, Ludvik B (1985): Atrial natriuretic peptide concentrations in blood from right atrium in patient with severe right heart failure. Lancet 2 , 93-94 
Heymans S, Schroen B, Vermeersch P, Milting H, Gao F, Kassner A, Gillijns H, Herijgers $P$, Flameng W, Carmeliet $P$ (2005): Increased cardiac expression of tissue inhibitor of metalloproteinase-1 and tissue inhibitor of metalloproteinase-2 is related to cardiac fibrosis and dysfunction in the chronic pressure-overloaded human heart. Circulation $\underline{112}$, 1136-1144

Hidalgo C, Granzier H (2013): Tuning the molecular giant titin through phosphorylation: role in health and disease. Trends Cardiovasc Med 23, 165-171

Ho KK, Pinsky JL, Kannel WB, Levy D (1993): The epidemiology of heart failure: the Framingham Study. J Am Coll Cardiol 22, 6A-13A

Ho Y, Lin Y, Lee C, Hsu R, Ting H, Chou N, Chao C, Wang S, Hsu H, Chen M (2009): Prognostic significance of adipocytokines and extracellular matrix activity in heart failure patients with high B-type natriuretic peptide. Clin Biochem 42, 1407-1412

Hobbs FD, Roalfe AK, Davis RC, Davies MK, Hare R (2007): Prognosis of all-cause heart failure and borderline left ventricular systolic dysfunction: 5 year mortality FollowUp of the Echocardiographic Heart of England Screening Study (ECHOES). Eur Heart J $\underline{28}, 1128-$ 1134

Hogg K, Swedberg K, McMurray J (2004): Heart failure with preserved left ventricular systolic function; epidemiology, clinical characteristics, and prognosis. J Am Coll Cardiol $\underline{43}, 317-327$

Hsueh WA, Goldstone R, Carlson EJ, Horton R (1985): Evidence that the beta-adrenergic system and prostaglandins stimulate renin release through different mechanisms. J Clin Endocrinol Metab 61, 399-403

Ingle L, Cleland JG, Clark AL (2014): The long-term prognostic significance of 6-minute walk test distance in patients with chronic heart failure. Biomed Res Int 2014, ArticleID 505969, 7 pages

Ishiyama Y, Kitamura K, Ichiki Y, Nakamura S, Kida O, Kangawa K, Eto T (1993): Hemodynamic effects of a novel hypotensive peptide, human adrenomedullin, in rats. Eur J Pharmacol 241, 271-273

Isnard R, Pousset F, Trochu J, Chafirovskaïa O, Carayon A, Golmard J, Lechat P, Thomas D, Bouhour J, Komajda M (2000): Prognostic value of neurohormonal activation and cardiopulmonary exercise testing in patients with chronic heart failure. Am J Cardiol $\underline{86}, 417-421$ 
Ito $\mathrm{H}$, Hirata $\mathrm{Y}$, Hiroe M, Tsujino M, Adachi S, Takamoto T, Nitta M, Taniguchi K, Marumo F (1991): Endothelin-1 induces hypertrophy with enhanced expression of muscle-specific genes in cultured neonatal rat cardiomyocytes. Circ Res $\underline{69}, 209-215$

Iwanaga Y, Nishi I, Furuichi S, Noguchi T, Sase K, Kihara Y, Goto Y, Nonogi H (2006): Btype natriuretic peptide strongly reflects diastolic wall stress in patients with chronic heart failure: comparison between systolic and diastolic heart failure. J Am Coll Cardiol $\underline{47}, 742-$ 748

Izumiya Y, Hanatani S, Kimura Y, Takashio S, Yamamoto E, Kusaka H, Tokitsu T, Rokutanda T, Araki S, Tsujita K (2014): Growth differentiation factor-15 is a useful prognostic marker in patients with heart failure with preserved ejection fraction. Can $\mathrm{J}$ Cardiol 30, 338-344

Jankowska EA, Filippatos GS, Haehling S von, Papassotiriou J, Morgenthaler NG, Cicoira M, Schefold JC, Rozentryt P, Ponikowska B, Doehner W (2011): Identification of chronic heart failure patients with a high 12-month mortality risk using biomarkers including plasma C-terminal pro-endothelin-1. PloS One $\underline{6}$, e14506

Jensen LT (1997): The aminoterminal propeptide of type III procollagen. Studies on physiology and pathophysiology. Dan Med Bull 44, 70-78

Jessup M, Brozena S (2003): Heart failure. N Engl J Med 쎤, 2007-2018

Jougasaki M, Rodeheffer RJ, Redfield MM, Yamamoto K, Wei CM, McKinley LJ, Burnett JC (1996): Cardiac secretion of adrenomedullin in human heart failure. J Clin Invest $\underline{97}$, 2370-2376

Karl J, Borgya A, Gallusser A, Huber E, Krueger K, Rollinger W, Schenk J (1999): Development of a novel, N-terminal-proBNP (NT-proBNP) assay with a low detection limit. Scand. J Clin Lab Invest Suppl 230, 177-181

Kawaguchi M, Hay I, Fetics B, Kass DA (2003): Combined ventricular systolic and arterial stiffening in patients with heart failure and preserved ejection fraction: implications for systolic and diastolic reserve limitations. Circulation 107, 714-720

Kennedy RL, Haynes WG, Webb DJ (1993): Endothelins as regulators of growth and function in endocrine tissues. Clin Endocrinol (Oxf) $\underline{39}, 259-265$

Kirk V, Bay M, Parner J, Krogsgaard K, Herzog TM, Boesgaard S, Hassager C, Nielsen OW, Aldershvile J, Nielsen H (2004): N-terminal proBNP and mortality in hospitalised 
patients with heart failure and preserved vs. reduced systolic function: data from the prospective Copenhagen Hospital Heart Failure Study (CHHF). Eur J Heart Fail $\underline{6}$, 335341

Kitamura K, Kangawa K, Kawamoto M, Ichiki Y, Nakamura S, Matsuo H, Eto T (1993): Adrenomedullin: a novel hypotensive peptide isolated from human pheochromocytoma. Biochem Biophys Res Commun 192, 553-560

Kitzman DW, Gardin JM, Gottdiener JS, Arnold A, Boineau R, Aurigemma G, Marino EK, Lyles M, Cushman M, Enright PL (2001): Importance of heart failure with preserved systolic function in patients or $=65$ years of age. CHS Research Group. Cardiovascular Health Study. Am J Cardiol $\underline{87}$, 413-419

Klappacher G, Franzen P, Haab D, Mehrabi M, Binder M, Plesch K, Pacher R, Grimm M, Pribill I, Eichler HG (1995): Measuring extracellular matrix turnover in the serum of patients with idiopathic or ischemic dilated cardiomyopathy and impact on diagnosis and prognosis. Am J Cardiol $\underline{75}, 913-918$

Koller L, Kleber M, Goliasch G, Sulzgruber P, Scharnagl H, Silbernagel G, Grammer T, Delgado G, Tomaschitz A, Pilz S (2014): C-reactive protein predicts mortality in patients referred for coronary angiography and symptoms of heart failure with preserved ejection fraction. Eur J Heart Fail 16, 758-766

Komajda M, Carson PE, Hetzel S, McKelvie R, McMurray J, Ptaszynska A, Zile MR, Demets D, Massie BM (2011): Factors associated with outcome in heart failure with preserved ejection fraction: findings from the Irbesartan in Heart Failure with Preserved Ejection Fraction Study (I-PRESERVE). Circ Heart Fail 4, 27-35

Krum H, Elsik M, Schneider HG, Ptaszynska A, Black M, Carson PE, Komajda M, Massie BM, McKelvie RS, McMurray JJ (2011): Relation of peripheral collagen markers to death and hospitalization in patients with heart failure and preserved ejection fraction: results of the I-PRESERVE collagen substudy. Circ Heart Fail $\underline{4}, 561-568$

Lamblin N, Mouquet F, Hennache B, Dagorn J, Susen S, Bauters C, Groote P de (2005): High-sensitivity C-reactive protein: potential adjunct for risk stratification in patients with stable congestive heart failure. Eur Heart J $\underline{26}, 2245-2250$

Lassus J, Gayat E, Mueller C, Peacock WF, Spinar J, Harjola V, van Kimmenade R, Pathak A, Mueller T, Disomma S (2013): Incremental value of biomarkers to clinical 
variables for mortality prediction in acutely decompensated heart failure: the Multinational Observational Cohort on Acute Heart Failure (MOCA) study. Int J Cardiol 168, 2186-2194

Latini R, Masson S, Anand I, Salio M, Hester A, Judd D, Barlera S, Maggioni AP, Tognoni G, Cohn JN (2004): The comparative prognostic value of plasma neurohormones at baseline in patients with heart failure enrolled in Val-HeFT. Eur Heart J $\underline{25}$, 292-299

Lewis LK, Smith MW, Yandle TG, Richards AM, Nicholls MG (1998): Adrenomedullin(152) measured in human plasma by radioimmunoassay: plasma concentration, adsorption, and storage. Clin Chem $\underline{44}, 571-577$

Li X, Chen C, Gan F, Wang Y, Ding L, Hua W (2014): Plasma NT pro-BNP, hs-CRP and big-ET levels at admission as prognostic markers of survival in hospitalized patients with dilated cardiomyopathy: a single-center cohort study. BMC Cardiovasc Disord 14, 67-75

Libby P, Ridker PM, Maseri A (2002): Inflammation and atherosclerosis. Circulation $\underline{105}$, 1135-1143

Lok DJ, Klip IT, Lok SI, Bruggink-André de la Porte PW, Badings E, van Wijngaarden J, Voors AA, de Boer RA, van Veldhuisen DJ, van der Meer P (2013): Incremental prognostic power of novel biomarkers (growth-differentiation factor-15, high-sensitivity Creactive protein, galectin-3, and high-sensitivity troponin-T) in patients with advanced chronic heart failure. Am J Cardiol 112, 831-837

Maisel A, Mueller C, Nowak R, Peacock WF, Landsberg JW, Ponikowski P, Mockel M, Hogan C, Wu AH, Richards M (2010): Mid-region pro-hormone markers for diagnosis and prognosis in acute dyspnea: results from the $\mathrm{BACH}$ (Biomarkers in Acute Heart Failure) trial. J Am Coll Cardiol $\underline{55}, 2062-2076$

Maisel A, Xue Y, Shah K, Mueller C, Nowak R, Peacock WF, Ponikowski P, Mockel M, Hogan C, Wu AH (2011): Increased 90-day mortality in patients with acute heart failure with elevated copeptin: secondary results from the Biomarkers in Acute Heart Failure (BACH) study. Circ Heart Fail $\underline{4}, 613-620$

Marcus LS, Hart D, Packer M, Yushak M, Medina N, Danziger RS, Heitjan DF, Katz SD (1996): Hemodynamic and renal excretory effects of human brain natriuretic peptide infusion in patients with congestive heart failure. A double-blind, placebo-controlled, randomized crossover trial. Circulation $\underline{94}$, 3184-3189 
Martos R, Baugh J, Ledwidge M, O'Loughlin C, Conlon C, Patle A, Donnelly SC, McDonald K (2007): Diastolic heart failure: evidence of increased myocardial collagen turnover linked to diastolic dysfunction. Circulation 115, 888-895

Martos R, Baugh J, Ledwidge M, O'Loughlin C, Murphy NF, Conlon C, Patle A, Donnelly SC, McDonald K (2009): Diagnosis of heart failure with preserved ejection fraction: improved accuracy with the use of markers of collagen turnover. Eur J Heart Fail 11, 191197

Masson S, Latini R, Anand IS, Barlera S, Angelici L, Vago T, Tognoni G, Cohn JN (2008): Prognostic value of changes in N-terminal pro-brain natriuretic peptide in Val-HeFT (Valsartan Heart Failure Trial). J Am Coll Cardiol 52, 997-1003

Masson S, Latini R, Carbonieri E, Moretti L, Rossi MG, Ciricugno S, Milani V, Marchioli R, Struck J, Bergmann A (2010a): The predictive value of stable precursor fragments of vasoactive peptides in patients with chronic heart failure: data from the GISSI-heart failure (GISSI-HF) trial. Eur J Heart Fail 12, 338-347

Masson S, Solomon S, Angelici L, Latini R, Anand IS, Prescott M, Maggioni AP, Tognoni G, Cohn JN (2010b): Elevated plasma renin activity predicts adverse outcome in chronic heart failure, independently of pharmacologic therapy: data from the Valsartan Heart Failure Trial (Val-HeFT). J Card Fail 16, 964-970

Matsubara J, Sugiyama S, Nozaki T, Sugamura K, Konishi M, Ohba K, Matsuzawa Y, Akiyama E, Yamamoto E, Sakamoto K (2011): Pentraxin 3 is a new inflammatory marker correlated with left ventricular diastolic dysfunction and heart failure with normal ejection fraction. J Am Coll Cardiol $\underline{57}$, 861-869

Matsubara J, Sugiyama S, Nozaki T, Akiyama E, Matsuzawa Y, Kurokawa H, Maeda H, Fujisue K, Sugamura K, Yamamoto E (2014): Incremental prognostic significance of the elevated levels of pentraxin 3 in patients with heart failure with normal left ventricular ejection fraction. J Am Heart Assoc $\underline{3}$, e000928

McKee PA, Castelli WP, McNamara PM, Kannel WB (1971): The natural history of congestive heart failure: the Framingham study. N Engl J Med $\underline{285}, 1441-1446$

McKelvie RS, Komajda M, McMurray J, Zile M, Ptaszynska A, Donovan M, Carson P, Massie BM (2010): Baseline plasma NT-proBNP and clinical characteristics: results from the irbesartan in heart failure with preserved ejection fraction trial. J Card Fail 16, 128-134 
McMurray JJ, Ray SG, Abdullah I, Dargie HJ, Morton JJ (1992): Plasma endothelin in chronic heart failure. Circulation $\underline{85}, 1374-1379$

McMurray JJ, Carson PE, Komajda M, McKelvie R, Zile MR, Ptaszynska A, Staiger C, Donovan JM, Massie BM (2008): Heart failure with preserved ejection fraction: clinical characteristics of 4133 patients enrolled in the I-PRESERVE trial. Eur J Heart Fail $\underline{10}$, 149-156

McMurray JJ, Adamopoulos S, Anker SD, Auricchio A, Böhm M, Dickstein K, Falk V, Filippatos G, Fonseca C, Gomez-Sanchez MA (2012): ESC Guidelines for the diagnosis and treatment of acute and chronic heart failure 2012: The Task Force for the Diagnosis and Treatment of Acute and Chronic Heart Failure 2012 of the European Society of Cardiology. Developed in collaboration with the Heart Failure Association (HFA) of the ESC. Eur Heart J $\underline{33}, 1787-1847$

Meeran K, O'Shea D, Upton PD, Small CJ, Ghatei MA, Byfield PH, Bloom SR (1997): Circulating adrenomedullin does not regulate systemic blood pressure but increases plasma prolactin after intravenous infusion in humans: a pharmacokinetic study. J Clin Endocrinol Metab $\underline{82}, 95-100$

Michowitz Y, Arbel Y, Wexler D, Sheps D, Rogowski O, Shapira I, Berliner S, Keren G, George J, Roth A (2008): Predictive value of high sensitivity CRP in patients with diastolic heart failure. Int J Cardiol $\underline{125}$, 347-351

Miller WL, Hartman KA, Grill DE, Struck J, Bergmann A, Jaffe AS (2012): Serial measurements of midregion proANP and copeptin in ambulatory patients with heart failure: incremental prognostic value of novel biomarkers in heart failure. Heart $\underline{98}, 389$ 394

Milner P, Bodin P, Loesch A, Burnstock G (1990): Rapid release of endothelin and ATP from isolated aortic endothelial cells exposed to increased flow. Biochem Biophys Res Commun $\underline{170}$, 649-656

Missbichler A, Hawa G, Schmal N, Woloszczuk W (2001): Sandwich ELISA for proANP 198 facilitates investigation of left ventricular dysfunction. Eur J Med Res $\underline{6}, 105-111$

Mizuno Y, Yoshimura M, Yasue H, Sakamoto T, Ogawa H, Kugiyama K, Harada E, Nakayama M, Nakamura S, Ito T (2001): Aldosterone production is activated in failing ventricle in humans. Circulation $\underline{103}, 72-77$ 
Moertl D, Berger R, Struck J, Gleiss A, Hammer A, Morgenthaler NG, Bergmann A, Huelsmann M, Pacher R (2009): Comparison of midregional pro-atrial and B-type natriuretic peptides in chronic heart failure: influencing factors, detection of left ventricular systolic dysfunction, and prediction of death. J Am Coll Cardiol $\underline{53}, 1783-1790$

Moravec CS, Reynolds EE, Stewart RW, Bond M (1989): Endothelin is a positive inotropic agent in human and rat heart in vitro. Biochem Biophys Res Commun $\underline{159}, 14-18$

Morgenthaler NG, Struck J, Thomas B, Bergmann A (2004): Immunoluminometric assay for the midregion of pro-atrial natriuretic peptide in human plasma. Clin Chem $\underline{50}, 234$ 236

Morgenthaler NG, Struck J, Alonso C, Bergmann A (2005): Measurement of midregional proadrenomedullin in plasma with an immunoluminometric assay. Clin Chem $\underline{51}, 1823-$ 1829

Morgenthaler NG, Struck J, Alonso C, Bergmann A (2006): Assay for the measurement of copeptin, a stable peptide derived from the precursor of vasopressin. Clin Chem $\underline{52}, 112$ 119

Mueller T, Gegenhuber A, Poelz W, Haltmayer M (2003): Comparison of the Biomedica NT-proBNP enzyme immunoassay and the Roche NT-proBNP chemiluminescence immunoassay: implications for the prediction of symptomatic and asymptomatic structural heart disease. Clin Chem $\underline{49}, 976-979$

Muscholl MW, Schunkert H, Muders F, Elsner D, Kuch B, Hense HW, Riegger GA (1998): Neurohormonal activity and left ventricular geometry in patients with essential arterial hypertension. Am Heart J $\underline{135}, 58-66$

Nathan DM, Turgeon H, Regan S (2007): Relationship between glycated haemoglobin levels and mean glucose levels over time. Diabetologia $\underline{50}, 2239-2244$

Naughton MT (2003): Sleep disorders in patients with congestive heart failure. Curr Opin Pulm Med $\underline{9}, 453-458$

Nelesen RA, Dimsdale JE, Ziegler MG (1992): Plasma atrial natriuretic peptide is unstable under most storage conditions. Circulation $\underline{86}, 463-466$

Neuhold S, Huelsmann M, Strunk G, Stoiser B, Struck J, Morgenthaler NG, Bergmann A, Moertl D, Berger R, Pacher R (2008): Comparison of copeptin, B-type natriuretic peptide, 
and amino-terminal pro-B-type natriuretic peptide in patients with chronic heart failure: prediction of death at different stages of the disease. J Am Coll Cardiol $\underline{52}, 266-272$

Neuhold S, Huelsmann M, Strunk G, Struck J, Adlbrecht C, Gouya G, Elhenicky M, Pacher R (2010): Prognostic value of emerging neurohormones in chronic heart failure during optimization of heart failure-specific therapy. Clin Chem $\underline{56}, 121-126$

Neville SE, Boye KS, Montgomery WS, Iwamoto K, Okamura M, Hayes RP (2009): Diabetes in Japan: a review of disease burden and approaches to treatment. Diabetes Metab Res Rev 25, 705-716

Nishikimi T, Saito Y, Kitamura K, Ishimitsu T, Eto T, Kangawa K, Matsuo H, Omae T, Matsuoka $H$ (1995): Increased plasma levels of adrenomedullin in patients with heart failure. J Am Coll Cardiol 26, 1424-1431

Okuyan E, Uslu A, Cakar MA, Sahin I, Onür I, Enhos A, Biter HI, Cetin S, Dinçkal MH (2010): Homocysteine levels in patients with heart failure with preserved ejection fraction. Cardiology $\underline{117}, 21-27$

Owan TE, Hodge DO, Herges RM, Jacobsen SJ, Roger VL, Redfield MM (2006): Trends in prevalence and outcome of heart failure with preserved ejection fraction. $\mathrm{N}$ Engl $\mathrm{J}$ Med $\underline{355}, 251-259$

Papassotiriou J, Morgenthaler NG, Struck J, Alonso C, Bergmann A (2006): Immunoluminometric assay for measurement of the C-terminal endothelin-1 precursor fragment in human plasma. Clin Chem $\underline{52}, 1144-1151$

Park JJ, Choi D, Yoon C, Oh I, Jeon E, Kim J, Cho M, Chae SC, Ryu K, Yoo B (2014): Prognostic value of $\mathrm{C}$-reactive protein as an inflammatory and $\mathrm{N}$-terminal probrain natriuretic peptide as a neurohumoral marker in acute heart failure (from the Korean Heart Failure registry). Am J Cardiol $\underline{113}, 511-517$

Paulus WJ, Tschöpe C (2013): A novel paradigm for heart failure with preserved ejection fraction: comorbidities drive myocardial dysfunction and remodeling through coronary microvascular endothelial inflammation. J Am Coll Cardiol 62, 263-271

Paulus WJ, Vantrimpont PJ, Shah AM (1994): Acute effects of nitric oxide on left ventricular relaxation and diastolic distensibility in humans. Assessment by bicoronary sodium nitroprusside infusion. Circulation 89, 2070-2078 
Paulus WJ, Tschöpe C, Sanderson JE, Rusconi C, Flachskampf FA, Rademakers FE, Marino P, Smiseth OA, de Keulenaer G, Leite-Moreira AF (2007): How to diagnose diastolic heart failure: a consensus statement on the diagnosis of heart failure with normal left ventricular ejection fraction by the Heart Failure and Echocardiography Associations of the European Society of Cardiology. Eur Heart J $\underline{28}, 2539-2550$

Pearson TA, Mensah GA, Alexander RW, Anderson JL, Cannon RO, Criqui M, Fadl YY, Fortmann SP, Hong Y, Myers GL (2003): Markers of inflammation and cardiovascular disease: application to clinical and public health practice: A statement for healthcare professionals from the Centers for Disease Control and Prevention and the American Heart Association. Circulation 107, 499-511

Phan TT, Abozguia K, Shivu GN, Mahadevan G, Ahmed I, Williams L, Dwivedi G, Patel K, Steendijk P, Ashrafian H (2009a): Heart failure with preserved ejection fraction is characterized by dynamic impairment of active relaxation and contraction of the left ventricle on exercise and associated with myocardial energy deficiency. J Am Coll Cardiol 54, 402-409

Phan TT, Abozguia K, Shivu GN, Ahmed I, Leyva F, Patel K, Frenneaux M (2009b): Increased atrial contribution to left ventricular filling compensates for impaired early filling during exercise in heart failure with preserved ejection fraction. J Card Fail 15, 890-897

Pieske B, Beyermann B, Breu V, Löffler BM, Schlotthauer K, Maier LS, Schmidt-Schweda S, Just H, Hasenfuss G (1999): Functional effects of endothelin and regulation of endothelin receptors in isolated human nonfailing and failing myocardium. Circulation $\underline{99}$, 1802-1809

Pio R, Martinez A, Unsworth EJ, Kowalak JA, Bengoechea JA, Zipfel PF, Elsasser TH, Cuttitta $F$ (2001): Complement factor $\mathrm{H}$ is a serum-binding protein for adrenomedullin, and the resulting complex modulates the bioactivities of both partners. J Biol Chem $\underline{276}$, $12292-12300$

Potocki M, Breidthardt T, Mueller A, Reichlin T, Socrates T, Arenja N, Reiter M, Morgenthaler NG, Bergmann A, Noveanu M (2010): Copeptin and risk stratification in patients with acute dyspnea. Crit Care $\underline{14}, \mathrm{R} 213$

Pousset F, Isnard R, Lechat P, Kalotka H, Carayon A, Maistre G, Escolano S, Thomas D, Komajda M (1997): Prognostic value of plasma endothelin-1 in patients with chronic heart failure. Eur Heart J $\underline{18}, 254-258$ 
Pousset F, Masson F, Chavirovskaia O, Isnard R, Carayon A, Golmard JL, Lechat P, Thomas D, Komajda M (2000): Plasma adrenomedullin, a new independent predictor of prognosis in patients with chronic heart failure. Eur Heart J 21, 1009-1014

Preibisz JJ, Sealey JE, Laragh JH, Cody RJ, Weksler BB (1983): Plasma and platelet vasopressin in essential hypertension and congestive heart failure. Hypertension $\underline{5}$, I129138

Price CP, Trull AK, Berry D, Gorman EG (1987): Development and validation of a particleenhanced turbidimetric immunoassay for C-reactive protein. J Immunol Methods $\underline{99}$, 205211

Radauceanu A, Ducki C, Virion J, Rossignol P, Mallat Z, McMurray J, van Veldhuisen DJ, Tavazzi L, Mann DL, Capiaumont-Vin J (2008): Extracellular matrix turnover and inflammatory markers independently predict functional status and outcome in chronic heart failure. J Card Fail 14, 467-474

Redfield MM, Jacobsen SJ, Burnett JC, Mahoney DW, Bailey KR, Rodeheffer RJ (2003): Burden of systolic and diastolic ventricular dysfunction in the community: appreciating the scope of the heart failure epidemic. JAMA $\underline{289}, 194-202$

Risteli J, Niemi S, Trivedi P, Mäentausta O, Mowat AP, Risteli L (1988): Rapid equilibrium radioimmunoassay for the amino-terminal propeptide of human type III procollagen. Clin Chem $\underline{34}, 715-718$

Robert V, van Thiem N, Cheav SL, Mouas C, Swynghedauw B, Delcayre C (1994): Increased cardiac types I and III collagen mRNAs in aldosterone-salt hypertension. Hypertension $\underline{24}$, 30-36

Rogowski O, Zeltser D, Shapira I, Burke M, Zakut V, Mardi T, Ben-Assayag E, Serov J, Rozenblat M, Berliner S (2004): Gender difference in C-reactive protein concentrations in individuals with atherothrombotic risk factors and apparently healthy ones. Biomarkers $\underline{9}$, 85-92

Rossi A, Cicoira M, Golia G, Zanolla L, Franceschini L, Marino P, Graziani M, Zardini P (2004): Amino-terminal propeptide of type III procollagen is associated with restrictive mitral filling pattern in patients with dilated cardiomyopathy: a possible link between diastolic dysfunction and prognosis. Heart $\underline{90}, 650-654$

Sanderson JE (2007): Heart failure with a normal ejection fraction. Heart $\underline{93}, 155-158$ 
Sanderson JE, Gibson DG, Brown DJ, Goodwin JF (1977): Left ventricular filling in hypertrophic cardiomyopathy. An angiographic study. Br Heart J $\underline{39}, 661-670$

Schrier RW, Abraham WT (1999): Hormones and hemodynamics in heart failure. N Engl J Med $\underline{341}$, 577-585

Schunkert H, Hense HW, Muscholl M, Luchner A, Kürzinger S, Danser AH, Riegger GA (1997): Associations between circulating components of the renin-angiotensin-aldosterone system and left ventricular mass. Heart $\underline{77}, 24-31$

Schwartz F, Hadas E, Harnik M, Solomon B (1990): Enzyme-linked immunosorbent assays for determination of plasma aldosterone using highly specific polyclonal antibodies. J Immunoassay 11, 215-234

Sealey JE, Atlas SA, Laragh JH (1980): Prorenin and other large molecular weight forms of renin. Endocr Rev 1, 365-391

Selvais PL, Robert A, Ahn S, van Linden F, Ketelslegers JM, Pouleur H, Rousseau MF (2000): Direct comparison between endothelin-1, N-terminal proatrial natriuretic factor, and brain natriuretic peptide as prognostic markers of survival in congestive heart failure. J Card Fail $\underline{6}, 201-207$

Seta Y, Shan K, Bozkurt B, Oral H, Mann DL (1996): Basic mechanisms in heart failure: the cytokine hypothesis. J Card Fail 2, 243-249

Shah RV (2007): Endothelins in health and disease. Eur J Intern Med 18, 272-282

Shah RV, Truong QA, Gaggin HK, Pfannkuche J, Hartmann O, Januzzi JL (2012): Midregional pro-atrial natriuretic peptide and pro-adrenomedullin testing for the diagnostic and prognostic evaluation of patients with acute dyspnoea. Eur Heart J $\underline{33}, 2197-2205$

Singh Ranger G (2002): The physiology and emerging roles of antidiuretic hormone. Int J Clin Pract $\underline{56}, 777-782$

Sirviö ML, Metsärinne K, Saijonmaa O, Fyhrquist F (1990): Tissue distribution and half-life of $125 \mathrm{I}$-endothelin in the rat: importance of pulmonary clearance. Biochem Biophys Res Commun 167, 1191-1195

Smith GL, Lichtman JH, Bracken MB, Shlipak MG, Phillips CO, DiCapua P, Krumholz HM (2006): Renal impairment and outcomes in heart failure: systematic review and metaanalysis. J Am Coll Cardiol 47, 1987-1996 
Soufer R, Wohlgelernter D, Vita NA, Amuchestegui M, Sostman HD, Berger HJ, Zaret BL (1985): Intact systolic left ventricular function in clinical congestive heart failure. Am J Cardiol 55, 1032-1036

Stahrenberg R, Edelmann F, Mende M, Kockskämper A, Düngen HD, Scherer M, Kochen MM, Binder L, Herrmann-Lingen C, Schönbrunn L (2010): Association of glucose metabolism with diastolic function along the diabetic continuum. Diabetologia $\underline{53}, 1331-$ 1340

Stoiser B, Mörtl D, Hülsmann M, Berger R, Struck J, Morgenthaler NG, Bergmann A, Pacher $R$ (2006): Copeptin, a fragment of the vasopressin precursor, as a novel predictor of outcome in heart failure. Eur J Clin Invest $\underline{36}, 771-778$

Struck J, Tao C, Morgenthaler NG, Bergmann A (2004): Identification of an Adrenomedullin precursor fragment in plasma of sepsis patients. Peptides $\underline{25}, 1369-1372$

Struck J, Morgenthaler NG, Bergmann A (2005a): Copeptin, a stable peptide derived from the vasopressin precursor, is elevated in serum of sepsis patients. Peptides $\underline{26}, 2500$ 2504

Struck J, Morgenthaler NG, Bergmann A (2005b): Proteolytic processing pattern of the endothelin-1 precursor in vivo. Peptides $\underline{26}, 2482-2486$

Sudoh T, Kangawa K, Minamino N, Matsuo H (1988): A new natriuretic peptide in porcine brain. Nature $\underline{332}, 78-81$

Sugo S, Minamino N, Kangawa K, Miyamoto K, Kitamura K, Sakata J, Eto T, Matsuo H (1994): Endothelial cells actively synthesize and secrete adrenomedullin. Biochem Biophys Res Commun 201, 1160-1166

Swedberg K, Eneroth P, Kjekshus J, Wilhelmsen L (1990): Hormones regulating cardiovascular function in patients with severe congestive heart failure and their relation to mortality. CONSENSUS Trial Study Group. Circulation 82, 1730-1736

Szymanski MK, Damman K, van Veldhuisen, Dirk J, van Gilst, Wiek H, Hillege HL, de Boer, Rudolf $A$ (2011): Prognostic value of renin and prorenin in heart failure patients with decreased kidney function. Am Heart J $\underline{162}, 487-493$

Tahara A, Tomura Y, Wada K, Kusayama T, Tsukada J, Ishii N, Yatsu T, Uchida W, Tanaka A (1998): Effect of YM087, a potent nonpeptide vasopressin antagonist, on 
vasopressin-induced protein synthesis in neonatal rat cardiomyocyte. Cardiovasc Res $\underline{38}$, 198-205

Tan YT, Wenzelburger F, Lee E, Heatlie G, Leyva F, Patel K, Frenneaux M, Sanderson JE (2009): The pathophysiology of heart failure with normal ejection fraction: exercise echocardiography reveals complex abnormalities of both systolic and diastolic ventricular function involving torsion, untwist, and longitudinal motion. J Am Coll Cardiol 54, 36-46

Tan YT, Wenzelburger F, Lee E, Nightingale P, Heatlie G, Leyva F, Sanderson JE (2010): Reduced left atrial function on exercise in patients with heart failure and normal ejection fraction. Heart $\underline{96}, 1017-1023$

Tang WH, Shrestha K, van Lente F, Troughton RW, Martin MG, Borowski AG, Jasper S, Klein AL (2008): Usefulness of C-reactive protein and left ventricular diastolic performance for prognosis in patients with left ventricular systolic heart failure. Am J Cardiol 101, 370373

Tei C, Ling LH, Hodge DO, Bailey KR, Oh JK, Rodeheffer RJ, Tajik AJ, Seward JB (1995): New index of combined systolic and diastolic myocardial performance: a simple and reproducible measure of cardiac function--a study in normals and dilated cardiomyopathy. J Cardiol 26, 357-366

Tschöpe C, Kasner M, Westermann D, Gaub R, Poller WC, Schultheiss H (2005): The role of NT-proBNP in the diagnostics of isolated diastolic dysfunction: correlation with echocardiographic and invasive measurements. Eur Heart J 26, $2277-2284$

Tsutamoto T, Sakai H, Tanaka T, Fujii M, Yamamoto T, Wada A, Ohnishi M, Horie M (2007): Comparison of active renin concentration and plasma renin activity as a prognostic predictor in patients with heart failure. Circ J $\underline{71}, 915-921$

Valle R, Aspromonte N, Feola M, Milli M, Canali C, Giovinazzo P, Carbonieri E, Ceci V, Cerisano S, Barro S (2005): B-type natriuretic peptide can predict the medium-term risk in patients with acute heart failure and preserved systolic function. J Card Fail 11, 498-503

Van Beneden R, Gurné O, Selvais PL, Ahn SA, Robert AR, Ketelslegers J, Pouleur HG, Rousseau MF (2004): Superiority of big endothelin-1 and endothelin-1 over natriuretic peptides in predicting survival in severe congestive heart failure: a 7-year FollowUp study. J Card Fail $\underline{10}$, 490-495 
Van Heerebeek L, Borbély A, Niessen HW, Bronzwaer JG, van der Velden J, Stienen GJ, Linke WA, Laarman GJ, Paulus WJ (2006): Myocardial structure and function differ in systolic and diastolic heart failure. Circulation $\underline{113}, 1966-1973$

Van Heerebeek L, Hamdani N, Falcão-Pires I, Leite-Moreira AF, Begieneman MP, Bronzwaer JG, van der Velden J, Stienen GJ, Laarman GJ, Somsen A (2012): Low myocardial protein kinase $G$ activity in heart failure with preserved ejection fraction. Circulation $\underline{126}$, 830-839

Van Veldhuisen DJ, Linssen GC, Jaarsma T, van Gilst WH, Hoes AW, Tijssen JG, Paulus WJ, Voors AA, Hillege HL (2013): B-type natriuretic peptide and prognosis in heart failure patients with preserved and reduced ejection fraction. J Am Coll Cardiol $\underline{61}, 1498-1506$

Venugopal SK, Devaraj S, Yuhanna I, Shaul P, Jialal I (2002): Demonstration that Creactive protein decreases eNOS expression and bioactivity in human aortic endothelial cells. Circulation $\underline{106}, 1439-1441$

Vergaro G, Emdin M, lervasi A, Zyw L, Gabutti A, Poletti R, Mammini C, Giannoni A, Fontana M, Passino C (2011): Prognostic value of plasma renin activity in heart failure. Am J Cardiol 108, 246-251

Verma S, Li S, Badiwala MV, Weisel RD, Fedak PW, Li R, Dhillon B, Mickle DA (2002): Endothelin antagonism and interleukin- 6 inhibition attenuate the proatherogenic effects of C-reactive protein. Circulation $\underline{105}, 1890-1896$

Volpe M, Francia P, Tocci G, Rubattu S, Cangianiello S, Elena Rao MA, Trimarco B, Condorelli M (2010): Prediction of long-term survival in chronic heart failure by multiple biomarker assessment: a 15-year prospective FollowUp study. Clin Cardiol $\underline{33}, 700-707$

Von Haehling S, Jankowska EA, Morgenthaler NG, Vassanelli C, Zanolla L, Rozentryt P, Filippatos GS, Doehner W, Koehler F, Papassotiriou J (2007): Comparison of midregional pro-atrial natriuretic peptide with $\mathrm{N}$-terminal pro-B-type natriuretic peptide in predicting survival in patients with chronic heart failure. J Am Coll Cardiol $\underline{50}, 1973-1980$

Von Haehling S, Filippatos GS, Papassotiriou J, Cicoira M, Jankowska EA, Doehner W, Rozentryt P, Vassanelli C, Struck J, Banasiak W (2010): Mid-regional pro-adrenomedullin as a novel predictor of mortality in patients with chronic heart failure. Eur $\mathrm{J}$ Heart Fail $\underline{12}$, 484-491

Voors AA, von Haehling S, Anker SD, Hillege HL, Struck J, Hartmann O, Bergmann A, Squire I, van Veldhuisen DJ, Dickstein K (2009): C-terminal provasopressin (copeptin) is a 
strong prognostic marker in patients with heart failure after an acute myocardial infarction: results from the OPTIMAAL study. Eur Heart J $\underline{30}, 1187-1194$

Wachter R, Schmidt-Schweda S, Westermann D, Post H, Edelmann F, Kasner M, Lüers C, Steendijk P, Hasenfuss G, Tschöpe C (2009): Blunted frequency-dependent upregulation of cardiac output is related to impaired relaxation in diastolic heart failure. Eur Heart J $\underline{30}, 3027-3036$

Weber KT (2001): Aldosterone in congestive heart failure. N Engl J Med $\underline{345}, 1689-1697$

Weber KT, Brilla CG (1991): Pathological hypertrophy and cardiac interstitium. Fibrosis and renin-angiotensin-aldosterone system. Circulation $\underline{83}, 1849-1865$

Weitzberg E, Ahlborg G, Lundberg JM (1991): Long-lasting vasoconstriction and efficient regional extraction of endothelin-1 in human splanchnic and renal tissues. Biochem Biophys Res Commun 180, 1298-1303

Westermann D, Kasner M, Steendijk P, Spillmann F, Riad A, Weitmann K, Hoffmann W, Poller W, Pauschinger M, Schultheiss $H$ (2008): Role of left ventricular stiffness in heart failure with normal ejection fraction. Circulation 117, 2051-2060

Windram JD, Loh PH, Rigby AS, Hanning I, Clark AL, Cleland JG (2007): Relationship of high-sensitivity C-reactive protein to prognosis and other prognostic markers in outpatients with heart failure. Am Heart J $\underline{153}, 1048-1055$

Wisniacki N, Taylor W, Lye M, Wilding JP (2005): Insulin resistance and inflammatory activation in older patients with systolic and diastolic heart failure. Heart $\underline{91}, 32-37$

Wohlfahrt P, Redfield MM, Lopez-Jimenez F, Melenovsky V, Kane GC, Rodeheffer RJ, Borlaug BA (2014): Impact of General and Central Adiposity on Ventricular-Arterial Aging in Women and Men. JACC Heart Fail 2, 489-499

Xue Y, Taub P, lqbal N, Fard A, Clopton P, Maisel A (2013): Mid-region proadrenomedullin adds predictive value to clinical predictors and Framingham risk score for long-term mortality in stable outpatients with heart failure. Eur J Heart Fail $\underline{15}, 1343-1349$

Yamamoto T, Kimura T, Ota K, Shoji M, Inoue M, Sato K, Ohta M, Yoshinaga K (1992): Central effects of endothelin-1 on vasopressin release, blood pressure, and renal solute excretion. Am J Physiol 262, E856-862 
Yanagisawa M, Kurihara H, Kimura S, Tomobe Y, Kobayashi M, Mitsui Y, Yazaki Y, Goto K, Masaki T (1988): A novel potent vasoconstrictor peptide produced by vascular endothelial cells. Nature $\underline{332}, 411-415$

Yasue $H$, Yoshimura M, Sumida $H$, Kikuta K, Kugiyama K, Jougasaki M, Ogawa $H$, Okumura K, Mukoyama M, Nakao K (1994): Localization and mechanism of secretion of $B$-type natriuretic peptide in comparison with those of A-type natriuretic peptide in normal subjects and patients with heart failure. Circulation $\underline{90}, 195-203$

Yin W, Chen J, Jen $H$, Chiang M, Huang W, Feng A, Young MS, Lin S (2004): Independent prognostic value of elevated high-sensitivity C-reactive protein in chronic heart failure. Am Heart J 147, 931-938

Yu C, Lin H, Yang H, Kong S, Zhang Q, Lee SW (2002): Progression of systolic abnormalities in patients with "isolated" diastolic heart failure and diastolic dysfunction. Circulation $\underline{105}, 1195-1201$

Yu CM, Cheung BM, Leung R, Wang Q, Lai WH, Lau CP (2001): Increase in plasma adrenomedullin in patients with heart failure characterised by diastolic dysfunction. Heart $\underline{86}, 155-160$

Zannad F, Alla F, Dousset B, Perez A, Pitt B (2000): Limitation of excessive extracellular matrix turnover may contribute to survival benefit of spironolactone therapy in patients with congestive heart failure: insights from the randomized aldactone evaluation study (RALES). Rales Investigators. Circulation 102, 2700-2706

Zhi H, Luptak I, Alreja G, Shi J, Guan J, Metes-Kosik N, Joseph J (2013): Effects of direct Renin inhibition on myocardial fibrosis and cardiac fibroblast function. PLoS One $\underline{8}$, e81612

Zile MR (2003): Heart failure with preserved ejection fraction: is this diastolic heart failure? J Am Coll Cardiol 41, 1519-1522

Zile MR, Brutsaert DL (2002): New concepts in diastolic dysfunction and diastolic heart failure: Part I: diagnosis, prognosis, and measurements of diastolic function. Circulation $\underline{105}, 1387-1393$

Zile MR, Gaasch WH, Carroll JD, Feldman MD, Aurigemma GP, Schaer GL, Ghali JK, Liebson PR (2001): Heart failure with a normal ejection fraction: is measurement of diastolic function necessary to make the diagnosis of diastolic heart failure? Circulation 104, 779-782 
Zile MR, Baicu CF, Gaasch WH (2004): Diastolic heart failure--abnormalities in active relaxation and passive stiffness of the left ventricle. N Engl J Med $\underline{350}, 1953-1959$

Zile MR, Desantis SM, Baicu CF, Stroud RE, Thompson SB, McClure CD, Mehurg SM, Spinale FG (2011a): Plasma biomarkers that reflect determinants of matrix composition identify the presence of left ventricular hypertrophy and diastolic heart failure. Circ Heart Fail $\underline{4}$, 246-256

Zile MR, Gottdiener JS, Hetzel SJ, McMurray JJ, Komajda M, McKelvie R, Baicu CF, Massie BM, Carson PE (2011b): Prevalence and significance of alterations in cardiac structure and function in patients with heart failure and a preserved ejection fraction. Circulation $\underline{124}, 2491-2501$ 


\section{Danksagung}

Mein besonderer Dank gilt zunächst meinem Doktorvater Herrn Prof. Dr. med. Frank Edelmann für die Überlassung des Dissertationsthemas und der stets raschen, geduldigen und unkomplizierten Betreuung während der Datenerhebung und Niederschrift.

Weiterhin gilt mein Dank Frau Doris von Grünhagen für ihr unermüdliches Engagement und ihre Hilfsbereitschaft, Frau Sabine Dreyer für die Unterstützung im Bereich der speziellen Laboranalytik sowie sämtlichen Mitarbeitern der Abteilung Kardiologie und Pneumologie.

Nicht zuletzt danke ich allen Patienten, die an der DIAST-CHF-Studie teilgenommen haben. 


\section{Lebenslauf}

Am 25. Mai 1988 wurde ich, Stefan Gonschior, als Sohn von Hans-Herbert Gonschior und Sabine Gonschior (geb. Frommelt) in Bremen geboren. Nach meiner Einschulung 1994 besuchte ich bis 1998 die Grundschule in Arsten und anschließend von 1999 - 2000 die Orientierungsstufe am Schulzentrum Habenhausen. Im Jahre 2001 wechselte ich auf das Gymnasium am Schulzentrum Habenhausen, welches ich bis 2004 besuchte. Die allgemeine Hochschulreife erwarb ich 2007 nach Besuch der Oberstufe am Gymnasium Obervieland.

Im Anschluss leistete ich vom 01.10.2007 bis 30.06.2008 meinen Grundwehrdienst im 9. Kdo SES FüEU Schwanewede ab und begann am 01.10.2008 mit dem Studium der Zahnmedizin an der Georg-August-Universität Göttingen. Nach erfolgreich bestandener naturwissenschaftlicher und zahnärztlicher Vorprüfung am 01.09.2009 bzw. 28.03.2011 schloss ich das Studium am 02.12.2013 mit Bestehen des Staatsexamens ab.

Die Arbeit an der hier vorliegenden Dissertation begann ich am 06.01.2014 unter der Betreuung von Herrn Prof. Dr. med. Frank Edelmann in der Abteilung Kardiologie und Pneumologie der Georg-August-Universität Göttingen.

Vom 05.01.2015 bis 05.01.2017 arbeitete ich als Assistenzzahnarzt in der Praxis von Dr. Nicolai Böhme in Emstek. Seit dem 06.01.2017 bin ich hier als angestellter Zahnarzt tätig. 